\title{
Analysis of Energy, Environmental and Life Cycle Cost \\ Reduction Potential of Ground Source Heat Pump (GSHP) in Hot and Humid Climate
}

\section{Final Report}

DOE Award Number: $\quad$ DE-EE0002802

Sponsor Name: U.S. Department of Energy

PI: Yong Tao, University of North Texas (formerly with Florida International University), Yong.Tao@unt.edu, 940-369-8801

Co-PI: Yimin Zhu, Florida International University, yimin.zhu@fiu.edu

Partners: ClimateMaster Geothermal Heat Pump Systems, Florida Power \& Light Company, Oak Ridge National Laboratory, Gulf Power Company, and Egg Geothermal Air Conditioning and Pool Heating 


\section{ACKNOWLEDGEMENTS}

The project team wishes to thank the financial support from Department of Energy to the graduate students who contributed to this project. During last two years, the following members of the research project have contributed to the various tasks with different roles:

Dr. Rambod Rayegan, Ph.D. student at FIU and later the Post-Doctoral Associate at UNT Dr. Junghyon Mun, Post -Doctoral Research Associate at UNT

Mr. Jiang Zhu, Master student in FIU and UNT

Dr. Teshome Jiru, Post-Doctoral Fellow at FIU

Mr. Sebastian Munera, Master student at FIU

Mr. Cetin Canbek, Master student at FIU

Mr. Shivam Phadtare, Master student at FIU

Sincere appreciations also go to our external collaborators and partners for the successful completion of the project. They are:

Dr. Xiaobing Liu, Oak Ridge National Lab, Oak Ridge, Tennessee, formerly at ClimateMaster, Inc., Oklahoma City, Oklahoma

Mr. Keith Swilley, Gulf Power Company, Pensacola, Florida

Mr. Jay Egg, Egg Geothermal Air Conditioning and Pool Heating, Tampa, Florida

Mr. C. V. Craig Muccio, Florida Power and Light Company, Miami, Florida

Finally, the project and its report cannot be completed without the supports from the staff members of both UNT and FIU for their diligent efforts to ensure the research team is on track and on-time to comply with the federal requirements. Thank you. 


\section{EXECUTIVE SUMMARY}

It has been widely recognized that the energy saving benefits of GSHP systems are best realized in the northern and central regions where heating needs are dominant or both heating and cooling loads are comparable. For hot and humid climate such as in the states of FL, LA, TX, southern AL, MS, GA, NC and SC, buildings have much larger cooling needs than heating needs. The Hybrid GSHP (HGSHP) systems therefore have been developed and installed in some locations of those states, which use additional heat sinks (such as cooling tower, domestic water heating systems) to reject excess heat. Despite the development of HGSHP the comprehensive analysis of their benefits and barriers for wide application has been limited and often yields non-conclusive results. In general, GSHP/HGSHP systems often have higher initial costs than conventional systems making short-term economics unattractive. Addressing these technical and financial barriers call for additional evaluation of innovative utility programs, incentives and delivery approaches.

From scientific and technical point of view, the potential for wide applications of GSHP especially HGSHP in hot and humid climate is significant, especially towards building zero energy homes where the combined energy efficient GSHP and abundant solar energy production in hot climate can be an optimal solution. To address these challenges, this report presents gathering and analyzing data on the costs and benefits of GSHP/HGSHP systems utilized in southern states using a representative sample of building applications.

The accomplished tasks in this project are as follows:

- Gather and analyze independent and statistically valid technical, cost, financial incentive data on installed GSHP/HGSHP applications in 
residential and commercial buildings in hot and humid climate regions, and develop a calibrated baseline and performance period model of new construction and retrofitted buildings in conjunction with the TRNSYS/EnergyPlus simulation programs.

- Develop a cost/benefit model and tool including life cycle cost (LCC) analysis of GSHP and HGSHP system based on data collected and correlate the data with identified parameters

By accomplishing the above-stated tasks the project not only fills the gap of uncertainty of benefits and trade-off of the applications of GSHP/HGSHP systems in hot and humid climate but more importantly provides a complete, easy-to-follow tool for the prospective end user of GSHP to analyze system cost and utility cost saving for their specific applications and to aid in their purchase and design decisions.

In summary, this report concludes:

- The existing GSHP systems studied consume less energy in comparison to conventional ASHP system on an annual basis regardless of the ground loop type, size of the system, and the building application.

- Closed-loop GSHP systems save more energy than the open loop systems in hot and humid climate.

- In general more complex GSHP systems with higher number of heat pumps present lower energy saving percentage in comparison to conventional systems.

- The cost of the system plays a key role to decide which portion of the load is compensated by the ground loop heat exchanger. 
- Within the scope of the project the wider application of GSHP systems to residential buildings is more uncertain than commercial or office buildings.

- Overall, the application of GSHP in Florida (and hot and humid climate in general) shows a good potential. 


\section{TABLE OF CONTENTS}

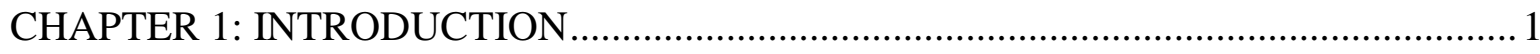

1.1. Background ................................................................................................................... 1

1.2. Organization of the Report ........................................................................................... 2

CHAPTER 2: Data Gathering and Analyzing ........................................................... 4

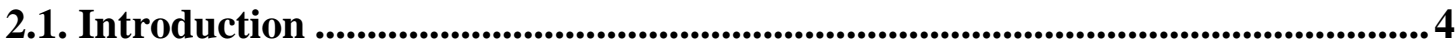

2.2. Walk Through Survey and Field Testing ........................................................6

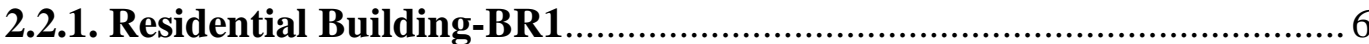

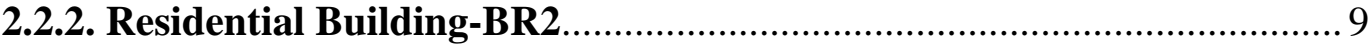

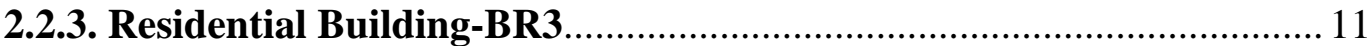

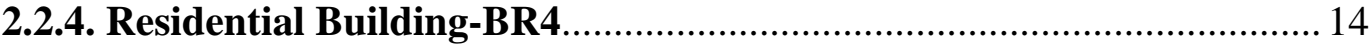

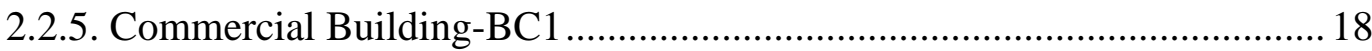

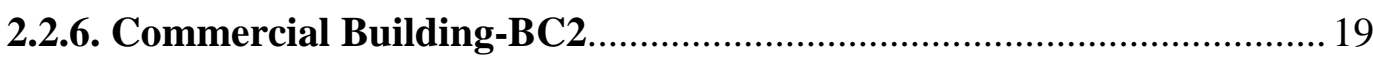

2.2.7. Commercial Building-BC3............................................................ 21

2.2.8. Commercial Building-BC4 ............................................................. 24

2.3. Utility Consumption Analysis............................................................................ 26

CHAPTER 3: Baseline Model Development and Calibration ......................................... 29

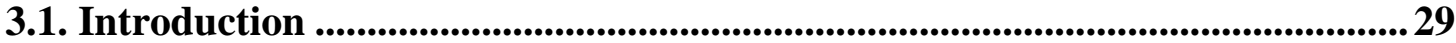

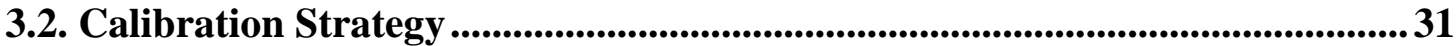

3.3. Case Study-BR1 .................................................................................................. 32

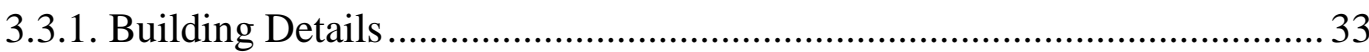

3.3.2. Building Model Specifications .............................................................. 33

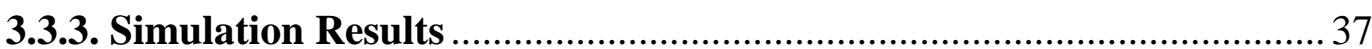

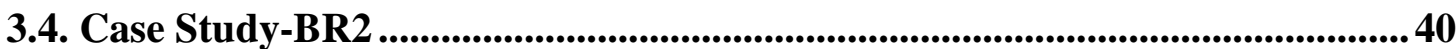

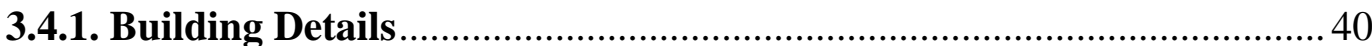

3.4.2. Building Model Specifications ......................................................... 41

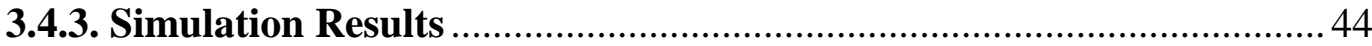

3.5. Case Study-BR3 ............................................................................................................ 46

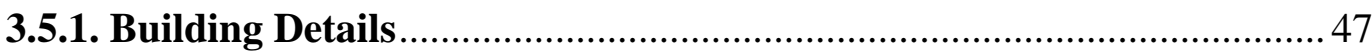

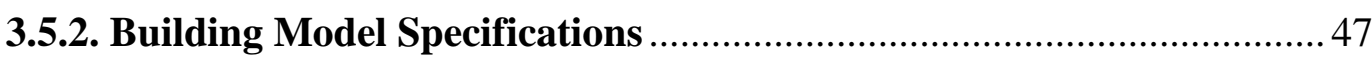

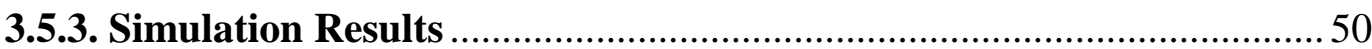

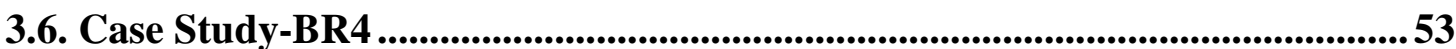

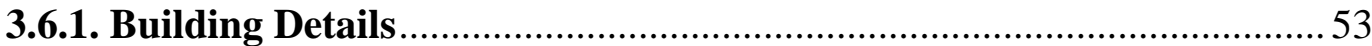

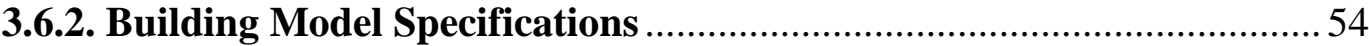

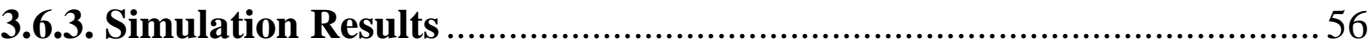




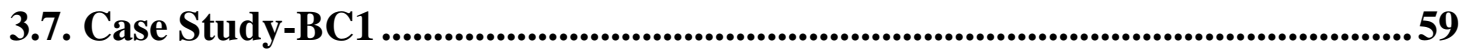

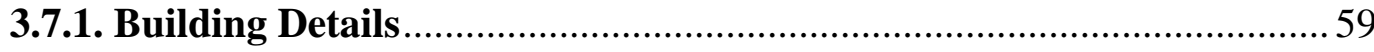

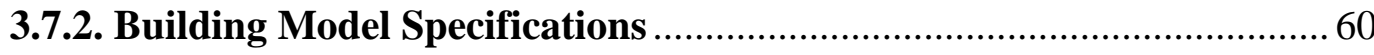

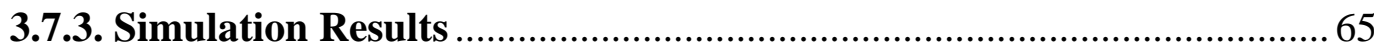

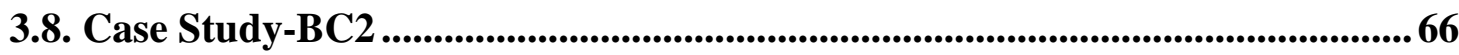

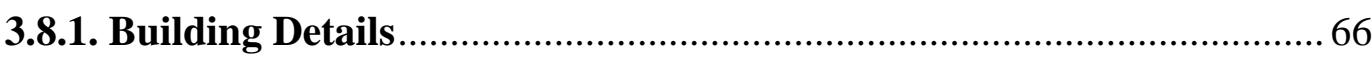

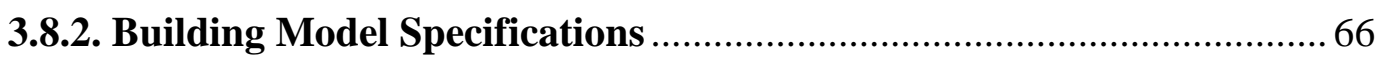

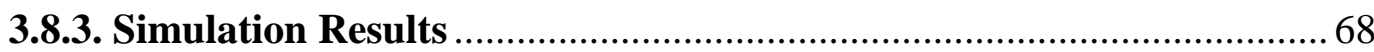

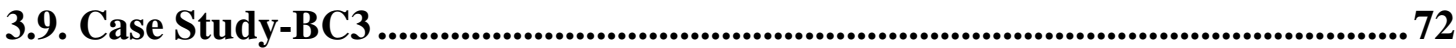

3.9.1. Building Details ................................................................................... 72

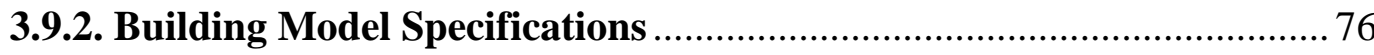

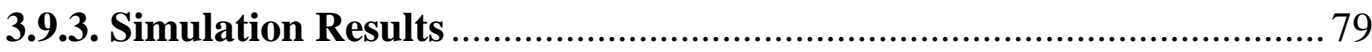

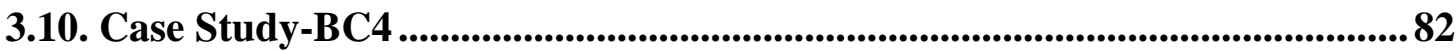

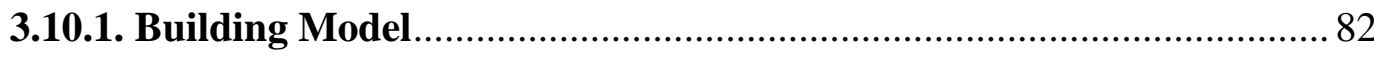

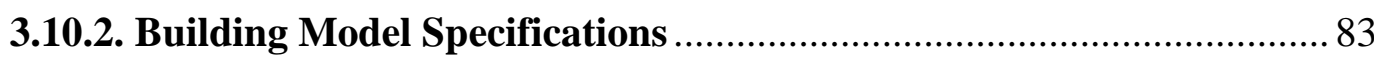

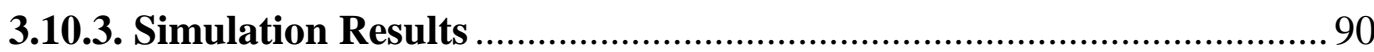

3.11. Performance Study ....................................................................................99

3.12. Comparative Study Between TRNSYS And EnergyPlus .................................97

3.12.1. Simulation Results ...................................................................... 100

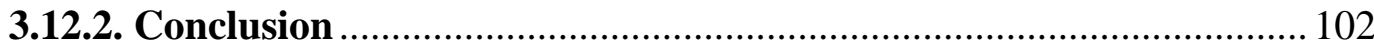

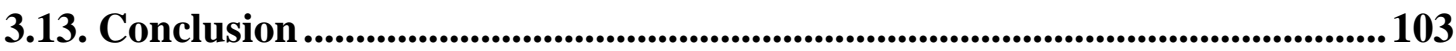

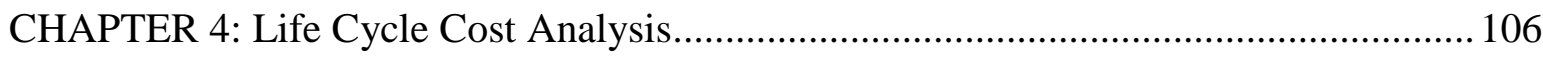

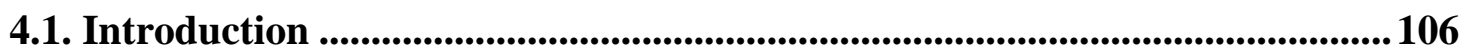

4.2. Life cycle costing considerations ..........................................................................107

4.2.1. Initial costs................................................................................... 107

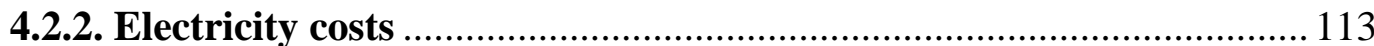

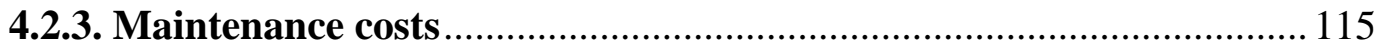

4.2.4. Replacement Costs........................................................................... 119

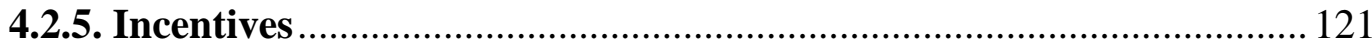

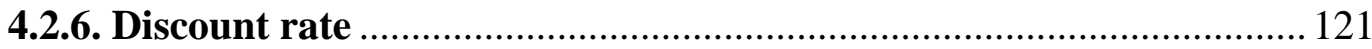

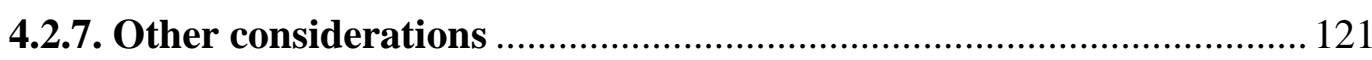

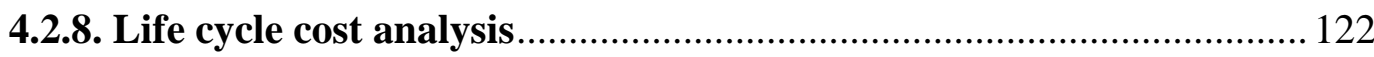

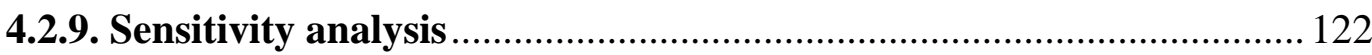

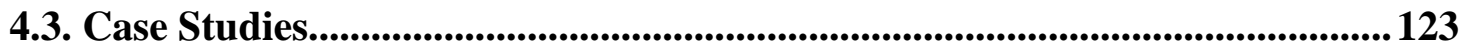

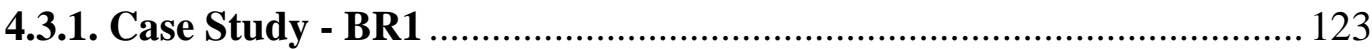

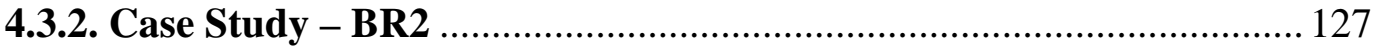




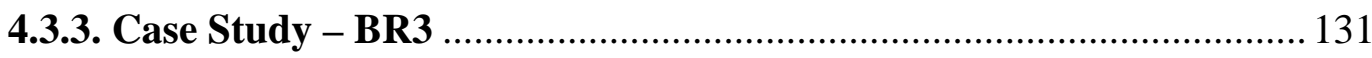

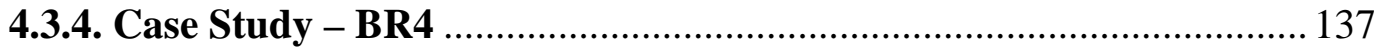

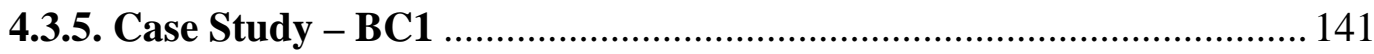

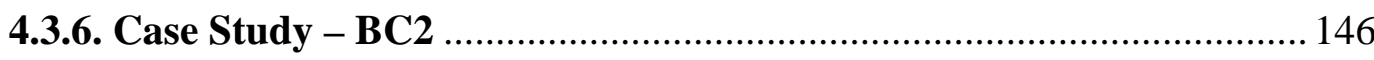

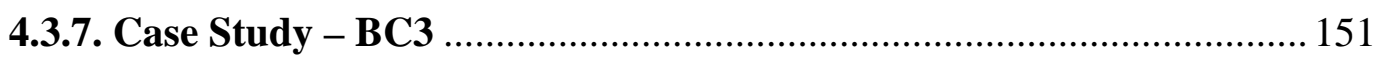

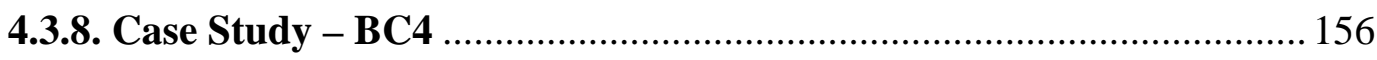

4.4. Conclusions.............................................................................................................161

CHAPTER 5: Summary and Conclusions....................................................................162

5.1. Main findings and Recommendations ...............................................................162

5.2. General guidelines for promoting the wider-adoption of GHP in the hot and

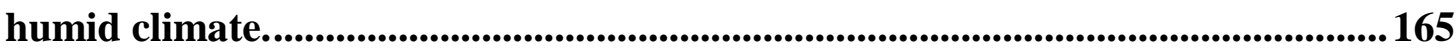

Appendix 1: Ground Source Heat Pumps Data Gathering Protocol in a Specific Climate

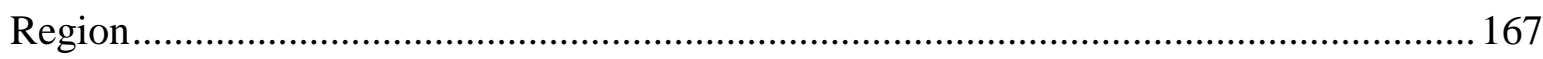

Appendix 1-A: A template for participation request letter to the potential

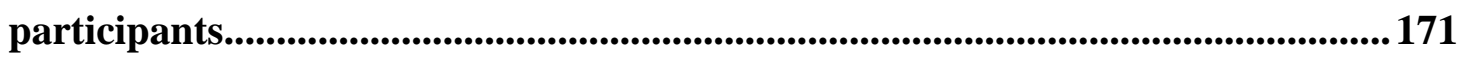

Appendix 1-B: A template for agreement letter for businesses to participate in GSHP project ...............................................................................................173

Appendix 1-C: A template for agreement letter for owners/key players to participate in GSHP project ........................................................................................177

Appendix 1-D: GSHP project short questionnaire.......................................................181

Appendix 1-E: GSHP project long questionnaire ......................................................182

Appendix 1-F: Ground source heat pump monitoring protocol ............................... 190 


\section{CHAPTER 1: INTRODUCTION}

\subsection{Background}

It has been widely recognized that the energy saving benefits of GSHP systems are best realized in the northern and central regions where heating needs are dominant or both heating and cooling loads are comparable. Buildings in hot and humid climates have much larger cooling needs than heating needs. The Hybrid GSHP (HGSHP) systems therefore have been developed and installed in some locations of those states, which use additional heat sinks (such as a cooling tower or domestic water heating systems) to reject excess heat. Despite the development of HGSHPs, the comprehensive analysis of their benefits and barriers for wide application has been limited and often yields non-conclusive results. In general, GSHP/HGSHP systems often have higher initial costs than conventional systems making short-term economics unattractive. Addressing these technical and financial barriers calls for additional evaluation of innovative utility programs, incentives, and delivery approaches.

From a scientific and technical point of view, the potential for wide applications of GSHP, especially HGSHP, in hot and humid climate is significant, especially towards building zero energy homes where the combined energy efficient GSHP and abundant solar energy production in hot climate can be an optimal solution. To address these challenges, we propose gathering and analyzing data on the costs and benefits of GSHP/HGSHP systems utilized in southern states using a representative sample of building applications. The proposed project will employ utility and available monitored data of GSHP systems to develop a calibrated baseline and performance period models of new construction and 
retrofitted buildings using TRNSYS/EnergyPlus simulation programs. Life cycle cost analysis will also be performed using utility, equipment, and maintenance cost data.

The purpose of this project is to provide a sound conclusion as whether or not ground source heat pumps/hybrid grounds source heat pumps (GSHP/HGSHP) will be a vital contribution to energy efficiency building solutions and towards zero-energy buildings for the hot and humid climates. The specific objectives of the study are to:

1. Gather and analyze independently validated technical, cost, and financial incentive data on installed GSHP/HGSHP applications in residential and commercial buildings in hot and humid climate regions, and develop a calibrated baseline and performance period model of new construction and retrofitted buildings in conjunction with the TRANSYS/EnergyPlus simulation programs,

2. Develop a cost/benefit model and tool including life cycle cost (LCC) analysis of GSHP and HGSHP systems based on data collected and correlate the data with identified parameters, and

3. Present a comprehensive report outlining the findings and recommendations addressing the goal of the project by providing the easy-to-follow guidelines.

\subsection{Organization of the Report}

This report is divided into four chapters to describe the work that has been completed to achieve the objectives set for this research project. The following sections describe briefly the contents of each chapter.

Chapter 1, the current chapter, provides a description and objectives of the research project. In particular, chapter 1 presents a background and the specific objectives of the project. 
Chapter 2 describes data gathering and analyzing of GSHP systems in hot and humid climates. In this step, the characteristics of GSHP systems and patterns of energy use in different types of buildings in hot and humid climates will be evaluated. This chapter includes a walk-through survey. During the visit, hand-held and clamped instruments are used to determine the variation of the building parameters such as indoor air temperature and energy use. The walk-through audit involves discussions with facility owners and filling out questionnaires. This chapter covers Task 1.0 and Subtask 1.1.

Chapter 3 presents development of Baseline Model and Calibration for the GSHP systems. The purpose of this chapter is to develop base-case models using TRNSYS/EnergyPlus that represents the pre-retrofit energy use and operating conditions for buildings, which will be used as a reference for estimating energy savings from installing GSHP/HGSHP systems in commercial and residential buildings. This chapter covers Task 3.0 and Subtasks 3.1 and 3.2.

Chapter 4 presents Cost Modeling of the GSHP systems. Cost models will be developed using the data described in Chapter 2. This chapter covers Tasks 2.0 and 4.0. 


\section{CHAPTER 2: Data Gathering and Analyzing}

\subsection{Introduction}

Ground Source Heat Pump (GSHP) / Hybrid GSHP (HGSHP) systems often have higher initial costs than conventional systems, making short-term economics unattractive. To overcome these financial barriers, various innovative utility programs, incentives and delivery approaches have been implemented or sought after. A critical component to validate those programs is gathering and analyzing data on the costs and benefits of GSHP/HGSHP systems using a representative sample of building applications. The main goal of this project is to focus on applications in southern states categorized as hot and humid climate regions. The first step is to develop and implement the data collection method within the limitation of time constraints and budget, specifically for hot and humid climates.

A data gathering protocol, presented in the Appendix I, has been designed to achieve the objectives of the project. After gathering required data, the characteristics of GSHP systems and patterns of energy use in different types of buildings in hot and humid climates are evaluated. The building characteristics are determined from drawings and interviews with building operators and owners. Installation, maintenance and utility data are gathered and analyzed for selected residential and commercial buildings, which use GSHP/HGSHP systems in hot and humid climate region. The utility bills are categorized based on the GSHP/HGSHP loop and building type.

Chapter 2 is documenting (1) completion of utility energy uses analysis for different building types and sizes by determination of electricity consumption index (electricity 
consumption per unit floor area), and (2) completion of a database of GSHP/HGSHP systems in hot and humid climate region.

The Subtask outlined in this chapter is a Walk-through Survey. The walk-through audit involves discussions with facility owners and filling out questionnaires. During the visit, hand-held and clamped instruments are used to determine the variation of the building parameters such as indoor air temperature and energy use. The walk-through survey will provide: (1) additional information on the facility and (2) a better understanding of the operation and the settings of the GSHP/HGSHP systems in a particular building.

Before visiting site, data of six buildings in Tampa, FL and six buildings in Pensacola, FL were collected via an online survey to identify the availability of data source and filed data. Complete data collection for four cases were unavailable due to constraints of time frame and equipment budgets. The building and system information for the four cases that were not monitored is described in Table 2-1.

Other eight buildings were only monitored thus they were used for detailed energy and life cycle cost analysis. The building information and system description for all monitored case studies are listed in Table 2-2. 
Table 2-1: General building information and system description for non-monitored case studies

\begin{tabular}{|c|c|c|c|c|c|c|}
\hline & \multicolumn{3}{|c|}{ General Information } & \multicolumn{3}{|c|}{ GSHP Information } \\
\hline ID & Location & $\begin{array}{c}\text { Building } \\
\text { Type }\end{array}$ & $\begin{array}{l}\text { Floor } \\
\text { Area } \\
\left(\mathrm{ft}^{2}\right)\end{array}$ & $\begin{array}{l}\text { Type of } \\
\text { Loop }\end{array}$ & $\begin{array}{c}\text { Total } \\
\text { Capacity } \\
\text { (tons) }\end{array}$ & Ground Loop Basic Dimensions \\
\hline $\begin{array}{c}\text { Case } \\
1\end{array}$ & $\begin{array}{c}\text { Tampa, } \\
\text { FL }\end{array}$ & Residential & 2663 & $\begin{array}{c}\text { Open } \\
\text { Loop / } \\
\text { Two Well }\end{array}$ & 5 & $160 \mathrm{ft}$ well depth \\
\hline $\begin{array}{c}\text { Case } \\
2\end{array}$ & $\begin{array}{c}\text { Tampa, } \\
\text { FL }\end{array}$ & Residential & 2550 & $\begin{array}{c}\text { Open } \\
\text { Loop / } \\
\text { Two Well }\end{array}$ & 4 & $N / A^{a}$ \\
\hline $\begin{array}{c}\text { Case } \\
3\end{array}$ & $\begin{array}{c}\text { Tampa, } \\
\text { FL }\end{array}$ & Residential & 3200 & $\begin{array}{c}\text { Open } \\
\text { Loop / } \\
\text { Two Well }\end{array}$ & 5 & $100 \mathrm{ft}$ well depth \\
\hline $\begin{array}{c}\text { Case } \\
4\end{array}$ & $\begin{array}{c}\text { Tampa, } \\
\text { FL }\end{array}$ & Residential & 16105 & & & $N / A^{b}$ \\
\hline
\end{tabular}

a. No well and pipe information is available.

b. No system information is available.

\subsection{Walk Through Survey and Field Testing}

\subsubsection{Residential Building-BR1}

BR1 is a residential building built in 1987 and is located in Tampa, Florida. It is a one story building, and its floor area is 1600 square ft. The building has three rooms and is three occupants. The interior is finished with drywall, and the exterior wall consists of concrete wall stucco. The building's exterior wall material is traditional Florida block. The roof structure is a gable or hip type with 1 inch foam that has been blown on it. The 
Table 2-2: General building information and system description for all monitored case studies

\begin{tabular}{|c|c|c|c|c|c|c|}
\hline & \multicolumn{3}{|c|}{ General Information } & \multicolumn{3}{|c|}{ GSHP Information } \\
\hline ID & Location & $\begin{array}{l}\text { Building } \\
\text { Type }\end{array}$ & $\begin{array}{l}\text { Floor } \\
\text { Area } \\
\left(\mathrm{ft}^{2}\right)\end{array}$ & $\begin{array}{l}\text { Type of } \\
\text { Loop }\end{array}$ & $\begin{array}{l}\text { Total } \\
\text { Capacity } \\
\text { (tons) }\end{array}$ & Ground Loop Basic Dimensions \\
\hline BR1 & $\begin{array}{c}\text { Tampa, } \\
\text { FL }\end{array}$ & Residential & 1600 & $\begin{array}{c}\text { Open } \\
\text { Loop / } \\
\text { Two Well }\end{array}$ & 3 & $\begin{array}{l}80 \mathrm{ft} \text { well depth } \\
4 \text { " well diameter } \\
60 \mathrm{ft} \text { well spacing } \\
\text { 1" pipe size @ pump }\end{array}$ \\
\hline BR2 & $\begin{array}{c}\text { Tampa, } \\
\text { FL }\end{array}$ & Residential & 1900 & $\begin{array}{c}\text { Open } \\
\text { Loop / } \\
\text { Two Well }\end{array}$ & 4 & $\begin{array}{l}150 \mathrm{ft} \text { well depth } \\
4 \text { " well diameter } \\
100 \mathrm{ft} \text { well spacing } \\
\text { 1" pipe size @ pump }\end{array}$ \\
\hline BR3 & $\begin{array}{c}\text { Pensacola, } \\
\text { FL }\end{array}$ & Residential & 2800 & $\begin{array}{l}\text { Closed } \\
\text { Loop / } \\
\text { Vertical }\end{array}$ & 5 & $\begin{array}{c}6 \text { boreholes } \\
250 \mathrm{ft} \text { depth-3/4" U-tube } \\
11 / 4 \text { " pipe size @ pump }\end{array}$ \\
\hline BR4 & $\begin{array}{l}\text { Robertsda } \\
\text { le, } A L\end{array}$ & Residential & 2800 & $\begin{array}{c}\text { Closed } \\
\text { Loop / } \\
\text { Horizontal }\end{array}$ & $5(2+3)$ & $\begin{array}{c}5 \text { trenches- } \\
100 \mathrm{ft}(\mathrm{L}) * 3 \mathrm{ft}(\mathrm{W}) * 6 \mathrm{ft}(\mathrm{D}) \\
600 \mathrm{ft} \text { of } 3 / 4 \text { " tube in each } \\
\text { trench } \\
11 / 4 \text { " pipe size @ pump }\end{array}$ \\
\hline $\mathrm{BC} 1$ & $\begin{array}{c}\text { Pensacola, } \\
\text { FL }\end{array}$ & $\begin{array}{l}\text { Commercial } \\
\text { / Operation } \\
\text { Center }\end{array}$ & 6000 & $\begin{array}{l}\text { Closed } \\
\text { Loop / } \\
\text { Vertical }\end{array}$ & 19 & $\begin{array}{c}17 \text { boreholes } \\
300 \mathrm{ft} \text { depth - 3/4" U-tube } \\
\text { 2" pipe size @ pump }\end{array}$ \\
\hline $\mathrm{BC} 2$ & $\begin{array}{c}\text { Pensacola, } \\
\text { FL }\end{array}$ & $\begin{array}{c}\text { Commercial } \\
\text { / Office }\end{array}$ & 4250 & $\begin{array}{l}\text { Closed } \\
\text { Loop / } \\
\text { Vertical }\end{array}$ & $\begin{array}{c}13 \\
(2 \times 6+1)\end{array}$ & $\begin{array}{c}14 \text { boreholes } \\
300 \mathrm{ft} \text { depth }-3 / 4 \text { " U-tube } \\
\text { 3" pipe size @ pump }\end{array}$ \\
\hline BC3 & $\begin{array}{c}\text { Pensacola, } \\
\text { FL }\end{array}$ & $\begin{array}{l}\text { Commercial } \\
\text { / Restaurant }\end{array}$ & 13600 & $\begin{array}{l}\text { Closed } \\
\text { Loop / } \\
\text { Vertical }\end{array}$ & 129 & $\begin{array}{c}135 \text { boreholes } \\
300 \mathrm{ft} \text { depth - 3/4" U-tube } \\
\text { 10" pipe size @ pump }\end{array}$ \\
\hline $\mathrm{BC} 4$ & $\begin{array}{c}\text { Pensacola, } \\
\text { FL }\end{array}$ & $\begin{array}{c}\text { Commercial } \\
\text { / Hotel }\end{array}$ & 80145 & $\begin{array}{c}\text { Closed } \\
\text { Loop / } \\
\text { Vertical / } \\
\text { Hybrid }\end{array}$ & $\begin{array}{c}340 \\
\text { (150 tons } \\
\text { cooling } \\
\text { tower) }\end{array}$ & $\begin{array}{c}96 \text { boreholes } \\
200 \mathrm{ft} \text { depth - 1" U-tube } \\
\text { 8" pipe size @ pump }\end{array}$ \\
\hline
\end{tabular}


insulation level of the roof is R33. The floor is concrete slab covered with cork or vinyl tiles.

The house used the conventional air cooled air conditioning system until April 2010, when it was converted to GSHP, which is a 3 ton unit. The system uses a two well open loop system with $80 \mathrm{ft}$ depth and $60 \mathrm{ft}$ well spacing. The well pump and the expansion tank are manufactured by Grundfos. The pump characteristics are: $1 \mathrm{hp}, 8 \mathrm{~A}$, and $220 \mathrm{~V}$. The heat pump is single phase that uses a 2 speed compressor and the refrigerant is R410a. Two PT ports are available for temperature and pressure measurements. The heat pump was located in the garage, and the piping system used for this heat pump is shown in Figure 2-1.

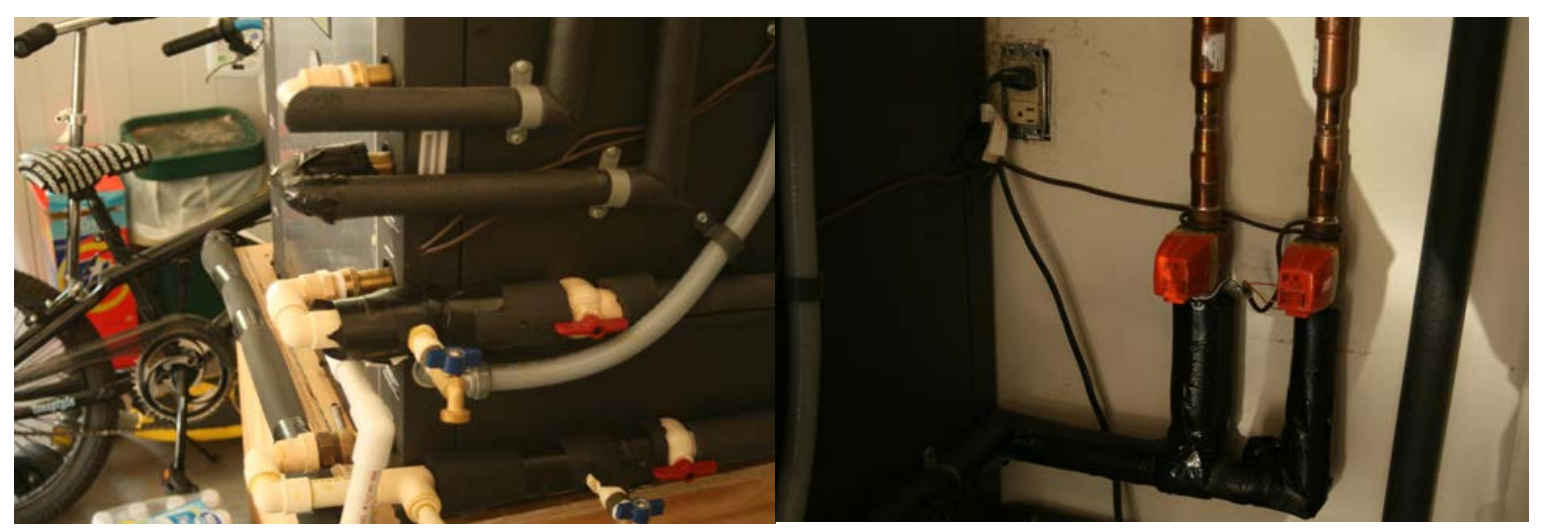

Figure 2-1: The heat pump piping system in BR1

The Geothermal research team visited BR1 building and made the first walk-through survey on June 11, 2010. The building owner was highly satisfied with his new HVAC system. The comfort level of the HVAC system has been increased substantially. House air temperature changes are smoother in comparison to the conventional system. The aircooled condenser of the old system was installed next to the bedroom, and the noise was reduced due to the elimination of outdoor equipment, a highly desirable benefit. According to the owner, the tap water is much warmer in the new system.

\section{Field Testing}


The building was monitored for 20 days from Nov $30^{\text {th }}$ to Dec $20^{\text {th }}$, 2011. The following equipment was installed at the location:

- Schenitec ultrasonic Btu meter, which was installed on the entering and existing positions of the ground loop to measure the water flow rate in the loop.

- Thermo-couples, which were installed on the entering and existing positions of the ground loop to measure the temperature difference between inlet temperature and outlet temperature of the ground loop.

- Wattnodes with Campbell Scientific data logger, which were installed to measure and log the power consumption of the heat pump.

- 5 Hobo sensors to measure and log temperature and relative humidity of inside and outside of the building and also before and after the coil in the monitored heat pump unit.

The data obtained for 20 days from Nov $30^{\text {th }}$ to Dec $20^{\text {th }}, 2011$ are:

- Air temperature before coil in a heat pump, air temperature after coil in a heat pump, living room air temperature, air temperature close to thermostat installed in hallway and outdoor air temperature

- Flow rate and inlet and outlet temperatures of the water in the ground loop

- Power consumption of the heat pump

The electricity bill used for the calibration is the data of 2010. The billing data were collected at the end of 2010.

\subsubsection{Residential Building-BR2}

BR2 is a residential building built on 1978 and is located in Tampa, Florida. It is a one story building, and its floor area is 2000 square $\mathrm{ft}$. There are three bedrooms and two 
bath- rooms in this building, and the number of occupants is four. The interior is finished with drywall, and the exterior wall consists of block wall stucco. The roof structure is a gable/hip type. The floor is concrete slab covered with carpet.

The house used the conventional air cooled air conditioning system until June 2010 when it was converted to GSHP shown in Figure 2-2. The capacity of the GSHP system is 4 ton, and it consists of two-well open loop system which is running with 1 hp water pump and 8 GPM flow rate.
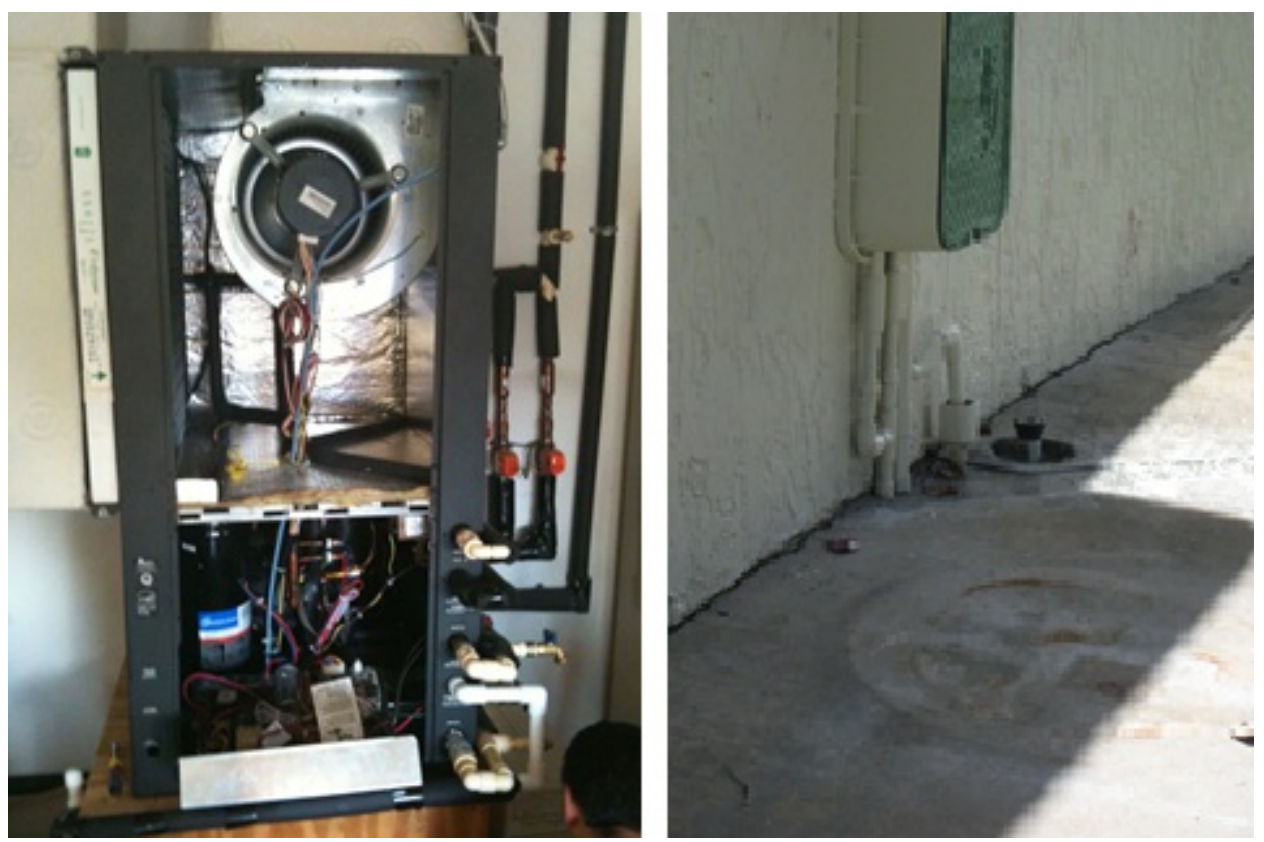

Figure 2-2: The GSHP system and piping connected to the ground loop in BR2

The Geothermal research team visited BR2 building and made the first walk-through survey on June 2010. The utility bill information was supplied by the utility company during this session.

\section{Field Testing}

The building was monitored for 20 days from Nov $30^{\text {th }}$ to Dec $20^{\text {th }}$, 2011. The following equipment was installed at the location: 
- Schenitec ultrasonic Btu meter, which was installed on the entering and existing positions of the ground loop to measure the water flow rate in the loop.

- Thermo-couples, which were installed on the entering and existing positions of the ground loop to measure the temperature difference between inlet temperature and outlet temperature of the ground loop.

- Wattnodes with Campbell Scientific data logger, which were installed to measure and log the power consumption of the heat pump.

- 5 Hobo sensors to measure and log temperature and relative humidity of inside and outside of the building and also before and after the coil in the monitored heat pump unit.

The data obtained for 20 days from Nov. $30^{\text {th }}$ to Dec. $20^{\text {th }}$, 2011, are:

- Air temperature before coil in a heat pump, air temperature after coil in a heat pump, living room air temperature, air temperature in kitchen area, and outdoor air temperature

- Flow rate and inlet and outlet temperatures of the water in the ground loop

- Power consumption of the heat pump

- The electricity bill used for the calibration is the data of 2010.

The billing data were collected at the end of 2010. The electricity bill used for the calibration is the data of 2010. The billing data were collected at the end of 2010.

\subsubsection{Residential Building-BR3}

BR3 is a residential building built located in Pensacola, Florida. It is a one story building, and its floor area is 3390 square ft. The BR3 consists of three rooms with 4 occupants. The exterior wall consists of brick with gypsum board. The roof structure is a gable/hip type, and its insulation level is R-33. The floor is concrete slab covered with carpet. This building is shown in Figure 2-3. 


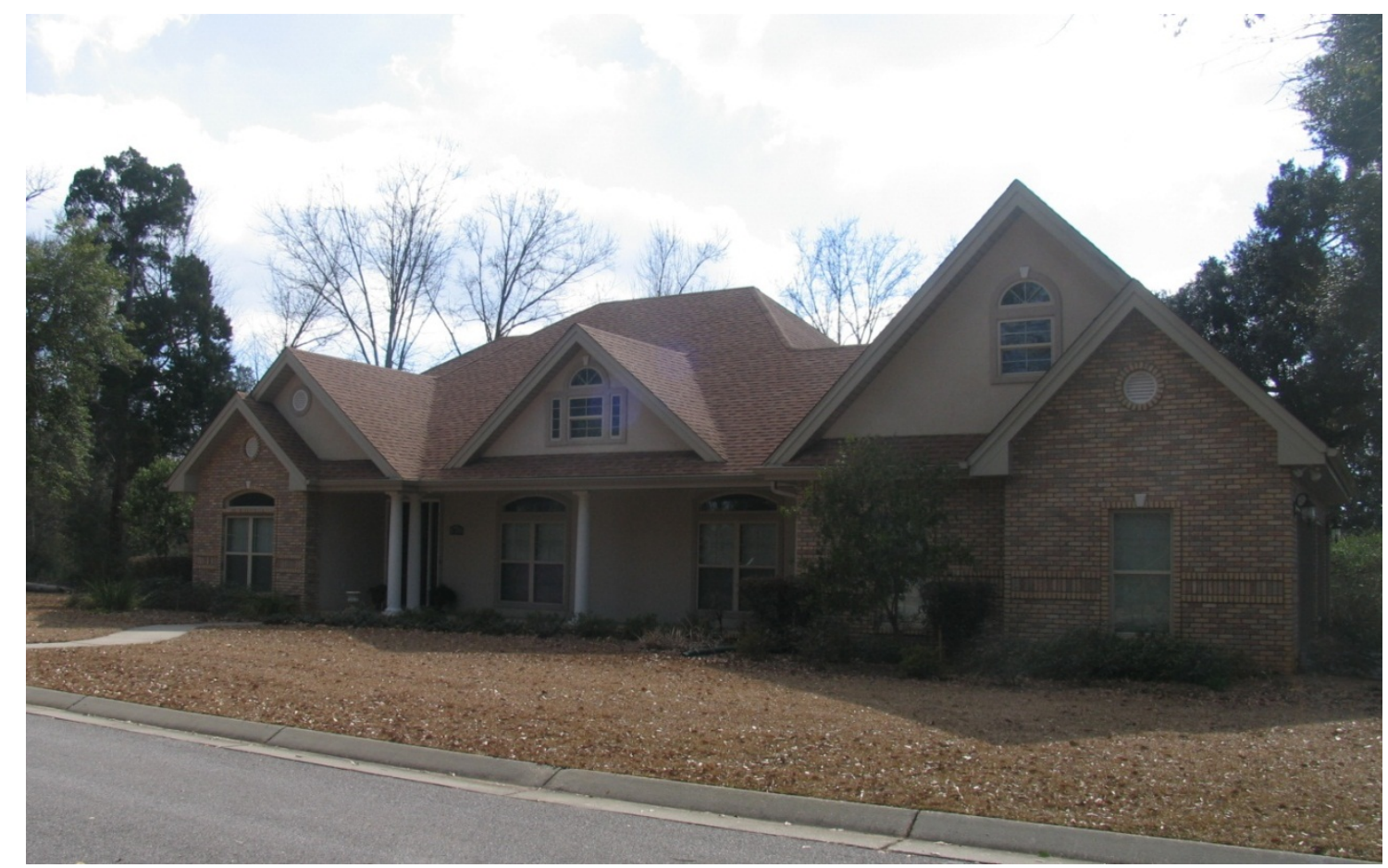

Figure 2-3: The front view of BR3

The GSHP system is located in the attic, which is very well insulated with ICYNENE spray foam on the living room. There is an electrical panel and a disconnect switch next to the heat pump in the attic that could be used to connect the monitoring devices. The water pumps in the garage are powered directly from the same panel in the attic, which will facilitate the monitoring procedure by reducing the number of Watt Nodes that would have to be employed. The capacity of the GSHP system is 5 ton, and it consists of 6 boreholes close loop ground heat exchanger system which is running with 1 hp water pump and 8GPM flow rate. There is a 6 hp two speed pump in the loop. Each borehole has a $250 \mathrm{ft}$ depth and 3/4 in diameter U-tube pipe. The main loop pipe’s diameter is $1 \frac{1 / 4}{\mathrm{in}}$. The system has been operating for 3 years. A heat recovery system has been implemented on the heat pump unit. 
The heating period is December to March, and the setpoint temperature is set to be $72^{\circ} \mathrm{F}$ in occupied time and $68-70{ }^{\circ} \mathrm{F}$ in unoccupied time during the heating season. The cooling period is April to November, and the setpoint temperature is set to be $72^{\circ} \mathrm{F}$ in occupied time and $77-80{ }^{\circ} \mathrm{F}$ in unoccupied time during the cooling season. On weekdays, the occupants in this building move out to their school or work place and return home around 4:30 PM. The setpoint of the room temperature is programmable, so the owner of the building changes the setpoint temperature of the building based on the schedule of the occupants and the outdoor temperature.

The Geothermal research team visited BR3 building and made the first walk-through survey on February 2010. The basic information of GSHP system and the available data for the building such as the lighting fixtures, appliances were searched for this walk through survey. The utility bill information was supplied by the utility company.

\section{Field Testing}

BR3 was monitored for three weeks during February, but one of the data gathering equipment to measure power consumption of the GSHP system did not work well. Therefore, additional monitoring was performed during middle of March.

The final data submitted are those monitored for 20 days from Mar. $14^{\text {th }}$ to Mar. $30^{\text {th }}$, 2011. The following equipment was installed at the location:

- Schenitec ultrasonic Btu meter, which was installed on the entering and existing positions of the ground loop to measure the water flow rate in the loop.

- Thermo-couples, which were installed on the entering and existing positions of the ground loop to measure the temperature difference between inlet temperature and outlet temperature of the ground loop. 
- Wattnodes with Campbell Scientific data logger, which were installed to measure and $\log$ the power consumption of the two heat pump (2tons and 3 tons units) on the second floor.

- 4 Hobo sensors to measure and log temperature and relative humidity of inside and outside of the building and also before and after the coil in the monitored heat pump unit.

The data obtained for 20 days from Nov $30^{\text {th }}$ to Dec $20^{\text {th }}$, 2011, are:

- Air temperature after coil in a heat pump, return air temperature in the duct, living room air temperature, and area outdoor air temperature

- Flow rate and inlet and outlet temperatures of the water in the ground loop

- Power consumption of the heat pump

The electricity bill used for the calibration is the data of 2010. The billing data were collected at the end of 2010.

\subsubsection{Residential Building-BR4}

BR4 is a residential building with 4 occupants and built in 1998 and located in Robertsdale, Alabama. It is a two story building and its floor area is 2800 square ft. There are a one bedroom, a living room, a bathroom, a computer room and a kitchen in the first floor and two bedrooms for children. There is one more building used for garage and additional residents in the same site as seen in Figure 2-4, but the building did not use the GSHP system and the electricity bill had been issued independently for the building. Therefore, this additional building is not considered here. The exterior wall of the building is wood stud wall with R-19 insulation. The floor is concrete slab covered with carpet. 


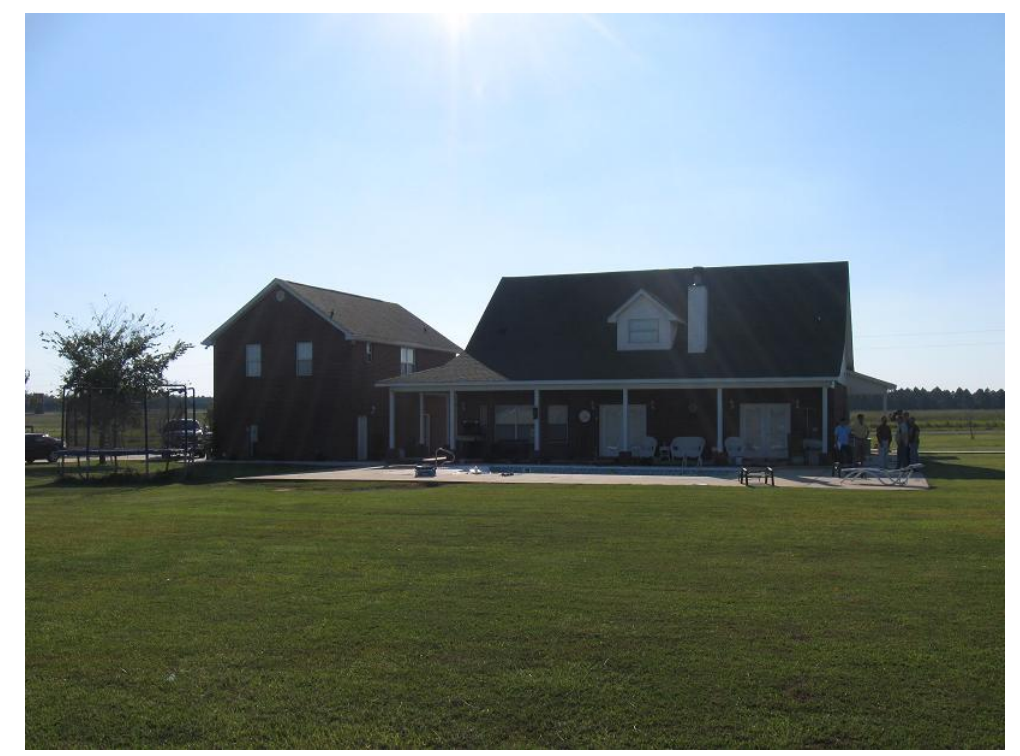

Figure 2-4: Main building and additional garage view of BR4

According to the owner of the building, the set point temperature for system is maintained very high in heating season $\left(78^{\circ} \mathrm{F}\right)$ and very low $\left(64^{\circ} \mathrm{F}\right)$ in cooling season for unoccupied time preventing energy waste. The system usually operates after 15:00PM and before 8:00 AM when the occupants stay in the building.

Two geothermal heat pump systems (3 ton \& 2 ton units) are installed in this building, which provide heating and cooling. Three ton unit runs across the first floor and 2 ton unit is used for the second floor. These two units are connected to horizontal type ground loop which is 5 slinky horizontal loop trenches that are 36 inches wide, $100 \mathrm{ft}$ long and 5 to $6 \mathrm{ft}$ deep for a total of $600 \mathrm{ft}$ of pipe with 8 to 10 inch coil separation. The pipe has 3/4 in diameter. The fluid used for the ground loop is water and two 1 H.P pumps are used for water circulation.

The Geothermal research team visited BR4 building on February and made the walk-through survey on February/2010. The basic information of GSHP system and the 
available data for the building such as the lighting fixtures, appliances were searched for this walk through survey. The utility bill information was supplied by the utility company.

\section{Field Testing}

The building was monitored for 20 days from Feb $18^{\text {th }}$ to March $9^{\text {th }}$, 2011. The

following equipment was installed at the location:

- Schenitec ultrasonic Btu meter, which was installed on the entering and existing positions of the ground loop to measure the water flow rate in the loop as shown in Figure 2-5.

- Thermo-couples, which were installed on the entering and existing positions of the ground loop to measure the temperature difference between inlet temperature and outlet temperature of the ground loop.

- Wattnodes with Campbell Scientific data logger, which were installed to measure and $\log$ the power consumption of the two heat pump (2tons and 3 tons units) on the second floor.

- 5 Hobo sensors to measure and log temperature and relative humidity of inside and outside of the building and also before and after the coil in the monitored heat pump unit.

- A hobo sensor was attached on the exterior wall, but it was dropped due to heavy wind and rain and it was soaked with water. The data from the hobo sensor were checked but it was determined to be corrupted. The replacement data for simulation were obtained from local internet weather data during that time.

The data obtained for 20 days from Nov $30^{\text {th }}$ to Dec $20^{\text {th }} 2011$ are: 


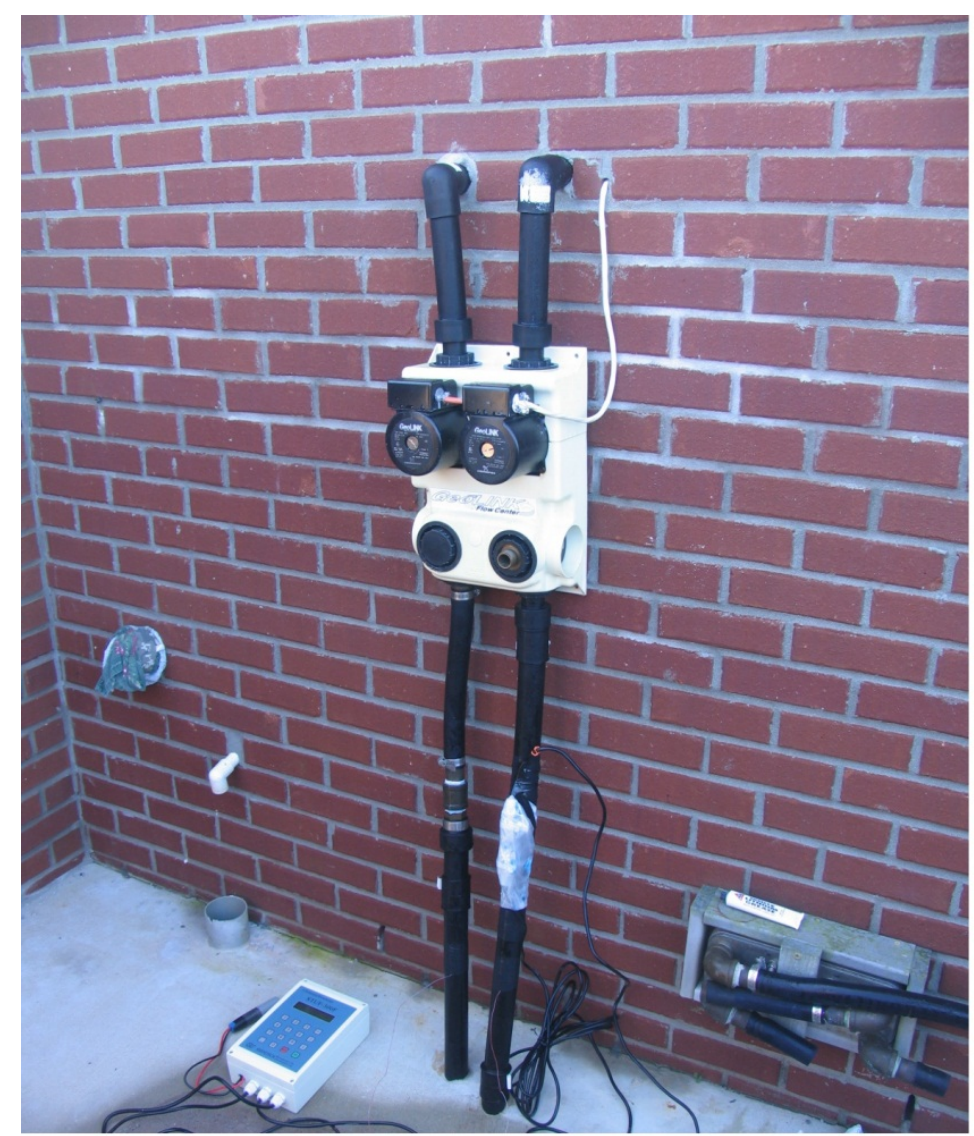

Figure 2-5: But meter connected to the ground loop

- Air temperature after coil in the 3 ton heat pump, air temperature close to a thermostat in the first floor, air temperature close to a thermostat in the second floor, and return air temperature

- outdoor air temperature but it is corrupted

- Flow rate and inlet and outlet temperatures of the water in the ground loop

- $\quad$ Power consumption of the heat pump

The electricity bill used for the calibration is the data of 2010. The billing data were collected at the end of 2010. 


\subsubsection{Commercial Building-BC1}

BC1 is a commercial building which consists of five offices with maximum 15 occupants located in Pensacola as seen in Figure 2-6. It is a 6,000 square $\mathrm{ft}$ one story building that operates $24 / 7$ the whole year.

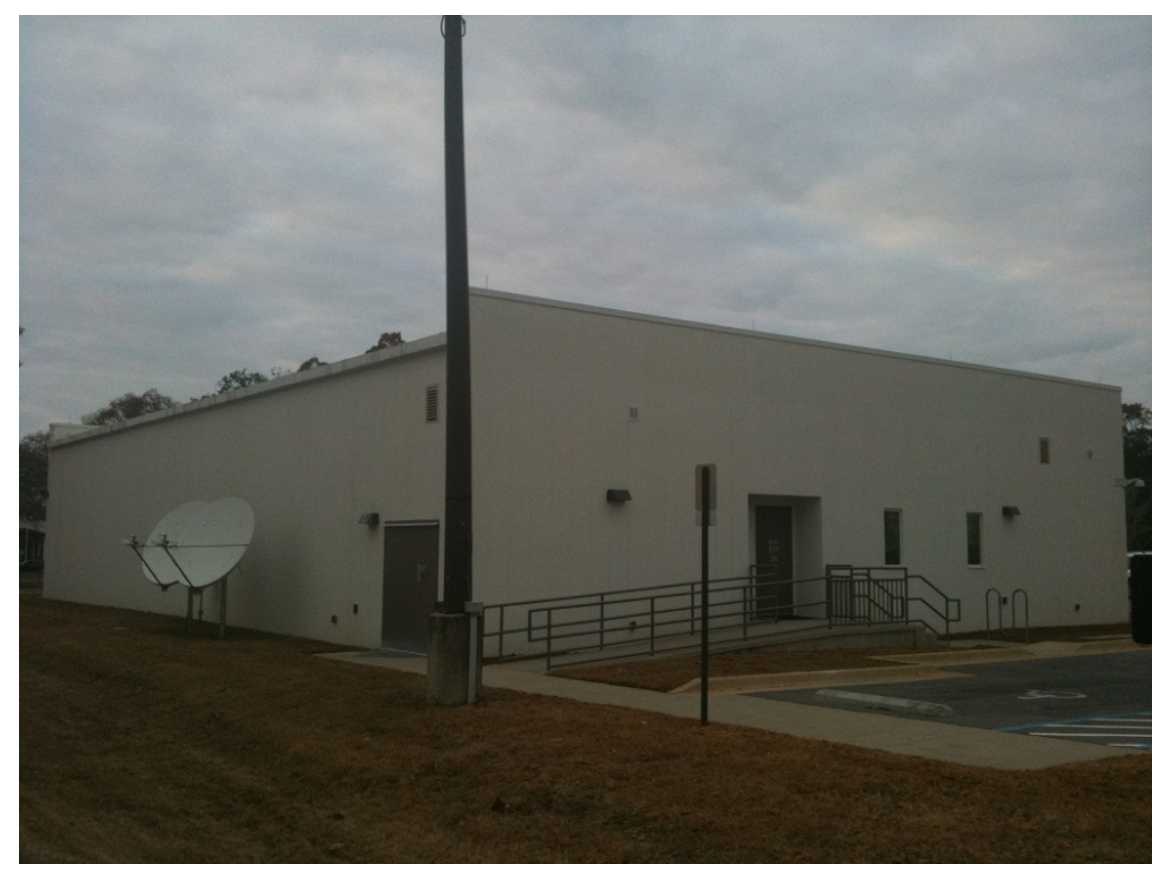

Figure 2-6: Front View of BC1

The exterior wall of the building is composed of concrete wall with gypsum board. The roof consists of concrete, plaster board, and insulation. The floor is concrete slab covered with carpet.

BC1 is a high level security building with a very organized mechanical room. It has a 19 ton GSHP system with vertical loops consists of 6 heat pump units. The system has 17 boreholes. Each borehole is $300 \mathrm{ft}$ deep. The building has been operated for about one and a half year. The power supply for the electrical panels is easy to access and the main supply and return pipes are for the loop are also well exposed. The drawings are available to 
disclose all the details. The fluid used for the ground loop is water and 6 hp pump is used for water circulation.

The Geothermal research team visited BC1 building on September, 2010 and February, 2011 and made the walk-through survey on the building. The basic information of GSHP system and the available data for the building such as the lighting fixtures, appliances were searched for this walk through survey.

\section{Field Testing}

The owner of BC1 is a U.S. investor-owned electric utility that is headquartered in Pensacola, Florida. There are many restrictions to install the data gathering equipment because there are security issues and safety regulation. In addition, because of complexity of the system and limitation number of the instruments, the measured data are not available but the electric bill for the BC1.

\subsubsection{Commercial Building-BC2}

BC2 is a commercial building in downtown Pensacola, built in 2010 and the system operation starts on August 2010 as seen in Figure 2-7. It is an office building and there are nine offices in this building. For the building construction, energy efficient materials like ICF walls and Low-E windows have been used. Building is one story having an area of 4,250 square ft. The HVAC system of this building consists of a 13 ton GSHP system, with two 6 ton units and one 1 ton unit. The GSHP system utilizes a vertical loop, which is composed of 14 boreholes reaching a depth of 300 feet.

In BC2, two 6 ton units were responsible from the main heating and cooling of the building while the one ton unit was used for a computer server system. Two 6 ton units are located in the attic and there was no access to them at the time. These units have variable 
speed fans and dual speed compressors. There are two $1 \mathrm{hp} \mathrm{pumps} \mathrm{in} \mathrm{the} \mathrm{main} \mathrm{loop} \mathrm{that} \mathrm{one}$ of them is standby pump.

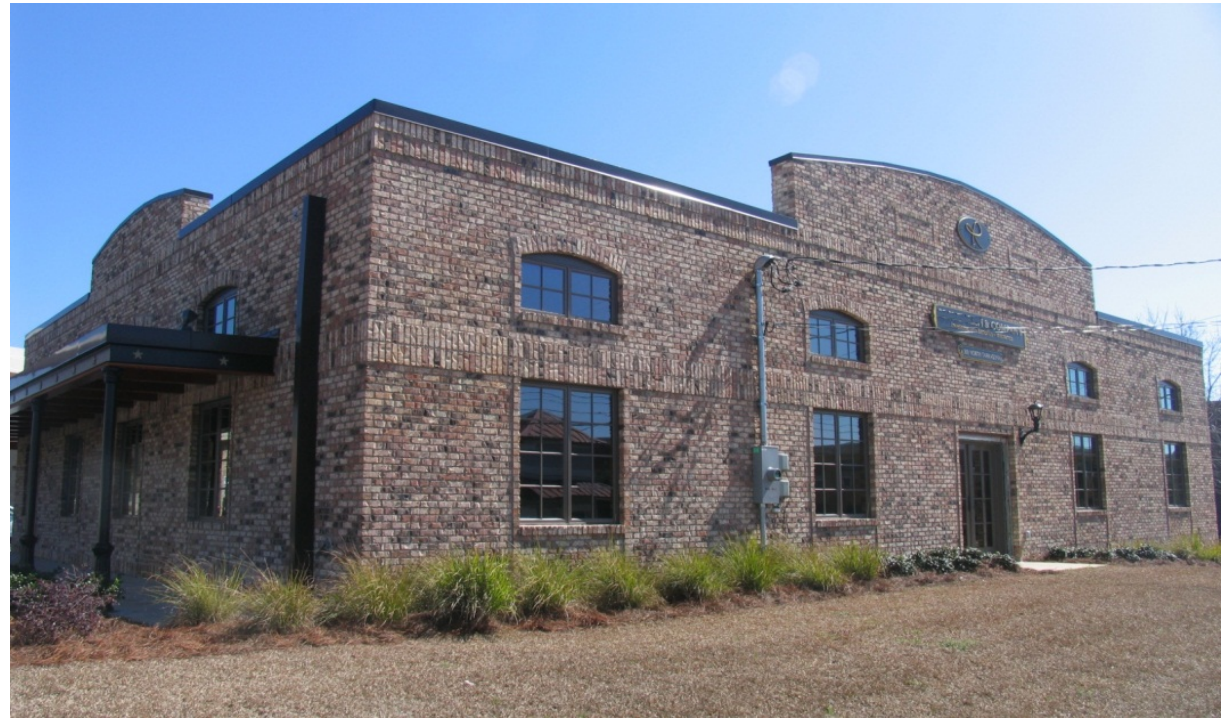

Figure 2-7: Front view of BC2

The Geothermal research team visited BC2 building on September, 2010 and February, 2011 and made the walk-through survey on the building. The basic information of GSHP system and the available data for the building such as the lighting fixtures, appliances were searched for this walk through survey.

\section{Field Testing}

The building was monitored for 20 days from Feb $18^{\text {th }}$ to March $9^{\text {th }}$, 2011. The following equipment was installed at the location:

- Fluxus ultrasonic Btu meter, that was installed on the main ground loop to measure and log the heat transfer rate to the ground

- Schenitec ultrasonic Btu meter, which was installed on one of the 6 ton units that serves north section of the building. 
- Wattnode with Campbell Scientific data logger, which was installed to measure and $\log$ the power consumption of the north section heat pump unit.

- 5 Hobo sensors to measure and log temperature and relative humidity of inside and outside of the building and also before and after the coil in the monitored heat pump unit.

The data obtained for 20 days from Feb $18^{\text {th }}$ to March $9^{\text {th }}, 2011$ are:

- Supply air temperature in the heat pump, return air temperature, air temperature close to a thermostat located on the northern building area, air temperature close to a thermostat located on the southern building area in the first floor and outdoor air temperature

- Flow rate and inlet and outlet temperatures of the water in the ground loop

- Power consumption of the heat pump

The electricity bill used for the calibration is the data of 2010. The billing data were collected at the end of 2010.

\subsubsection{Commercial Building-BC3}

BC3 is a commercial building in downtown Pensacola. It is three story restaurants building as seen in Figure 2-8. The first floor is used for open parking lot and storage. In the first floor area, there is no conditioned space. The second floor is 11,600 square feet and it is used for restaurant, bar and club. The third floor is used for office and club. The size of the third floor is 6300 square feet. The exterior wall consists of steel reinforce concrete block and gypsum board with rigid insulation. The roof structure is a prefinished Standing Seam Metal Room System with rigid insulation. The floor is concrete slab. 


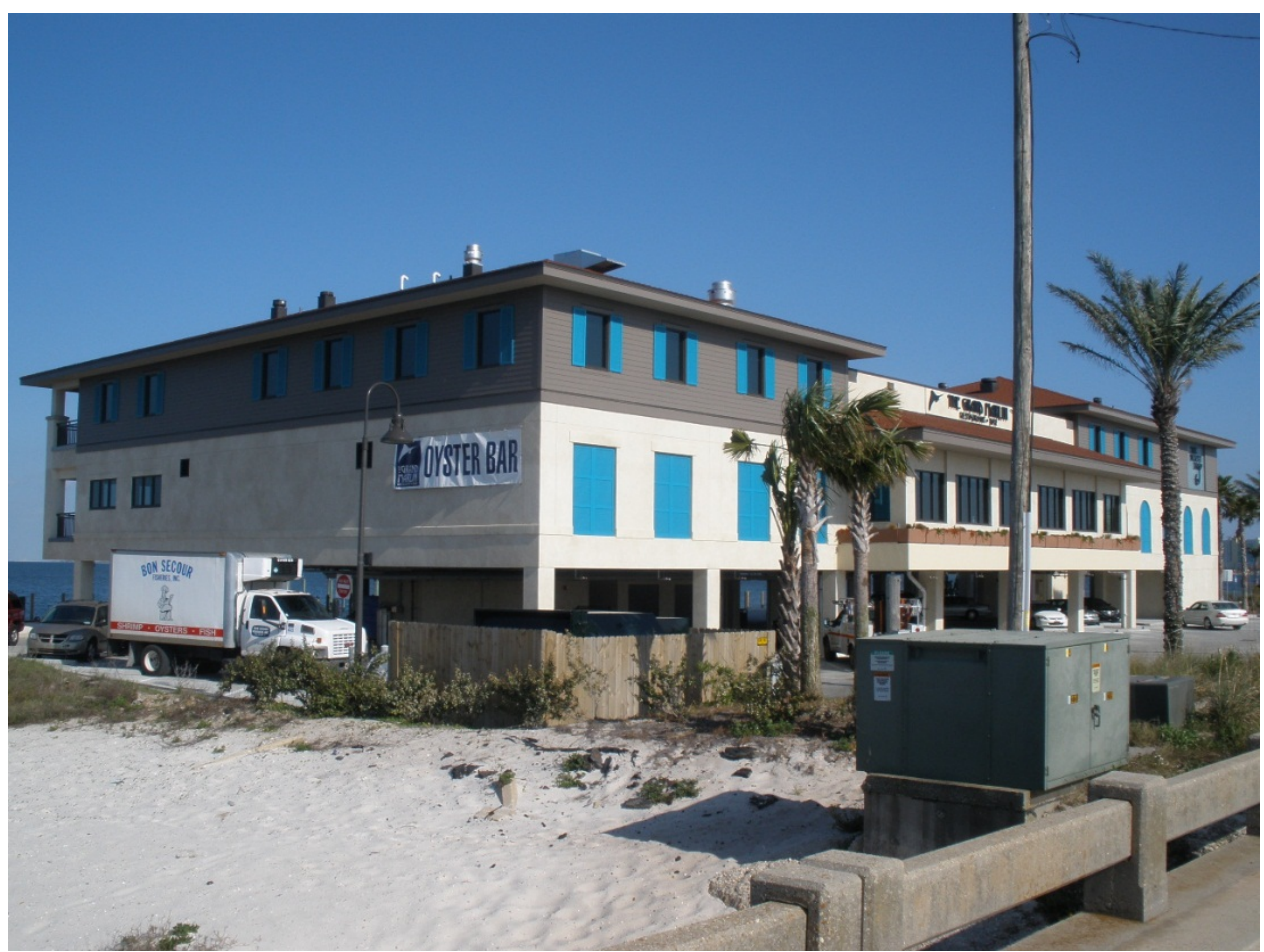

Figure 2-8: Front view of BC3

The HVAC system used for this building is a 129 ton GSHP system. The ground loop is composed of 5 circuits with 28 boreholes in each circuit. Each borehole has a $300 \mathrm{ft}$ depth and 3/4 in diameter U-tube pipe. Supply and return of each circuit are 4 inches pipes. Main loop pipe has an 8 inches diameter. Polyethylene pipes have been used in the whole ground loop and connected branches piping system. There are two 10 hp pumps in the main loop that one of them is standby pump.

The ground loop construction has been started at May 2009. The whole GSHP system construction took about one year and the system has been in operation since April 2010.

The Geothermal research team visited BC3 building on September, 2010 and February and March, 2011 and made the walk-through survey on the building. The basic information of GSHP system and the available data for the building such as the lighting fixtures, appliances were searched for this walk through survey. When the field test and 
walk-through survey was performed for this building, the third floor area was not used for its original plan because it was on the construction to make interior spaces. Therefore, half of the space was used for storage purpose.

There is no domestic water heating system using the ground loop in the facility. Mechanical contractor of the project has been changed once by the owner because of the unsatisfactory performance. The initial contractor built two times more loop than necessary so owners were very keen on reducing any cost possible. For this reason, a geothermal domestic water heating system, which could have worked very efficiently, has been abandoned.

\section{Field Testing}

The building was monitored for 21 days from March $11^{\text {th }}$ to March $31^{\text {st }}$, 2011. The following equipment was installed at the location:

- Schenitec ultrasonic Btu meter, which was installed on the entering and existing positions of a water pipe to measure the water flow rate in the pipe.

- Fluxus ultrasonic Btu meter, that was installed on the main ground loop to measure and log the heat transfer rate to the ground

- Wattnodes with Campbell Scientific data logger, which were installed to measure and log the power consumption of the heat pump systems in four mechanical room.

- 5 Hobo sensors to measure and log temperature and relative humidity of inside and outside of the building and also before and after the coil in the monitored heat pump unit.

At the last day of measurement, the research uninstalled data gathering equipment from electrical panels and electrical short occurred in this process. Due to this accident, the 
power supply to the restaurant and all services by the restaurant were all stopped for 30 minutes. All customers and employees in this restaurant had severe inconvenience in this time. The uninstallation time coincided with the restaurant service time because the uninstallation time was longer than the time the research team predicted due to the huge number of the GSHP system and its complexity. Therefore, the research team tried to avoid turning off the supplied power as much as it can, but it caused this accident.

As a result, the data of the GSHP power consumption were corrupted.

The data obtained for 21 days from March $11^{\text {th }}$ to March $31^{\text {st }}, 2011$ are:

- Supply air temperature in 3 ton heat pump, air temperature close to a thermostat located on the first floor, air temperature close to a thermostat located on the second floor, air temperature close to a thermostat located on the third floor

- Flow rate and inlet and outlet temperatures of the water in the ground loop

- Power consumption of the heat pump was corrupted

The electricity bill used for the calibration is the data of 2010. The billing data were collected at the end of 2010.

\subsubsection{Commercial Building-BC4}

BC4 is a hotel building located in Pensacola Beach. It consists of 117 rooms with 80,000 square ft area. It has been constructed in 2002. There are 117 room facilities with large public parking area, a meeting room, a large dining room and a limited breakfast area which is in total $80,145 \mathrm{ft}^{2}$, and the hotel includes some amenities such as one health club, two large outdoor heated pools, one outdoor heated spa and a large, shallow children's pool. The front view of BC4 is shown in Figure 2-9. 


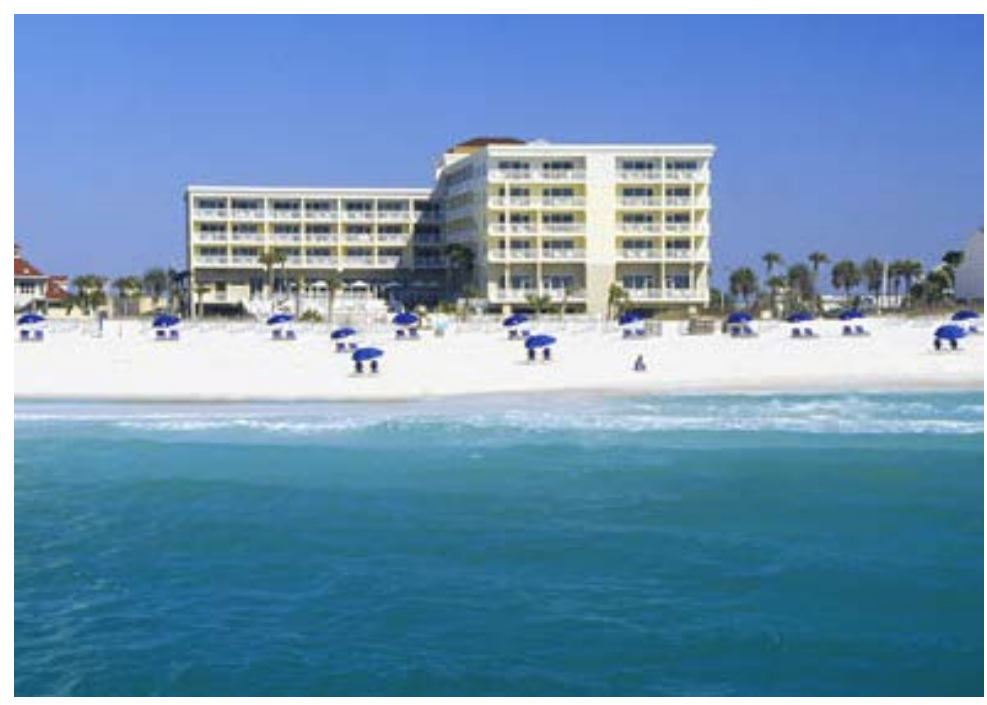

Figure 2-9: Southwest view of BC4

The exterior wall consists of concrete block stucco with gypsum board and is finished with exterior insulation. The insulation level of the roof structure is R-19. The floor is concrete slab covered with cork cover.

The HVAC system is a 300 tons hybrid GSHP. The system features a 150-ton closed-loop evaporative fluid cooler. Because of the limited installation field area available for the geothermal heat exchanger loop, the designer selected a 150 tons closed-loop evaporative fluid cooler to parallel the ground-coupled loop field which owns 98 boreholes with 200 depths and 1” U-tube to compose the HYGSHP system. The loop field is set up in parallel with the 150-ton fluid cooler, which offers considerable heat rejection control and redundancy. The primary domestic water heaters are three each, 35 tons and five horsepower water-to-water geothermal heat pumps. All pool and spa heating is provided by geothermal heat pumps. In addition, over 300 tons of room unitary, ducted geothermal heat pumps are used in guest suites and to serve all other conditioned areas of the hotel. The ground loop construction has been started at December 2001 and it took one and a half 
month to construct. The whole GSHP system construction took 7 months and the system has been operated at the early July 2002.

The ground loop is composed of 4 circuits with 24 boreholes in each circuit. Each borehole has a $200 \mathrm{ft}$ depth and 1 in diameter U-tube pipe. Supply and return of each circuit are 4 inches pipes. Main loop pipe has an 8 inches diameter. Polyethylene pipes have been used in the whole ground loop and connected branches piping system. There are two 40 hp pumps in the main loop that one of them is standby pump.

The Geothermal research team visited BC4 building on September, 2010 and made the walk-through survey on the building. The basic information of GSHP system and the available data for the building such as the lighting fixtures, appliances were searched for this walk through survey.

\section{Field Testing}

Because of security and safety issues of the building, the measurement was not available. The available data are the construction data, walk-through survey data and the electricity bill. The billing data were collected at the end of 2010.

\subsection{Utility Consumption Analysis}

Except the case BC1, electricity bills are available for the cases mentioned earlier. BC1 is a building in a complex that there is no separate meter for that. The available energy bills have been used to calibrate the models that will be discussed in the next chapter. In this section the analysis of the electricity consumption for different building applications (i.e. residential and commercial) and sizes by determination of the electricity consumption index (electricity consumption per unit floor area) is presented. 
The available billing information for the above-mentioned cases covers different periods of the year. The overlap period between the all available building information periods consists August, September and October. The electricity consumptions per unit floor area of the buildings have been depicted in Figure 2-10 for August, September and October.

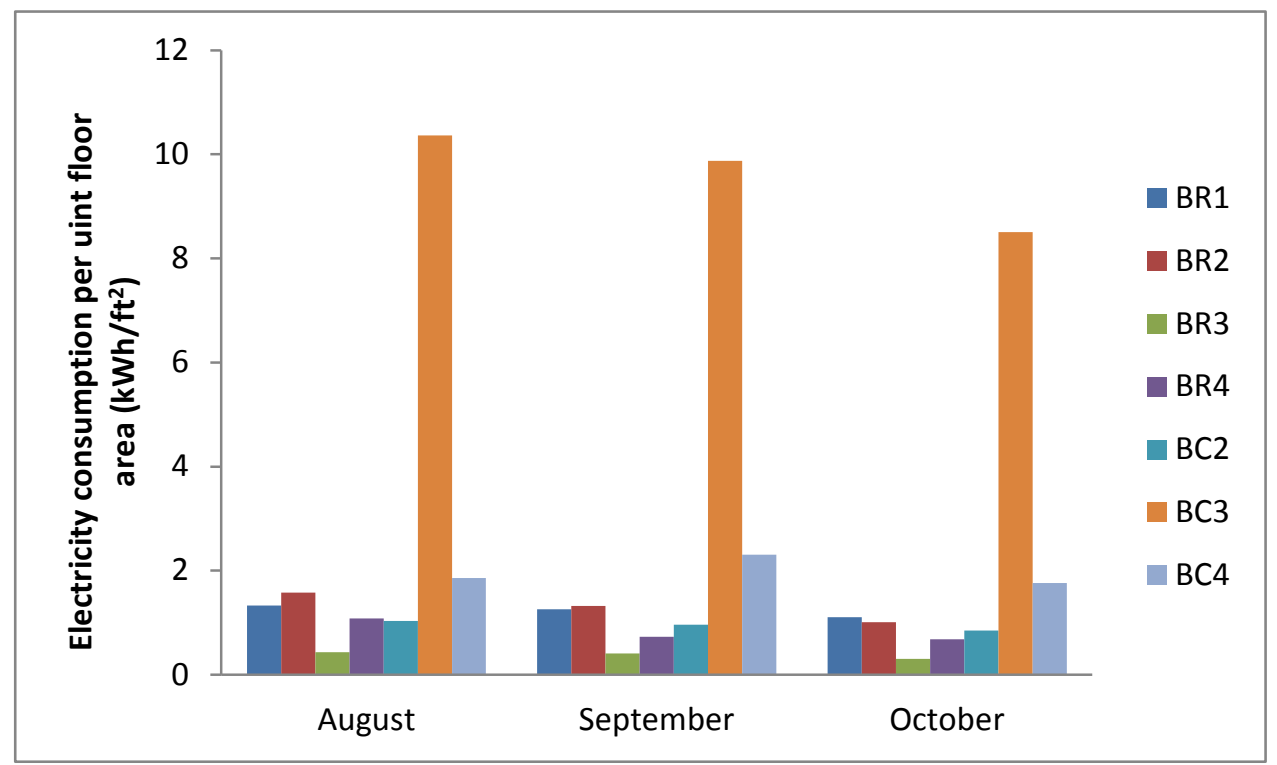

Figure 2-10: The electricity consumptions per unit floor area of the

BR1 and BR2 are residential buildings located at Tampa area and equipped with open loop GSHP systems. The electricity consumption indices for these two buildings are at the same order for all three months. For example the electricity consumption index in September is 1.26 for BR1 and 1.32 for BR2.

BR3 and BR4 are residential buildings located at Pensacola area and equipped with closed loop GSHP systems. The electricity consumption index for residential buildings in Pensacola area is much lower than that in Tampa area which cannot be a result of difference between the weather condition in Tampa and Pensacola. Thus the better 
performance of close loop GSHP with respect to open loop GSHP system is the major reason of lower electricity consumption indices of BR3 and BR4 compared to BR1 and BR2. The milder weather condition of Pensacola area with respect to Tampa area during the cooling season can be considered as a minor result of relatively low electricity consumption index for residential buildings in Pensacola area. GSHP system of BR4 consists of a horizontal ground loop that has been reflected in its higher electricity consumption index in comparison to the electricity consumption index of BR3 which equipped with vertical ground loop.

Electricity consumption index varies greatly with changing the application of a commercial building. As can be seen in Figure 2-10 for BC2 as a relatively small office building with a few number of employees the electricity consumption index is around 1 . For BC3 which is a restaurant with 13,600 square feet floor area the electricity consumption index is around twice of the electricity consumption index of BC2. For BC4 which is a 117 room Hotel with more than 80,000 square feet floor area the electricity consumption index rises up to 10.4 . 


\section{CHAPTER 3: Baseline Model Development and Calibration}

\subsection{Introduction}

Present case studies will be carried out to research on a variety of geothermal heat pump systems and to investigate the energy performance of existing buildings located in Florida and Alabama. The total case studies include 4 residential houses and 3 commercial buildings, with different ID numbers respectively (e.g. BR1, residential building1 and BC1, commercial building1), due to the reason of owner's privacy.

The main purpose of this chapter is to illustrate the advantages or disadvantages of the geothermal heat pump systems, compared with air source heat pump systems (conventional air condition system) from the energy consumption point view.

In this chapter, four residential (BR1 to BR4) and four commercial building (BC1 to BC4) will be studied, and the building details and simulation methodology will be briefly presented and explained. At last, the simulation comparison results between the ground source heat pump and air source heat pump will be given and discussed. The performance of the GSHP system has been monitored for about 3 weeks for cases BR1 to BR4, BC2, and BC3. There are 3 steps in energy saving calculation of GSHP system in each building.

1- To model the building and GSHP system using TRNSYS/EnergyPlus

2- To calibrate the model using monitoring data and available billing information of the building

3- To replace GSHP unit in calibrated model with a commonly used Air Source Heat Pump (ASHP) unit with the same capacity

4- Subtract the energy use of the GSHP model from the energy use of the ASHP model 
The GSHP unit models which are employed in each building and commonly used equivalent AHSP units have been shown in Table 3-1.

Table 3-1: GSHP unit models of studied buildings and the equivalent ASHP unit models

\begin{tabular}{|c|c|c|}
\hline Building & GSHP unit model & $\begin{array}{l}\text { Equivalent ASHP unit } \\
\text { model }\end{array}$ \\
\hline BR1 & $\begin{array}{c}\text { CLIMATE MASTER TTH038 } \\
\text { (3 tons) }\end{array}$ & $\begin{array}{c}\text { Carrier 50TCQ A04 } \\
\text { (3 tons) }\end{array}$ \\
\hline BR2 & $\begin{array}{l}\text { CLIMATE MASTER TTH049 } \\
\text { (4 tons) }\end{array}$ & $\begin{array}{c}\text { Carrier } 50 T C Q \text { A05 } \\
\text { (4 tons) }\end{array}$ \\
\hline BR3 & $\begin{array}{c}\text { WaterFurnace Envision NDH064 } \\
\text { (5 tons) }\end{array}$ & $\begin{array}{r}\text { Carrier 50TCQ A06 } \\
\text { (5 tons) }\end{array}$ \\
\hline BR4 & $\begin{array}{c}\text { WaterFurnace } \\
\text { 1- E Series (E036) (3 tons) }\end{array}$ & $\begin{array}{c}\text { Carrier } \\
\text { 1-HBC3 ( } 2 \text { tons) }\end{array}$ \\
\hline & 2- Versatec (2 tons) & 2-50TCQ A04 (3 tons) \\
\hline $\mathrm{BC} 1$ & $\begin{array}{l}\text { WaterFurnace Envision } \\
\text { 1-ND064 (5 tons) } \\
\text { 2-ND038 (3 tons) }\end{array}$ & $\begin{array}{l}\text { Carrier 50TCQ } \\
\text { 1- A06 (5 tons) } \\
\text { 2-A04 (3 tons) }\end{array}$ \\
\hline $\mathrm{BC} 2$ & $\begin{array}{c}\text { WaterFurnace Envision NDH072 } \\
\text { (6 tons) }\end{array}$ & $\begin{array}{crc}\text { Carrier } & \text { 50TCQ } & \text { A07 } \\
& \text { (6 tons) } & \end{array}$ \\
\hline $\mathrm{BC} 3$ & FHP EC series & Carrier 50TCQ series \\
\hline $\mathrm{BC} 4$ & $\begin{array}{l}\text { CLIMATE MASTER } \\
\text { (Total } 180 \text { tons) }\end{array}$ & $\begin{array}{c}\text { Carrier } \\
\text { (Total } 180 \text { tons) }\end{array}$ \\
\hline
\end{tabular}

TRNSYS will be employed to simulate three residential buildings and three commercial buildings with both geothermal heat pump system and conventional air conditioning system. TRNSYS is a transient systems simulation FORTRAN program with a modular structure for simulating energy systems. TRNSYS is also notably powerful for steady problems. A TRNSYS project is typically setup by connecting components graphically in an interface called Simulation Studio. TRNSYS components are often referred to as Types. Each type based on the mathematical model of the component calculates the output parameters using supplied parameters and input data. 
One residential building and one commercial building will be analyzed using EnergyPlus. EnergyPlus is a whole building energy simulation program that engineers, architects, and researchers use to model energy and water use in buildings. EnergyPlus models heating, cooling, lighting, ventilation, other energy flows, and water use. The building geometry is created by the Google SketchUp ${ }^{\mathrm{TM}}$ using individual plug-ins for TRNSYS and EnergyPlus.

At the end a comparative study between TRNSYS and EnergyPlus has been done in to see the difference between the simulation results of TRNSYS and EnergyPlus of a building.

\subsection{Calibration Strategy}

The performance of the GSHP system has been monitored for about 3 weeks for cases BR1 to BR4, BC2, and BC3. The following parameters were measured in each building:

- Water flow rate and supply and return temperatures of the main loop.

- Water flow rate and supply and return temperatures of one (or more) heat pump unit(s).

- Power consumption of one (or more) heat pump unit(s).

- Temperature and relative humidity of the inside and outside of the building.

For building with more than one heat pump unit the number of monitored heat pump units is dependent of available monitoring devices at the time. From above-mention parameters water flow rates and temperature and relative humidity outside of the building are inputs of the modeling. Other parameters are used as check points of simulation results. These parameters and available electricity bills of the building are employed to calibrate the 
building and GSHP system simulation. The TRNSYS/EnergyPlus models are run for the monitoring period and billing periods for calibration purposes.

For simulation of each case a number of parameters are assumed in the modeling. The assumed parameters in the modeling procedure in importance order are:

1- Cooling/Heating set point

2- Infiltration rate

3- Ground temperature

4- People schedule

5- Equipment schedule

6- Lighting schedule

The main modeling calibration strategy is changing the assumed parameters in an acceptable range $( \pm \% 10)$ to match the simulation results and the check points that have been mentioned earlier.

\subsection{Case Study-BR1}

Input data of BR1 simulation model will be presented in this section. The input data for the TRNSYS model are acquired based on limited information including the floor plan and survey data from the owner. Due to this limited information, several input data for the simulation model are assumed based on the information from other similar constructions in the local area or the default value in the software.

The BR1 consists of three rooms with 3 occupants located in Tampa. It has a total floor area of 1,600 square ft one story building.

This residential GSHP consists of two-well open loop system which is running with 1 hp water pump and 8 GPM flow rate. 


\subsubsection{Building Details}

Table 3-2 summarizes the floor areas for various conditioned and unconditioned spaces considered in the building baseline model.

Table 3-2: The list of Building Area

\begin{tabular}{|l|l|l|l|}
\hline $\begin{array}{l}\text { Building Use } \\
\text { (Occupancy Type) }\end{array}$ & $\begin{array}{l}\text { Conditioned } \\
\text { Area (sf) }\end{array}$ & $\begin{array}{l}\text { Unconditioned } \\
\text { Area (sf) }\end{array}$ & Total Area (sf) \\
\hline Garage & & 441 & 441 \\
\hline $\begin{array}{l}\text { Living area (including } \\
\text { bathrooms, kitchen, } \\
\text { bedrooms) }\end{array}$ & 1265 & 1265 \\
\hline Total Area (sf) & 1265 & 441 & 1706 \\
\hline
\end{tabular}

\subsubsection{Building Model Specifications}

From the architectural drawings, the simulation model of the building was developed by the GOOGLE SKETCHUP as illustrated in Figure 3-1. Table 3-3 provides a summary of model basic features and Table 3-4 presents the gathered input data from the drawing and some assumptions used for the baseline building model. Any difference between the building data from the drawings and the actual building condition was inspected during the walk-through survey.

Table 3-3: Building Model Features

\begin{tabular}{|l|c|l|c|}
\hline Project Name & BR1 & Project Address & Tampa, FL \\
\hline Simulation Program & TRNSYS & Number of Floors & 1 \\
\hline Principal Heating Source & Electricity & Weather File & Tampa12842.tm2 \\
\hline Operation & $24 / 7$ & Set point Temperature & $\begin{array}{c}21 / 23^{\circ} \mathrm{C} \\
\text { (heating/cooling) }\end{array}$ \\
\hline
\end{tabular}




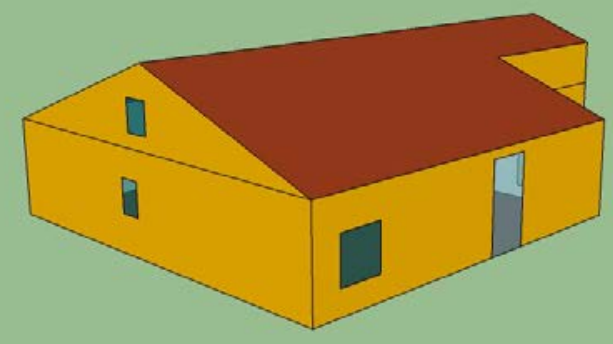

(a) Northeast view of BR1 model

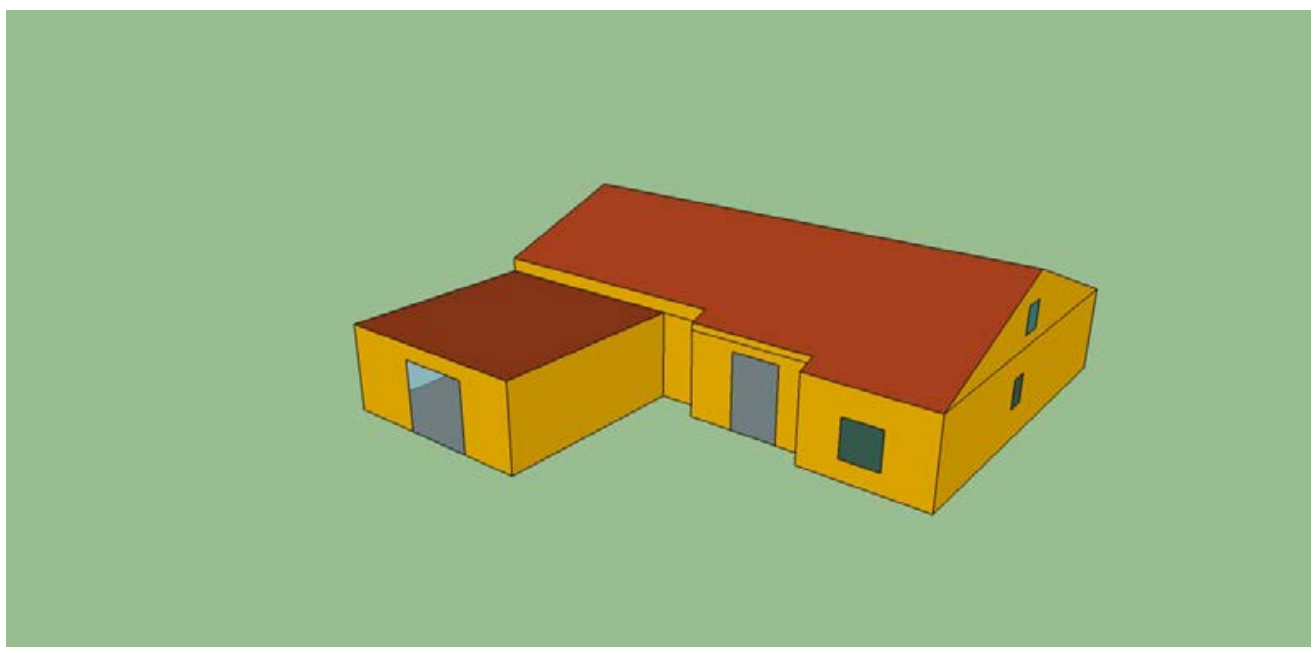

(b) Southeast view of BR1 model

Figure 3-1: 3-D Renderings for Building Energy Simulation Model 
Table 3-4: Input Summary for the Baseline Building Model

\begin{tabular}{|c|c|}
\hline Construction Details & Existing Building \\
\hline Total Conditioned Area $\left(\mathrm{m}^{2}\right)$ & 158 \\
\hline Exterior wall layers & Wall: Concrete block stucco $0.07 \mathrm{~m}$, Drywall $0.03 \mathrm{~m}$ \\
\hline Wall insulation & Total U-value $=2.021 \mathrm{~W} / \mathrm{m}^{2} \mathrm{k}$ \\
\hline Roof Layer & $\begin{array}{l}\text { Insulation(R-33), Metal Deck, plasterboard } \\
\qquad \text { Total U-value }=0.361 \mathrm{~W} / \mathrm{m}^{2} \mathrm{k}\end{array}$ \\
\hline Floor Construction & $0.08 \mathrm{~m}$ concrete on ground, Cork cover \\
\hline Percent Glazing Area & $6 \%$ \\
\hline Glazing U-Value & $\mathrm{U}-2.89 \mathrm{~W} / \mathrm{m}^{2} \mathrm{k}$ (assumed) \\
\hline \multicolumn{2}{|l|}{ Plant Details } \\
\hline Ground heat exchanger & Open loop \\
\hline Borehole hole & $80 \mathrm{ft}$ deep \\
\hline Water Pump & $1 \mathrm{hp}, 8 \mathrm{GPM}$ \\
\hline Ground water temperature $\left({ }^{\circ} \mathrm{C}\right)$ & 24 \\
\hline \multicolumn{2}{|l|}{ water Source HEAT PUMP } \\
\hline System Type & Climatemaster TTV38(3 tons) \\
\hline Total System Airflow & Constant air flow \\
\hline Cooling Setpoint Daytime/nighttime $\left({ }^{\circ} \mathrm{C}\right)$ & 23.3 \\
\hline Heating Setpoint - Daytime/Nighttime $\left({ }^{\circ} \mathrm{C}\right)$ & 21.1 \\
\hline \multicolumn{2}{|l|}{ Air Source Heat Pump (ASHP) } \\
\hline System Type & Carrier 50 TCQ A04 \\
\hline Cooling Setpoint Daytime/nighttime $\left({ }^{\circ} \mathrm{C}\right)$ & 23.3 \\
\hline Heating Setpoint - Daytime/Nighttime $\left({ }^{\circ} \mathrm{C}\right)$ & 21.1 \\
\hline \multicolumn{2}{|l|}{ Internal Loads } \\
\hline Lighting Power Density (W/ft²) & 1.0 (assumed) \\
\hline Lighting/ Daylighting Controls & NA \\
\hline Equipment/Plug load Density (W/ft $\left.{ }^{2}\right)$ & 1.5 (assumed) \\
\hline \multicolumn{2}{|l|}{ Miscellaneous } \\
\hline Occupancy Density & $\operatorname{Max}=3$ \\
\hline Operating Schedules & Residential Schedule \\
\hline Occupancy & Residential Schedule \\
\hline Lighting & $17: 00-24: 00$ \\
\hline Infiltration & 0.5 \\
\hline
\end{tabular}




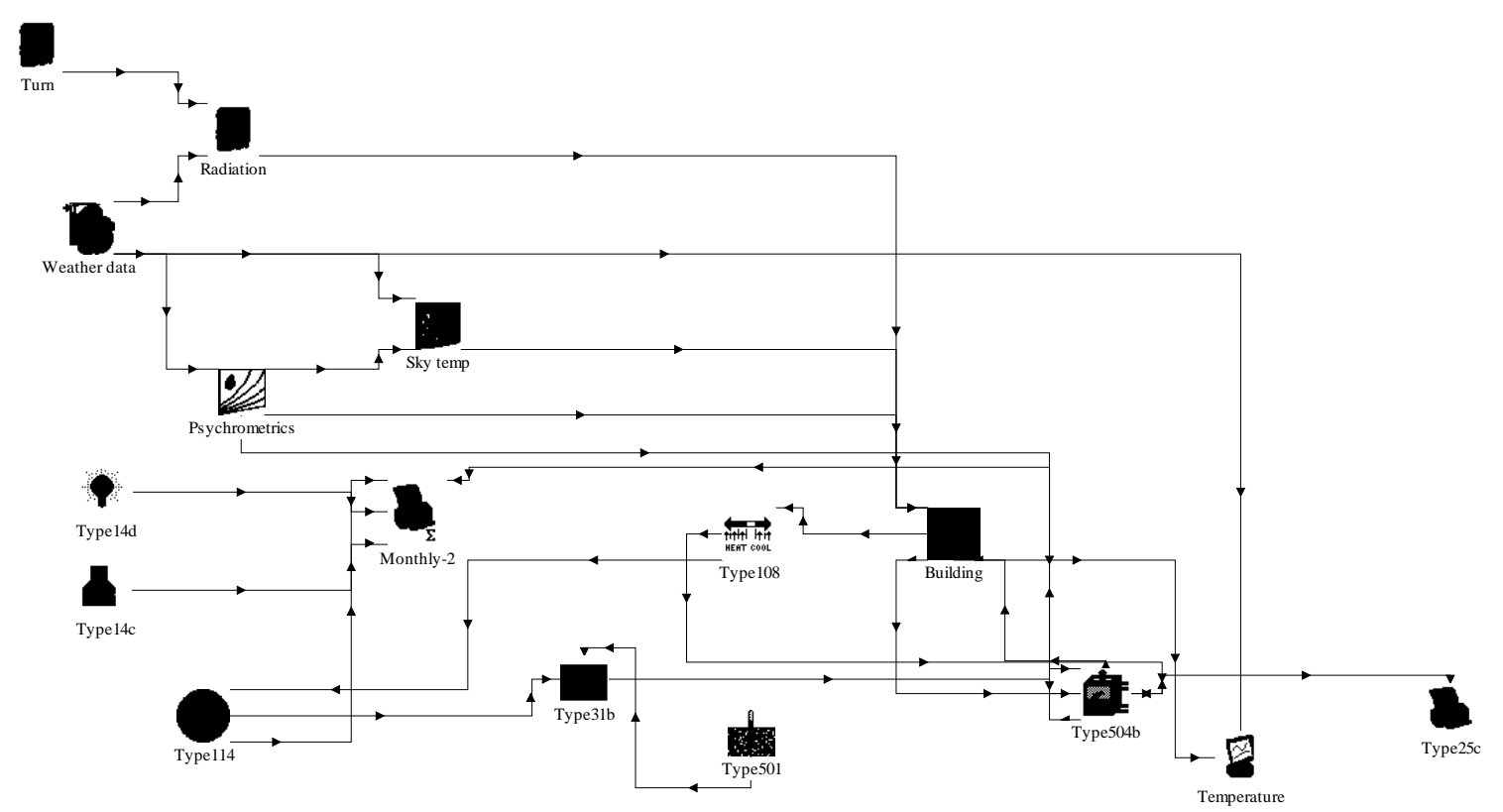

Figure 3-2: Open loop ground source heat pump -TRNSYS connection map

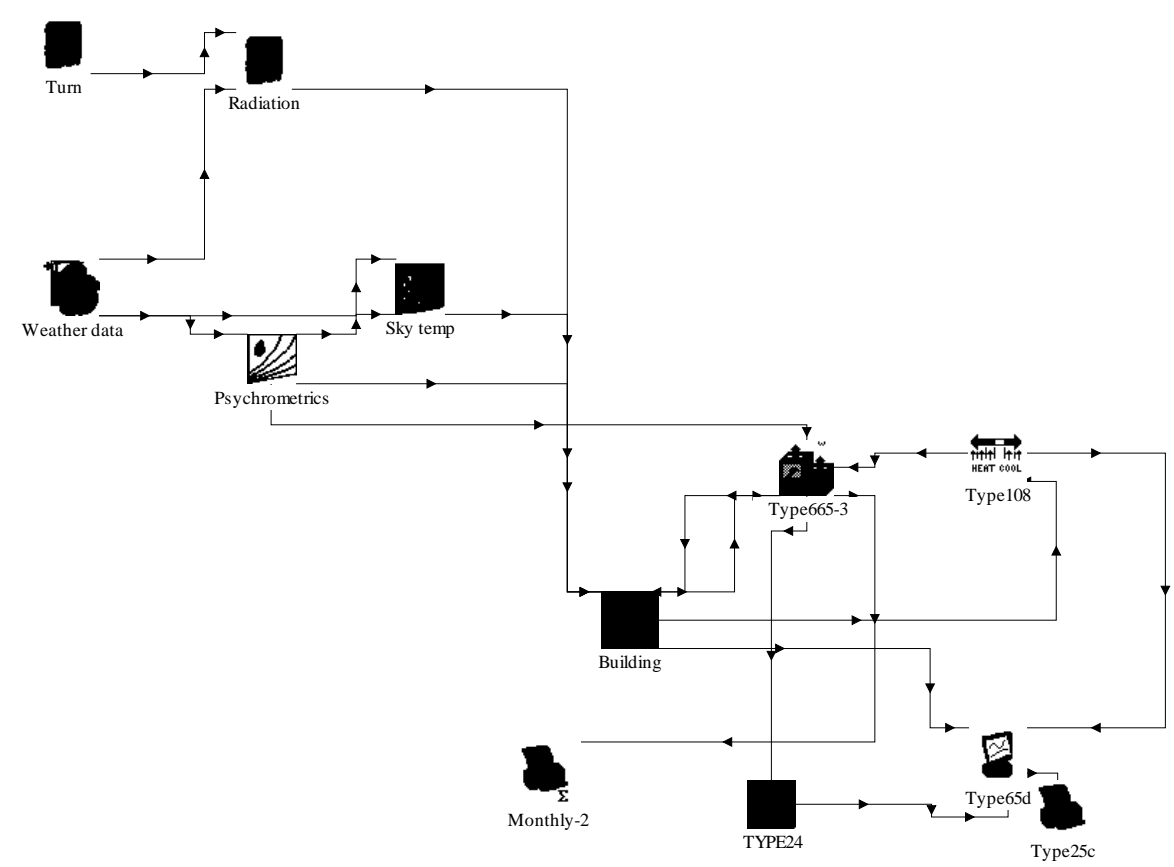

Figure 3-3: Conventional air source heat pump-connection map 
Building with GSHP system is modeled in the simulation studio. The performance of each of the system components is characterized before the system can be characterized.

Figure 3-2 and Figure 3-3 show the TRNSYS maps of GHSP system and Air source heat pump (ASHP) system which is with the same capacity. And the types in the TRNSYS are explained as below. System is composed of following main TRNSYS components that are included in the simulation environment:

- Type 56-Multi-zone building

- Type114-Single speed pump

- Type 108-Five-stage thermostat

- TMY2-Weather generator

- Type 69b- Effective Solar temperature

- Type 33e-Psychrometrics: dry bulb and relative humidity known

The following TRNSYS types belonging to the TESS library are employed:

- Type-31b- horizontal pipe

- Type 504b-Water to water heat pump

- Type 501- Soil temperature profile

- Type14b-lighting consumption/schedule

- Type14c-other equipment consumption/schedule

- Type665 air source heat pump

\subsubsection{Simulation Results}

After two comparative simulation with different HVAC system in the same envelop, and the system are carefully calibrated with the limited measure and gathered data, such as heat pump consumption and, Annual electric consumption. The mainly result will 
focus on the energy saving between the geothermal heat pump system and conventional HVAC consumption.

From Figure 3-4, the difference of heat pump electric energy consumption between the simulation result and measured data is less than $8 \%$ during the same period (20 days in Dec).

In the Figure 3-5, the result of comparison of total energy consumption between the simulation data and electric bill shows this simulation result match with the real electric bill data, and the trend of the simulation data is consistent with the real electric bill. But several variables are still the uncertainty of this simulation that we should not omit the lighting and equipment schedule, typical weather data. However, with the reasonable assumption and the carefully calibration, the result below is trustable and convincing in many points.

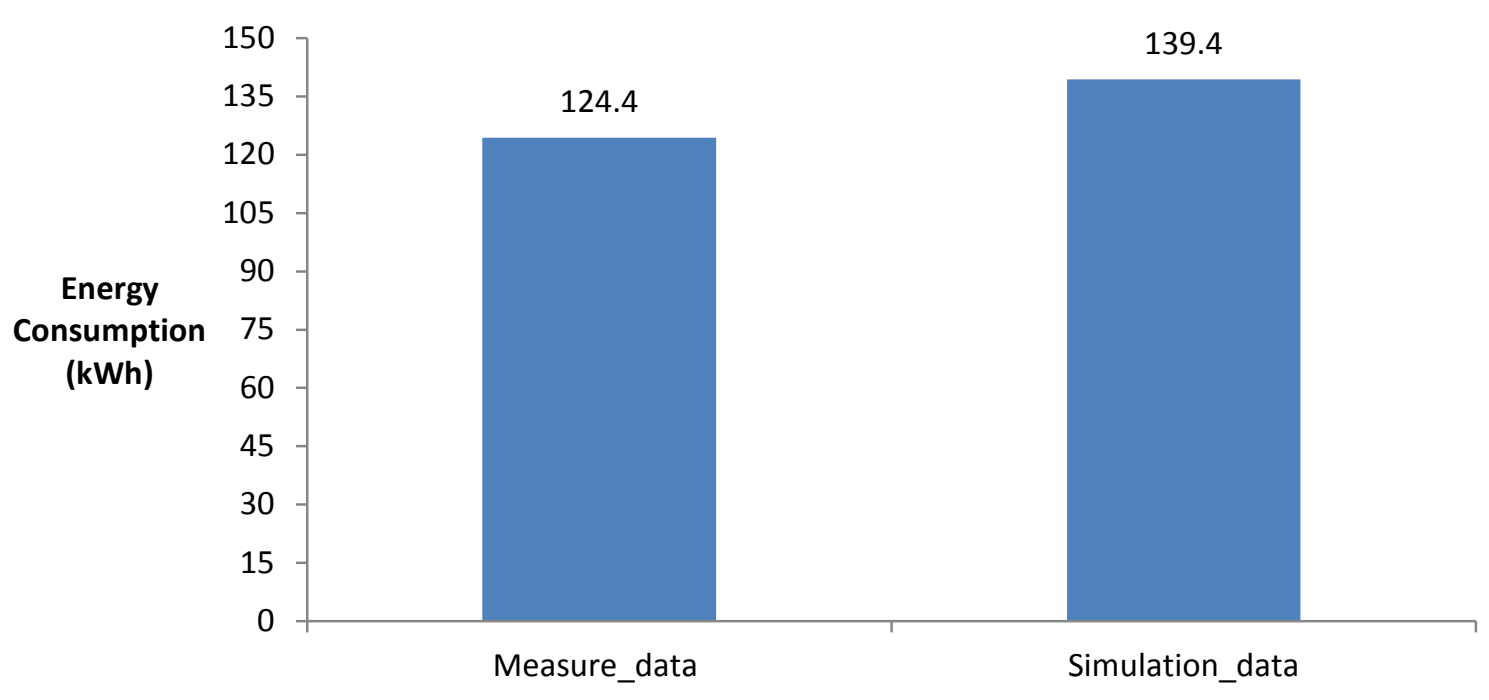

Figure 3-4: Comparison of heat pump consumption between simulation data and measure data 


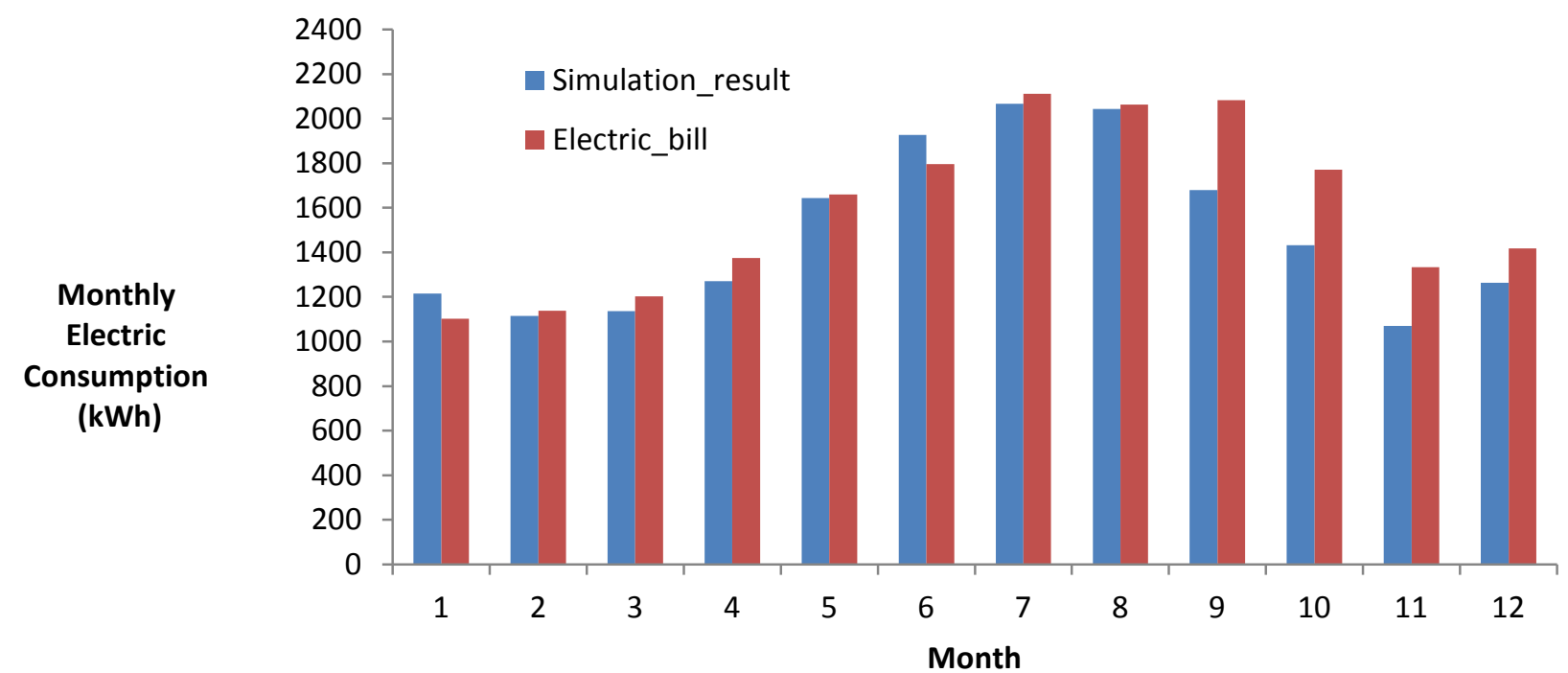

Figure 3-5: Comparison between monthly electric data from simulation and owner’s electric bill

From Figure 3-7, the ground source heat pump will save $14 \%$ of annual energy consumption compared with conventional heat pump (air source heat pump) when we consider the HVAC system only, and it will save $6.2 \%$ in the whole building energy consumption (with the same lighting and equipment consumption for both GSHP and conventional system) from Figure 3-6.

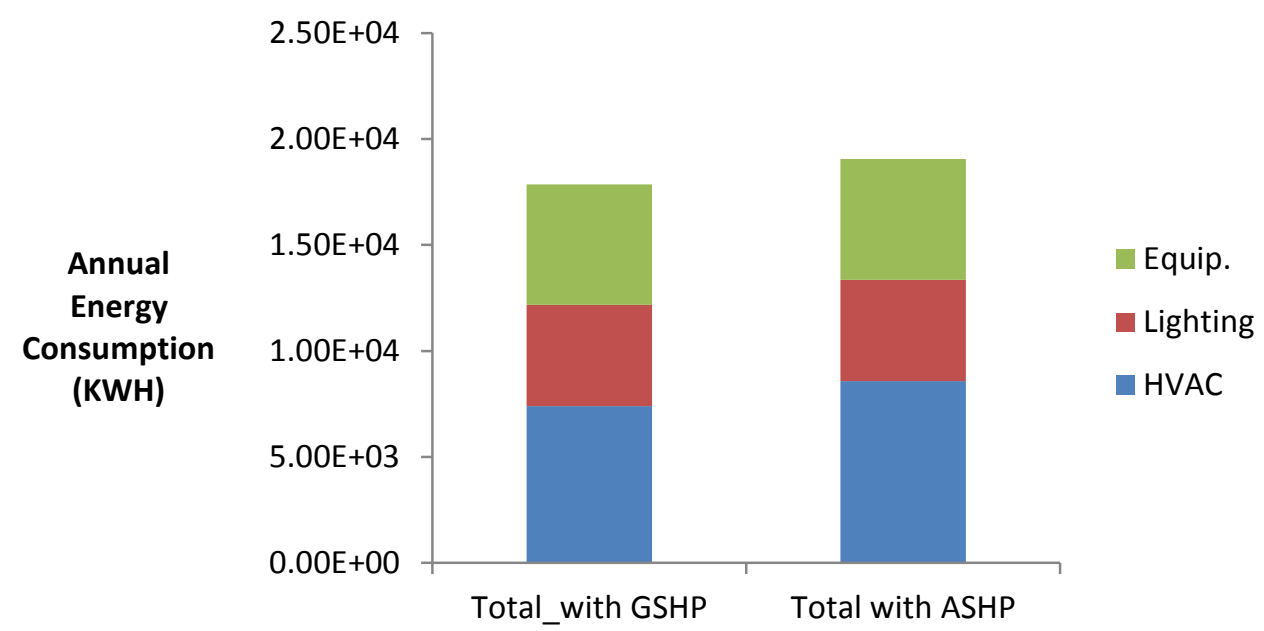

Figure 3-6: Comparison of total building energy consumption between GHSP and ASHP 


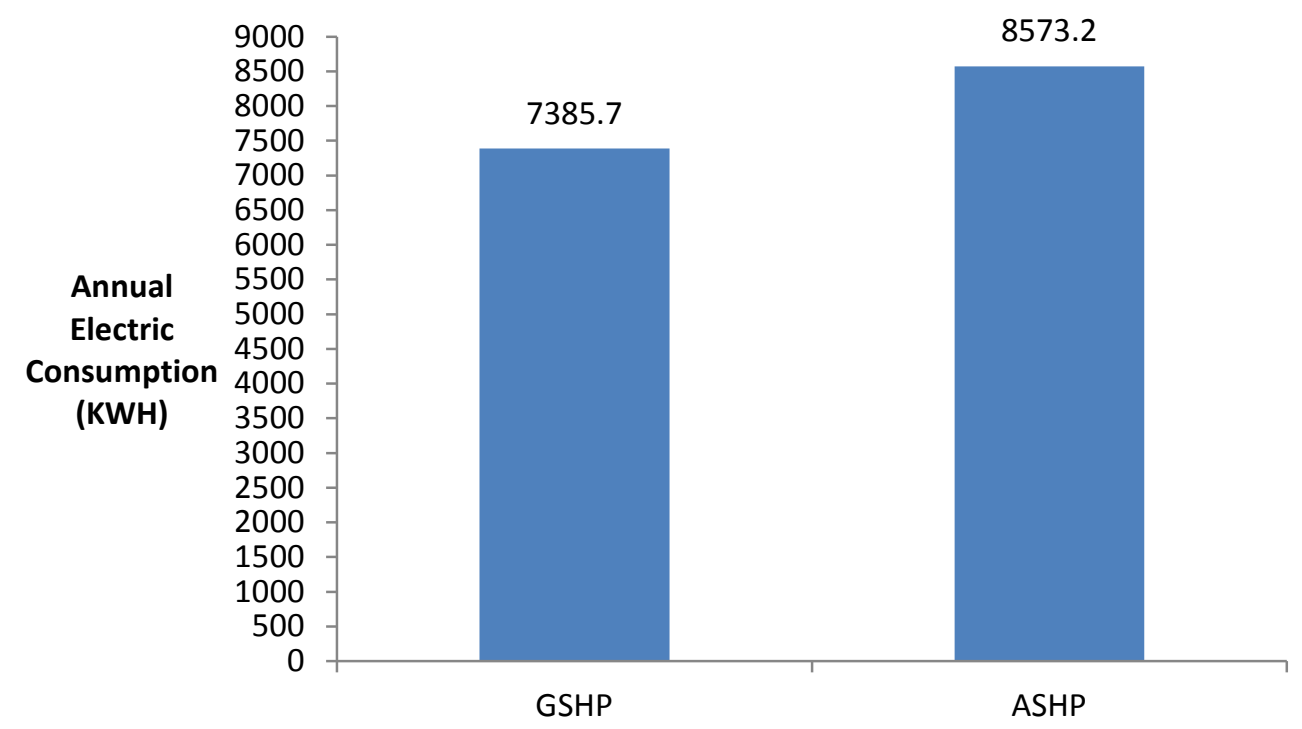

Figure 3-7: Comparison of annual HVAC energy consumption between GSHP and ASHP

\subsection{Case Study-BR2}

Input data and simulation results of BR2 simulation model will be presented in this section. The input data for the TRNSYS model are acquired based on limited information including the floor plan and survey data from the owner. Due to this limited information, several input data for the simulation model are assumed based on the information from other similar constructions in the local area or the default value in the software.

The BR2 consists of three rooms with 4 occupants located in Tampa. It has a total floor area of 2,000 square $\mathrm{ft}$ one story building.

This residential GSHP consists of two-well open loop system which is running with 1 hp water pump and 8 GPM flow rate. The details of the system will be provided in the Tables 3-4, 3-5and 3-6 as below.

\subsubsection{Building Details}

Table 3-5 summarizes the floor areas for various conditioned and unconditioned spaces considered in the building baseline model. 
Table 3-5: The list of Building Area

\begin{tabular}{|l|l|l|l|}
\hline $\begin{array}{l}\text { Building Use } \\
\text { (Occupancy Type) }\end{array}$ & $\begin{array}{l}\text { Conditioned } \\
\text { Area (sf) }\end{array}$ & $\begin{array}{l}\text { Unconditioned } \\
\text { Area (sf) }\end{array}$ & Total Area (sf) \\
\hline Garage & 785 & 315 & 315 \\
\hline $\begin{array}{l}\text { Bedrooms (including } \\
\text { bathroom) }\end{array}$ & 720 & 785 \\
\hline $\begin{array}{l}\text { Living room (including } \\
\text { Kitchen) }\end{array}$ & 125 & & 720 \\
\hline Hallway & 55 & & 125 \\
\hline Laundry room & 1685 & 315 & 55 \\
\hline Total Area & & 2000 \\
\hline
\end{tabular}

\subsubsection{Building Model Specifications}

From the architectural drawings, the simulation model of the building was developed by the GOOGLE SKETCHUP as illustrated in Figure3-8. Table 3-6 provides a summary of model basic features and Table 3-7 presents the gathered input data from the drawing and some assumptions used for the baseline building model. Any difference between the building data from the drawings and the actual building condition was inspected during the walk-through survey.

Table3-6: Building Model Features

\begin{tabular}{|l|c|l|c|}
\hline Project Name & BR2 & Project Address & Tampa, FL \\
\hline Simulation Program & TRNSYS & Number of Floors & 1 \\
\hline Principal Heating Source & Electricity & Weather File & Tampa12842.tm2 \\
\hline \multicolumn{1}{|c|}{ Operation } & $24 / 7$ & Set point Temperature & $\begin{array}{c}21 / 23^{\circ} \mathrm{C} \\
\text { (heating/cooling) }\end{array}$ \\
\hline
\end{tabular}

The TRNSYS map for BR2 is similar with the BR1 with open loop system; please see the Figure 3-2 and Figure 3-3 for reference. 


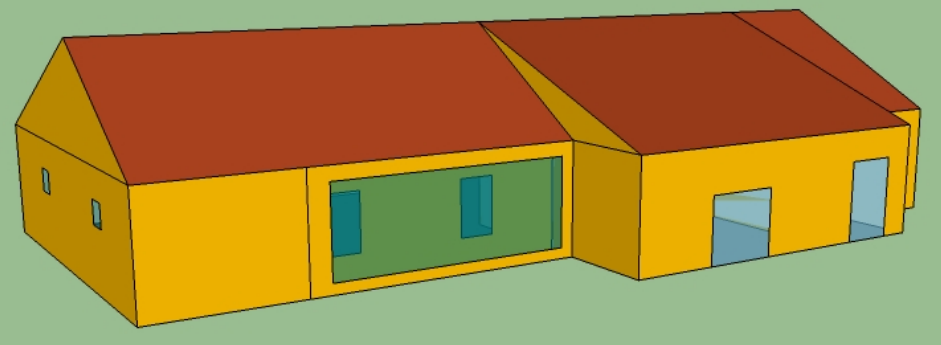

(a)Northeast view of BR2 model

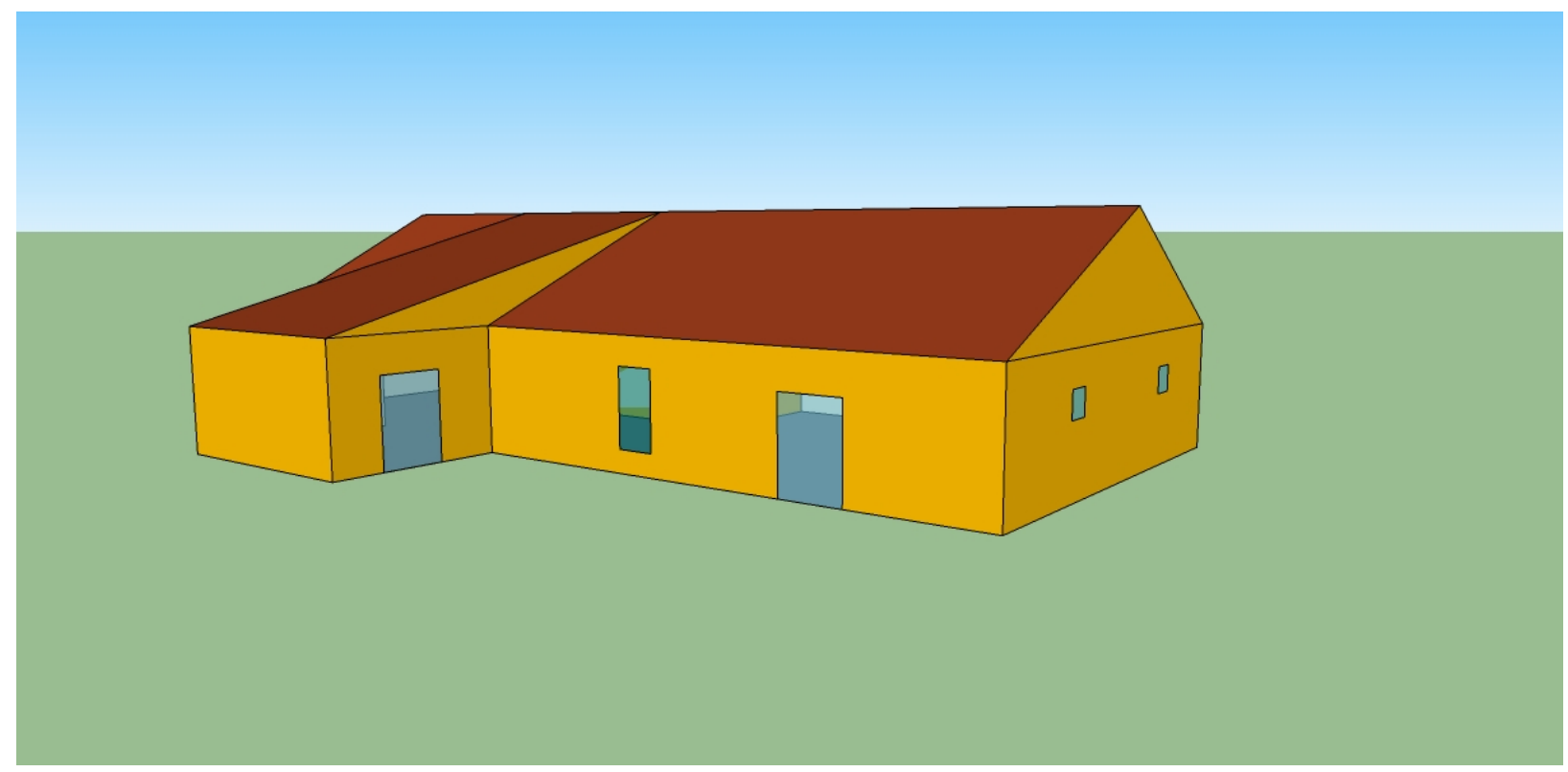

(b) Southeast view of BR2 model

Figure 3-8: 3-D Renderings for Building Energy Simulation Model 
Table 3-7: Input Summary for the Baseline Building Model

\begin{tabular}{|c|c|}
\hline Construction Details & Existing Building \\
\hline Total Conditioned Area $\left(\mathrm{m}^{2}\right)$ & 223 \\
\hline Exterior wall layers & $\begin{array}{c}\text { Concrete block stucco } 0.1 \mathrm{~m} \text {, Insulation, ASHRAE } 0.112 \\
\text { Drywall } 0.012 \mathrm{~m}, \quad \text { Total U-value }=0.309 \mathrm{~W} / \mathrm{m}^{2} \mathrm{k}\end{array}$ \\
\hline Roof Layer & Insulation(R-33), plywood, plasterboard Total U-value $=0.317 \mathrm{~W} / \mathrm{m}^{2} \mathrm{k}$ \\
\hline Floor Construction & $0.08 \mathrm{~m}$ concrete on ground, carpet, Floor_insulation_ashrae900 \\
\hline Percent Glazing Area & $6 \%$ \\
\hline Glazing U-Value & $\mathrm{U}-2.89 \mathrm{~W} / \mathrm{m}^{\wedge} 2 \mathrm{k}$ (assumed) \\
\hline \multicolumn{2}{|l|}{ Plant Details } \\
\hline Ground heat exchanger & Open loop \\
\hline Borehole hole & $150 \mathrm{ft}$ deep $100 \mathrm{ft}$ well spacing \\
\hline Water Pump & $1 \mathrm{hp}, 8 \mathrm{GPM}$ \\
\hline Ground water temperature & $23^{\circ} \mathrm{C}$ \\
\hline \multicolumn{2}{|l|}{ water Source HEAT PUMP } \\
\hline System Type & Climatemaster TTV49(4 tons) \\
\hline Total System Airflow & Constant air flow \\
\hline Cooling Setpoint Daytime/nighttime $\left({ }^{\circ} \mathrm{C}\right)$ & 23 \\
\hline Heating Setpoint - Daytime/Nighttime $\left({ }^{\circ} \mathrm{C}\right)$ & 21 \\
\hline \multicolumn{2}{|l|}{ Air Source Heat Pump (ASHP) } \\
\hline System Type & Carrier 50 TCQ A05 \\
\hline Cooling Setpoint Daytime/nighttime $\left({ }^{\circ} \mathrm{C}\right)$ & 23 \\
\hline Heating Setpoint - Daytime/Nighttime $\left({ }^{\circ} \mathrm{C}\right)$ & 21 \\
\hline \multicolumn{2}{|l|}{ Internal Loads } \\
\hline Lighting Power Density $\left(\mathrm{W} / \mathrm{m}^{2}\right)$ & 10.0 \\
\hline Lighting/Daylighting Controls & NA \\
\hline Equipment/Plug load Density (W/fm²) & 15 (assumed) \\
\hline Occupancy Density & $\operatorname{Max}=4$ \\
\hline Operating Schedules & Residential Schedule \\
\hline Occupancy & Residential Schedule \\
\hline Lighting & $17: 00-24: 00$ \\
\hline Infiltration $(\mathrm{ACH})$ & 0.5 \\
\hline HVAC Fans & $24 / 7$ \\
\hline
\end{tabular}




\subsubsection{Simulation Results}

After two comparative simulation with different HVAC system in the same envelop, and the system are carefully calibrated with the limited measure and gathered data, such as heat pump consumption and COP, Annual electric bill. The mainly result will focus on the energy saving between the geothermal heat pump system and conventional HVAC consumption.

From Figure 3-9, the difference of heat pump consumption between the simulation result and measure data electric consumption is less than $6 \%$ during the same time with the measure period (20 days in Dec.), considering the uncertainty of weather data, the result is reasonable and is one of the proofs of the simulation system validation.

In the Figure 3-10, the result of comparison of total energy consumption between the simulation data and electric bill shows this simulation result match with the real electric bill data, and the trend of the simulation data is consistent with the real electric bill. But several variables are still the uncertainty of this simulation that we should not omit, such as the lighting and equipment schedule, typical weather data. However, with the reasonable assumption and the carefully calibration, the result below is trustable and convincing in many points. 


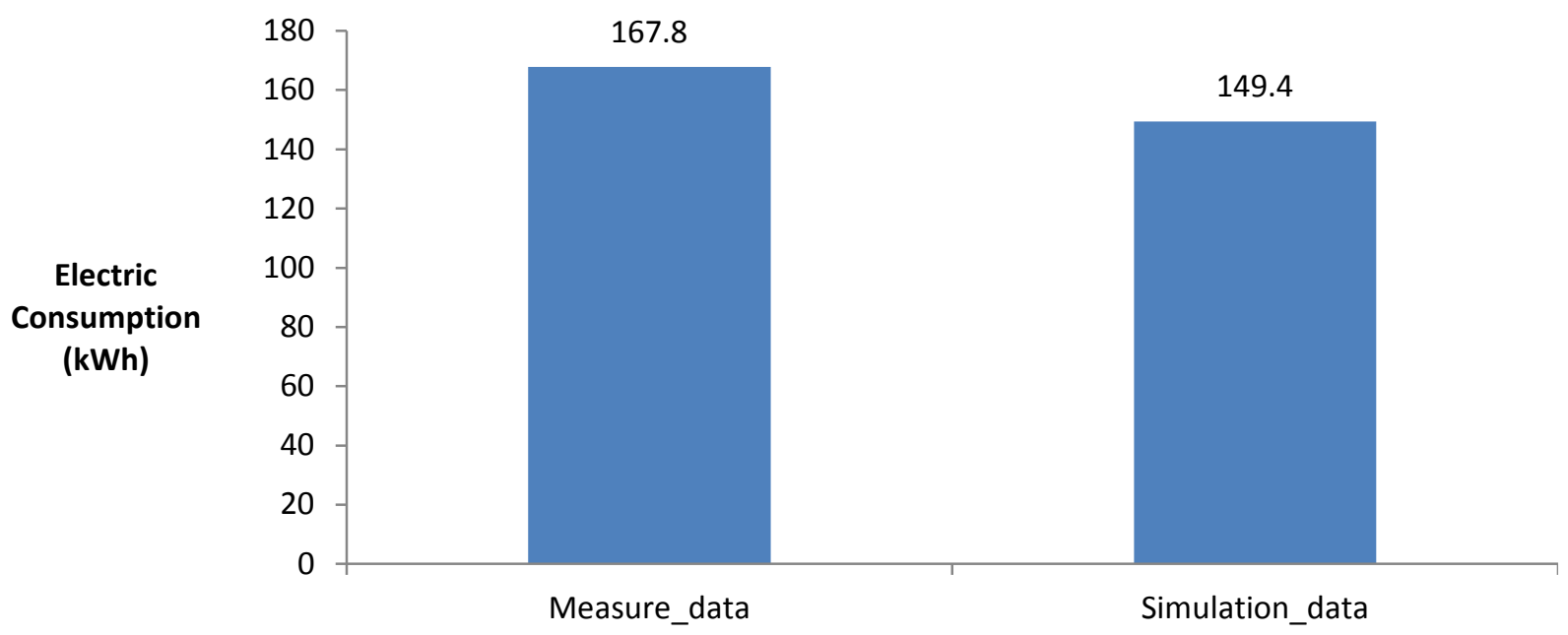

Figure 3-9: Comparison of heat pump consumptions between simulation data and measure data

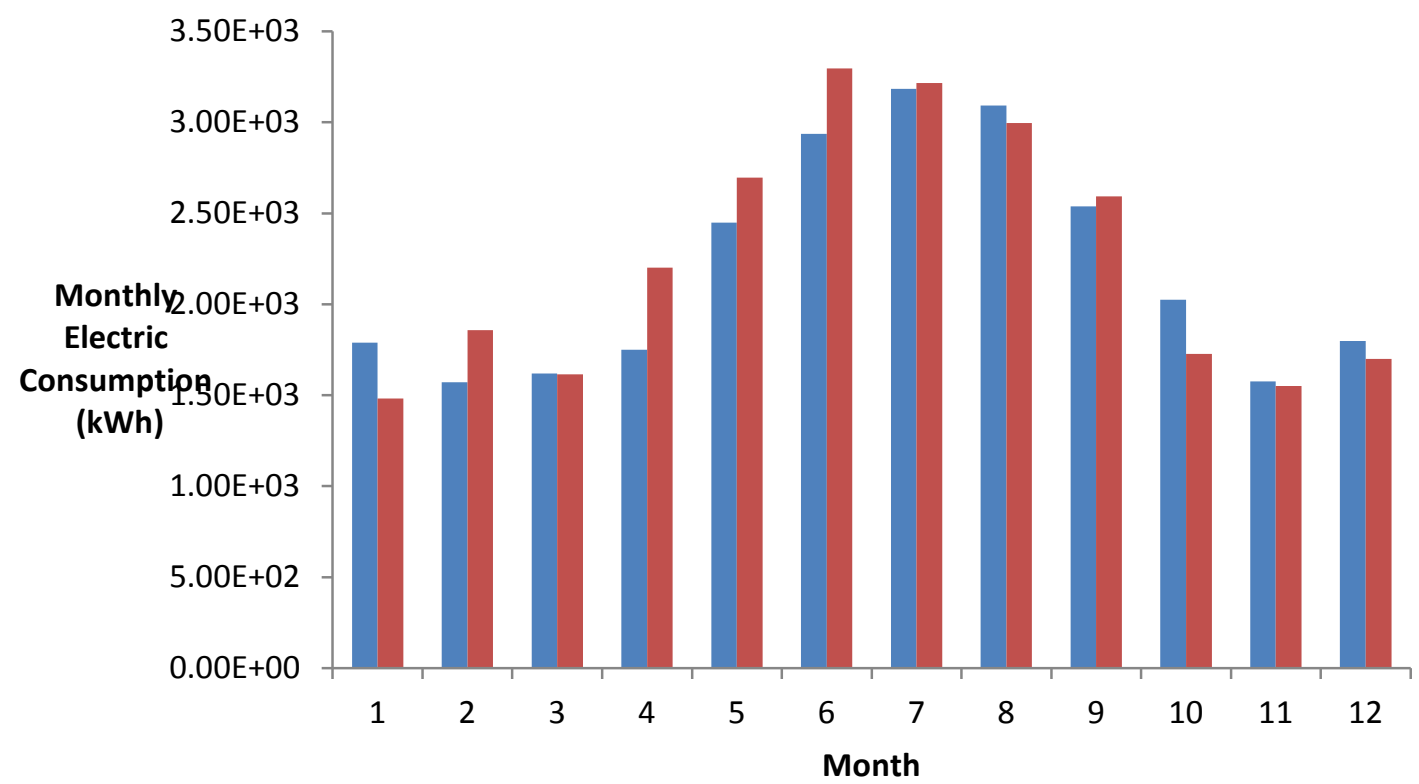

Figure 3-10: Comparison between annual electric data from simulation and owner's electric bill

From Figure 3-11, the ground source heat pump will save $18.6 \%$ of annual energy consumption that conventional heat pump (air source heat pump) when we consider the 
HVAC system only, and it will save $10.3 \%$ in the whole building consumption( with the same lighting and equipment consumption for both GSHP and conventional system) from Figure 3-11 and 3-12.

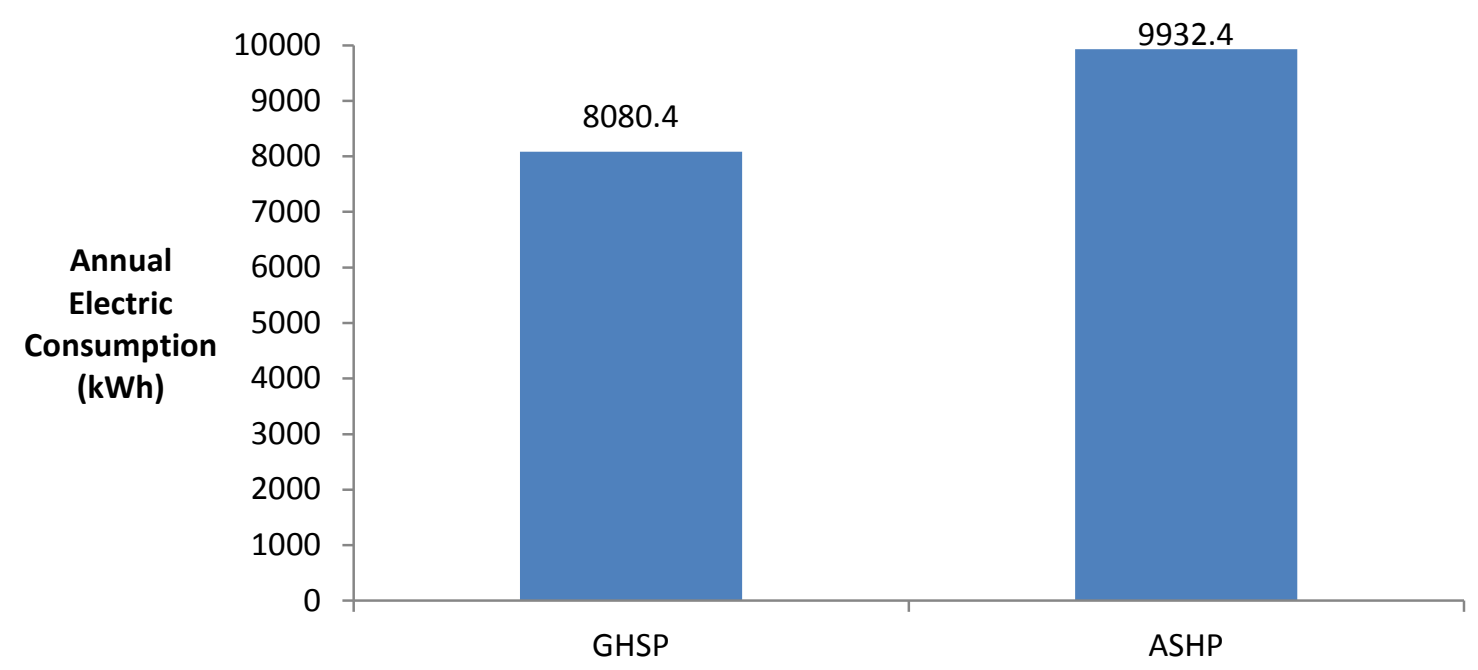

Figure 3-11: Comparison of annual heat pump consumption between GSHP and ASHP

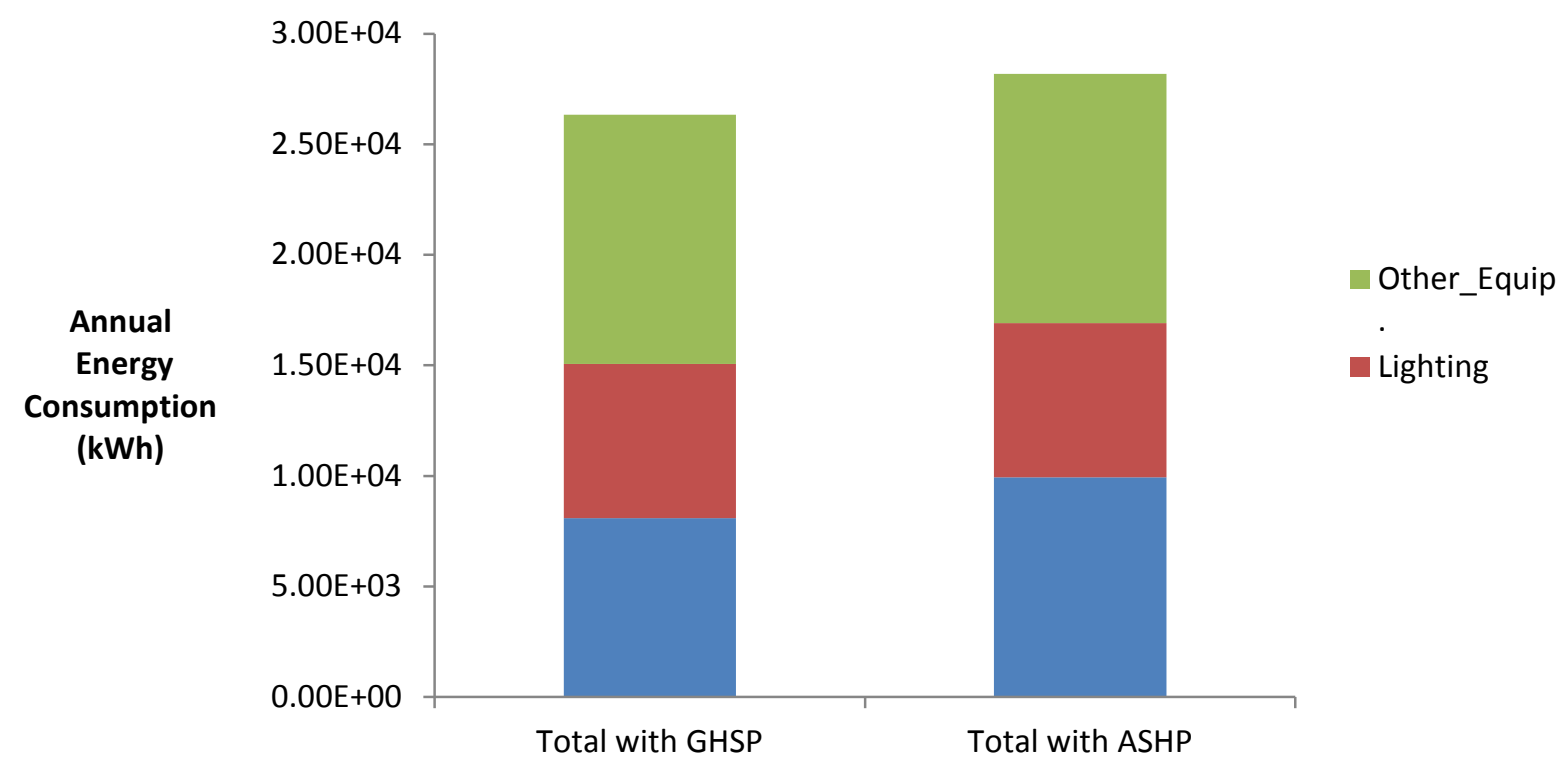

Figure 3-12: Comparison of total energy consumption between GHSP and ASHP

\subsection{Case Study-BR3}

Input data of BR3 simulation model will be presented in this section. The input data for the TRNSYS model are acquired based on limited information including the floor plan 
and survey data from the owner. Due to this limited information, several input data for the simulation model are assumed based on the information from other similar constructions in the local area or the default value in the software.

The BR3 consists of three rooms with 4 occupants located in Pensacola, FL. It has a total floor area of 3,390 square ft one story building.

This residential building with GSHP consists of 6 boreholes close loop ground heat exchanger system which is running with 1 hp water pump and 8GPM flow rate.

\subsubsection{Building Details}

Table 3-8 summarizes the floor areas for various conditioned and unconditioned spaces considered in the building baseline model.

Table 3-8: The list of Building Area Can be in the text instead of table

\begin{tabular}{|l|l|l|l|}
\hline $\begin{array}{l}\text { Building Use } \\
\text { (Occupancy Type) }\end{array}$ & $\begin{array}{l}\text { Conditioned } \\
\text { Area (sf) }\end{array}$ & $\begin{array}{l}\text { Unconditioned } \\
\text { Area (sf) }\end{array}$ & Total Area (sf) \\
\hline Garage & 301 & 301 \\
\hline $\begin{array}{l}\text { Living area (including bathrooms, } \\
\text { kitchen, bedrooms ) }\end{array}$ & 3089 & 3089 \\
\hline Total Area (sf) & 3089 & 301 & 3390 \\
\hline
\end{tabular}

\subsubsection{Building Model Specifications}

From the architectural drawings, the simulation model of the building was developed by the GOOGLE SKETCHUP as illustrated in Figure 3-13. Table 3-9 provides a summary of model basic features and Table 3-10 presents the gathered input data from the drawing and some assumptions used for the baseline building model. 
Table 3-9: Building Model Features

\begin{tabular}{|l|c|l|c|}
\hline Project Name & BR3 & Project Address & Pensacola, FL \\
\hline Simulation Program & TRNSYS & Number of Floors & 1 \\
\hline Principal Heating Source & Electricity & Weather File & Pensacola.tm2 \\
\hline Operation & $24 / 7$ & Set point Temperature & $\begin{array}{c}21 / 23^{\circ} \mathrm{C} \\
\text { (heating/cooling) }\end{array}$ \\
\hline
\end{tabular}

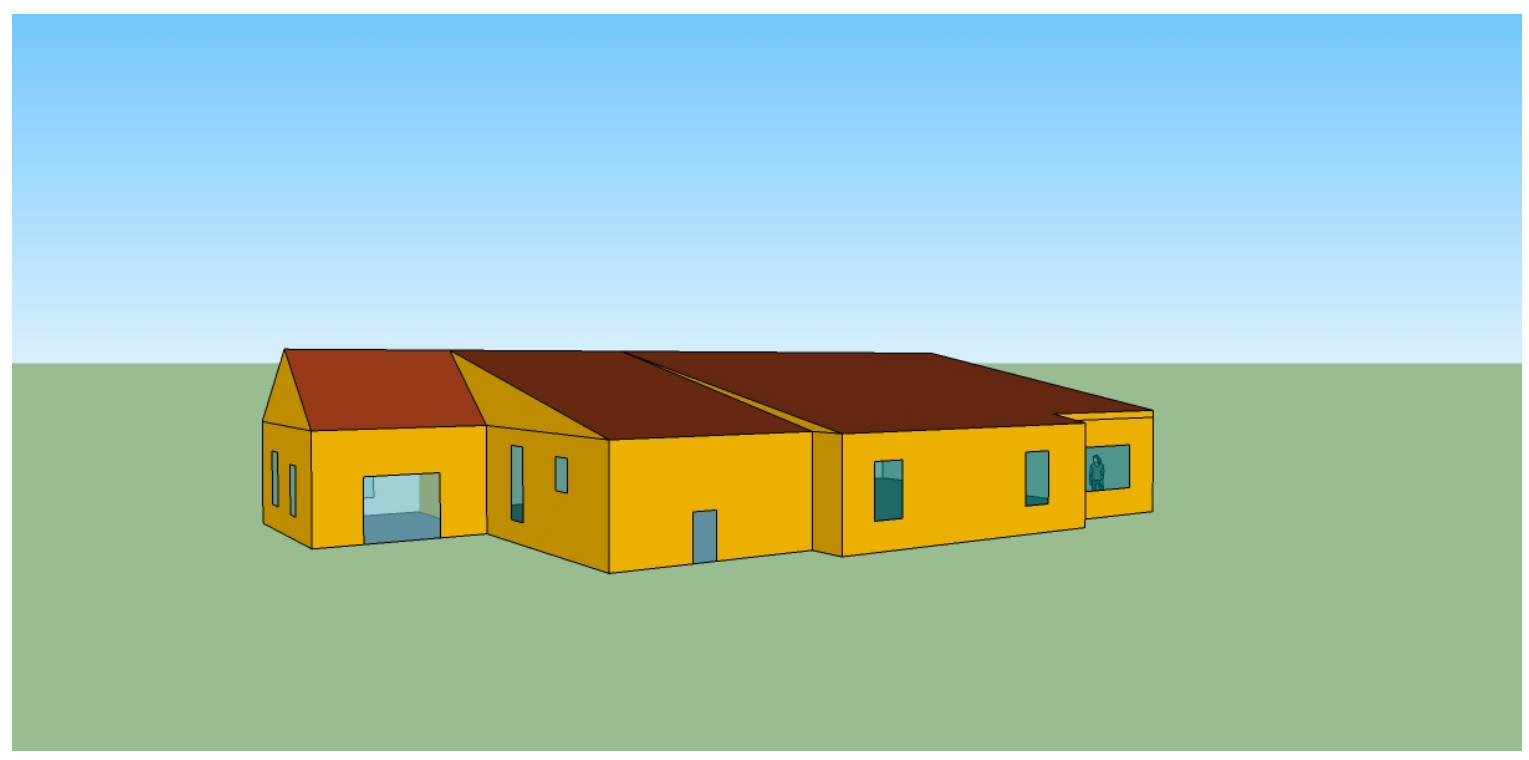

(a)Northwest view of BR3 model

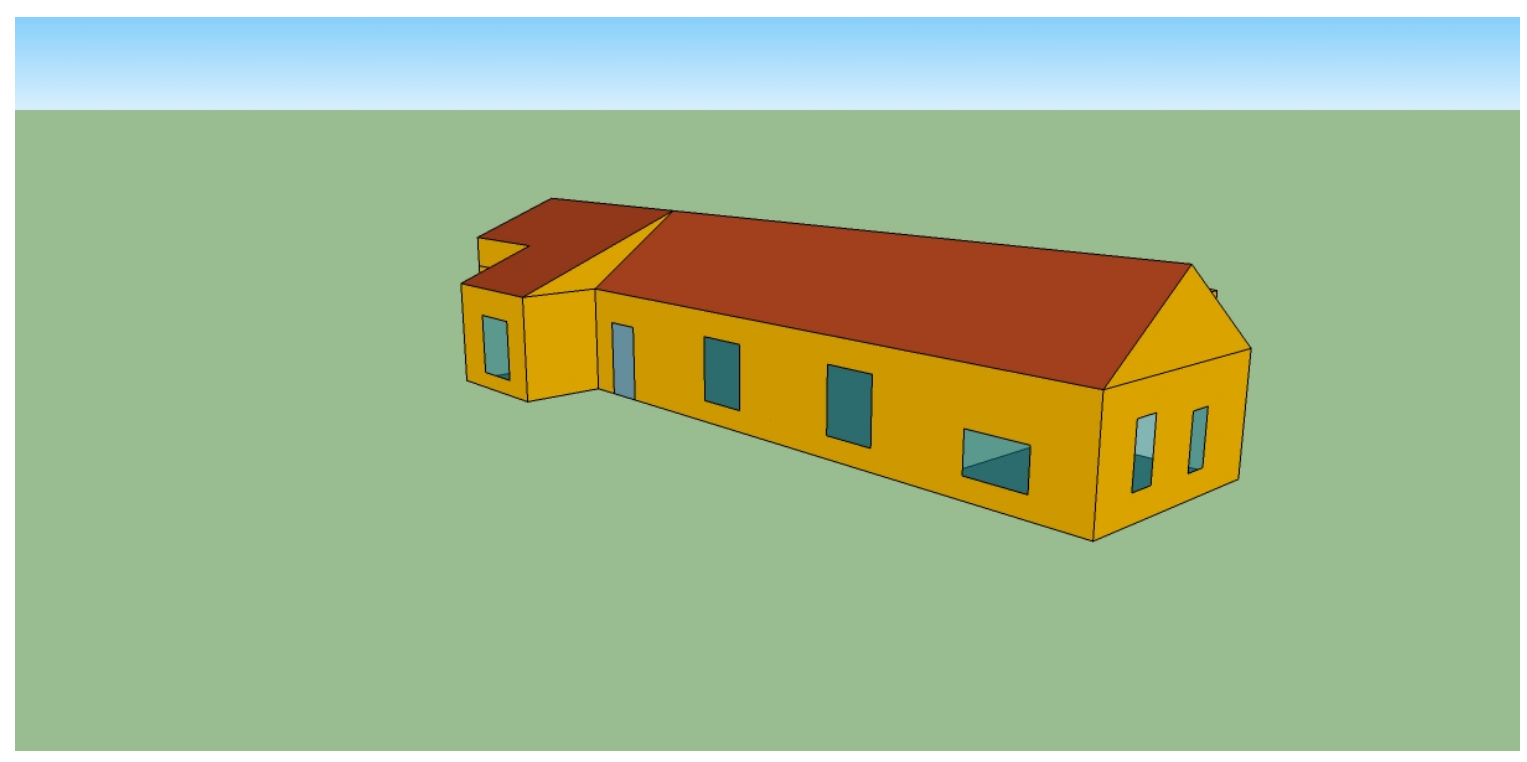

(b) Southeast view of BR3 model

Figure 3-13: 3-D Renderings for Building Energy Simulation Model 
Table 3-10: Input Summary for the Baseline Building Model

\begin{tabular}{|c|c|}
\hline Construction Details & Existing Building \\
\hline Total Conditioned Area $\left(\mathrm{m}^{2}\right)$ & 278 \\
\hline Exterior layers & $\begin{array}{c}\text { Brick VENEER } 0.1 \mathrm{~m} \text {, Insulation_ASHRAE } 0.112 \\
\text { Gypsum board } 0.0127 \mathrm{~m} \text {, Total U-value }=0.312 \mathrm{~W} / \mathrm{m}^{2} \mathrm{k}\end{array}$ \\
\hline Roof Layer & Insulation(R-33), roof deck, plasterboard Total U-value $=0.316 \mathrm{~W} / \mathrm{m}^{2} \mathrm{k}$ \\
\hline Floor Construction & 0.08 m concrete on ground, carpet, Floor_insulation_ashrae900 \\
\hline Percent Glazing Area & $6 \%$ \\
\hline Glazing U-Value & $\mathrm{U}-2.89 \mathrm{~W} / \mathrm{m}^{\wedge} 2 \mathrm{k}$ (assumed) \\
\hline \multicolumn{2}{|l|}{ Plant Details } \\
\hline Ground heat exchanger & Close loop \\
\hline Borehole hole & 6 (number)\& 3/4" U loop\& $76.2 \mathrm{~m}$ (depth) \\
\hline Water Pump & $1 \mathrm{hp}, 8 \mathrm{GPM}$ \\
\hline Ground water temperature & $23^{\circ} \mathrm{C}$ \\
\hline Storage conductivity & $8.722 \mathrm{KJ} / \mathrm{hr} \cdot \mathrm{m} . \mathrm{k}$ \\
\hline \multicolumn{2}{|l|}{ water Source HEAT PUMP } \\
\hline System Type & WATERFurnace Envision NDH064(5 tons) \\
\hline Total System Airflow & Constant air flow \\
\hline Cooling Setpoint Daytime/nighttime $\left({ }^{\circ} \mathrm{C}\right)$ & 23 \\
\hline Heating Setpoint - Daytime/Nighttime $\left({ }^{\circ} \mathrm{C}\right)$ & 21 \\
\hline \multicolumn{2}{|l|}{ Air Source Heat Pump (ASHP) } \\
\hline System Type & Carrier 50 TCQ A06 \\
\hline Cooling Setpoint Daytime/nighttime $\left({ }^{\circ} \mathrm{C}\right)$ & 23 \\
\hline Heating Setpoint - Daytime/Nighttime $\left({ }^{\circ} \mathrm{C}\right)$ & 21 \\
\hline \multicolumn{2}{|l|}{ Internal Loads } \\
\hline Lighting Power Density $\left(\mathrm{W} / \mathrm{m}^{2}\right)$ & 10.0 \\
\hline Lighting/Daylighting Controls & NA \\
\hline Equipment/Plug load Density (W/fm²) & 12 (assumed) \\
\hline Occupancy Density & $\operatorname{Max}=4$ \\
\hline Operating Schedules & Residential Schedule \\
\hline Occupancy & Residential Schedule \\
\hline Lighting & $17: 00-24: 00$ \\
\hline Infiltration $(\mathrm{ACH})$ & 0.5 \\
\hline HVAC Fans & $24 / 7$ \\
\hline
\end{tabular}


The configuration of BR3 system in TRNSYS is similar with the TRNSYS connection of BR2.

\subsubsection{Simulation Results}

After two comparative simulation with different HVAC system in the same envelop, and the system are carefully calibrated with the limited measure and gathered data, such as heat pump consumption and Annual electric bill. The mainly result will focus on the energy saving between the geothermal heat pump system and conventional HVAC consumption.

From Figure 3-14, when the cooling set point is $23^{\circ} \mathrm{C}$, the difference of heat pump consumption between the simulation result and measure data electric consumption is about $50 \%$, the reason is there is a lot of cooling consumption due to the automatic switching heating/cooling when the simulation running, it causes the deviation with the real case, which is the owner usually will not make the cooling on when the temperature is not high enough by hand during mild season, to make sure this reason, when the set point is set to $24^{\circ} \mathrm{C}$, the simulation decrease a large number, and the difference with measure data is less than $10 \%$ during the same time with the measure period (15 days in March).Considering the uncertainty of weather data, the result is reasonable and is one of the proofs of the simulation system validation.

In the Figure 3-15, the result of comparison of total energy consumption between the simulation data and electric bill shows this simulation result match with the real electric bill data, and the trend of the simulation data is consistent with the real electric bill. But several variables are still the uncertainty of this simulation that we should not omit, such as the lighting and equipment schedule, typical weather data. However, with the reasonable 
assumption and the carefully calibration, the result below is trustable and convincing in many points.

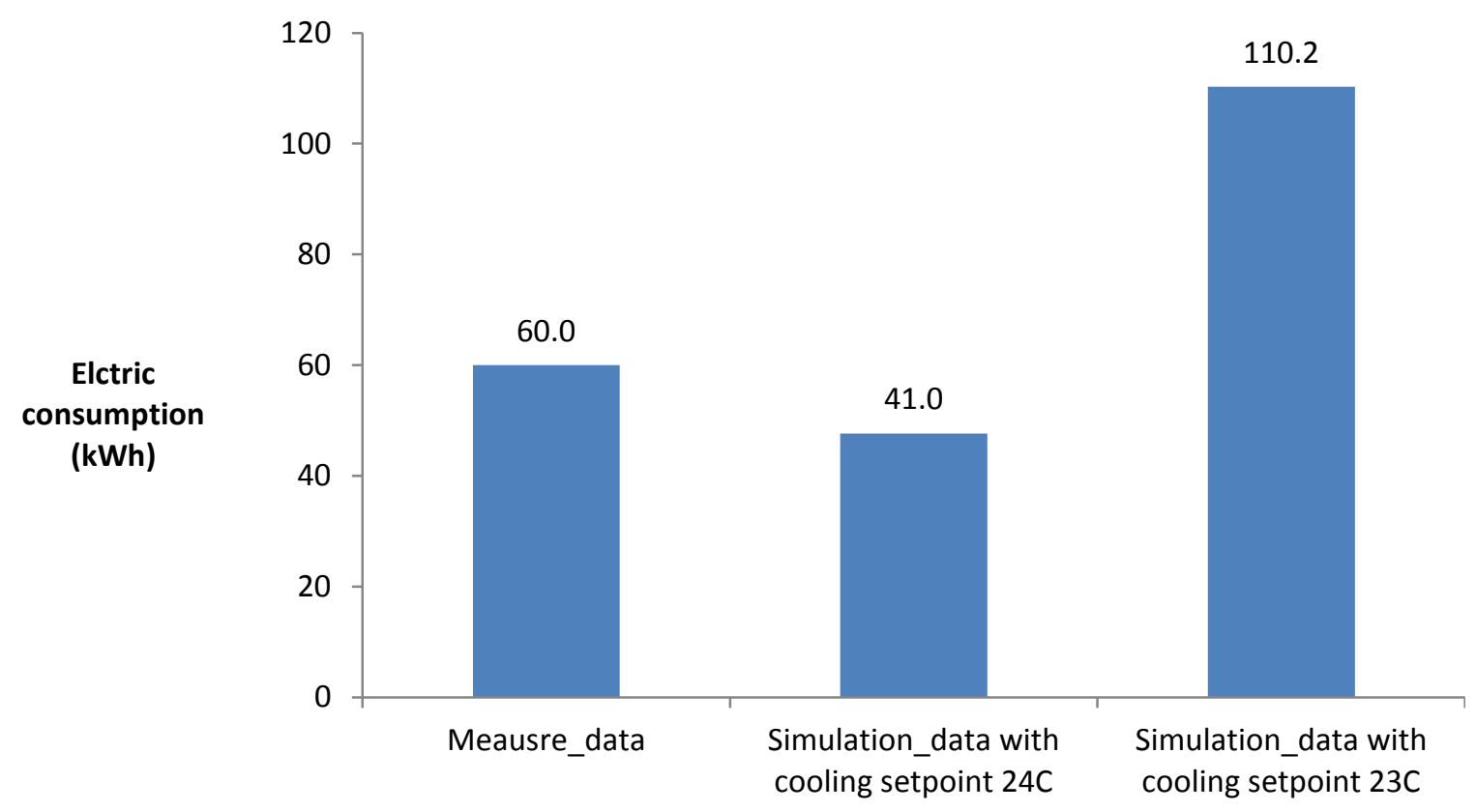

Figure 3-14: Comparison of heat pump consumptions between simulation data and measure data

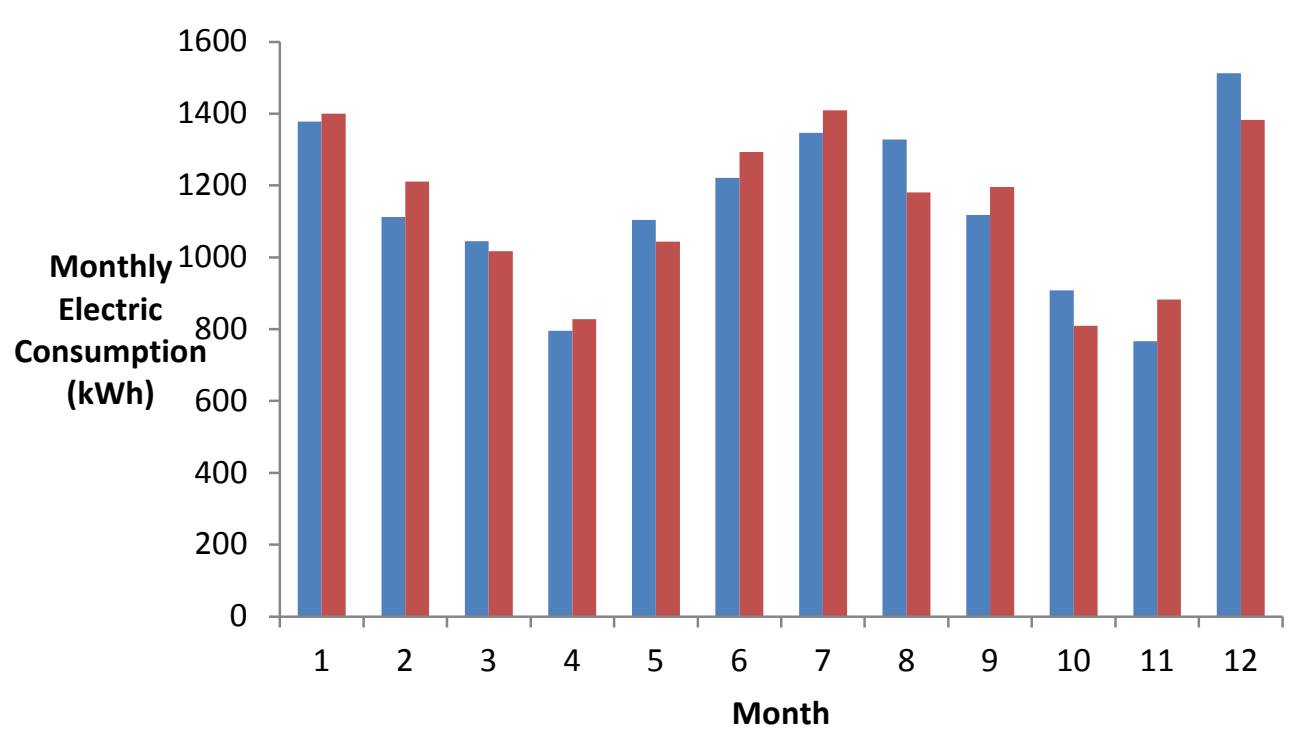

Figure 3-15: Comparison between annual electric data from simulation and owner’s electric bill 
From Figure 3-16, the ground source heat pump will save 34.6\% of annual energy consumption that conventional heat pump (air source heat pump) when we consider the HVAC system only, and it will save $19.3 \%$ in the whole building consumption( with the same lighting and equipment consumption for both GSHP and conventional system) from Figure 3-17.

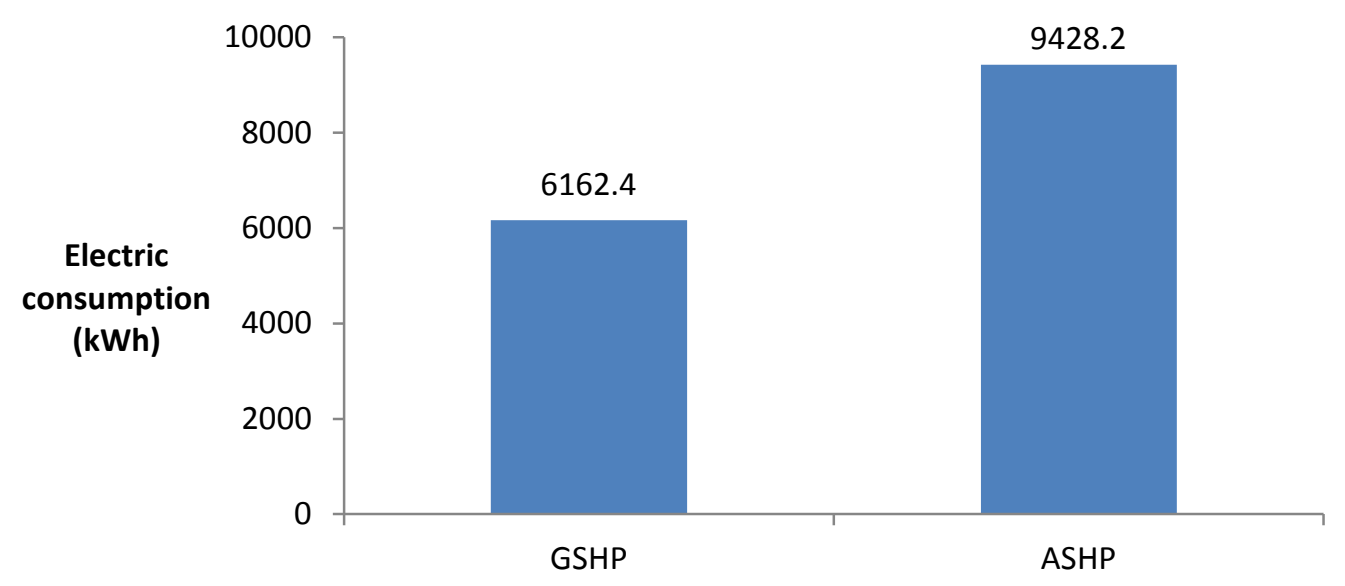

Figure 3-16: Comparison of annual heat pump consumption between GSHP and ASHP

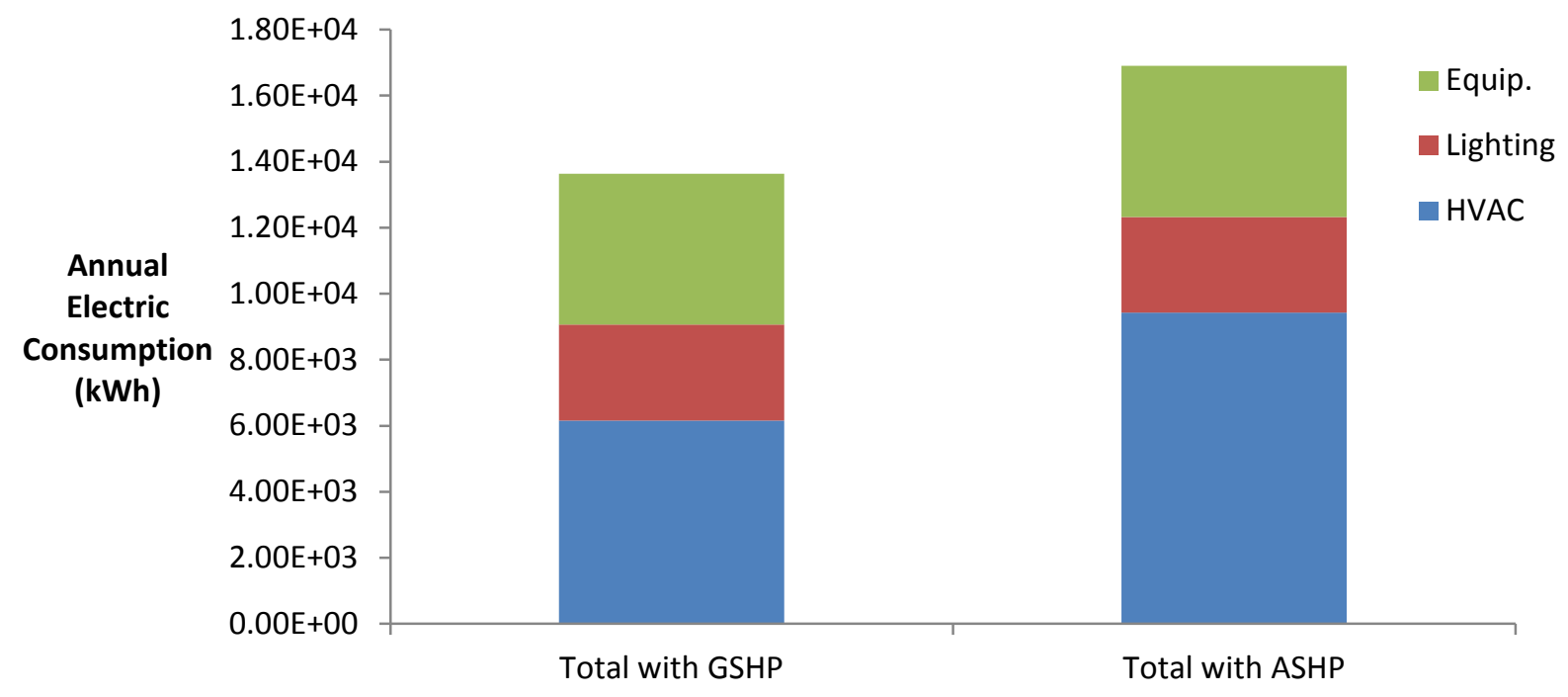

Figure 3-17: Comparison of total energy consumption between GHSP and ASHP 


\subsection{Case Study-BR4}

Input data of BR4 simulation model will be presented in this section. The input data for the ENERGYPLUS model are acquired based on limited information including the floor plan and survey data from the owner. Due to this limited information, several input data for the simulation model are assumed based on the information from other similar constructions in the local area or the default value in the software.

\subsubsection{Building Details}

BR4 is located in Robertsdale, Alabama, which was built in 1998. This is two story residential building. The first floor is 2800 square feet and includes a family room, a kitchen and a master and sub bedrooms. The second floor is 866 square feet with son and daughter's rooms. The front view of the building is seen in Figure 3-18.

All exterior walls are made of 2"x6”@16”o.c. wood stud wall and R-19 insulation is added into the wall. The ceiling height of the first floor is 10' and that of the second floor is 8”.

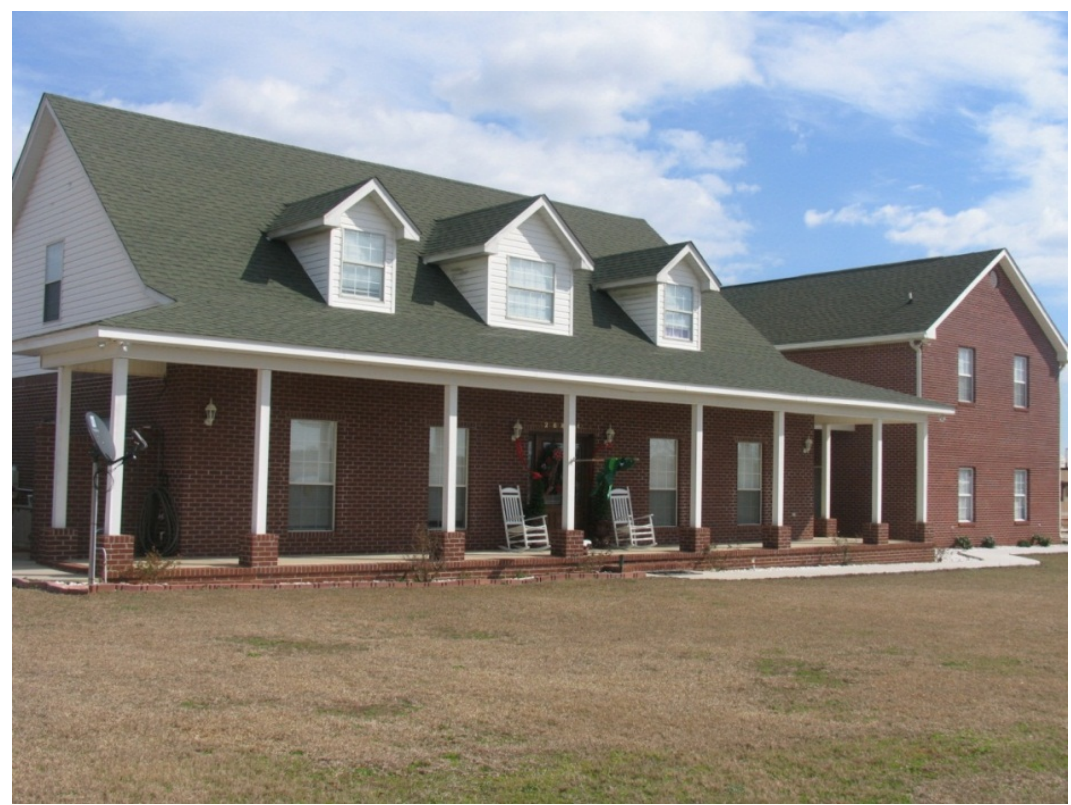

Figure 3-18: Front View of BR4 


\section{Mechanical system}

Two geothermal heat pump systems are installed in this building, which provide heating and cooling. 3 tons unit runs across the first floor and 2 ton unit is used for the second floor. These two units are connected to horizontal type ground loop. The fluid used for the ground loop is water and two 1 H.P pumps are used for water circulation. According to the owner of the building, the set point temperature for system is maintained very high in heating season $\left(78^{\circ} \mathrm{F}\right)$ and very low $\left(64^{\circ} \mathrm{F}\right)$ in cooling season for unoccupied time preventing energy waste. The system usually operates after 15:00PM and before 8:00 AM when the occupants stay in the building.

\section{Lighting and Equipment}

The lights include sixteen 30-Watt incandescent lamps, which are in the first and second floor bathrooms. There are also twelve 60-Watt incandescent lamp are used for bedroom, kitchen and family room. There are TVs in the family room and bedroom and one computer and a printer in the first floor bedroom. There is also an exercise machine in the family room.

\subsubsection{Building Model Specifications}

From the architectural drawings, ENERGYPLUS simulation model of the building was developed as illustrated in Figure 3-19. This model offers a detailed look at all of the major systems within the area, including information about the materials used in the building construction, space details, air and plant systems and schedules for occupancy, equipment, lighting, infiltration, fans, temperature. The ENERGYPLUS model was chosen for this modeling because this program has several different types of geothermal modules including a horizontal type system. GroundHeatExchanger:Surface module was used for making a simulation model the ground loop for this building. There is a garage space 
attached to the main building, but the space was not modeled because the energy consumption is collected separately and the heat pump in the space in not connected to the existing ground loop. The roof shape modeling was simplified as a box shape as seen in Figure 3-19.

There are two thermal zones in the model: the first floor zone and the second floor zone. The occupancy schedule was derived from the survey. Occupancy schedules were considered for weekdays and for weekend separately. There are two elementary school students who use the second floor zone. Therefore, the occupancy schedule for the second floor zone was considered for the vacation time and the school time of the occupants, too.

The equipment and lighting schedule reflect the occupant schedules for the first floor zone and the second floor zone.

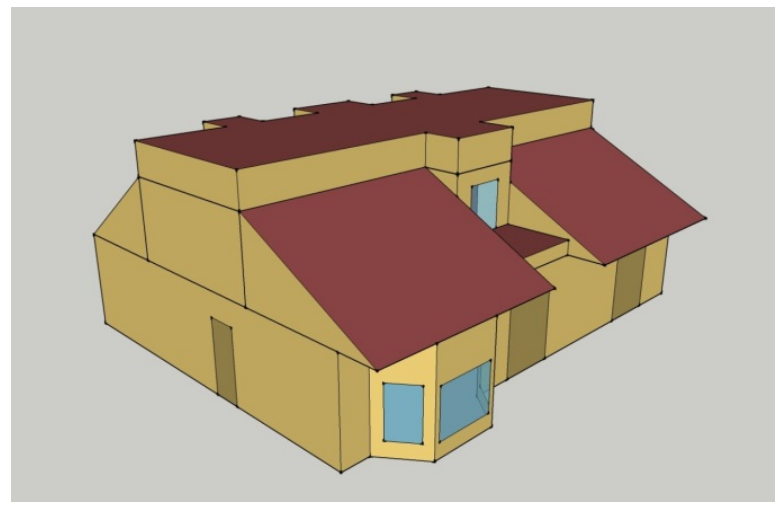

(a) Northeast view of BR4 model

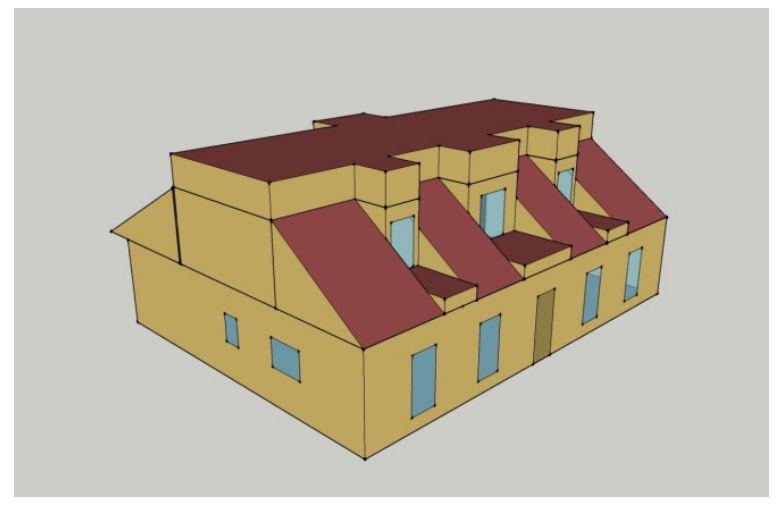

(b) Southeast view of BR4 model

Figure 3-19: 3-D Renderings for Building Energy Simulation Model 


\subsubsection{Simulation Results}

\section{Model Calibration}

The utility bill data and the monitoring data were used to calibrate the model. The monitoring data were specially used to improve and calibrate the mode of the ground source heat pump system.

The electricity bill used for the calibration is the data of 2010. The billing data were collected at the end of 2010. Therefore, the available data are only from January to October.

With all these adjustment and comparison, the final annual difference between the utility bills and the simulation model was found to be $0.4 \%$. Figure $3-20$ and 3-21 shows the base case electricity consumption profile.

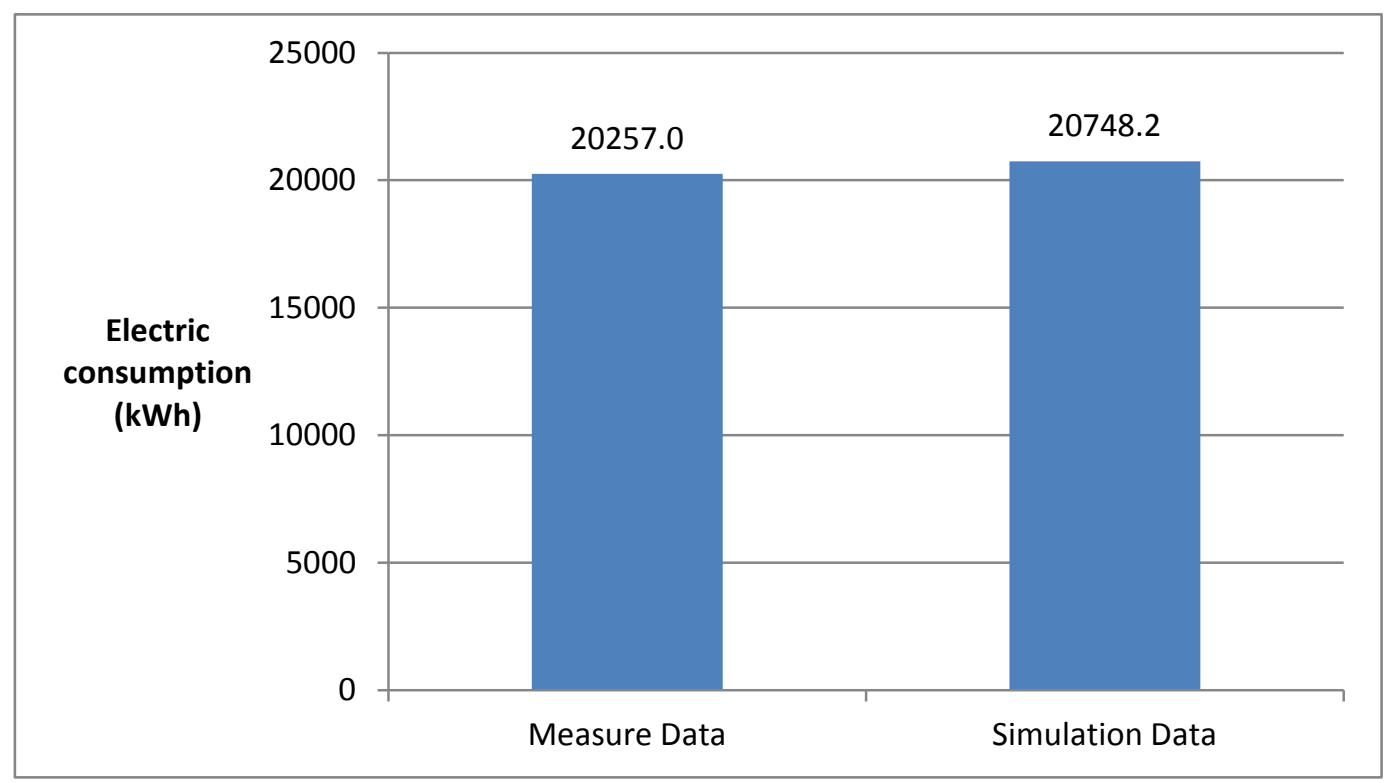

Figure 3-20: Comparison of heat pump consumptions between simulation data and measure data 


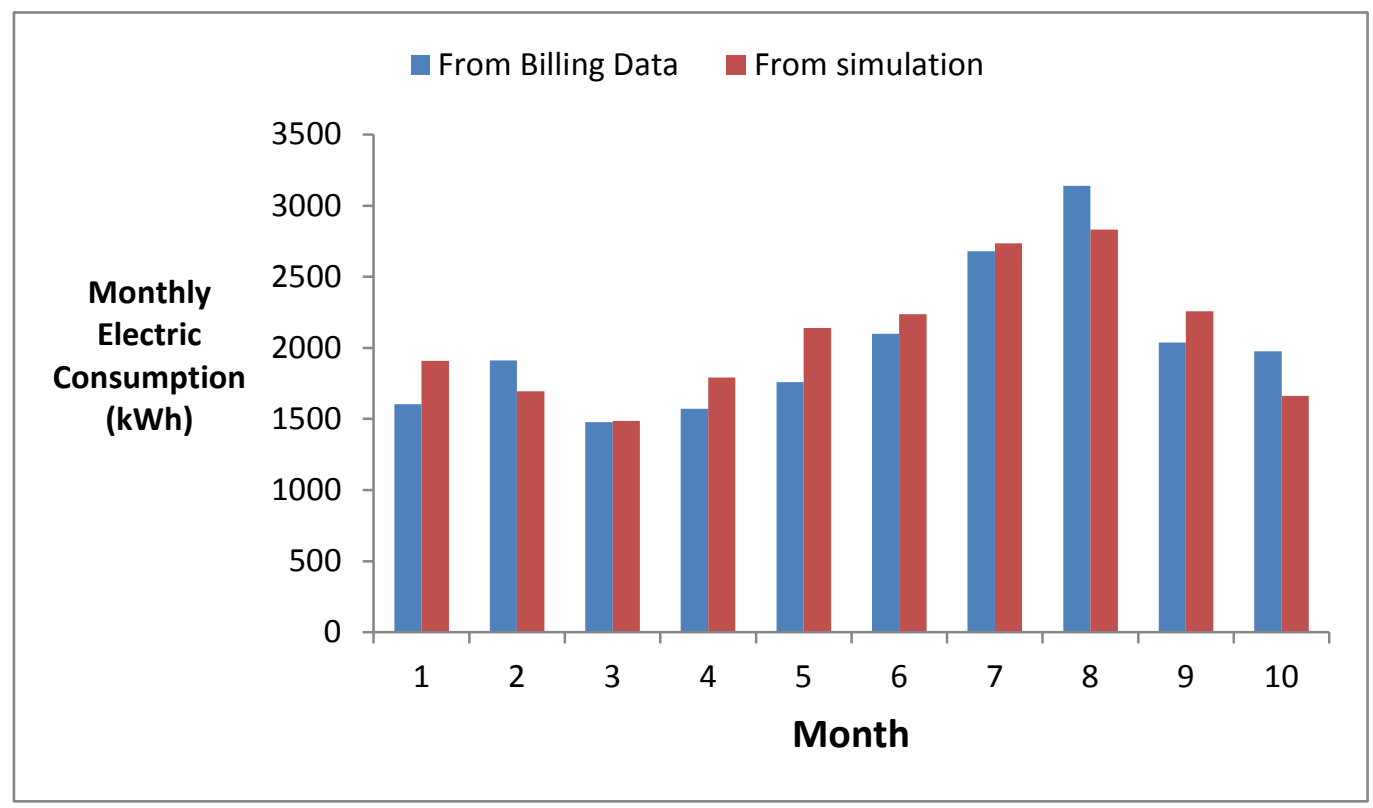

Figure 3-21: Comparison between annual electric data from simulation and owner's electric bill

Table 3-11 below shows the comparison between actual billing data and the simulation data.

In this step, geothermal heat pumps have been replaced by conventional air source heat pumps with the same capacity to compare the energy consumption of the geothermal system with the conventional system. In ENERGYPLUS, Unitary heat pump: Air-to-Air module was used to make a case for this system. Table 3-11 summarizes annual saving for the geothermal heat pump and the conventional system used in this building.

As seen in Table 3-12, it is estimated that the geothermal heat pump system consumes $13 \%$ less energy than the conventional heat pump system for this residential house. 
Table 3-11: Comparison between actual billing data and the simulation results

\begin{tabular}{|c|c|c|c|c|c|}
\hline \multirow[b]{2}{*}{ Billing Period } & \multicolumn{4}{|c|}{ Simulation Results } & \multirow[b]{2}{*}{$\begin{array}{c}\text { Billed Total } \\
\text { Power } \\
\text { Consumption } \\
\text { (kWh) }\end{array}$} \\
\hline & $\begin{array}{c}\text { HVAC Power } \\
\text { Consumption } \\
\text { (kWh) }\end{array}$ & $\begin{array}{c}\text { Non-HVAC } \\
\text { Power } \\
\text { Consumption } \\
\text { (kWh) }\end{array}$ & $\begin{array}{c}\text { Lighting } \\
\text { Power } \\
\text { Consumption } \\
\text { (kWh) }\end{array}$ & $\begin{array}{c}\text { Total Power } \\
\text { Consumption } \\
\text { (kWh) }\end{array}$ & \\
\hline $\begin{array}{c}\text { From: } 12 / 30 / 2009 \\
\text { To: } 1 / 27 / 2010\end{array}$ & 411 & 950 & 507 & 1868 & 1603 \\
\hline $\begin{array}{c}\text { From: } 1 / 28 / 2010 \\
\text { To: } 3 / 1 / 2010\end{array}$ & 343 & 814 & 458 & 1615 & 1913 \\
\hline $\begin{array}{c}\text { From: 3/2/2010 } \\
\text { To: 4/1/2010 }\end{array}$ & 373 & 602 & 471 & 1446 & 1478 \\
\hline $\begin{array}{l}\text { From: 4/2/2010 } \\
\text { To: 5/3/2010 }\end{array}$ & 673 & 581 & 497 & 1751 & 1571 \\
\hline $\begin{array}{l}\text { From: 5/4/2010 } \\
\text { To: 6/2/2010 }\end{array}$ & 1010 & 602 & 489 & 2101 & 1759 \\
\hline $\begin{array}{c}\text { From: } 6 / 3 / 2010 \\
\text { To: 7/2/2010 }\end{array}$ & 1157 & 581 & 460 & 2198 & 2098 \\
\hline $\begin{array}{l}\text { From: } 7 / 3 / 2010 \\
\text { To: } 7 / 30 / 2010 \\
\end{array}$ & 1204 & 968 & 526 & 2698 & 2680 \\
\hline $\begin{array}{c}\text { From: } 7 / 31 / 2010 \\
\text { To: 8/31/2010 }\end{array}$ & 1355 & 967 & 471 & 2793 & 3141 \\
\hline $\begin{array}{l}\text { From: 9/1/2010 } \\
\text { To: 9/30/2010 }\end{array}$ & 1004 & 718 & 497 & 2219 & 2037 \\
\hline $\begin{array}{l}\text { From: } 10 / 1 / 2010 \\
\text { To: } 10 / 31 / 2010\end{array}$ & 372 & 743 & 507 & 1622 & 1977 \\
\hline \multicolumn{4}{|c|}{ Total Energy Consumption (kWh) } & 20311 & 20257 \\
\hline (Actual Power C & umption - Si & $\begin{array}{l}\text { Ilation Result)/ } \\
100(\%)\end{array}$ & ual Power C & umption $\mathrm{x}$ & $0.3 \%$ \\
\hline
\end{tabular}


Table 3-12: Comparison between geothermal and conventional air source heat pump system

\begin{tabular}{|c|c|c|}
\hline \multirow{2}{*}{$\begin{array}{c}\text { Geothermal } \\
\text { System }\end{array}$} & $\begin{array}{c}\text { Whole Building Annual Power Consumption } \\
(\mathrm{kWh})\end{array}$ & 24030 \\
\cline { 2 - 3 } & $\begin{array}{c}\text { System Annual Power Consumption } \\
(\mathrm{kWh})\end{array}$ & 8250 \\
\hline \multirow{2}{*}{$\begin{array}{c}\text { Conventional } \\
\text { System }\end{array}$} & $\begin{array}{c}\text { Whole Building Annual Power Consumption } \\
(\mathrm{kWh})\end{array}$ & 25500 \\
\cline { 2 - 3 } & $\begin{array}{c}\text { System Annual Power Consumption } \\
(\mathrm{kWh})\end{array}$ & 1300 \\
\hline \multirow{2}{*}{$\begin{array}{c}\text { Annual } \\
\text { Saving }\end{array}$} & (Kwh) & 13.6 \\
\cline { 2 - 3 } & & \\
\hline
\end{tabular}

\subsection{Case Study-BC1}

Input data of BC1 simulation model will be presented in this section. The input data for the TRNSYS model are acquired based on limited information including the floor plan and survey data from the owner. Due to this limited information, several input data for the simulation model are assumed based on the information from other similar constructions in the local area or the default value in the software.

The BC1consists five offices with maximum 15 occupants located in Pensacola. It has a total floor area of 6000 square ft one story operation center.

This commercial building GSHP consists of 17boleholes of ground heat exchanger at 300ft depth which is running with 1 hp water pump and 8GPM flow rate.

\subsubsection{Building Details}

Table 3-13 summarizes the floor areas for various conditioned and unconditioned spaces considered in the building baseline model. 
Table 3- 13: The list of Building Area

\begin{tabular}{|l|l|l|l|}
\hline $\begin{array}{l}\text { Building Use } \\
\text { (Occupancy Type) }\end{array}$ & $\begin{array}{l}\text { Conditioned } \\
\text { Area (sf) }\end{array}$ & $\begin{array}{l}\text { Unconditioned } \\
\text { Area (sf) }\end{array}$ & Total Area (sf) \\
\hline Mechanical room & & 400 & 400 \\
\hline Office room & 5551 & & 5551 \\
\hline Total Area (sf) & 5551 & 400 & 5951 \\
\hline
\end{tabular}

\subsubsection{Building Model Specifications}

From the architectural drawings, the simulation model of the building was developed by the GOOGLE SKETCHUP as illustrated in Figure 3-22. Table 3-14 provides a summary of model basic features and Table 3-15 presents the gathered input data from the drawing and some assumptions used for the baseline building model.

Table 3-14: Building Model Features

\begin{tabular}{|l|c|l|c|}
\hline Project Name & BC1 & Project Address & Pensacola, FL \\
\hline Simulation Program & TRNSYS & Number of Floors & 1 \\
\hline Principal Heating Source & Electricity & Weather File & Pensacola.tm2 \\
\hline Energy Code Used & N/A & Climate Zone & $3 \mathrm{~A}$ \\
\hline Operation & $24 / 7$ & Set point Temperature & $\begin{array}{c}21 / 23^{\circ} \mathrm{C} \\
\text { (heating/cooling) }\end{array}$ \\
\hline
\end{tabular}




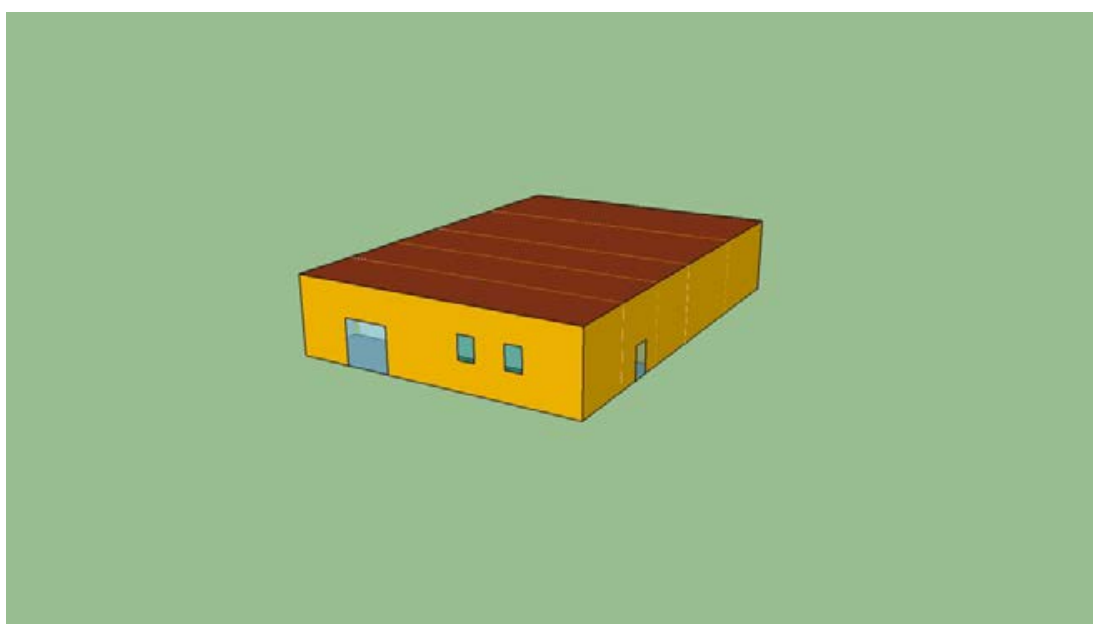

(a)Northeast view of BC1 model

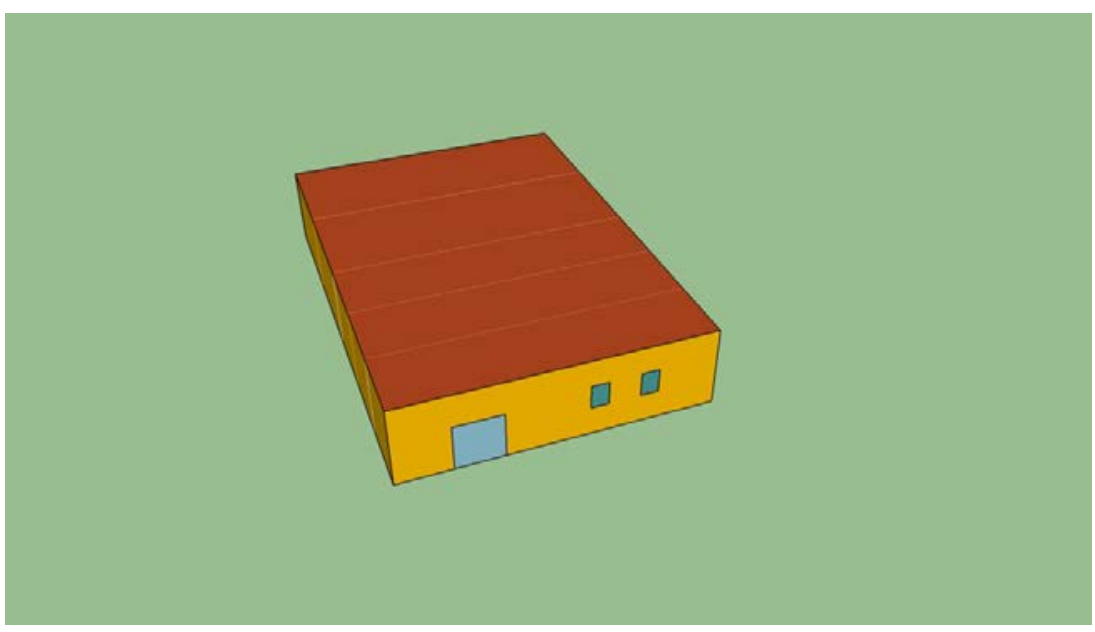

(b) Southeast view of BC1 model

Figure 3-22: 3-D Renderings for Building Energy Simulation Model

Table 3-15: Input Summary for the Baseline Building Model

\begin{tabular}{|c|c|}
\hline Construction Details & Existing Building \\
\hline Total Conditioned Area $\left(\mathrm{m}^{2}\right)$ & 5551 \\
\hline Exterior wall layers & $\begin{array}{c}\text { Concrete Block } 0.012 \mathrm{~m} \text {, Air Layer,steel } 0.010 \mathrm{~m} \\
\text { Gypsum board } 0.012 \mathrm{~m} \text {, Total U-value }=2.627 \mathrm{~W} / \mathrm{m}^{2} \mathrm{k}\end{array}$ \\
\hline Roof Layer & Insulation, concrete, plasterboard Total U-value $=0.327 \mathrm{~W} / \mathrm{m}^{2} \mathrm{k}$ \\
\hline Floor Construction & $0.08 \mathrm{~m}$ concrete on ground, carpet, Floor_insulation_ashrae900 \\
\hline Percent Glazing Area & $1 \% \quad \mathrm{U}-2.89 \mathrm{~W} / \mathrm{m}^{2} \mathrm{k}$ (assumed) \\
\hline
\end{tabular}




\begin{tabular}{|c|c|}
\hline Plant Details & \\
\hline Ground heat exchanger & Close loop \\
\hline Borehole hole & 17 (number)\& 3/4" U loop\& 91.2m(depth) \\
\hline Water Pump & $6 \mathrm{hp}$ \\
\hline Ground water temperature & $21^{\circ} \mathrm{C}$ \\
\hline Storage conductivity & $8.722 \mathrm{KJ} / \mathrm{hr} . \mathrm{m} . \mathrm{k}$ \\
\hline \multicolumn{2}{|l|}{ water Source HEAT PUMP } \\
\hline System Type & 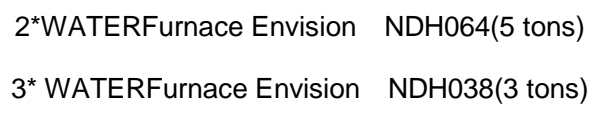 \\
\hline Total System Airflow & Constant air flow \\
\hline Cooling Setpoint Daytime/nighttime $\left({ }^{\circ} \mathrm{C}\right)$ & 24 \\
\hline Heating Setpoint - Daytime/Nighttime $\left({ }^{\circ} \mathrm{C}\right)$ & 21 \\
\hline \multicolumn{2}{|l|}{ Air Source Heat Pump (ASHP) } \\
\hline System Type & $2 *$ Carrier 50 TCQ A06, 3* Carrier 50 TCQ A05 \\
\hline Cooling Setpoint Daytime/nighttime $\left({ }^{\circ} \mathrm{C}\right)$ & 24 \\
\hline Heating Setpoint - Daytime/Nighttime $\left({ }^{\circ} \mathrm{C}\right)$ & 21 \\
\hline \multicolumn{2}{|l|}{ Internal Loads } \\
\hline Lighting Power Density $\left(\mathrm{W} / \mathrm{m}^{2}\right)$ & 10.0 \\
\hline Lighting/ Daylighting Controls & NA \\
\hline Equipment/Plug load Density (W/fm²) & 12 (assumed) \\
\hline Occupancy Density & $\operatorname{Max}=4$ \\
\hline Operating Schedules & Residential Schedule \\
\hline Occupancy & Residential Schedule \\
\hline Lighting & $17: 00-24: 00$ \\
\hline Infiltration $(\mathrm{ACH})$ & 0.5 \\
\hline HVAC Fans & $24 / 7$ \\
\hline
\end{tabular}




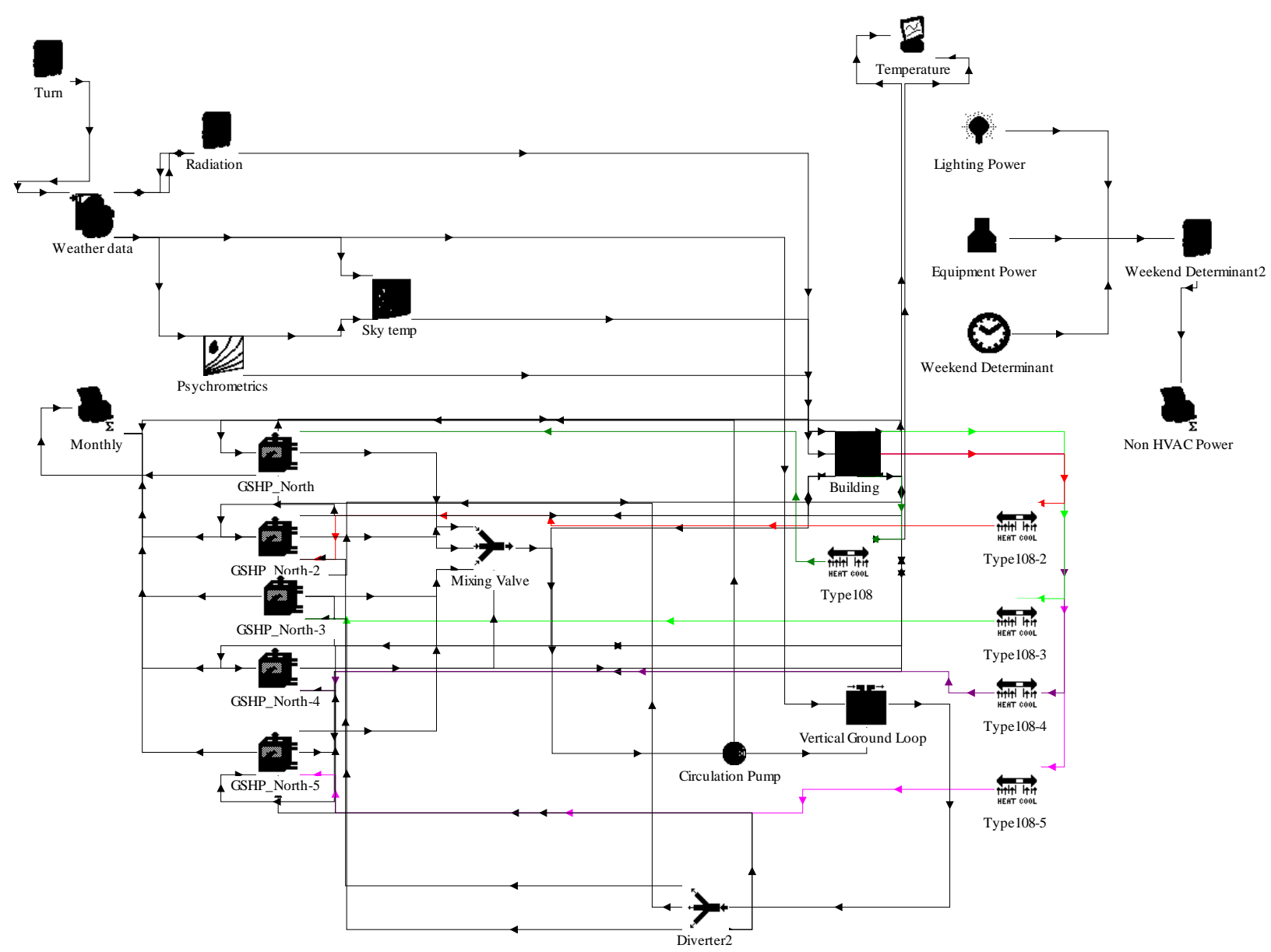

Figure 3-23: Close loop ground source heat pump -TRNSYS connection map 


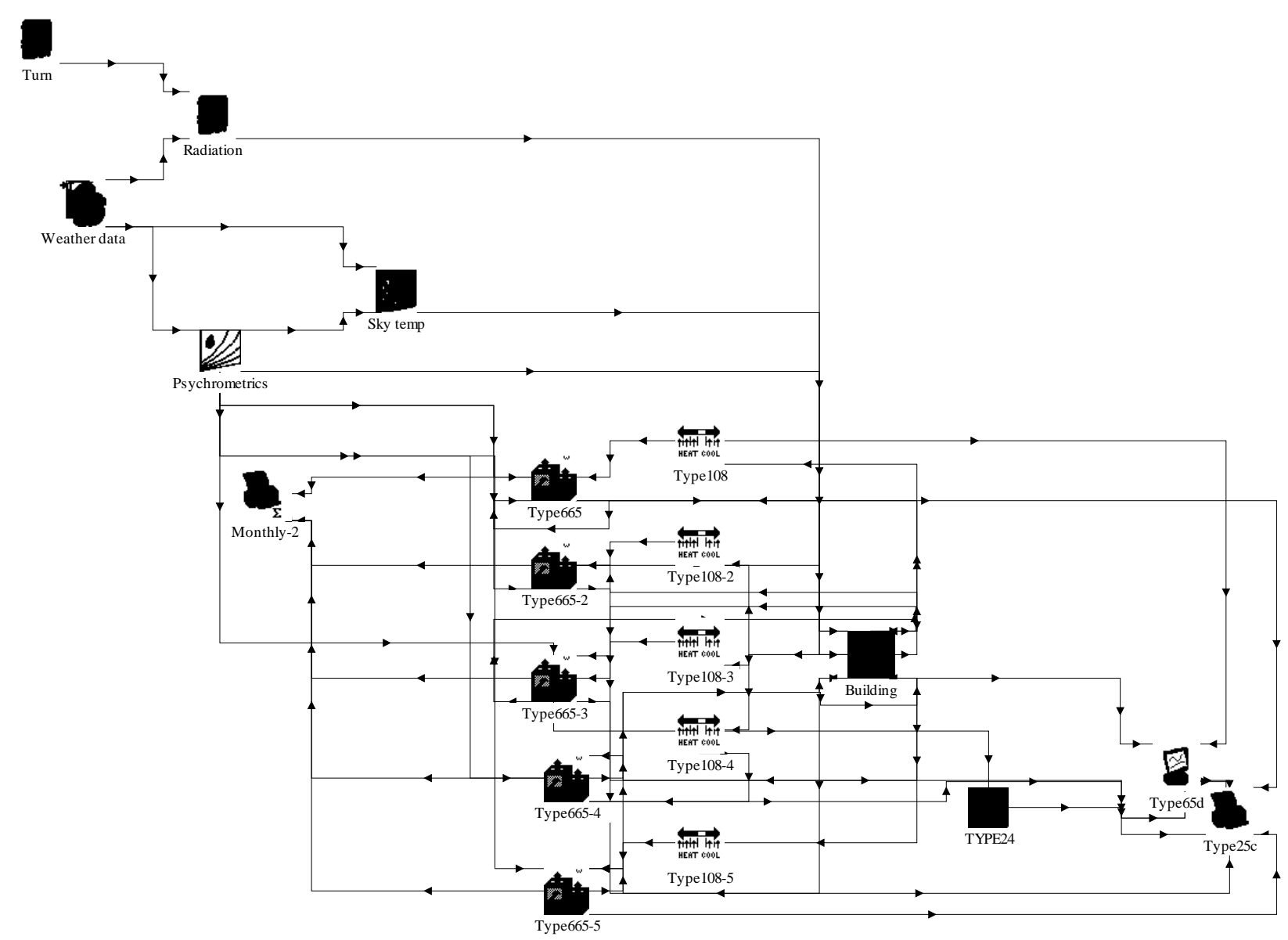

Figure 3-24: Air source heat pump -TRNSYS connection map

Figure 3-23 and Figure 3-24 show the TRNSYS maps of GHSP system and Air source heat pump (ASHP) system which is with the same capacity. And the types in the TRNSYS are explained as below.

System is composed of following main TRNSYS components that are included in the simulation environment:

Type 557a: Vertical ground heat exchanger

(Note: the other types which are same with the TRNYS map as above will not list here, please refer the previous chapter for details.) 


\subsubsection{Simulation Results}

Because of complexity of the system and limitation number of the instruments, the measure data and the electric bill for the BC1 is not available; there is only the simulation result in this part without calibrated.

From Figure 3-25, we can see the trend of monthly electric consumption for BC1in Pensacola. And in the Figure 3-26, the simulation result shows that the GSHP with continuous running water pump will save $17.2 \%$ of energy consumption, and GSHP with variable speed or controlled will save up to $51.8 \%$.

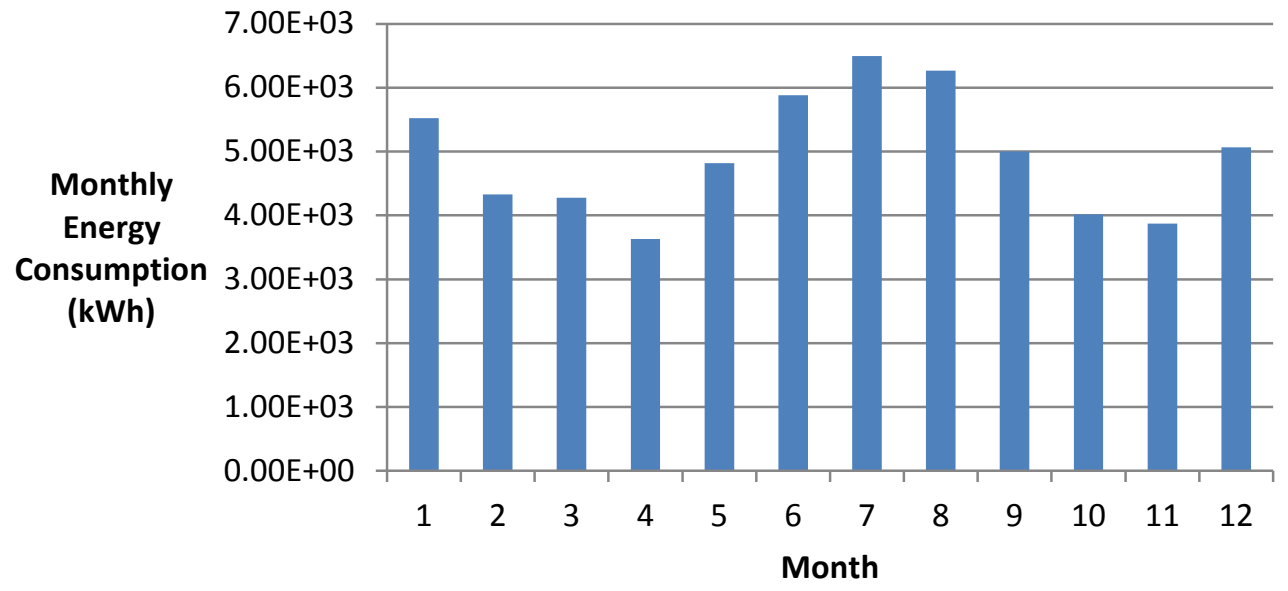

Figure 3-25: The trend of monthly electric consumption for BC1 in Pensacola.

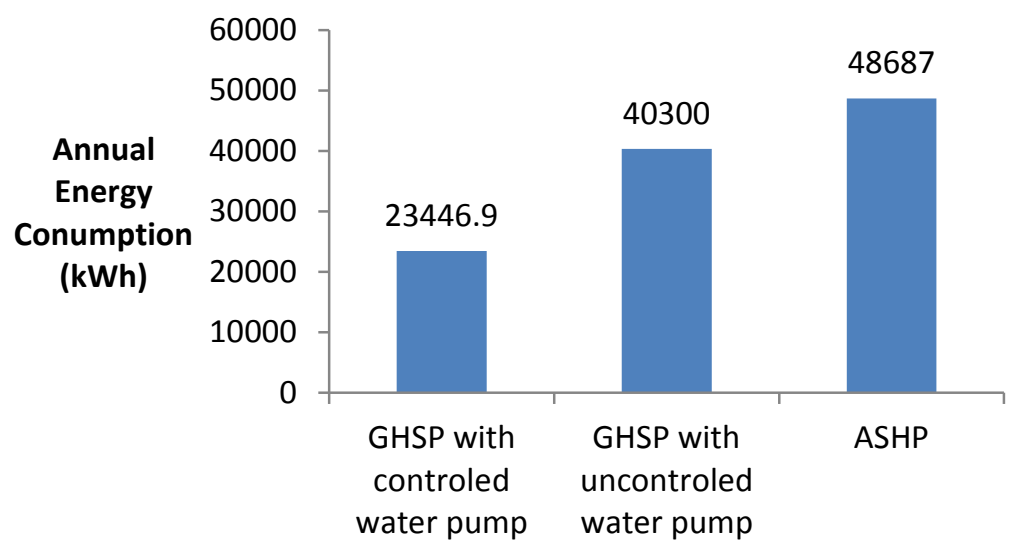

Figure 3-26: Comparison of annual heat pump consumption between GSHP and ASHP 


\subsection{Case Study-BC2}

\subsubsection{Building Details}

BC2 is a commercial building in downtown Pensacola that the system operation started on August 2010. The building is one story having an area of 4250 square ft. The HVAC system of this building consists of a 13 ton GSHP system, with two 6 ton units and one 1 ton unit. The GSHP system utilizes a vertical loop, which is composed of 14 boreholes reaching a depth of 300 feet.

\subsubsection{Building Model Specifications}

TRNSYS has been employed for modeling of the building and the system. Building has been modeled using GOOGLE SKETCHUP and the model has been exported to TRNSYS for adding weather and system components. Figure 3-27 shows theBC2 model created in GOOGLE SKETCHUP. The TRNSYS model of the building and the geothermal system has been depicted in Figure 3-28.

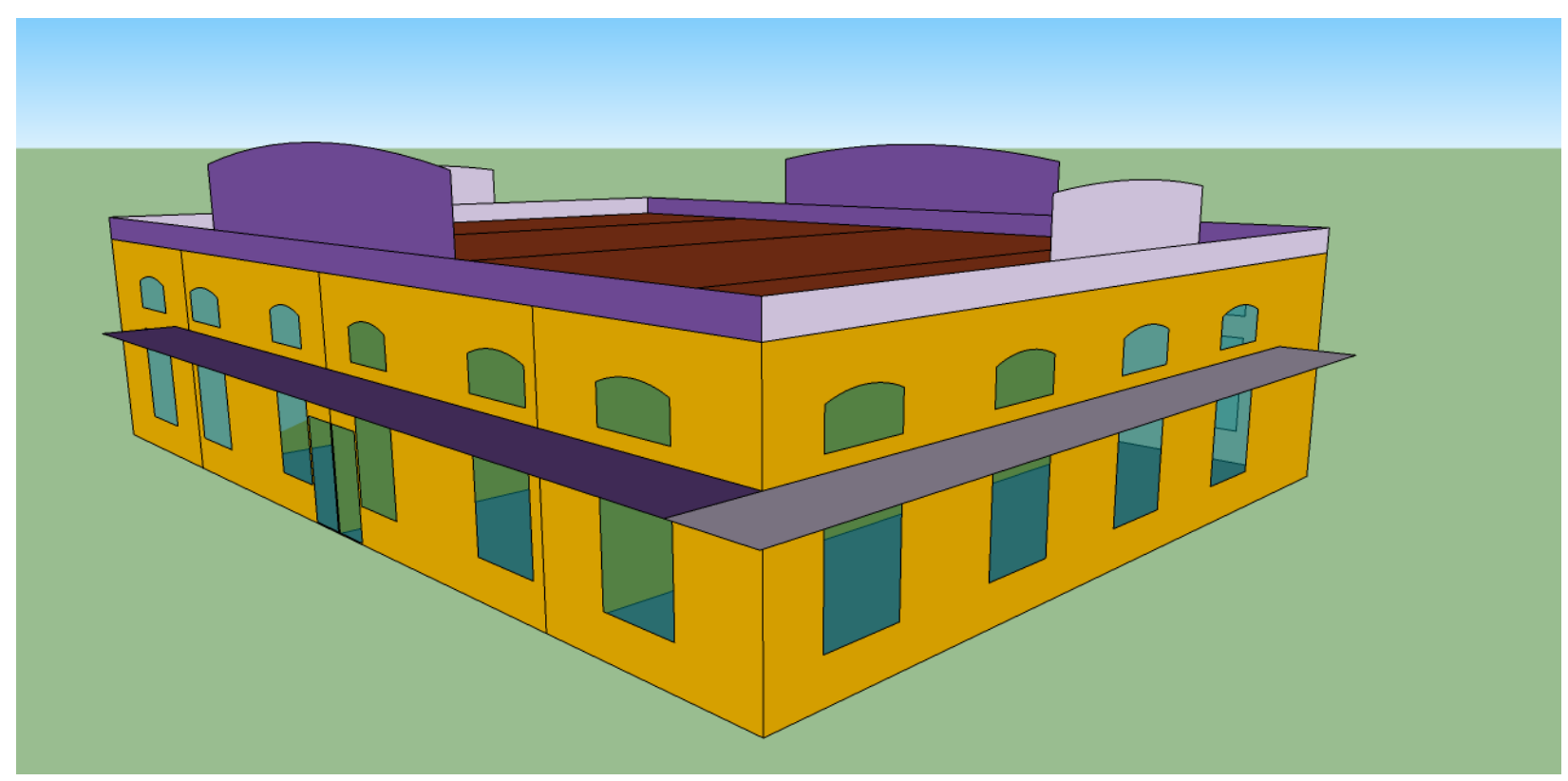

Figure 3-27: BC2 model created in GOOGLE SKETCHUP 


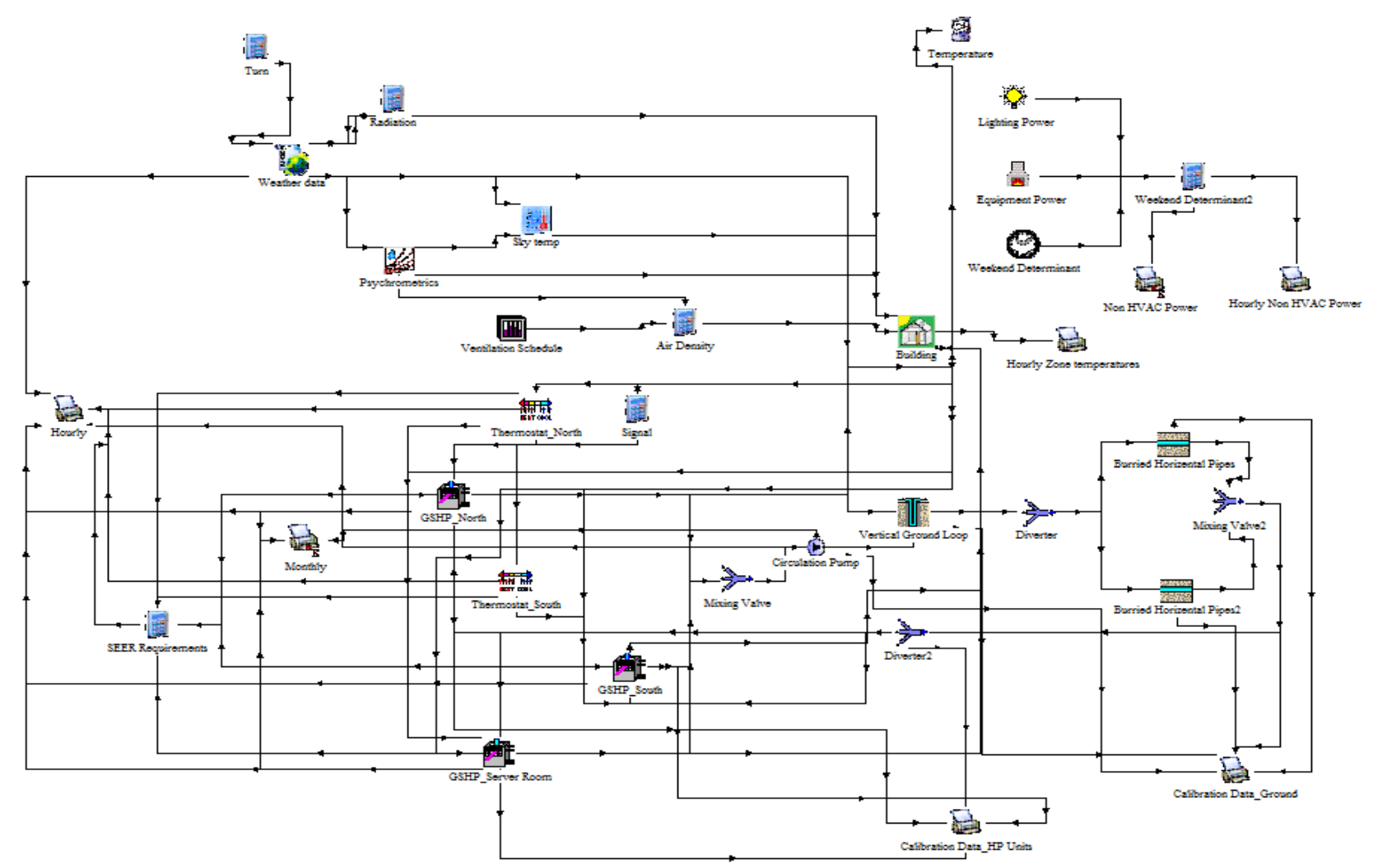

Figure 3-28: BC2 TRNSYS model- Geothermal HVAC System

The monitoring data have been used for calibrating the system in the TRNSYS model. Table 3-16 shows the assumptions that have been made in the modeling. In this table number of people and also type and number of equipment have been assumed based on information of the owner of the building. BC2 is a commercial building and number of people and also equipment for first month of running the business were less than next months. Some Equipment like computer server work 24/7 but most of equipment's power consumption is aligned with people presence schedule. Heating and cooling set point temperatures have been read from thermostats at the building. The occupants do not change the thermostat when they leave the building. 
Table 3-16: Made assumptions in computer modeling. Schedule A: Weekdays From 8:00 AM to 5:00 PM, Schedule B: 24/7

Simulation period I: $1^{\text {st }}$ billing period (7/30/2010-8/12/2010)

Simulation period II: All other billing periods and annual period

\begin{tabular}{|c|c|c|c|c|}
\hline & & \multirow{2}{*}{ Schedule } & \multicolumn{2}{|c|}{ Simulation period } \\
\hline & & & I & II \\
\hline \multicolumn{2}{|c|}{ Number of people } & $A$ & 4 & 8 \\
\hline \multicolumn{2}{|c|}{ lighting $\left(\mathrm{W} / \mathrm{m}^{2}\right)$} & $A$ & 13 & 13 \\
\hline \multicolumn{2}{|c|}{ Equipment (W) } & A & 920 & 920 \\
\hline \multicolumn{2}{|c|}{ Equipment (W) } & B & 920 & 4600 \\
\hline \multirow{2}{*}{ Heating set point $(F)$} & $\begin{array}{l}\text { North } \\
\text { Zone }\end{array}$ & B & 72 & 72 \\
\hline & $\begin{array}{l}\text { South } \\
\text { Zone }\end{array}$ & B & 70 & 70 \\
\hline \multirow{2}{*}{ Cooling set point (F) } & $\begin{array}{l}\text { North } \\
\text { Zone }\end{array}$ & B & 75 & 75 \\
\hline & $\begin{array}{l}\text { South } \\
\text { Zone }\end{array}$ & B & 73 & 73 \\
\hline
\end{tabular}

\subsubsection{Simulation Results}

Figure 3-29 shows the heat pump power consumption based on measured data and simulation results. Power consumption of each unit from the software is $30.6 \mathrm{kWh}$ while the measured power consumption is $22.8 \mathrm{kWh}$. The discrepancy is the result of difference between real weather data and the software weather data that is calculated based on statistical weather data of previous years for the region. 


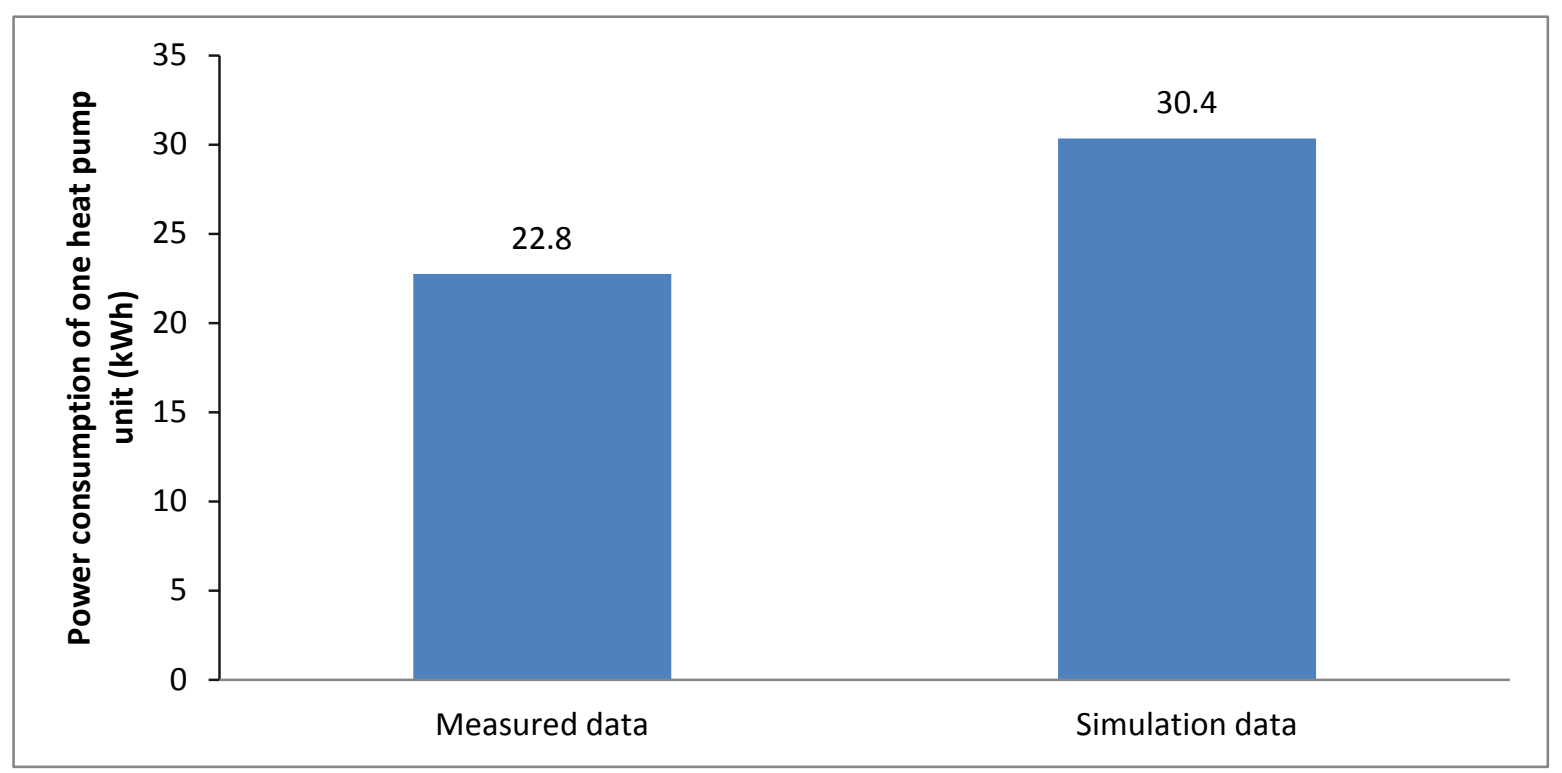

Figure 3-29: Power consumption of each heat pump unit based on measured data and simulation results

Real electricity consumption of the building has been used to calibrate the whole modeling, including the system and the building. Table 3-17 shows the real electricity consumption of the building and electricity consumption resulted from simulation for different billing periods.

As the next step, geothermal heat pumps have been replaced by conventional air source heat pumps with the same capacity to compare the energy consumption of the geothermal system with the conventional system. Figure 3-30 shows the TRNSYS model of the building using conventional heat pump system.

Table 3-18 shows the annual power consumption and SEER of the units and the system for geothermal and conventional air source heat pump system. 
Table 3-17: Power consumption during billing periods in BC2

\begin{tabular}{|c|c|c|c|c|c|c|c|}
\hline \multirow{3}{*}{$\begin{array}{l}\text { Billing } \\
\text { Period }\end{array}$} & \multicolumn{5}{|c|}{ Simulation Results } & \multirow{3}{*}{$\begin{array}{c}\text { Billed Total } \\
\text { Power } \\
\text { Consumption } \\
\text { (kWh) }\end{array}$} & \multirow{3}{*}{$\begin{array}{c}\text { |Billed- } \\
\text { Simulation| } \\
\text { /Billed \% }\end{array}$} \\
\hline & \multirow{2}{*}{$\begin{array}{c}\text { HVAC Power } \\
\text { Consumption } \\
\text { (kWh) }\end{array}$} & \multicolumn{3}{|c|}{$\begin{array}{l}\text { Non-HVAC Power } \\
\text { Consumption (kWh) }\end{array}$} & \multirow{2}{*}{$\begin{array}{c}\text { Total Power } \\
\text { Consumption } \\
\text { (kWh) }\end{array}$} & & \\
\hline & & Equipment & Lighting & Total & & & \\
\hline $\begin{array}{c}\text { 7/30/2010 } \\
- \\
8 / 12 / 2010\end{array}$ & 871 & 308 & 493 & 801 & 1672 & 1688 & 0.92 \\
\hline $\begin{array}{c}\text { 13/8/2010 } \\
- \\
9 / 16 / 2010\end{array}$ & 2548 & 1467 & 1028 & 2495 & 5043 & 5072 & 0.56 \\
\hline $\begin{array}{c}17 / 9 / 2010 \\
- \\
10 / 13 / 2010\end{array}$ & 1617 & 1173 & 822 & 1995 & 3612 & 3668 & 1.53 \\
\hline $\begin{array}{c}\text { 10/14/2010 } \\
- \\
11 / 11 / 2010\end{array}$ & 1230 & 1292 & 905 & 2197 & 3427 & 3379 & 1.41 \\
\hline $\begin{array}{c}11 / 12 / 2010 \\
- \\
12 / 13 / 2010\end{array}$ & 1123 & 1349 & 946 & 2295 & 3418 & 3610 & 5.33 \\
\hline
\end{tabular}

In the real case, the water pump is always on. Annual power consumption based on synchronized pumping system has been calculated too.

Results in table 3-18 shows however the power consumption rate of the water pump is low in comparison to units' power consumption; non-stop working of water pump has a dramatic negative effect on the performance of the system. As it can be seen from the results system SEER in geothermal system is comparable with system SEER in conventional system when we synchronize the running time of the water pump and the units. Otherwise the SEER value of the geothermal system is much lower than it in 
conventional system. It can be seen from energy consumption point of view, even with nonstop water pump running, there is 13.49 percent annual energy saving in comparison to conventional air source heat pump system that can be increased by 29.21 percent by synchronized running of water pump.

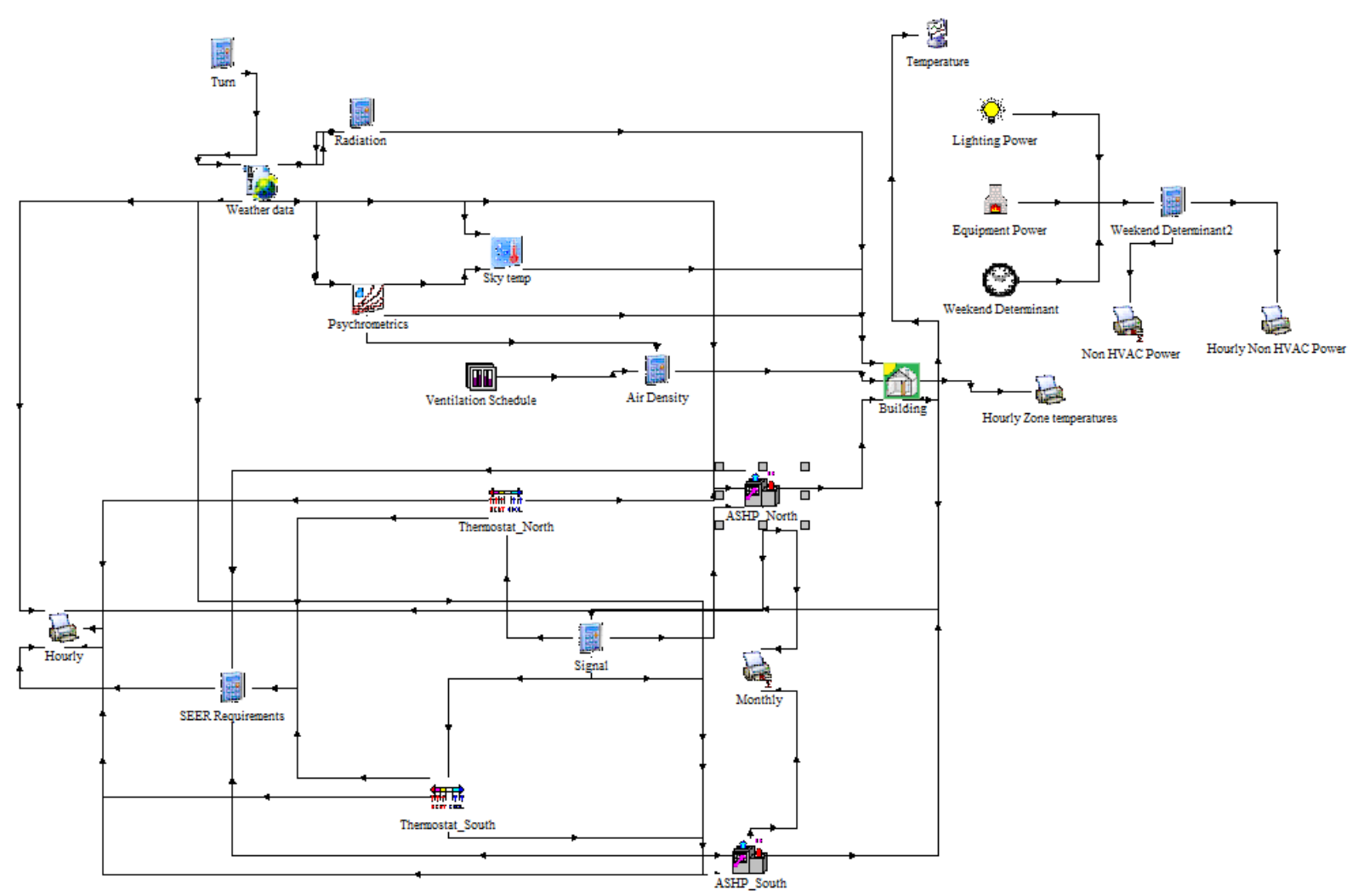

Figure 3-30: BC2 TRNSYS model- Conventional air source HVAC System 
Table 3-18: Comparison between geothermal and conventional air source heat pump

\begin{tabular}{|c|c|c|c|}
\hline \multicolumn{4}{|c|}{ system } \\
\hline \multirow{7}{*}{$\begin{array}{l}\text { Geothermal } \\
\text { System }\end{array}$} & \multirow{2}{*}{$\begin{array}{l}\text { Annual Power Consumption } \\
\qquad(\mathrm{kWh})\end{array}$} & Real mode & 19299.62 \\
\hline & & $\begin{array}{c}\text { Synchronized pumping } \\
\text { mode }\end{array}$ & 15792.16 \\
\hline & \multirow{2}{*}{$\begin{array}{c}\text { Water pump Consumption / Total } \\
\text { Geothermal system Power } \\
\text { Consumption } \\
\%\end{array}$} & Real mode & 40.59 \\
\hline & & $\begin{array}{c}\text { Synchronized pumping } \\
\text { mode }\end{array}$ & 27.39 \\
\hline & \multicolumn{2}{|c|}{ Unit SEER } & 14.9 \\
\hline & \multirow[b]{2}{*}{ System SEER } & Real mode & 8.9 \\
\hline & & $\begin{array}{c}\text { Synchronized pumping } \\
\text { mode }\end{array}$ & 12.9 \\
\hline \multirow{2}{*}{$\begin{array}{c}\text { Conventional } \\
\text { System }\end{array}$} & \multicolumn{2}{|c|}{$\begin{array}{l}\text { Annual Power Consumption } \\
\qquad(\mathrm{kWh})\end{array}$} & 22309.12 \\
\hline & \multicolumn{2}{|c|}{ Unit SEER } & 12.0 \\
\hline \multirow{2}{*}{$\begin{array}{c}\text { Annual } \\
\text { Saving } \\
\%\end{array}$} & \multicolumn{2}{|c|}{ Real mode } & 13.49 \\
\hline & \multicolumn{2}{|c|}{ Synchronized mode } & 29.21 \\
\hline
\end{tabular}

\subsection{Case Study-BC3}

Input data of BC3 simulation model will be presented in this section. The input data for the ENERGYPLUS model are acquired based on limited information including the floor plan and survey data from the owner. Due to this limited information, several input data for the simulation model are assumed based on the information from other similar constructions in the local area or the default value in the software.

\subsubsection{Building Details}

BC3 is located in Pensacola Beach, Pensacola, Florida, which was built on 3.1 acres site in 2010. It is three story restaurant building. The first floor is used for open parking lot and storage. In first floor area, there is no conditioned space. The second floor is 11,600 
square feet and it is used for restaurant, bar and club. In second floor, restaurant and bar area is located in interior space but the club is open to exterior space. The third floor is used for office and club. The size of the third floor is 6300 square feet. When the field test and walk-through survey was performed for this building, the third floor area was not used for its original plan because it was on the construction to make interior spaces. Therefore, half of the space was used for storage purpose. The entrance view of the building is seen in Figure 3-31. Table 3-19 provides a summary of the construction information used for modeling.

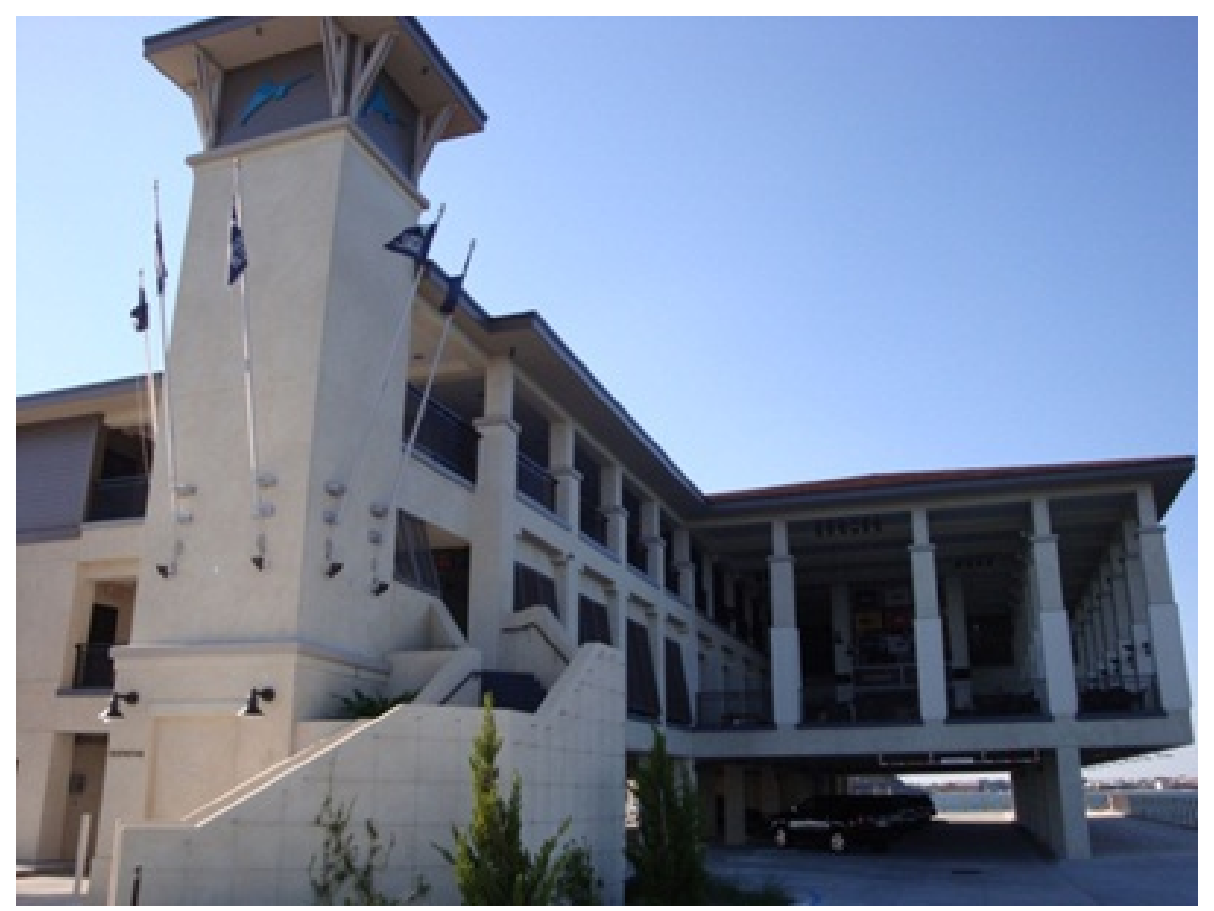

Figure 3-31: Entrance view of BR3 
Table 3-19: Construction Input Summary for the Baseline Building Model

\begin{tabular}{|c|c|}
\hline Construction Details & Existing Building Baseline \\
\hline Total Area $\left(\mathrm{ft}^{2}\right)$ & $2^{\text {nd }}$ floor: $11,600 \mathrm{ft}^{2}$ \\
& $3^{\text {rd }}$ floor: $6300 \mathrm{ft}^{2}$ \\
\hline Number of Floors & 2 \\
\hline \multirow{2}{*}{ Wall Construction } & Wall: 8" or 12" Steel Reinforced Concrete Masonry Unit \\
& Water Proofing Coat \\
& 3/4" KDAT furring Strips@ 16"O.C. \\
& Fiber-Cement Board Siding \\
& $5 / 8$ " Gypsum Board Siding \\
& 1-1/2" Furring Channel @ 16" O.C \\
& 1-1/2" Rigid Insulation \\
\hline Roof Construction & Prefinished Standing Seam Metal Room System: \\
& 4 " Rigid Insulation \\
& Metal Room Deck \\
\hline
\end{tabular}

\section{Mechanical system}

Thirteen geothermal heat pump units are used in this building, which provide heating and cooling. The ground loop is vertical type and the depth of one borehole pipe is 300”. The number of borehole for this ground loop is 135 . The fluid used for the ground loop is water and 15 H.P pumps are used for water circulation. Table 3-20 shows the summary of the geothermal system used for input data of the building modeling. 
Table 3-20: Geothermal System Input Summary for the Baseline Building Model

\begin{tabular}{|l|l|l|l|l|l|l|l|}
\hline $\begin{array}{l}\text { Geothermal } \\
\text { Heat pump }\end{array}$ & $\begin{array}{l}\text { Serving } \\
\text { Zone }\end{array}$ & $\begin{array}{l}\text { Cooling } \\
\text { Capacity } \\
(\mathrm{MBH})\end{array}$ & $\begin{array}{l}\text { Supply } \\
\text { CPM }\end{array}$ & $\begin{array}{l}\text { Geothermal } \\
\text { Heat pump }\end{array}$ & $\begin{array}{l}\text { Serving } \\
\text { Zone }\end{array}$ & $\begin{array}{l}\text { Cooling } \\
\text { Capacity } \\
(\mathrm{MBH})\end{array}$ & $\begin{array}{l}\text { Supply } \\
\text { CPM }\end{array}$ \\
\hline AH-1 & $\begin{array}{l}\text { Rest room, } \\
\text { store area }\end{array}$ & 68.6 & 1800 & AH-5 & $\begin{array}{l}\text { Restaurant, } \\
\text { Club }\end{array}$ & 108.3 & 2000 \\
\hline AH-2 & Restaurant & 389.8 & 8200 & AH-6 & Office & 151.3 & 3000 \\
\hline AH-3A & Bar & 68.61 & 2000 & AH-7 & Storage & 68.8 & 1950 \\
\hline AH-3B & Kitchen & 190.4 & 2695 & AH-8 & Restaurant & 106.9 & 1800 \\
\hline AH-3C & Kitchen & 190.4 & 2695 & AH-9 & Storage & 29.4 & 800 \\
\hline AH-3D & $\begin{array}{l}\text { Kitchen, } \\
\text { Office }\end{array}$ & 129.4 & 2275 & AH-10 & Storage & 216.6 & 4550 \\
\hline AH4 & Restaurant & 152.8 & 3200 & & & & \\
\hline
\end{tabular}

This building is used for a restaurant. Therefore the exhaust fan system is very important and should be considered, especially in the kitchen. Propeller wall fans are also installed on the wall in the club area. Roof fan is also installed in every room. The summary of the fan system is depicted in the Table 3-21.

The set point temperature for restaurant and office area is $72^{\circ} \mathrm{F}$ for all seasons. The set-point temperature for storage area is maintained to $73-74^{\circ} \mathrm{F}$.

Table 3-21: Fan System Input Summary for the Baseline Building Model

\begin{tabular}{|c|c|c|c|}
\hline Fan & Serving area & Motor H.P & CPM \\
\hline KEF-1 & Kitchen hood exhaust & 5 & 6444 \\
\hline KEF-2 & Kitchen hood exhaust & 3 & 5143 \\
\hline KSF-1 & Kitchen hood exhaust & 5 & 5800 \\
\hline KSF-2 & Kitchen hood exhaust & 2 & 4629 \\
\hline EF-1 to 7 & Roof Fan & $1 / 40-1 / 8$ & $80-840$ \\
\hline EF-8, 9 & Wall Fan & $1 / 10$ & 600 \\
\hline
\end{tabular}




\section{Lighting and Equipment}

In this building, thirty one different types of lighting fixtures are used, which include interior and exterior lightings. The types of the lighting fixture are summarized in Table 322.

This is a commercial restaurant. Therefore, the internal heat gain from the cooking equipment is significant and the energy consumption of the kitchen equipment is also very high. The large capacity refrigerators used for storing raw sea food are installed in the kitchen and $3^{\text {rd }}$ floor storage room. There are computers and office equipment in the office area.

Table 3-22: lighting System Input Summary for the Baseline Building Model

\begin{tabular}{|c|c|c|c|}
\hline & Lighting type & EA & Total(W) \\
\hline \multirow{2}{*}{$2^{\text {nd }}$ floor store and rest } & $64 \mathrm{~W}$ lamp & 37 & 2368 \\
room area & 32W lamp & 9 & 288 \\
& $600 \mathrm{~W}$ lamp & 4 & 2400 \\
\hline \multirow{2}{*}{$2^{\text {nd }}$ floor Restaurant } & $600 \mathrm{~W}$ lamp & 4 & 2400 \\
& $75 \mathrm{~W}$ lamp & 12 & 900 \\
\hline \multirow{2}{*}{ Kitchen } & $64 \mathrm{~W}$ lamp & 38 & 2432 \\
\hline $2^{\text {nd }}$ floor small & $32 \mathrm{~W}$ lamp & 8 & 256 \\
restaurant area & $64 \mathrm{~W}$ lamp & 6 & 384 \\
\hline \multirow{2}{*}{$2^{\text {nd }}$ floor club } & $64 \mathrm{~W}$ lamp & 3 & 192 \\
\hline
\end{tabular}

\subsubsection{Building Model Specifications}

The ENERGYPLUS computer simulation model is used in this case study. The configuration of the ground loop for this building is vertical type. Therefore, the geothermal module used for this building modeling was chosen as GroundHeatExchanger:Vertical. The module of GroundHeatExchanger:Vertical is using G-function that was developed by Eskilson, Yavuzturk and Spitler (1999). The G-function factors are infinite series of 
numbers, which relate the current value of a heat flux to past values of other variables at discrete time interval.

There is one zone in the first floor, which is used for a storage facility and an unconditioned space. In main restaurant area on the $2^{\text {nd }}$ floor, two large capacity heat pumps serve the area. Therefore, the restaurant area was divided into two zones. Due to high internal gain, three heat pump units are connected to the duct system of the kitchen area. On the third floor, there are areas designed for restaurant, but it was on construction. The area was used for a storage facility. There is one high capacity refrigerator.

The ENERGYPLUS simulation model of the building was developed as illustrated in Figure 3-35. The roof shape modeling was simplified as a box shape as seen in Figure 332. The elevator tower located at the entrance area was not modeled but the electricity energy consumption was considered in the modeling process.

The occupancy schedules were derived from the survey for the modeling. Occupancy schedules were considered for weekdays and schedules for Saturday, Sunday and Holidays. The space usages are divided into restaurant and offices. Therefore, the occupancy schedules for restaurant related area including bar, club and kitchen and for office area reflect this pattern.

The equipment schedule reflects two schedules for the restaurant equipment and for office room. This is because the restaurant area is used throughout all weeks, but the office equipment is needed to be turned off typically in weekend. 


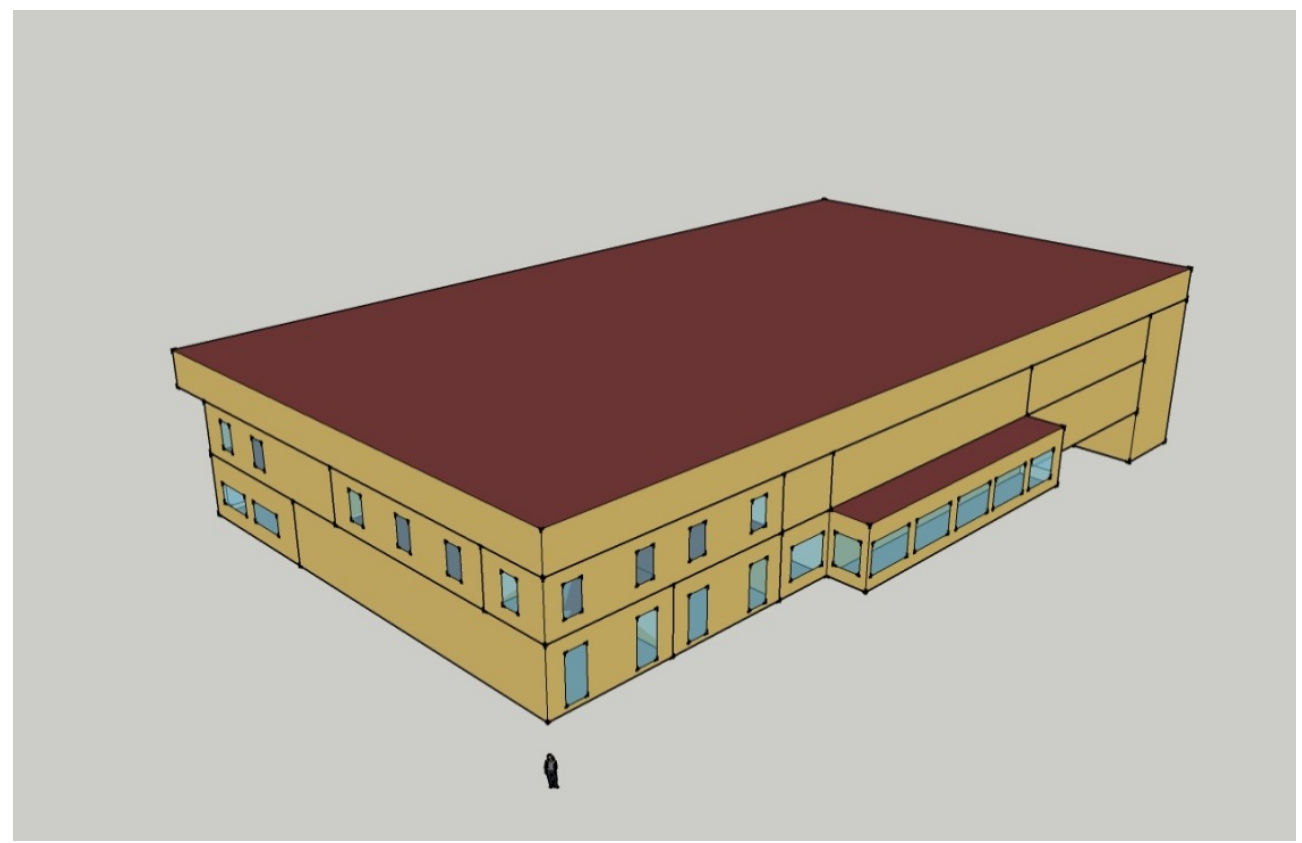

(a)Northeast view of BC3 model

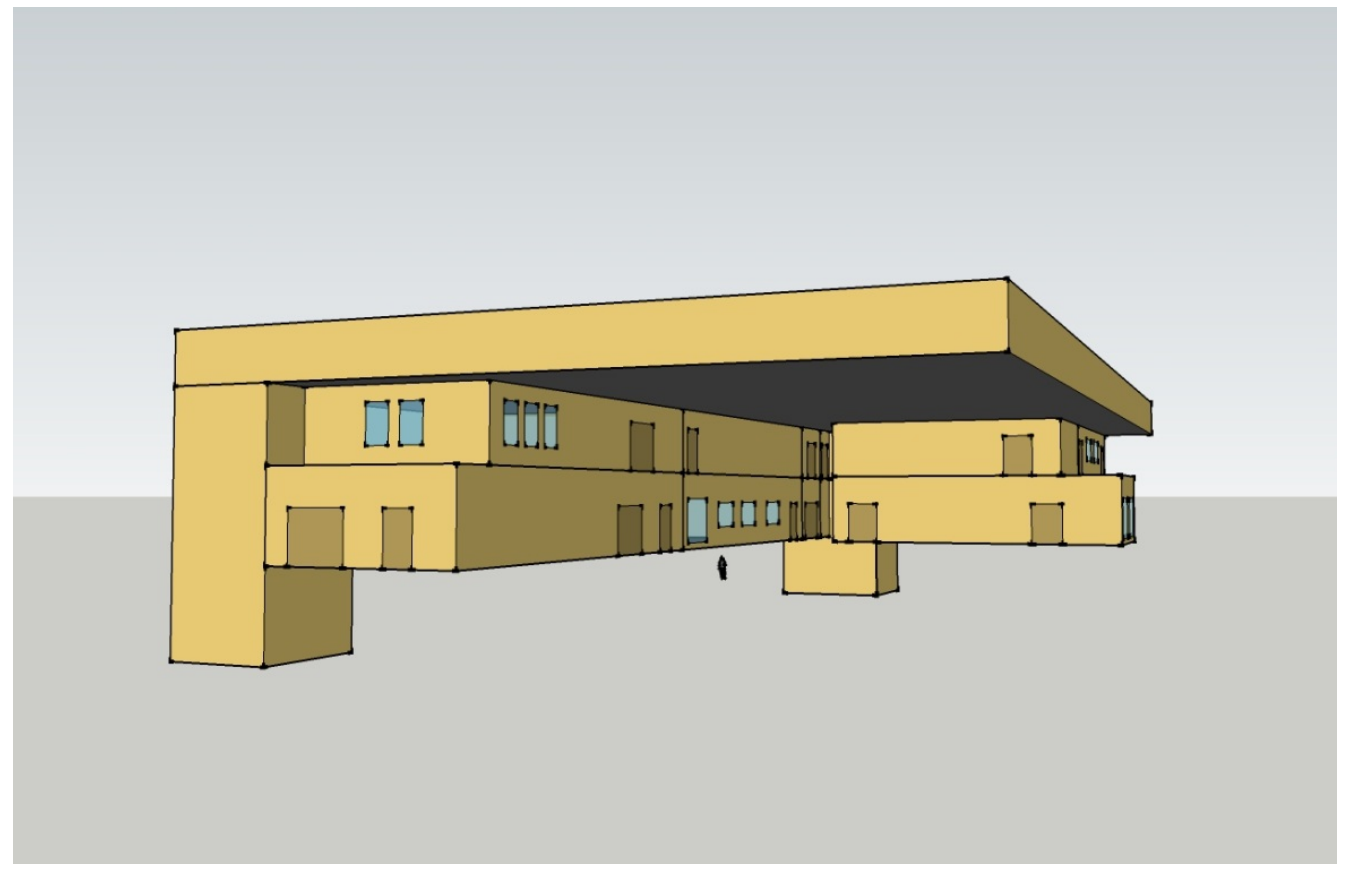

(b) Southwest view of BC3 model

Figure 3-32: 3-D Renderings for Building Energy Simulation Model

The lighting schedule varies during the weekday and weekend. The exterior lighting schedules was determined separately from the interior lighting schedules. 


\subsubsection{Simulation Results}

The utility bill data and the monitoring data were used to calibrate the model. The monitoring data were specially used to improve and calibrate the mode of the ground source heat pump system.

The electricity bill used for the calibration is the data of 2010. The billing data were collected at the end of 2010. The restaurant opened at the end of February of 2010. The values of the first and second month data were much lower than others since the opening time. Therefore, the available data are only from April to November.

With all these adjustment and comparison, the final annual difference between the utility bills and the simulation model was found. Figure 3-33 and 3-34 shows the base case electricity consumption profile. Table 3-23 below shows the comparison between actual billing data and the simulation data.

In this step, geothermal heat pumps have been replaced by conventional air source heat pumps with the same capacity to compare the energy consumption of the geothermal system with the conventional system. In ENERGYPLUS, Unitaryheatpump:Air-to-Air module was used to make a case for this system. Table 3-24 summarizes annual saving for the geothermal heat pump and the conventional system used in this building. 


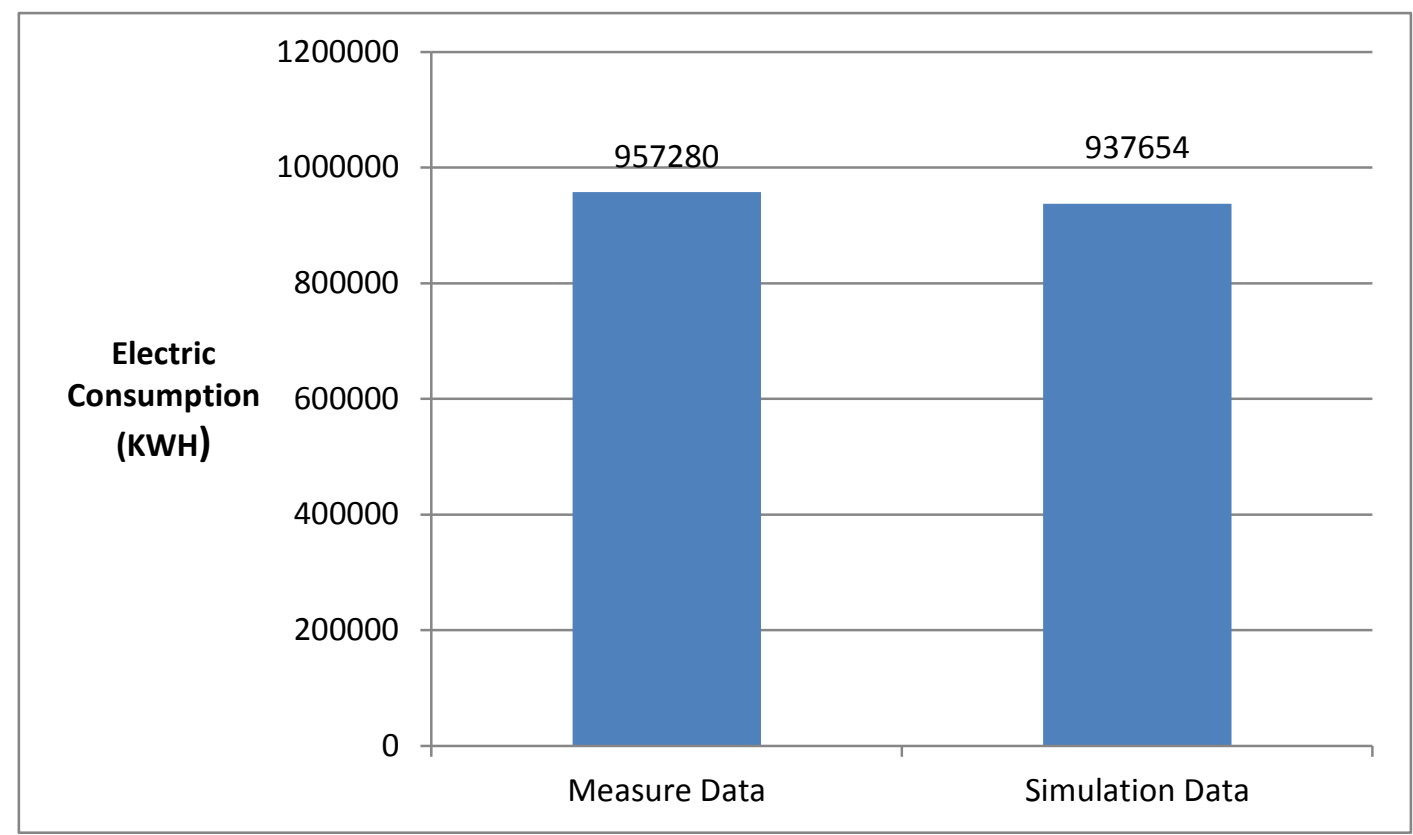

Figure 3-33: Comparison of heat pump consumptions between simulation data and measure data

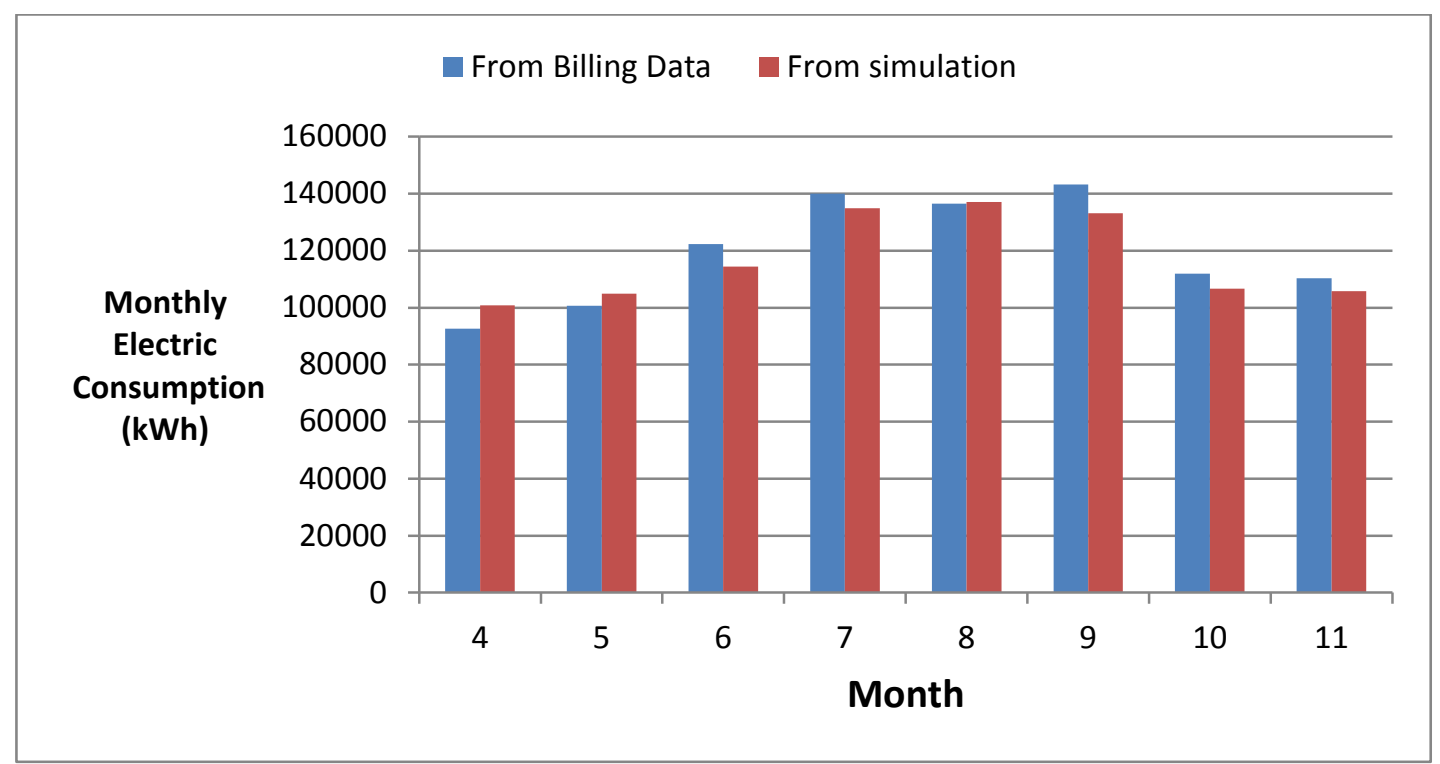

Figure 3-34: Comparison between annual electric data from simulation and owner's electric bill 
Table 3-23: Comparison between actual billing data and the simulation results

\begin{tabular}{|c|c|c|c|c|c|}
\hline \multirow[b]{2}{*}{$\begin{array}{l}\text { Billing } \\
\text { Period }\end{array}$} & \multicolumn{4}{|c|}{ Simulation Results } & \multirow{2}{*}{$\begin{array}{l}\text { Billed Total } \\
\text { Power } \\
\text { Consumption } \\
\text { (kWh) }\end{array}$} \\
\hline & $\begin{array}{l}\text { HVAC Power } \\
\text { Consumption } \\
\text { (kWh) }\end{array}$ & $\begin{array}{l}\text { Non-HVAC Power } \\
\text { Consumption } \\
\text { (kWh) }\end{array}$ & $\begin{array}{l}\text { Lighting Power } \\
\text { Consumption } \\
\text { (kWh) }\end{array}$ & $\begin{array}{c}\text { Total Power } \\
\text { Consumption } \\
\text { (KWh) }\end{array}$ & \\
\hline $\begin{array}{c}\text { 3/30/2010 } \\
- \\
4 / 28 / 2010\end{array}$ & 13719 & 79506 & 7621 & 100846 & 92560 \\
\hline $\begin{array}{c}4 / 29 / 2010 \\
- \\
5 / 27 / 2010\end{array}$ & 16665 & 80251 & 7935 & 104851 & 100640 \\
\hline $\begin{array}{c}5 / 28 / 2010 \\
- \\
6 / 25 / 2010 \\
\end{array}$ & 17081 & 89659 & 7734 & 114474 & 122240 \\
\hline $\begin{array}{c}\text { 6/26/2010 } \\
- \\
7 / 27 / 2010\end{array}$ & 17247 & 109769 & 7823 & 134839 & 139960 \\
\hline $\begin{array}{c}\text { 7/28/2010 } \\
- \\
8 / 26 / 2010 \\
\end{array}$ & 18529 & 110530 & 8006 & 137065 & 136440 \\
\hline $\begin{array}{c}\text { 8/26/2010 } \\
- \\
\text { 9/27/2010 }\end{array}$ & 15932 & 109617 & 7621 & 133170 & 143200 \\
\hline $\begin{array}{c}\text { 9/28/2010 } \\
- \\
10 / 27 / 2010\end{array}$ & 8333 & 90496 & 7863 & 106692 & 111920 \\
\hline $\begin{array}{c}\text { 10/28/2010 } \\
- \\
11 / 29 / 2010\end{array}$ & 8065 & 90020 & 7631 & 105716 & 110320 \\
\hline & Total Energ & Consumption(kWh) & & 937653 & 957280 \\
\hline (Actual F & er Consumptio & $\begin{array}{c}\text { - Simulation Resu } \\
100(\%)\end{array}$ & Actual Powe & umption $x$ & $2 \%$ \\
\hline
\end{tabular}


Table 3-24: Comparison between geothermal and conventional air source heat pump system

\begin{tabular}{|c|c|c|}
\hline \multirow{2}{*}{$\begin{array}{c}\text { Geothermal } \\
\text { System }\end{array}$} & $\begin{array}{c}\text { Whole Building Annual Power Consumption } \\
(\mathrm{kWh})\end{array}$ & 1331600 \\
\cline { 2 - 3 } & $\begin{array}{c}\text { System Annual Power Consumption } \\
(\mathrm{kWh})\end{array}$ & 148300 \\
\hline \multirow{2}{*}{$\begin{array}{c}\text { Conventional } \\
\text { System }\end{array}$} & $\begin{array}{c}\text { Whole Building Annual Power Consumption } \\
(\mathrm{kWh})\end{array}$ & 1346720 \\
\cline { 2 - 3 } & $\begin{array}{c}\text { System Annual Power Consumption } \\
(\mathrm{kWh})\end{array}$ & 163400 \\
\hline \multirow{2}{*}{$\begin{array}{c}\text { Annual } \\
\text { Saving }\end{array}$} & $\%$ & 9.2 \\
\cline { 2 - 3 } & & 15098 \\
\hline
\end{tabular}

As seen in table 3-24, it is estimated that the geothermal heat pump system consumes $9 \%$ less energy than the conventional heat pump system for the Grand Marlin restaurant.

\subsection{Case Study-BC4}

The hotel which to be simulated is located on a barrier island on the Florida Gulf coast, and there are 117 room facilities with large public parking area, a meeting room, a large dining room and a limited breakfast area which is in total $80,145 \mathrm{ft}^{2}$, and the hotel includes some amenities such as one health club, two large outdoor heated pools, one outdoor heated spa and a large, shallow children’s pool.

\subsubsection{Building Model}

Based on the blueprint and the images, the building model is created using GOOGLE SKETCHUP which is a free 3D modeling program. Figures 3-35 and 3-36 show the simulation building model. Several considerations are made when the building model are created in Google Sketchup and TRNSYS software package. 


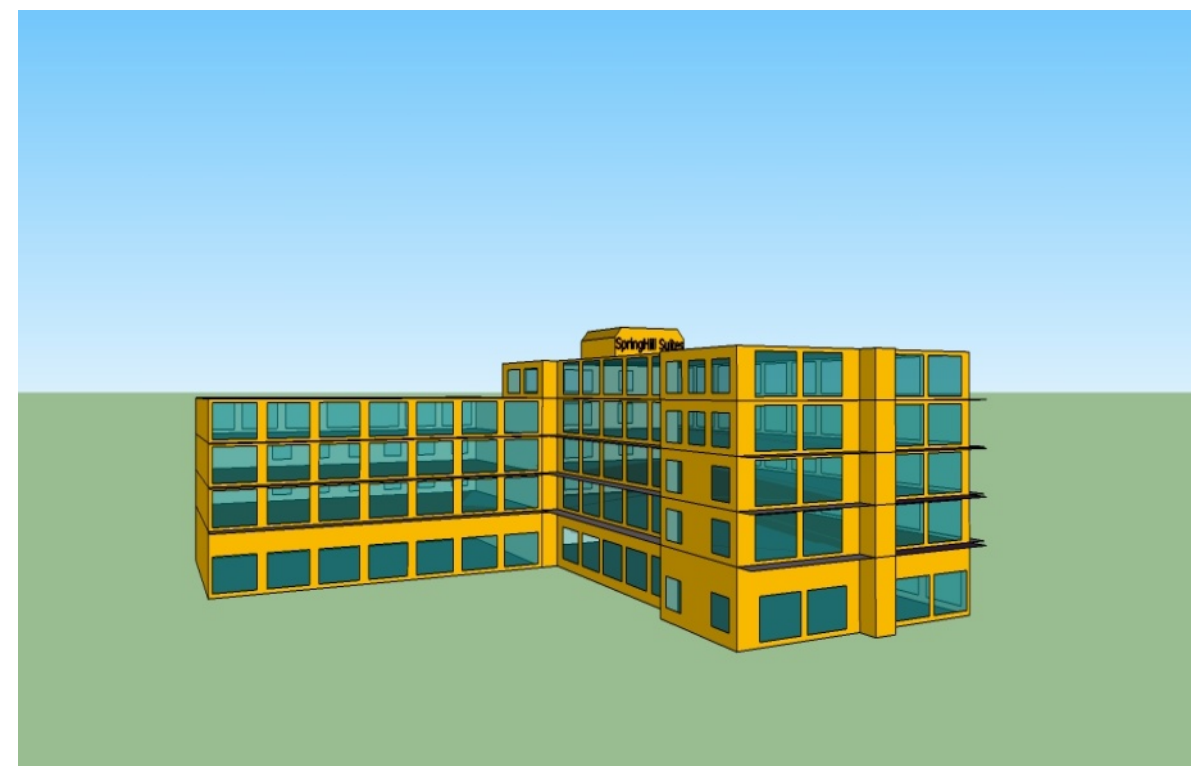

Figure 3-35: Southwest view of simulation building model

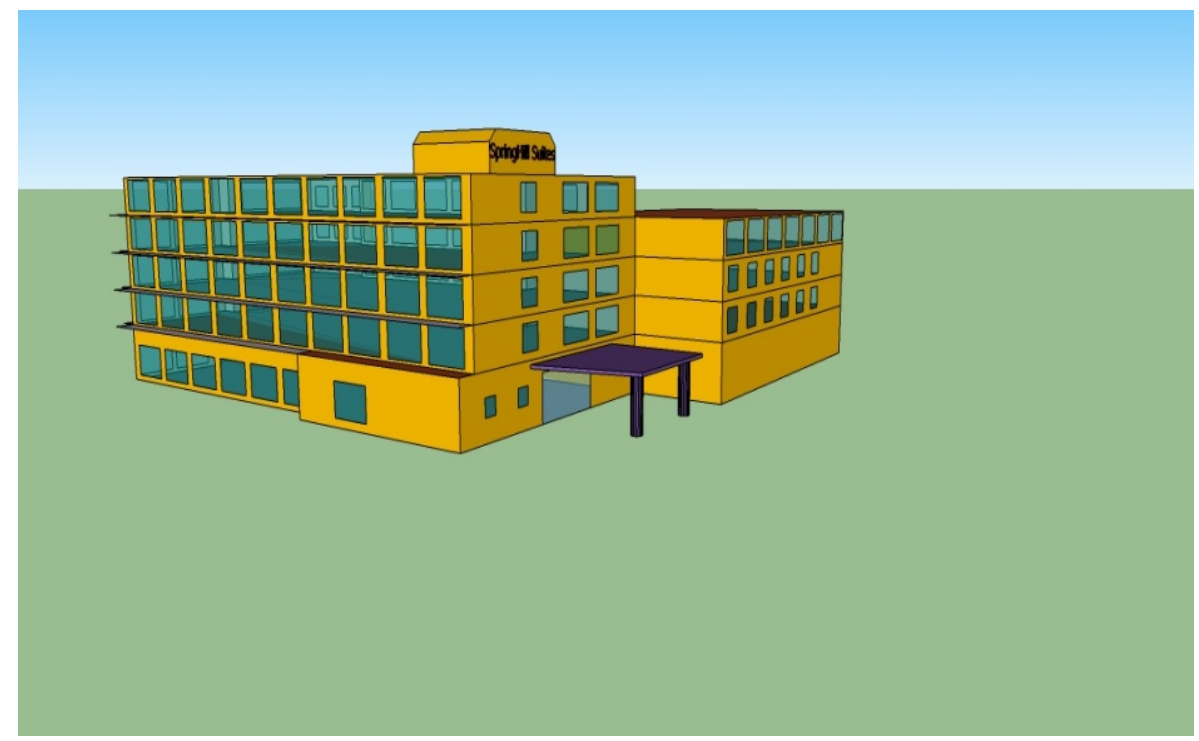

Figure 3-36: Building model by GOOGLE SKTCHUP

\subsubsection{Building Model Specifications}

The hotel includes 117 room unitary heat pump units (180 tons in total), two 100\% outside air rooftop air conditioners ,three $64 \mathrm{KBtu} / \mathrm{h}$ water to water heat pumps for domestic heat water and two $390 \mathrm{KBtu} / \mathrm{h}$ water to water heat pump for swimming pool and spa heating equipment's. 
Because of the limited installation field area available for the geothermal heat exchanger loop, the designer selected a 150 tons closed-loop evaporative fluid cooler to parallel the ground-coupled loop field which owns 98 boreholes with 200 depths and 1" Utube to compose the HYGSHP system.

In order to simulate the HyGSHP system, the transient simulation software package TRNSYS is employed to simulate the short time step for one year period simulation (5 minutes is set as the simulation time step), and the hourly typical meteorological year for the Pensacola is used. The HVAC system worked with the well validated building model can predict the enter water temperate, the system profile and the building energy consumption etc. And the building model and all the heat rejecting and extraction system like water to water heat pumps, air source heat pumps, cooling tower are included in the simulation system.

The diagram of HyGSHP in the hotel is shown in Figure 3-37; the cooling tower is activated when the entering water temperature is over $29^{\circ} \mathrm{C}$. The components such as closed circuit cooling tower, vertical ground heat exchanger, water to air heat pump etc is included in the TRNSYS model. The TRNSYS map for this hotel HyGSHP system is shown in Figure 3-38. Figure 3-39 shows the same building model with conventional HVAC system for the purpose of comparison with the existing HyGHSP system. Another TRNSYS map for GSHP system isn't listed in the paper due to using the similar components with HyGSHP system. 


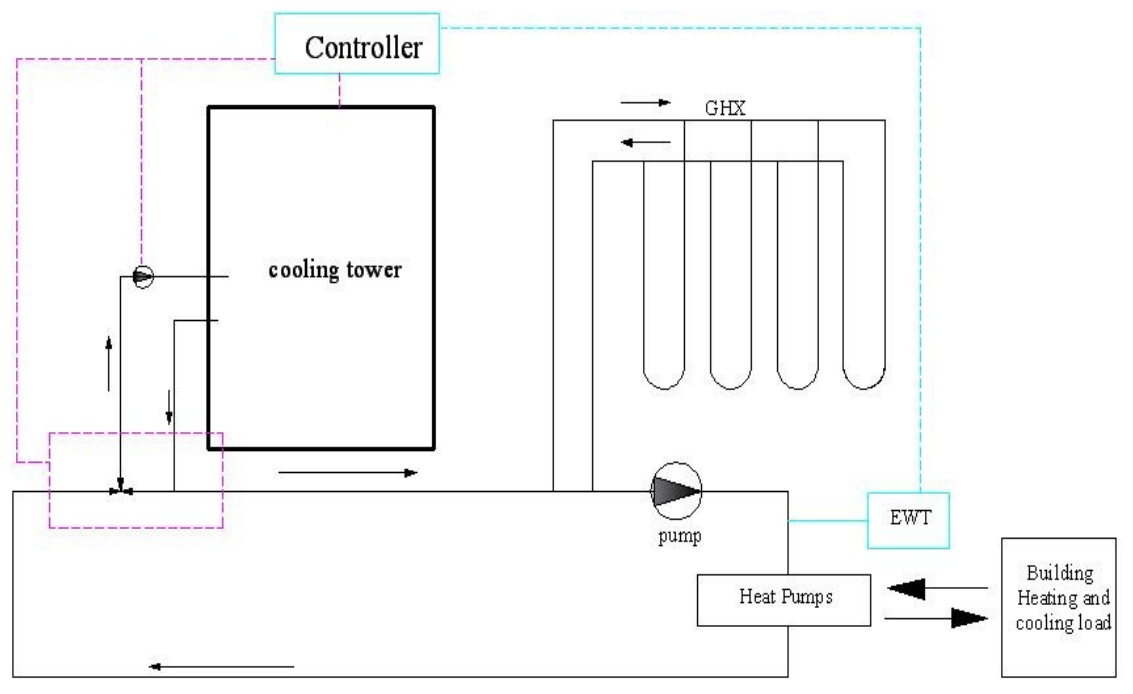

Figure 3-37 Schematic diagram the existing HyGSHP configuration

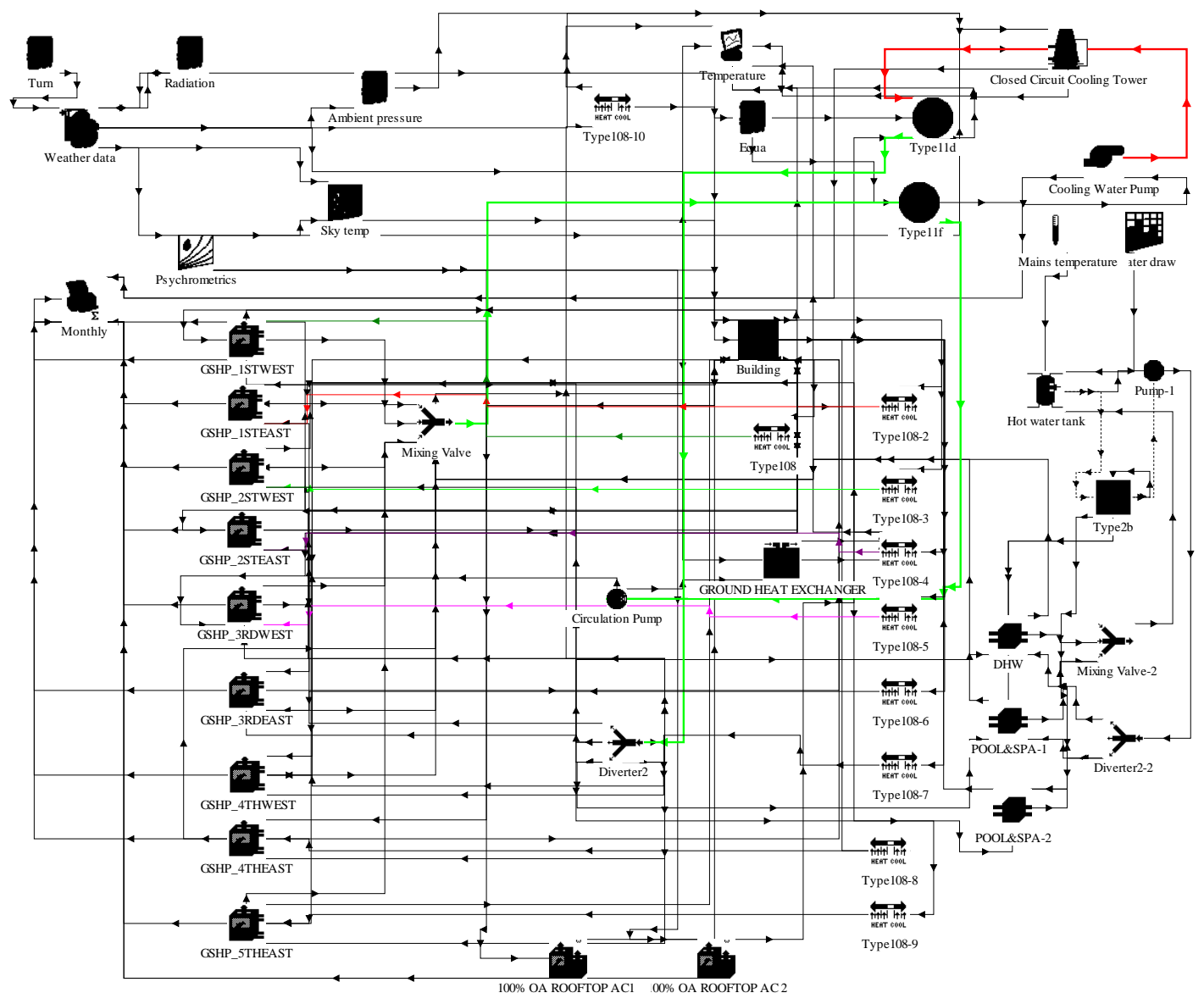

Figure 3-38: TRNSYS map for HyGSHP system 
The components which are used in the simulation model are listed below:

- TYPE 56-Multi-zone building

- $\quad$ TYPE3b-Single speed pump

- TYPE 4a- Storage Tank

- TYPE14e: Temperature

- TYPE14h-Time Dependent Forcing Function: water draw

- TYPE14b-lighting consumption/schedule

- TYPE14c-other equipment consumption/schedule

- TYPE108-Five-stage thermostat

- TYPE69b- Effective Solar temperature

- TYPE33e-Psychrometrics: dry bulb and relative humidity

- TYPE504b-Water to air heat pump

- TYPE557- Vertical U-Tube Ground Heat Exchanger

- TYPE647- Fluid Diverting Valve

- $\quad$ TYPE 649 - Mixing valve for fluids

- TYPE 665 -AIR-SOURCE HEAT PUMP

- TYPE 668 -Water to Water Heat Pump

- $\quad$ TYPE510 -Closed Circuit Cooling Tower

- TYPE11f -controlled mix valve

- TYPE11d -controlled fluid diverter

9 TYPE 577-water to air heat pumps (named as GSHP_1st west, GSHP_1steast and so in the TRNSYS map) are connected with the TYPE56-the building model in order to control the room temperature and humidity. Each heat pump is controlled by one TYPE 108-thermostat which room set points use $21^{\circ} \mathrm{C}$ for cooling and $23^{\circ} \mathrm{C}$ for heating 
respectively. The main geothermal loop cycle comprises of heat pumps ( including water to air heat pump for room conditioning, water to water to water heat pumps for domestic hot water and heating spa), water pumps ( controlling the flow rate of the main loop), and TYPE 557 vertical ground heat exchanger model. The TYPE 510-closed circuit cooling tower is connected with the main loop according to TYPE11d controlled mix valve and TYPE 11f controlled fluid diverter that are partly opened when entering water temperature is over $29^{\circ} \mathrm{C}$ monitored by TYPE108 controlled.

The weather system is installed to simulate the environment condition of cooling tower, building, ground heat exchanger, heat pumps and so on. The domestic hot water and heating spa are simulated by three TYPE668-water to water heat pumps and TYPE4astorage tank which temperature and flow rate are controlled by the 14h- water draw and the $14 \mathrm{e}$ temperature. And the $100 \%$ outside air roof top conditioner in the system is simulated by TYPE 665 air source heat pump which supply air temperature is set as ambient temperate in the simulation.

The components connection in the TRNSYS map of the complete ground source heat pump system is the same as hybrid system except only without the cooling tower system.

Air source heat pump system (shown Figure 3-39) utilizes the 9 TYPE665 air source heat pumps to control the room temperature and humidity. The water to water heat pump is used to simulate the domestic hot water and heating spa.

Table 3-25 presents the list of variable inputs for HyGSHP system in the TRNSYS model. 


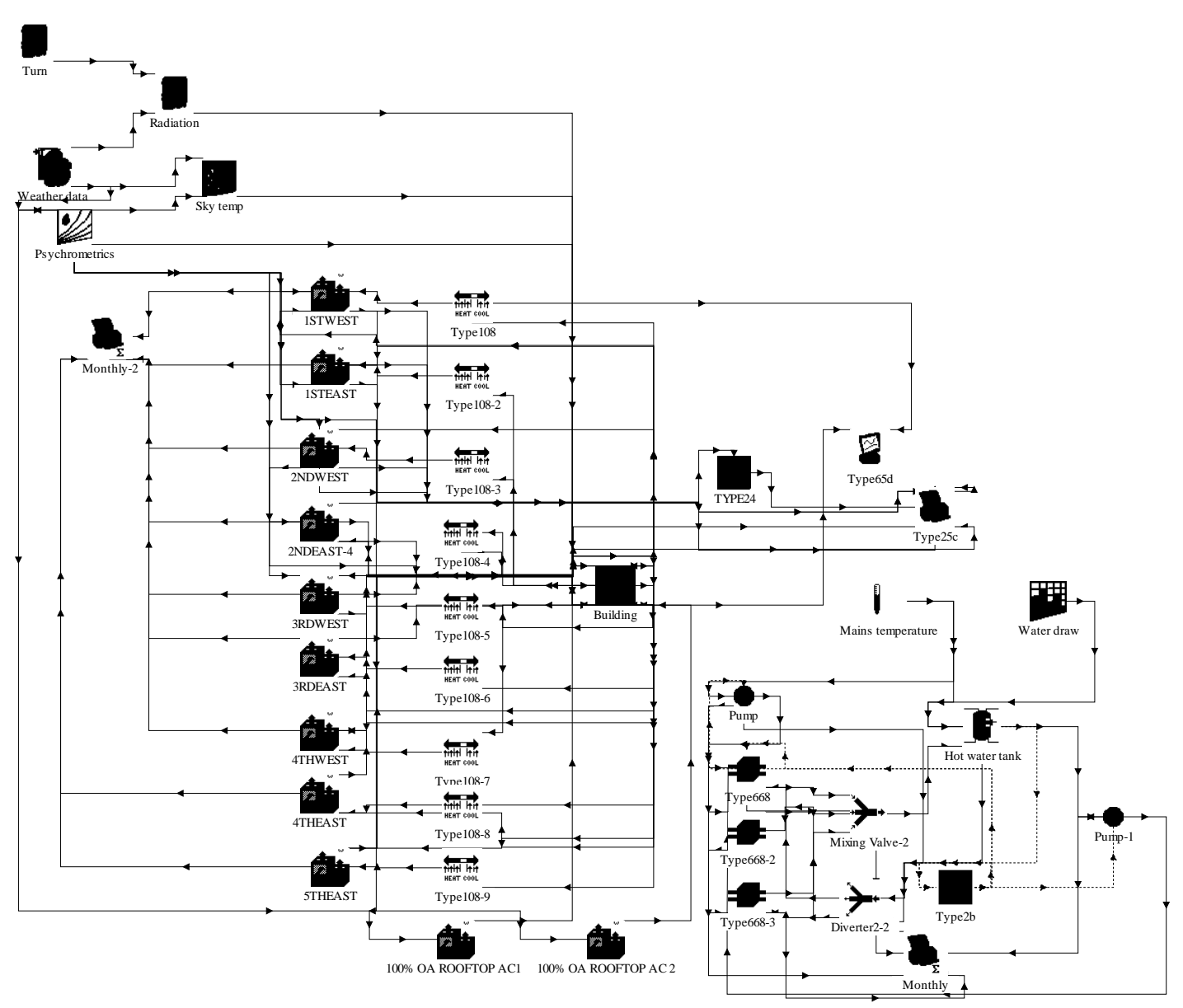

Figure 3-39: TRNSYS map for ASHP system

Table 3-25: Input Summary for the HyGSHP Simulation Model

\begin{tabular}{|c|c|}
\hline Construction Details & Existing Building \\
\hline Total Conditioned Area $\left(\mathrm{m}^{2}\right)$ & 7595 \\
\hline number of floors & 5 \\
\hline Ext_wall layer & $\begin{array}{c}\text { Gypsum broad 2” } \\
\text { Wall:Concrete block stucco 12”, } \\
\text { exterior insulation and finish }\end{array}$ \\
\hline Roof Layer & Insulation(R-19), 6” STUD \\
\hline Floor Construction & 0.08 m concrete on ground, Cork cover \\
\hline Percent Glazing Area & $50 \%$ \\
\hline Glazing U-Value & $\mathrm{U}-2.89 \mathrm{~W} / \mathrm{m}^{\wedge} 2 \mathrm{k}$ \\
\hline
\end{tabular}


Table 3-25(Cont.): Input Summary for the HyGSHP Simulation Model

\begin{tabular}{|c|c|}
\hline Plant Details & HyGSHP \\
\hline Ground heat exchanger & HyGSHP \\
\hline Borehole hole & 98@200 ft deep \\
\hline Borehole spacing & $20 \mathrm{ft}$ \\
\hline U TUBE & 1 inch \\
\hline Ground conductivity & 5.22 KJ/hr.m.k [33] \\
\hline Fill conductivity & $4.2 \mathrm{KJ} / \mathrm{hr} . \mathrm{m} . \mathrm{k}$ \\
\hline HVAC & $\begin{array}{l}180 \text { tons unitary heat pump \& } 70 \text { tons water to water heat } \\
\qquad \text { pump } \\
50 \text { tons } 100 \% \text { roof top air conditioner } \\
150 \text { tons cooling tower }\end{array}$ \\
\hline Initial Ground water temperature $\left({ }^{\circ} \mathrm{C}\right)$ & 21 \\
\hline Total System Airflow & Constant air flow \\
\hline Cooling Setpoint Daytime/nighttime $\left({ }^{\circ} \mathrm{C}\right)$ & 23.3 \\
\hline Heating Setpoint - Daytime/Nighttime $\left({ }^{\circ} \mathrm{C}\right)$ & 21.1 \\
\hline Air Source Heat Pump (ASHP) & ASHP \\
\hline Cooling Setpoint Daytime/nighttime $\left({ }^{\circ} \mathrm{C}\right)$ & 23.3 \\
\hline Heating Setpoint - Daytime/Nighttime $\left({ }^{\circ} \mathrm{C}\right)$ & 21.1 \\
\hline \multicolumn{2}{|l|}{ Internal Loads } \\
\hline Lighting Power Density $\left(\mathrm{W} / \mathrm{ft}^{2}\right)$ & 1.0 (assumed) \\
\hline Lighting Controls & specified \\
\hline Equipment/Plug load Density $\left(\mathrm{W} / \mathrm{ft}^{2}\right)$ & 1.1 (assumed) \\
\hline Occupancy Density & $\operatorname{Max}=300$ \\
\hline Operating Schedules & Specified \\
\hline Lighting equipment schedule & See Pictures 1 and 2 \\
\hline Infiltration & 1.0 \\
\hline Plant Details & GSHP \\
\hline Ground heat exchanger & GSHP \\
\hline Borehole hole & 245@ $200 \mathrm{ft}$ deep \\
\hline Borehole spacing & $20 \mathrm{ft}$ \\
\hline U TUBE & 1 inch \\
\hline Ground conductivity & $4.68 \mathrm{KJ} / \mathrm{hr} . \mathrm{m} . \mathrm{k}$ \\
\hline Fill conductivity & 5.22 KJ/hr.m.k \\
\hline
\end{tabular}




\subsubsection{Simulation Results}

In order to verify the simulation model and building model, the validation process is important to make the results convincing and accurate.

In this study, the first year measure data is used for validation of the first year of simulation in order to verify the building model and system model in TRNSYS. The hotel is monitored by Al Barfield (2006) during the first year of hotel open to the public, and the average return water temperature, domestic hot water and heating spa consumption and total building consumption are metered.

The simulation results and the measured data are compared comprehensively in the Figure 3-40, Figure 3-41, Figure 3-42, Figure 3-43 and Figure 3-44 based on the first year of system operation. According to Figure 3-40, the Average entering water temperature from the simulation is well matched with measure data. And several energy consumption comparisons are illustrated in the Figures 3-41, and 3-42 which shows the DHW\&SPA heating consumption, and the total building calendar energy consumption respectively.

According to these three pictures, there is difference between the simulation data and measure data. There are three main reasons to explain it.

1. The typical meteorological year weather data is different from the real weather data; it causes the errors between the simulation and real operation.

2. For the validation with DHW and SPA heating, it is difficult to be consistent with the actual operation and is hard to simulate the usage with accurate water draw and operation schedule.

3. The assumed lighting and equipment consumption is not accurate to predict the real energy consumption and heat gain. 
Furthermore, Figure 3-43 shows the composition of the annual total building consumption, the simulation result have less than $2 \%$ of difference with the statistic map from utility company (shown in Figure 3-44)

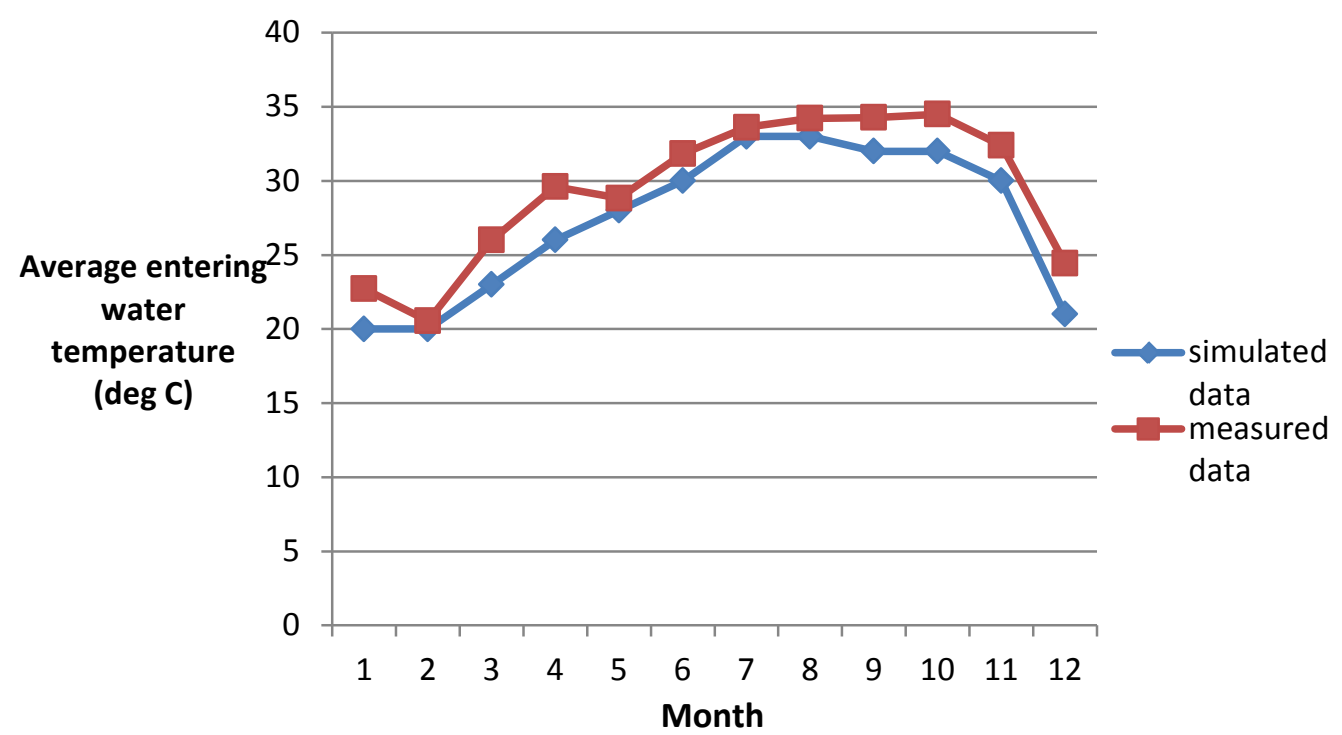

Figure 3-40: Validation of average entering water temperature to heat pumps

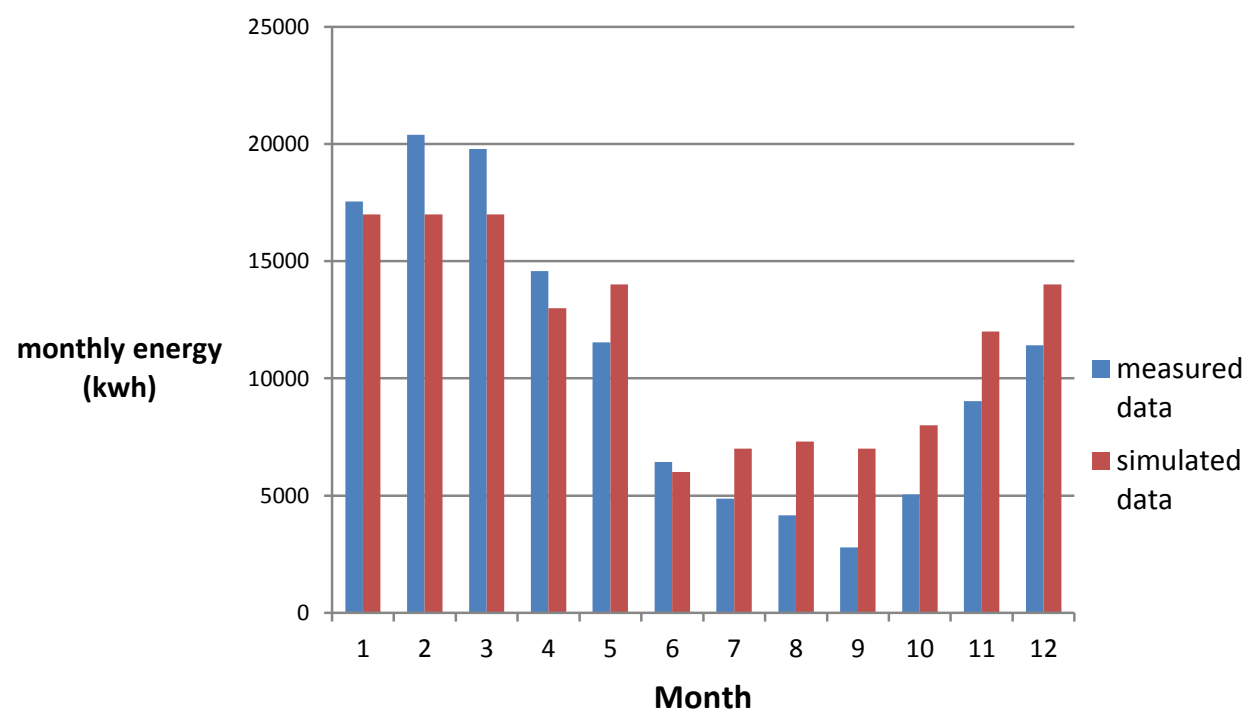

Figure 3-41: Validation of DHW and SPA heating consumption 


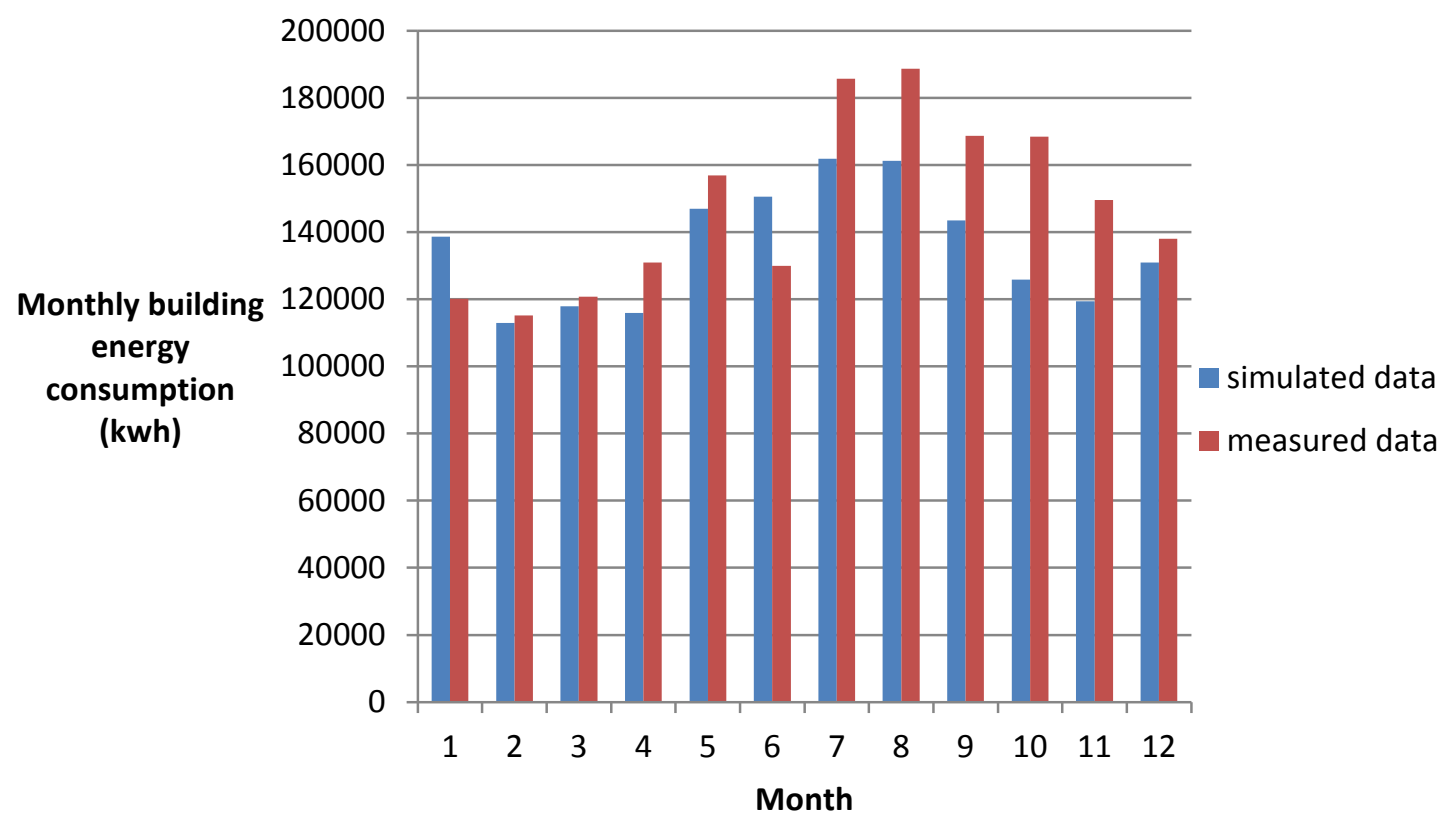

Figure 3-42: Validation of building calendar energy consumption

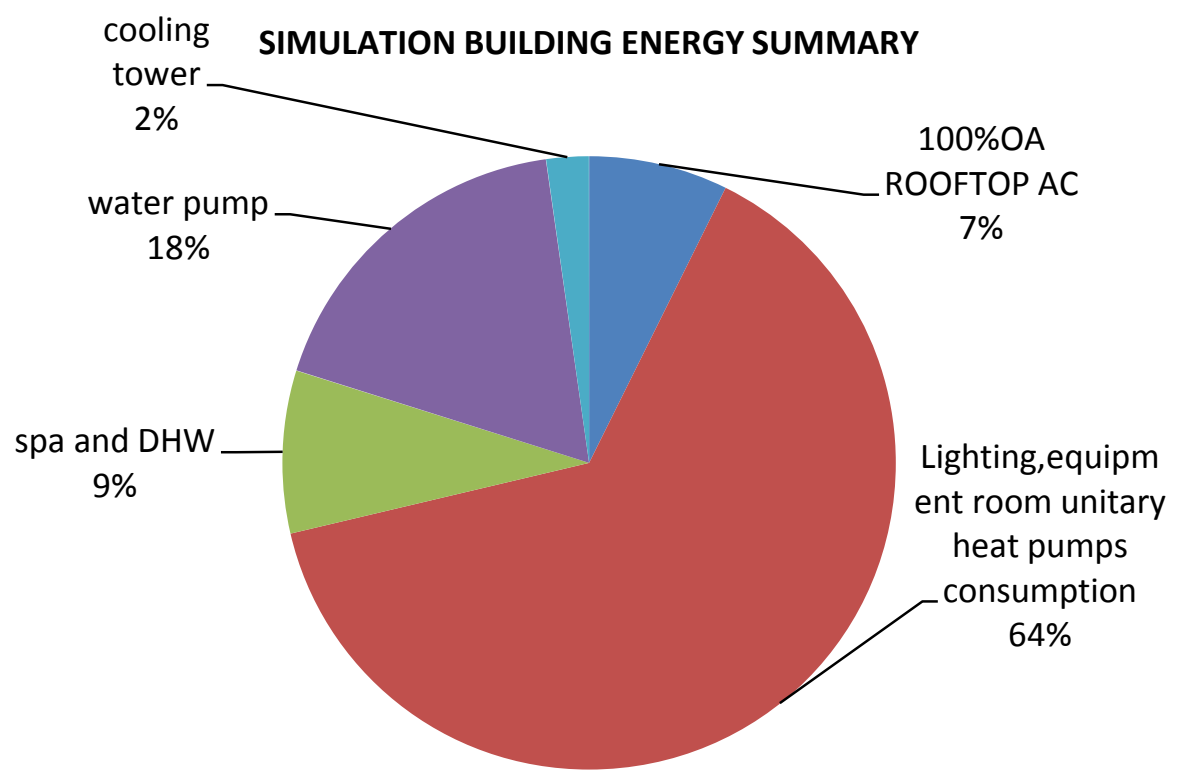

Figure 3-43: The simulated energy consumption composition 


\section{Geothermal Energy Summary(Kwh)}

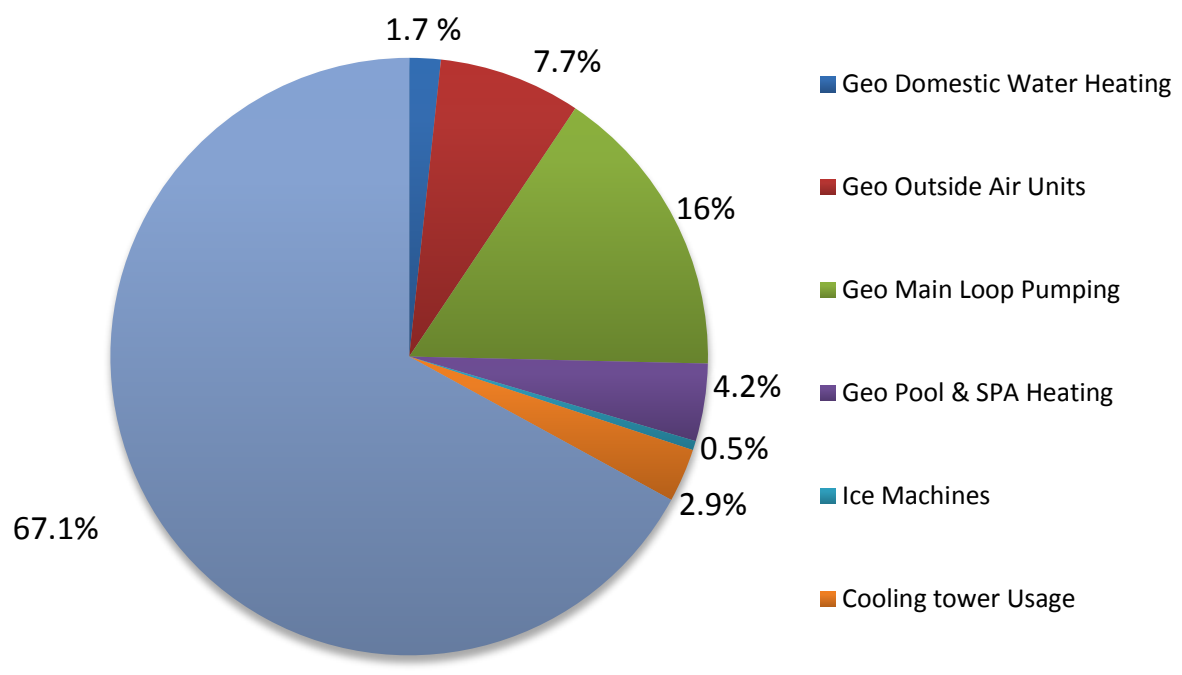

Figure 3-44: The statistic from utility company

After the validations above, the validated building model and system model are set up well. In order to research the advantage and disadvantage of HyGSHP compared with other type of HVAC system, the building model with the alternative complete GSHP and ASHP system is simulated. The result is shown in Figure 3-45.

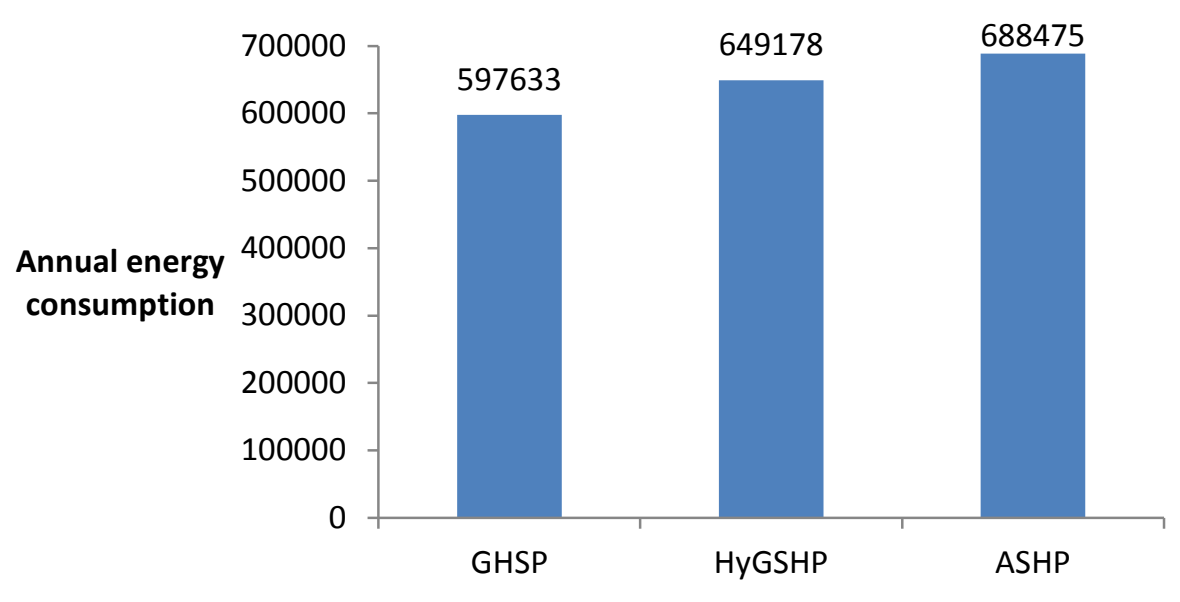

Figure 3-45: Comparison of annual system energy consumption among three types of system 


\subsection{Performance Study}

Coefficient of Performance (COP) is a classical parameter to evaluate cooling or heating performance of a heat pump. In order to calculate the COP of each heat pump unit during a cooling/heating period, we need to know the total supplied cooling/heating load by the heat pump and the total energy consumption of it during that period. Instantaneous cooling/heating COP can be defined as the quotient of cooling/heating load rate of the unit and the power consumption of it at the moment.

Parameters measured during monitoring periods for different buildings in this study cannot be used to calculate COP or instantaneous COP. Cooling/heating load and energy consumption during constant time intervals (5-10 minutes) have been measured for cases BR1 to BR4, BC2, and BC3. As a matter of fact the heat pump unit may work partially in each interval. The partially functioning of the heat pump has a significant effect on the amount of load/consumption ratio. For this reason we call this parameter LCR (Load/Consumption Ratio) in forthcoming graphs and put it with the COP from the simulation results in one graph for each case in order to see the difference between them.

In Figures 3-46 to 3-48 COP and LCR as performance indices of heat pump units have been depicted for buildings BR2 to BR4. In these figures, the $\mathrm{X}$ axis is the time interval indicator. The time intervals which the heat pump was shut down have been pulled

out from the data set before generating the graph. Buildings have been selected based of their ground loop type. BR2, BR3 and BR4 are buildings with open loop, vertical closedloop and horizontal closed loop respectively. 


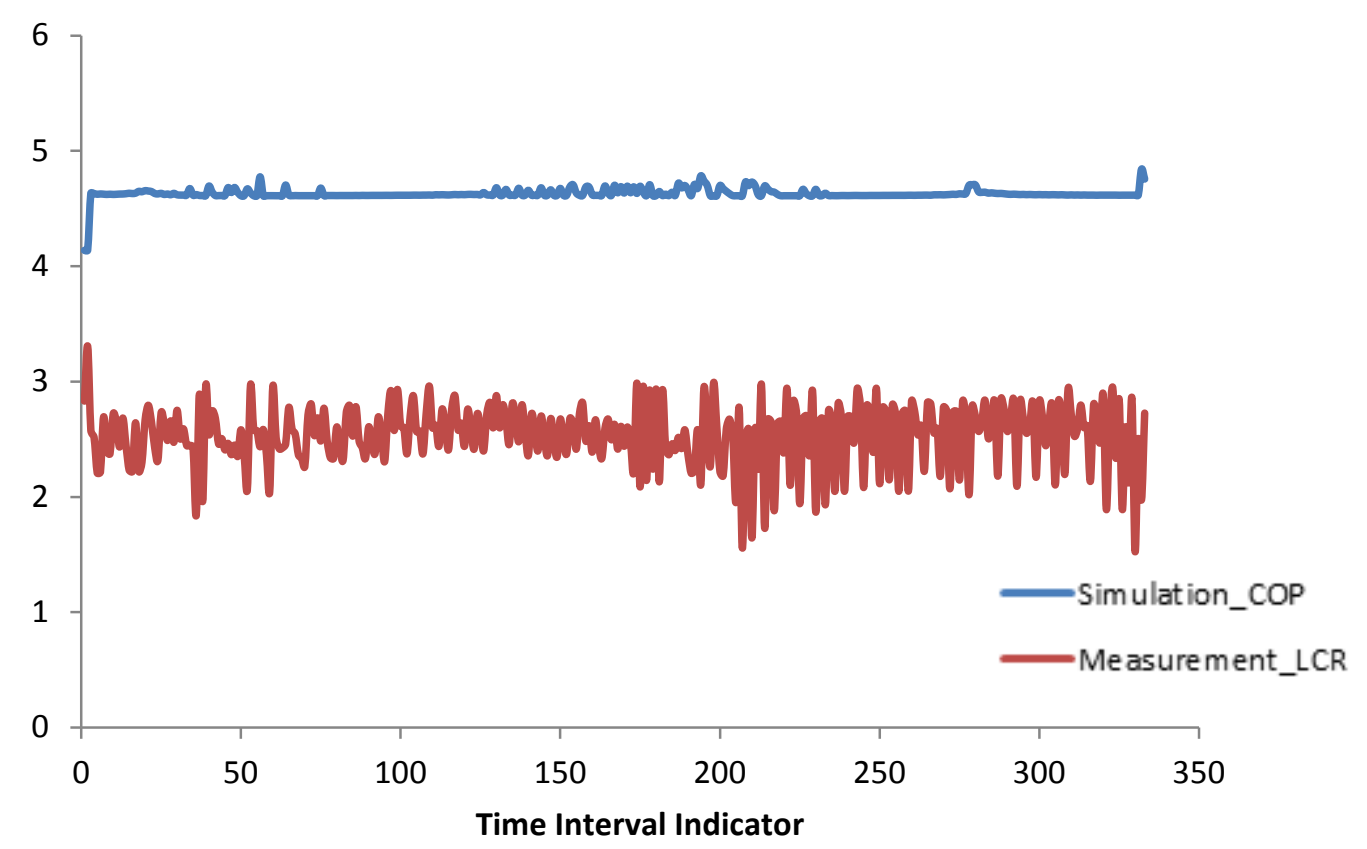

Figure 3-46: Performance indices of the heat pump unit in BR2 based on simulation results and measured data

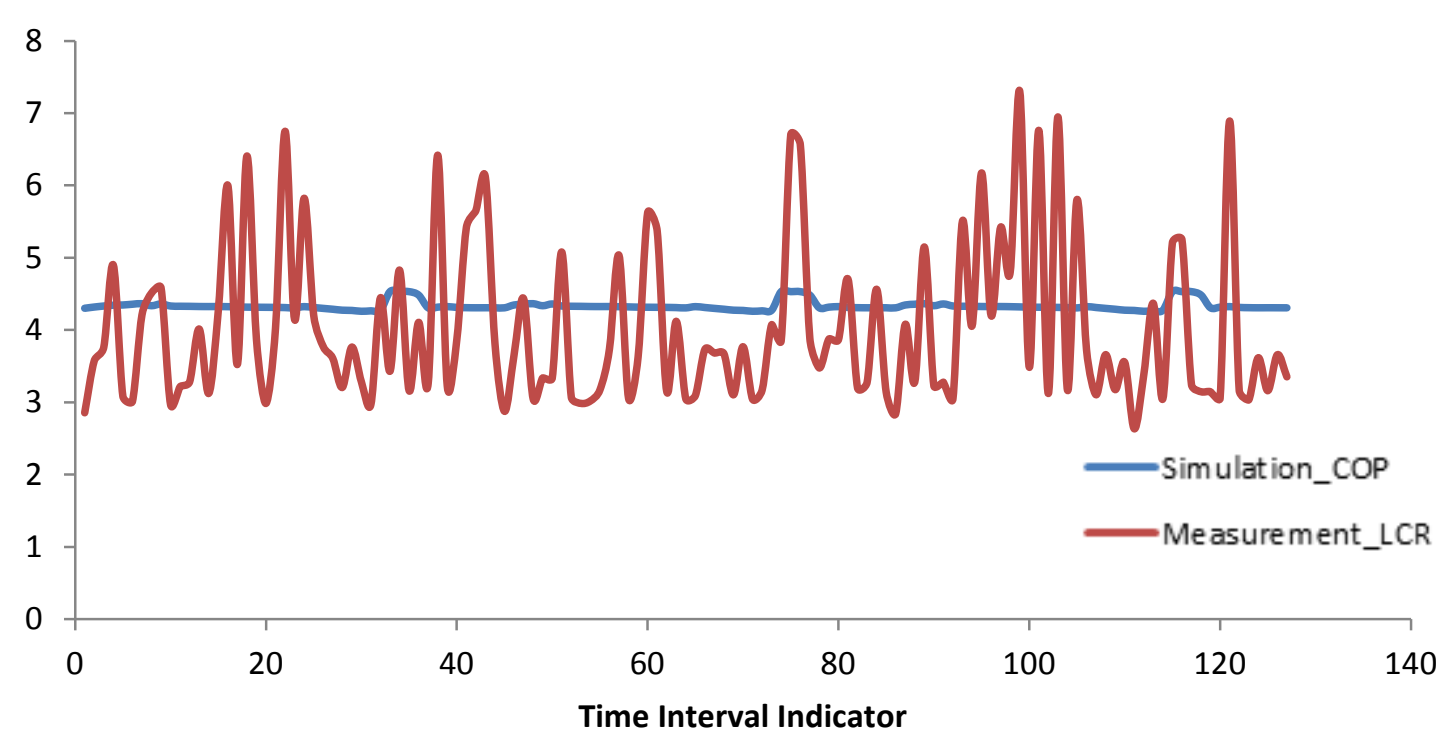

Figure 3-47: Performance indices of the heat pump unit in BR3 based on simulation results and measured data 


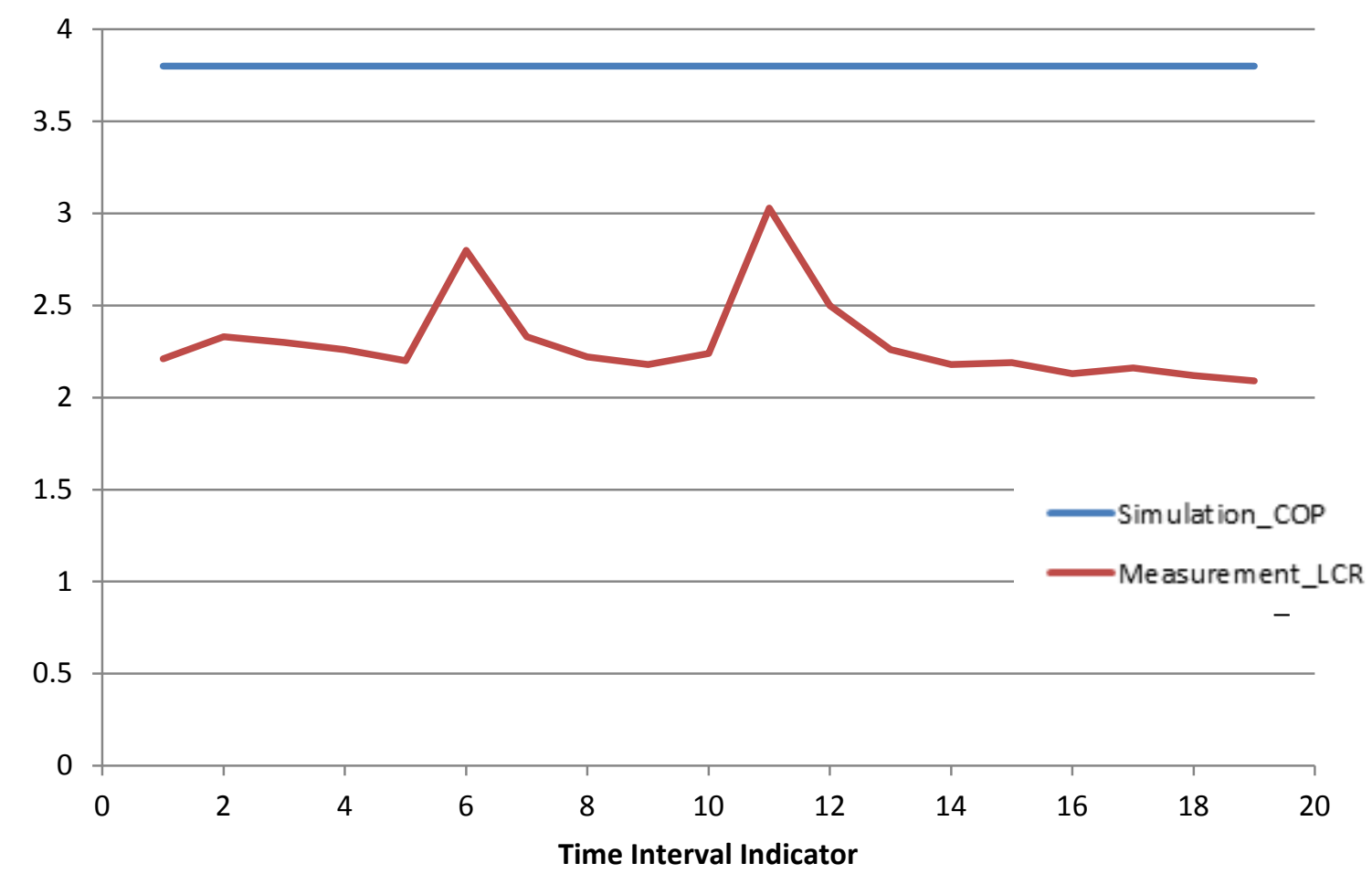

Figure 3-48: Performance indices of the heat pump unit in BR4 based on simulation results and measured data

The larger fluctuation of calculated LCR based on measured data with respect to COP of simulated systems is the common characteristic of all 3 graphs. Small measurement time interval (5-10 minutes) is not long enough to get the steady state for the heat pump. In addition, there are some minor changes in the parameters that affect the system performance (i.e. ground temperature, grid voltage and amperage) that are not considered in the simulation.

Monitoring periods of the each building is less than 3 weeks and it is during transition season with a moderate temperature and relative humidity. For this reason the actual operation time of the heat pump system is only few hours for the whole monitoring period. 
Above-mentioned facts imply that the LCR variation range (not its exact value) can give us an insight to the performance of the hat pump unit and it is not a parameter that can be compared with the COP of the unit.

\subsection{Comparative Study Between TRNSYS And EnergyPlus}

Ahead of the main project, we started to investigate different simulation tools including EnergyPlus and TRNSYS. TRNSYS and EnergyPlus have the capability to complete detailed sub-hourly models of hybrid ground-source heat pumps systems and both programs are well-tested full-building simulation softwares.

TRNSYS is a transient system simulation program with a modular structure that was designed to solve energy system problems using a series of smaller components. The component is described as a black-box with mathematical equation, user need to specify the inputs, outputs, parameters, etc. And TRNSYS components are often referred to as Types (e.g. Type 1 is the solar collector). The Multizone building model is known as Type 56 . The text input file which the simulation studio generates is sent to TRNSYS. That input file is referred to as the deck file.

The ground heat exchanger is one of the most important parts for the GSHP/HGSHP simulation. In TRNSYS, Type 557 is created for the model of vertical ground heat exchanger which thermal interaction between fluid loop and ground based on the duct storage (DST) theory. The DST model assumes that the boreholes are placed uniformly in the cylinder storage and the transient temperature distribution is calculated from three parts: a global temperature solution (at the scale of entire field), a local solution (at the scale of single borehole) and a stead-flux solution (interaction between both scales). The global and local problems are solved by the explicit finite difference method, whereas the steady flux 
solution is obtained by the analytical solution. The total temperature is then calculated by the superposition of these three parts.

Energyplus is a modular structured software tool based on the features and capabilities of BLAST and DOE-2.1E such as time steps of less than an hour, modular systems and plant integrated with heat balance-based zone simulation, multizone air flow, thermal comfort, water use, natural ventilation, and photovoltaic systems. Equations utilized by EnergyPlus are based on engineering, industry and The Department of Energy Standards. Based on a user's description of a building from the perspective of the building's physical make-up, associated mechanical systems, etc., EnergyPlus will calculate the heating and cooling loads necessary to maintain thermal control setpoints. The HVAC system, coil loads, and the energy consumption of the plant equipment as well as many other simulation details are necessary to verify that the simulation is performing as the actual building would.

The ground loop heat exchanger (GLHE) model is based partly on the long time gfunctions developed by Eskilson (Eskilson 1987) and partly on one-dimensional numerical model used to determine the short time response developed by Xu and Spitler (2006). As the method developed by Eskilson is the basis for the ground loop heat exchanger model. Eskilson's approach to the problem of determining the temperature distribution around a borehole is based on a hybrid model combining analytical and numerical solution techniques. A two-dimensional numerical calculation is made using transient finite difference equations on a radial-axial coordinate system for a single borehole in homogeneous ground with constant initial and boundary conditions. The thermal capacitance of the individual borehole elements such as the tube wall and the grout are 
neglected. The temperature fields from a single borehole are superimposed in space to obtain the response from the whole borehole field.

In this section, the comparisons between Energyplus and TRNSYS are carried out for a house model using GSHP system. The feasibility to use two different programs for a project is searched for by this comparative study.

GARD Analytics Inc. published a report sponsored by DOE in 2011 when new version of Energyplus has been released. The report describes the modeling methodology and results for testing with building thermal envelope and fabric load tests using ANSI/ASHARE Standard 140. The results of Energyplus are compared with results from other building simulation programs including TRNSYS in GRAD Analytics’ report.

The Section 5.2 of ANSI/ASHARE Standard 140, Standard Method of Test for the Evaluation of Building Energy analysis Computer Programs (ANSI/ASHARE, 2007), describes the test methodology used in GARD Analytics' report. This test suites is based on the previous works; Building Energy Simulation Test (BESTEST) and Diagnostic Method (IEA 1995). ANSI/ASHARE Standard 140 is a standard method of test that "can be used for identifying and diagnosing predictive differences from whole building energy simulation software that may possibly because by algorithmic differences, modeling limitations, input differences, or coding errors”.

In GARD Analytics' report, the predicted thermal loads by Energyplus are compared for low mass and high mass construction with those of other programs as the orientation of windows, window shading, night ventilation and thermostat setback conditions are changed. The predicted thermal loads include the annual heating, annual cooling, peak heat and peak cooing load. 
In GRAD Analytics’ study 62 individual cases are compared to results from 8 other whole building simulation programs and the Energyplus results are within the range of spread of results for the other programs for all cases except eight cases. They are all for annual heating case comparisons. The differences between Energyplus and TRNSYS for the eight cases exist between 0.3 and 1 MWh. Additional BASIC and IN-DEPTH test are performed for over 100 cases. In these case tests, Energyplus are within the range of spread of results for the other 8 other programs for all but seven cases. The seven cases outside of range are all less than $10.7 \%$ out of bounds.

\subsubsection{Simulation Results}

The objective of this section to establish baseline energy consumption for the existing building with Energyplus and TRNSYS and to compare the results to see if the results are within reasonable ranges. The building which was simulated with Energyplus and TRNSYS is BR3 and the building features and building model specifications are described in section 2.2.3 and 3.6.

The same input data for geometry and envelope are used and the same assumption to determine the schedules used for internal gain and infiltration calculation are applied for TRNSYS and Energyplus at the same time. For plant and HVAC system modeling, the input data for each program are selected from the same manufacturer’s brochure.

Table 3-26 shows baseline building annual energy consumption. Actual electric energy consumption data is given by utility company and it was compared to the calculated energy consumption programs, Enegyplus and TRNSYS. In Figures 3-49, the actual monthly energy end-use is compared to the values of Energyplus and TRNSYS for the baseline building energy model. As seen in the table and graph, the difference between 
actual electric data and energy simulations is less than 3\%. The difference of annual energy consumption between TRNSYS and Energyplus is 1.7\%.

Table 3-26. Energy Consumption for the Baseline Models by Energyplus and TRNSYS

\begin{tabular}{|c|c|c|c|}
\cline { 2 - 4 } \multicolumn{1}{c|}{} & $\begin{array}{c}\text { Actual Electrical } \\
\text { Energy Consumption }\end{array}$ & TRNSYS & EnergyPlus \\
\cline { 2 - 4 } & $\mathrm{kWh} / \mathrm{yr}$ & $\begin{array}{c}\text { Cooling/Heating } \\
\mathrm{kWh} / \mathrm{yr}\end{array}$ & $\begin{array}{c}\text { Cooling/Heating } \\
\mathrm{kWh} / \mathrm{yr}\end{array}$ \\
\hline Base Case & 13641 & 13580 & 13350 \\
\hline
\end{tabular}

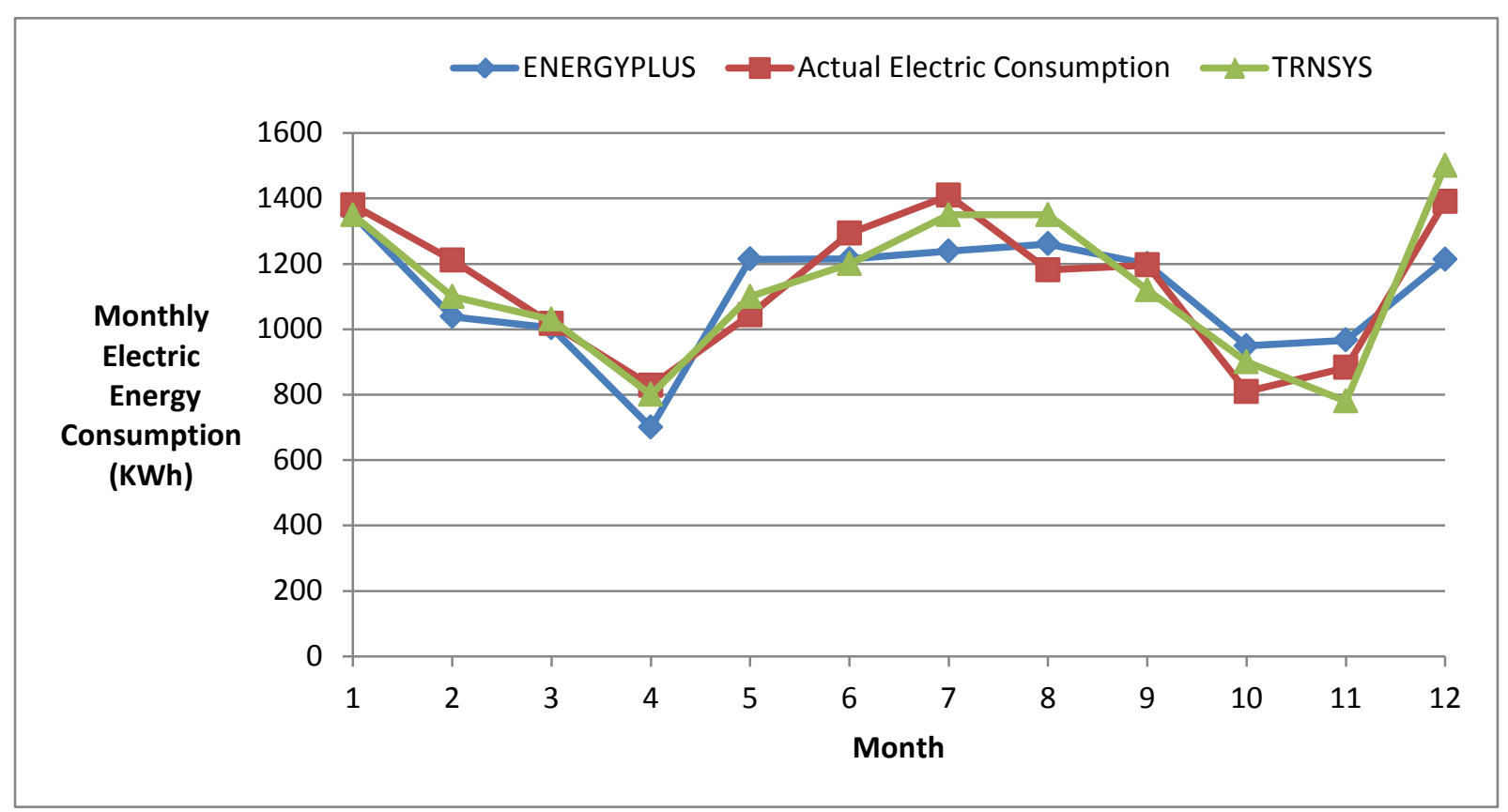

Figure 3-49: Comparison of total energy consumption between actual electric energy consumption and Energy simulation results

Figure 3-50 shows the breakdown of annual electric energy consumption calculated by TRNSYS and EnergyPlus. As seen in the graph, biggest difference of calculation results is found for HVAC energy consumption but the relative difference is less than $3 \%$. 


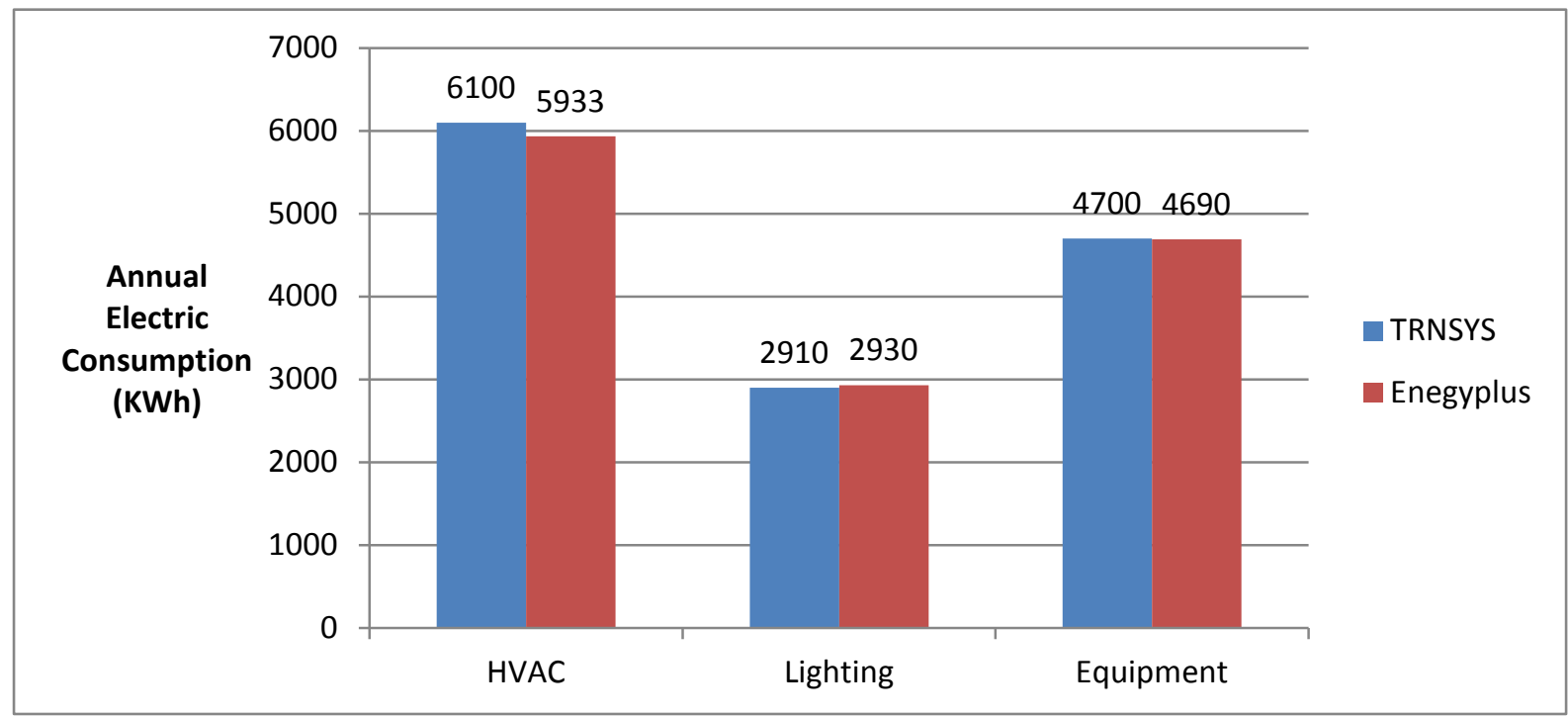

Figure 3-50: Comparison of Annual Electric Energy Consumption of a Baseline Building Model

\subsubsection{Conclusion}

This section shows the difference in the prediction of building models by Energyplus and TRNSYS to see whether the both program can be used for a same project. For the load prediction, broad studies have been performed and they showed the difference of load prediction between the whole building simulations. For the energy consumption prediction, a case study is performed for a residential building which GSHP system is installed in. Even though the number of cases is only one, therefore it is hard to affirm whether Energyplus and TRNSYS give a similar result all the time, the results of this case study shows only $2 \%$ difference for predicting annual electric energy consumption in this case. The electric energy prediction data for each electric component also show less than $3 \%$ difference between Energyplus and TRNSYS. 


\subsection{Conclusion}

Energy saving calculation results in this chapter show that in each building the existing GSHP system is consuming less energy in comparison to conventional ASHP system on an annual basis regardless of the ground loop type, size of the system, and the building application. Figure 3-51 shows the variation of energy saving percentages by using GSHP system for studied buildings.

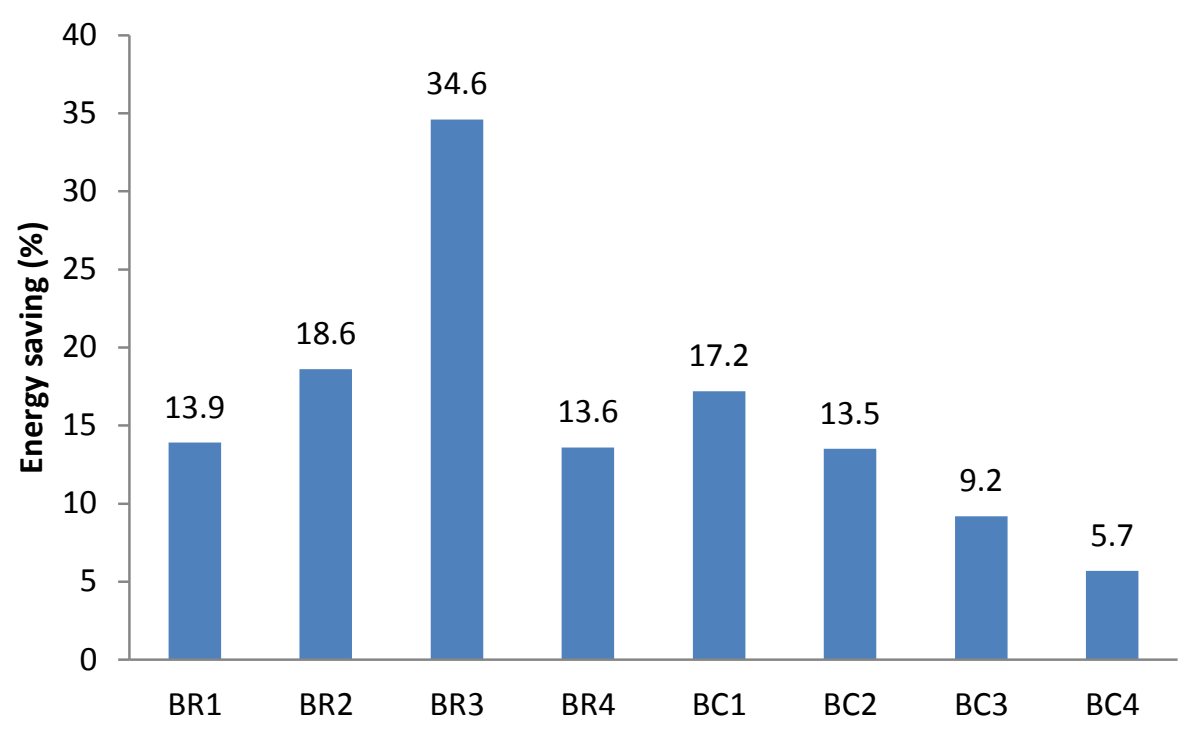

Figure 3-51: Energy saving percentages of studied buildings by using GSHP system

As depicted in Figure 3-51 the energy saving varies from 5.7\% for BC4 to $34.6 \%$ for BR3. The best result has been achieved in a residential building with a vertical closedloop ground heat exchanger. This result is consistent with the lowest electricity consumption of the building BR3 that has been discussed in section 2.3. The energy saving percentage of vertical closed loop system in Pensacola area is much lower than open loop systems in Tampa area which cannot be a result of difference between the weather condition in Tampa and Pensacola. It means that we can consider the vertical closed-loop 
system is the best GSHP system for the average scale residential systems in hot and humid climate. The higher required pumping power for the open loop systems (1 hp for the studied cases) in comparison to the required pumping power for the vertical closed loop (1/2 hp for the studied case) is one of the reasons which makes the vertical closed loop system a better choice. The higher depth of the vertical closed loop (250 ft. for the studied case) in comparison to the well depth of the open loop systems in the area $(80 \mathrm{ft}$. and $150 \mathrm{ft}$. for the studied cases) definitely enhance the performance of the vertical closed loop GSHP system with respect to the open loop system. For residential applications the cases BR1, BR2 and BR4 can be considered as the same order of energy saving of GSHP system. This conclusion put the open-loop system and horizontal closed-loop system at the same group for residential buildings in hot and humid climate. However the open-loop system of BR1 and BR2 shows slightly better energy saving in comparison to horizontal closed-loop system of BR4.

All studied commercial buildings use closed-loop GSHP system. In general more complex GSHP systems with higher number of heat pumps present lower energy saving percentage in comparison to conventional systems. The difference among energy consumption patterns of commercial buildings due to their different internal gains (e.g. people and equipment) can be a factor which affects the percentage of energy saving for GSHP system in comparison to conventional system. For the hybrid systems the cost of the system plays a key role to decide which portion of the load is compensated by the ground loop heat exchanger.

The amount of energy which is saved by using GSHP system in a building should be considered in addition to the percentage of annual energy saving. For big systems, each percent of energy consumption of GSHP system is equal a greater amount of energy. Figure 
3-52 shows the kWh of annual energy saving by using GSHP in the studied buildings. It can be seen that the largest amount of energy saving belongs to the BC4 with lowest energy saving percentage. For this reason the amount of annual energy saving and its percentage should be considered at the same time to evaluate the effect of the GSHP system on the annual energy consumption of the system.

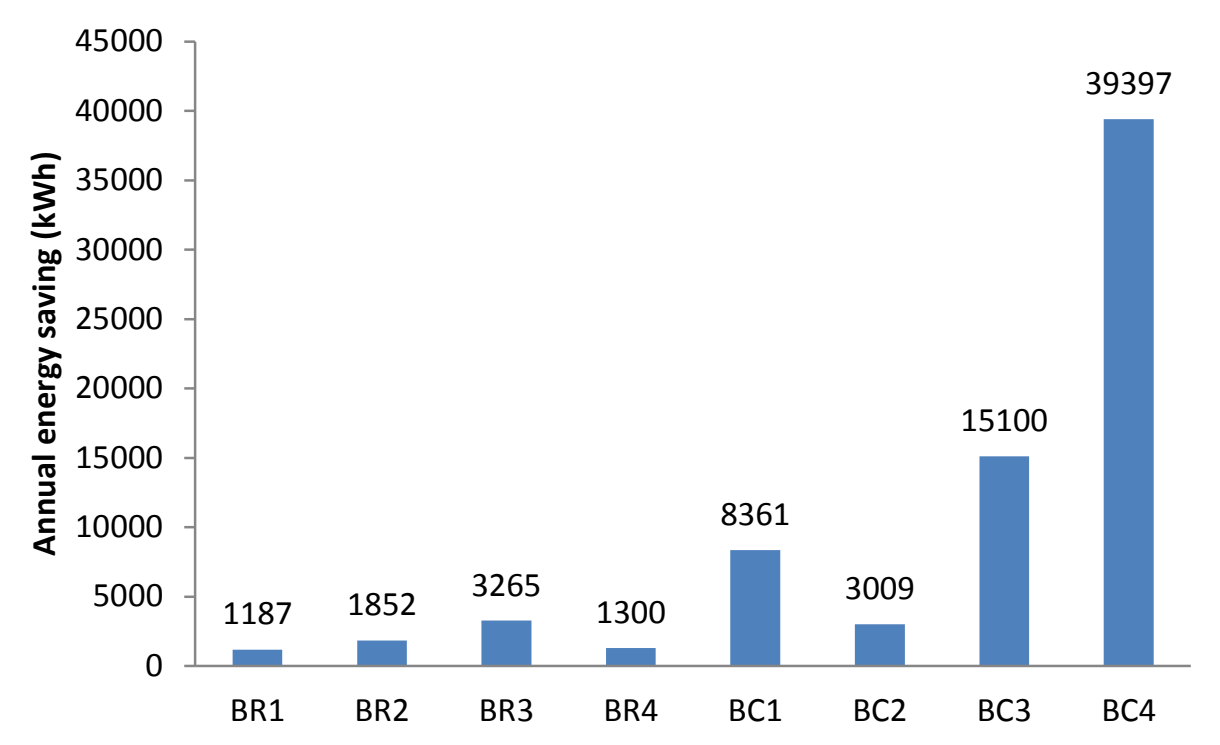

Figure 3-52: Annual energy saving (kWh) of studied buildings by using GSHP system 


\section{CHAPTER 4: Life Cycle Cost Analysis}

\subsection{Introduction}

The major goal of this study is to present a life-cycle cost analysis on collected cases of GSHP systems in order to understand the economic feasibility of using GSHP systems in Florida. GSHP systems have been applied in many other areas of the United Stated. There is sufficient anecdotal evidence over the last decades showing superior performance of GSHP systems comparing with conventional systems. However, the applicability of GSHP systems in hot and humid climate such as Florida is not well documented.

This study presented an analysis of eight cases in Florida, four residential buildings and four commercial/office buildings. Among the four residential cases, two used open loop systems. The rest of cases demonstrated the application of vertical closed loop systems. Each case study discussed a comparison of the geothermal heat pump system with a conventional system to understand the effectiveness of the GSHP system. Monte Carlo simulation was applied to life cycle cost analyses to account for uncertainties in data. The number of iterations and simulations performed by the Monte Carlo simulation on each case was 10,000 and 1 respectively. Since the projects were started at different years, all costs used in the life cycle cost analysis were discounted to the starting year of a project, using a $3 \%$ discount rate.

In the following, considerations given to life cycle cost analysis in this study are discussed first, including the selection and modeling of each cost element and other issues related to the life cycle cost analysis. Then, each case, including the results of life cycle analysis, is discussed in details. Finally, conclusions, limitation and recommendation for future studies are presented. 


\subsection{Life cycle costing considerations}

In this section, elements of life cycle cost analysis applied to this study are discussed. Life-cycle costing takes into account of all possible cost items during the expected life time of a system. This study has been focused on life-cycle cost analysis of ground source heat pump (GSHP) systems. The economical effectiveness of GSHPs is compared with conventional HVAC systems, which are typically used in hot and humid climate regions. In this study, the following types of cost have been considered:

1. Initial costs

2. Electricity costs

3. Maintenance costs

4. Replacement costs

In addition, several cost parameters and economic analysis variables have also been evaluated and/or considered, including:

1. Incentives

2. Electricity rates

3. Discount rates

4. Life cycle

5. Residual value of GSHP systems

\subsubsection{Initial costs}

\section{Initial cost assemblies of GSHPs}

Assemblies are a collection of components or activities that are required to perform a task. Assemblies are widely used in construction management such as assembly estimating. In this study, assemblies are used to estimate major components of GSHP systems. Two types of initial costs are modeled, construction costs and engineering design 
costs. Unfortunately, data collected in the case studies were not in the format that was desired. However, the structure of the assemblies can be useful for future data collection.

The construction costs of vertical closed-loop GSHPs can be divided into borehole drilling cost, ground loop cost, lump bump system cost, water pump control and valve cost, pipe and fitting cost, and heat pump cost. Cost of installation and auxiliary materials such as grouting is also included. Another type of initial costs is engineering design cost, which can be modeled as a percentage of total construction cost, includes civil or mechanical design cost. These assemblies are presented in Table 4-1. The cost of drilling can show a significant variation depending on the type of soil.

The construction cost of horizontal closed-loop GSHPs covers major activities or components including trenching and backfilling, ground loop, loop pump system, water pump controls and valves, pipes and fittings, and heat pumps. These costs include material and installation costs. Similar to the closed-loop systems, engineering design costs can also be included. The costs associated with this type of systems are tabulated in Table 4-2. The depth of the trench can show some variation depending on the type and thermal conductivity of the soil but, generally a 6 to 8-foot trench is used for most applications.

The construction costs of open-loop heat exchanger consist of well drilling costs, well caisson, well water pump, water pump controls and valves, pipes and fittings and heat pumps. Engineering cost is modeled similar to other types of systems. The breakdown of initial costs for open loop systems is as defined in Table 4-3. The depth of the well and sizing of the pipes may depend on the system capacity, the depth of the groundwater and amount of discharge of the groundwater. 
Table 4-1: Initial cost assembly for vertical closed loop systems

\begin{tabular}{|c|c|c|}
\hline Cost Assembly & Definition of Assembly & Unit \\
\hline Engineering design & $\begin{array}{l}\text { Modeled as a percentage of total construction cost, includes } \\
\text { civil or mechanical design cost }\end{array}$ & \$/each \\
\hline Borehole drilling & $\begin{array}{l}\text { Depth of the borehole and type of soil determines the type of } \\
\text { equipment used (Main component is augers, rented daily) }\end{array}$ & \$/day \\
\hline Ground loop & $\begin{array}{l}\text { The polyethylene pipe used for ground loop, depends on } \\
\text { capacity requirements }\end{array}$ & $\$ / \mathrm{ft}$ \\
\hline Loop pump system & $\begin{array}{l}\text { The pump used circulation of heat exchange fluid inside the } \\
\text { loop, the capacity of the system determines }\end{array}$ & \$/each \\
\hline $\begin{array}{l}\text { Water pump controls } \\
\text { and valves }\end{array}$ & Controls and valves associated with the water pump & \$/each \\
\hline Pipes and fittings & Includes all pipes and fitting to and from loop & $\$ / \mathrm{ft}$ \\
\hline Heat pump & $\begin{array}{l}\text { Depends on the capacity required, size and location of the } \\
\text { building }\end{array}$ & \$/each \\
\hline
\end{tabular}

Table 4-2: Initial cost Assembly for horizontal closed loop systems

\begin{tabular}{|c|c|c|}
\hline Cost Assembly & Definition of Assembly & Unit \\
\hline Engineering design & $\begin{array}{l}\text { Modeled as a percentage of total construction cost, includes } \\
\text { civil or mechanical design cost }\end{array}$ & $\$$ \\
\hline $\begin{array}{l}\text { Trenching and } \\
\text { backfilling }\end{array}$ & $\begin{array}{l}\text { Depth of the trench, type of soil determines the type of } \\
\text { equipment used (Main component is augers, rented daily) }\end{array}$ & \$/day \\
\hline Ground loop & $\begin{array}{l}\text { The polyethylene pipe used for ground loop, depends on } \\
\text { capacity requirements }\end{array}$ & $\$ / \mathrm{ft}$ \\
\hline Loop pump system & $\begin{array}{l}\text { The pump used circulation of heat exchange fluid inside the } \\
\text { loop, the capacity of the system determines }\end{array}$ & \$/each \\
\hline $\begin{array}{l}\text { Water pump controls } \\
\text { and valves }\end{array}$ & Controls and valves associated with the water pump & \$/each \\
\hline Pipes and fittings & Includes all pipes and fitting to and from loop & $\$ / \mathrm{ft}$ \\
\hline Heat pump & $\begin{array}{l}\text { Depends on the capacity required, size and location of the } \\
\text { building }\end{array}$ & \$/each \\
\hline
\end{tabular}


Table 4-3: Initial cost Assembly for open loop systems

\begin{tabular}{|c|c|c|}
\hline Cost Assembly & Definition of Assembly & Unit \\
\hline Engineering design & $\begin{array}{l}\text { Modeled as a percentage of total construction cost, includes } \\
\text { civil or mechanical design cost }\end{array}$ & $\$$ \\
\hline Drilling & $\begin{array}{l}\text { Depth of the well, type of soil determines the type of } \\
\text { equipment used (Main component is augers, rented daily) }\end{array}$ & $\$ /$ day \\
\hline $\begin{array}{l}\text { Well casing and } \\
\text { grouting }\end{array}$ & $\begin{array}{l}\text { The casing placed inside the well and grouting in between, } \\
\text { depth and diameter of the well determines }\end{array}$ & $\$ / \mathrm{ft}$ \\
\hline $\begin{array}{l}\text { Well water pump } \\
\text { system }\end{array}$ & $\begin{array}{l}\text { The pump used for withdrawing and injecting water, the } \\
\text { capacity of the system determines }\end{array}$ & \$/each \\
\hline $\begin{array}{l}\text { Water pump controls } \\
\text { and valves }\end{array}$ & Controls and valves associated with the water pump & \$/each \\
\hline Pipes and Fittings & Includes all pipes and fitting to and from wells & $\$ / l f$ \\
\hline Heat Pump & $\begin{array}{l}\text { Depends on the capacity required, size and location of the } \\
\text { building }\end{array}$ & \$/each \\
\hline
\end{tabular}

\section{Initial costs of GSHPs}

Initial data were collected from two cities, Tampa, FL and Pensacola, FL. Engineering design cost data were not available and not included in the life cycle cost analysis in this study. Data of five vertical closed-loop systems and one horizontal closedloop system were collected from projects in Pensacola, FL through site visits, which were designed according to the assemblies shown in tables 4-1 and 4-2.

Data of six open-loop systems were collected from projects in Tampa, FL area via survey, which was designed according to the assemblies shown in a table 4-3. The six cases were all residential houses. It was found that many surveyed were not able to break their cost data down according to the structure of each assembly. In addition, all of them were only able to provide data with respect to an entire job and were not able to provide other types of unit cost such as cost by linear foot. A more realistic unit cost is by tonnage as used by this project. 
Table 4-4: Costs of Closed-loop systems (Projects in Pensacola, FL area)

\begin{tabular}{|c|c|c|c|c|c|c|}
\hline & BR3 & BR4 & BC1 & BC2 & BC3 & BC4 \\
\hline Capacity (ton) & 5 & 5 & 19 & 13 & 129 & 340 \\
\hline Floor Area (Square Foot) & 2800 & 2800 & 6000 & 4250 & 13600 & 80145 \\
\hline Type & Residential & Residential & Office & Bank & Restaurant & Hotel \\
\hline \multicolumn{7}{|l|}{ Engineering Design Cost } \\
\hline \multicolumn{7}{|l|}{ Drilling Cost } \\
\hline \multicolumn{7}{|l|}{ Ground Loop } \\
\hline \multicolumn{7}{|l|}{ Loop pump system } \\
\hline \multicolumn{7}{|l|}{$\begin{array}{l}\text { Water pump controls and } \\
\text { valves }\end{array}$} \\
\hline \multicolumn{7}{|l|}{ Heat Pump Installation } \\
\hline \multicolumn{7}{|l|}{ Pipes and Fittings } \\
\hline Total Cost & 25,000 & 25,000 & 87,500 & 72,555 & 538,148 & 874,900 \\
\hline Cost/Ton & 5000 & 5000 & 4605 & 5379 & 4172 & 2573 \\
\hline Cost/sf & 8.93 & 8.93 & 14.58 & 17.07 & 39.56 & 10.92 \\
\hline
\end{tabular}

The initial cost of a project shown in Tables 4-4 and 4-5 was assumed to be the cost incurred in the year when the system was actually installed. BR1 and BR2 in Table 4-5 were monitored and actual data of both cases were collected. Both cases were used for detailed energy and life cycle cost analysis. However, it was noted that the initial cost in both cases was on the high-end. For this reason, a triangle distribution with a range of [$30 \%, 1.01 \%]$ of the observed cost was used. Initial costs of other cases (Case1, Case2, Case3 and Case 4) in Table 4-5 were collected via an online survey. Buildings of those cases were not monitored thus they were not used for detailed energy and life cycle cost analysis. A range of $\pm 10 \%$ was considered to account for uncertainties associated with these initial costs. 
Table 4-5: Costs of Closed-loop systems (Residential houses in Tampa, FL area)

\begin{tabular}{|c|c|c|c|c|c|c|}
\hline & $\mathrm{BR} 1^{\mathrm{a}}$ & $\mathrm{BR} 2^{\mathrm{b}}$ & Case $1^{c}$ & Case $2^{d}$ & Case $3^{\mathrm{e}}$ & Case $4^{\mathrm{f}}$ \\
\hline Capacity (ton) & 3 & 4 & 5 & 4 & 5 & 31 \\
\hline Floor Area (Square Foot) & 1600 & 1900 & 2663 & 2550 & 3200 & 16105 \\
\hline Engineering Design Cost & $\$ 600$ & & & & $\$ 900$ & $\$ 6,110$ \\
\hline Drilling Cost & $\$ 6,800$ & $\$ 8,770$ & $\$ 7,075$ & $\$ 12,100$ & & $\$ 23,050$ \\
\hline Well casing and grouting & & & $\$ 5,575$ & $\$ 23,000$ & & \\
\hline Water Pump and/or control in Wells & $\$ 1,700$ & & & $\$ 2,350$ & & \\
\hline Pipes and Fittings in well & $\$ 1,250$ & & & & $\$ 1,700$ & \\
\hline Heat Pump Installation & $\$ 18,000$ & $\$ 18,896$ & $\$ 4,793$ & & $\$ 14,000$ & $\$ 51,573$ \\
\hline Pipes and Fittings from wells to Pump & $\$ 1,250$ & & & & $\$ 1,700$ & \\
\hline Total Cost & $\$ 29,600$ & $\$ 27,666$ & $\$ 17,443$ & $\$ 37,450$ & $\$ 18,300$ & $\$ 80,733$ \\
\hline Cost/Ton & $\$ 9,867$ & $\$ 6,917$ & $\$ 3,489$ & $\$ 9,363$ & $\$ 3,660$ & $\$ 2,604$ \\
\hline Cost/sf & $\$ 18.50$ & $\$ 14.56$ & $\$ 6.55$ & $\$ 14.69$ & $\$ 5.72$ & $\$ 5.01$ \\
\hline
\end{tabular}

c. Well casing and grouting cost is included in drilling.

d. The costs are inclusive without more information on the breakdown.

e. The project used existing wells so there are not drilling cost, casing and grouting cost or pumps and controls in wells

f. Water pump, pipes and fitting costs are included in well casing and grouting $(\$ 5,575)$. Heat pump installation cost $(\$ 4,793)$ also includes pipes and fitting.

g. The drilling cost includes well casing, grouting water pump, pipes and fitting. The heat pump installation includes pipes and fitting as well.

h. The costs are inclusive without more information on the breakdown.

\section{Initial costs of conventional HVAC systems}

An air-sourced direct exchange (DX) split system, a very typical residential unit in southern States, was used for comparing with cases of residential buildings. For office, bank and restaurant buildings, a single-zone, air cooled split system was assumed. Cost data were estimated based on RS Means (See Table 4-6). 
Table 4-6: Unit Cost Estimates for Conventional HVAC System in 2009 Value

\begin{tabular}{|c|c|c|c|}
\hline Type of buildings & Assembly Type & Unit & $\begin{array}{c}\text { Unit Cost, } \\
\$ / \text { sf }\end{array}$ \\
\hline Residential buildings & $\begin{array}{r}\text { Split system with air cooled } \\
\text { condensing unit }\end{array}$ & sf & 4 \\
\hline Office buildings & $\begin{array}{c}\text { Split system with air cooled } \\
\text { condensing unit, single zone }\end{array}$ & sf. & 10 \\
\hline Banks & $\begin{array}{c}\text { Split system with air cooled } \\
\text { condensing unit, single zone }\end{array}$ & sf & 10 \\
\hline Restaurants & $\begin{array}{c}\text { Split system with air cooled } \\
\text { condensing unit, multi-zone }\end{array}$ & sf & 25 \\
\hline Hotels & $\begin{array}{c}\text { Split system with air cooled } \\
\text { condensing unit, multi-zone }\end{array}$ & sf & 13 \\
\hline
\end{tabular}

Table 4-7: Unit Cost Estimates for Conventional HVAC System in Starting Year Value

\begin{tabular}{|c|c|c|c|}
\hline Case & Starting Year & Unit Cost $\mathbf{( \$ / s f )}$ & Distribution \\
\hline BR1 & 2010 & 4.12 & Triangle [-10\%, 10\%] \\
\hline BR2 & 2010 & 4.12 & Triangle [-10\%, 10\%] \\
\hline BR3 & 2005 & 3.55 & Triangle [-10\%, 10\%] \\
\hline BR4 & 1998 & 2.89 & Triangle [-10\%, 10\%] \\
\hline BC1 & 2010 & 13.39 & Triangle [-10\%, 10\%] \\
\hline BC2 & 2010 & 10.3 & Triangle [-10\%, 10\%] \\
\hline
\end{tabular}

\subsubsection{Electricity costs}

Electricity rates, which were relative steady in the past, are following an increasing trend in the recent years (Figure 4-1). The electricity rates are particularly important as they are the main source of savings for a GSHP system. The information regarding the electricity rates are acquired from U.S. Energy Information Administration website. For the state of Florida, the electricity cost per kWh is as shown in Figure 4-1. Using the Matlab 
polyfit tool, it is found that, if $\mathrm{Y}$ represents electricity rates and $\mathrm{X}$ represents data series (starting from 1 that represents year 1990), the relationship between $\mathrm{X}$ and $\mathrm{Y}$ is derived as:

$$
\mathrm{Y}=0.0013 * \mathrm{X} 3-0.0145 * \mathrm{X} 2+0109 * \mathrm{X}+7.1498
$$

The correlation between the original data and the predicted data is 0.98 .

According the original data and the predicted data between 1999 and 2009, the minimum prediction difference is $-4.49 \%$ and the maximum prediction difference is $10.76 \%$. This range will be used in Monte Carlo simulation where a PERT distribution is assumed for the electricity rate in a certain year.

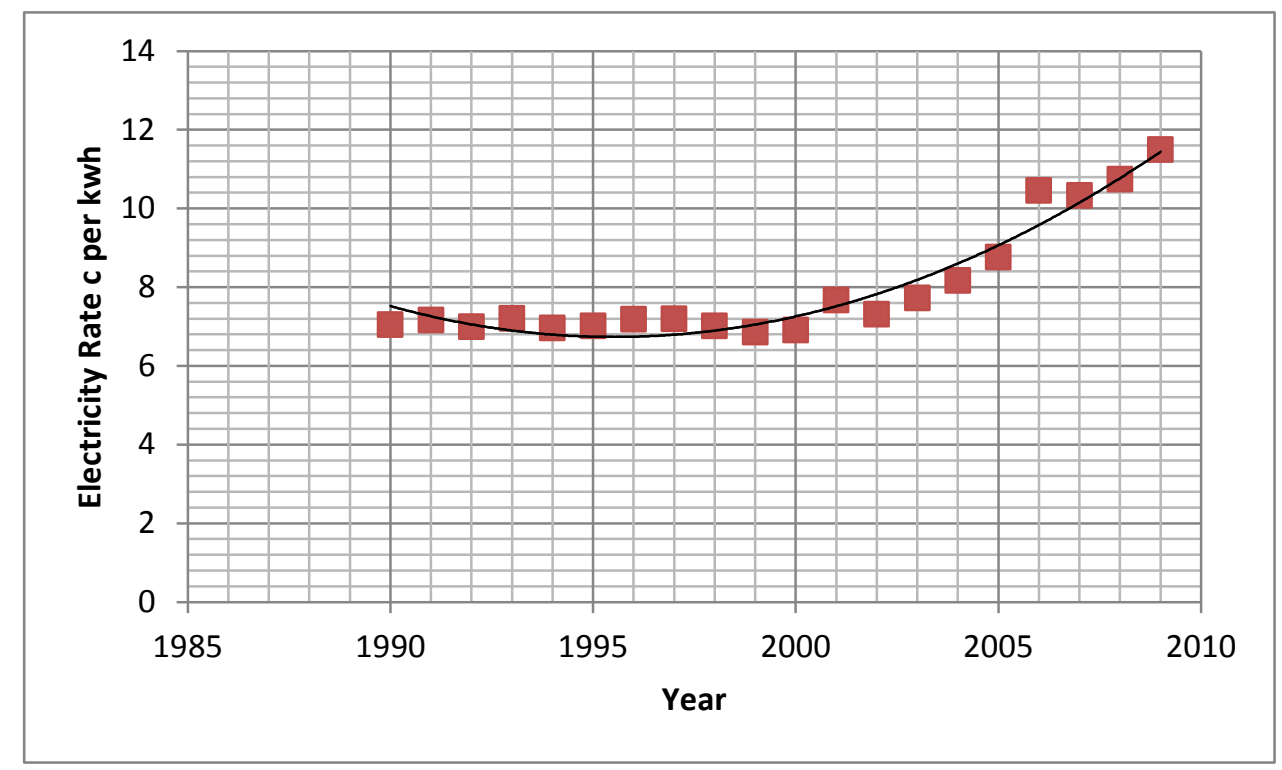

Figure 4-1: Average Electricity Retail Prices by Year (Source: US EIA)

Since the electricity rate may have a significant impact on life cycle analysis, it is critical to determine the rate for each case. Table 4-8 shows the case, its starting year, its electricity rate for analysis and assumed distribution. 
Table 4-8: Average Electricity Rates in Starting Year Value

\begin{tabular}{|c|c|c|c|}
\hline Case & Starting Year & Electricity Rate (\$/kwh) & Distribution \\
\hline BR1 & 2010 & 0.128 & PERT [-4.49\%, 10.76\%] \\
\hline BR2 & 2010 & 0.128 & PERT [-4.49\%, 10.76\%] \\
\hline BR3 & 2005 & 0.088 & PERT [-4.49\%, 10.76\%] \\
\hline BR4 & 1998 & 0.070 & PERT [-4.49\%, 10.76\%] \\
\hline BC1 & 2010 & 0.128 & PERT [-4.49\%, 10.76\%] \\
\hline BC2 & 2010 & 0.128 & PERT [-4.49\%, 10.76\%] \\
\hline BC3 & 2010 & 0.128 & PERT [-4.49\%, 10.76\%] \\
\hline BC4 & 2002 & 0.073 & PERT [-4.49\%, 10.76\%] \\
\hline
\end{tabular}

\subsubsection{Maintenance costs}

This cost item includes expected and unexpected costs that are associated with the repair and corrective maintenance of HVAC systems. In terms of maintenance cost, the only available source was the literature. The contractors or the manufacturers were not able to provide any information for this cost item during data collection. In addition, there is very little information about the maintenance costs for residential GSHP system. In this study, a low maintenance cost rate was assumed. In addition, according to Bloomquist (2001), the annual maintenance cost for conventional systems is assumed as 2.6 times of GSHP systems in order to reflect the relative difference of maintenance cost between GSHP systems and conventional systems. Chiasson (2006) reported that the annual maintenance cost for rooftop units w. gas heat \& DX cooling is 2.4 times more than geothermal heat pumps. If comparing with air-source heat pumps, they were 2.1times more than geothermal heat pumps.

According to a few studies on this subject (Figure 4-2), maintenance costs for residential applications in this study were estimated as \$0.027/sf per year for the GSHP 
system. These costs are usually associated with possible leakages, problems with valves, motor or thermostat problems.

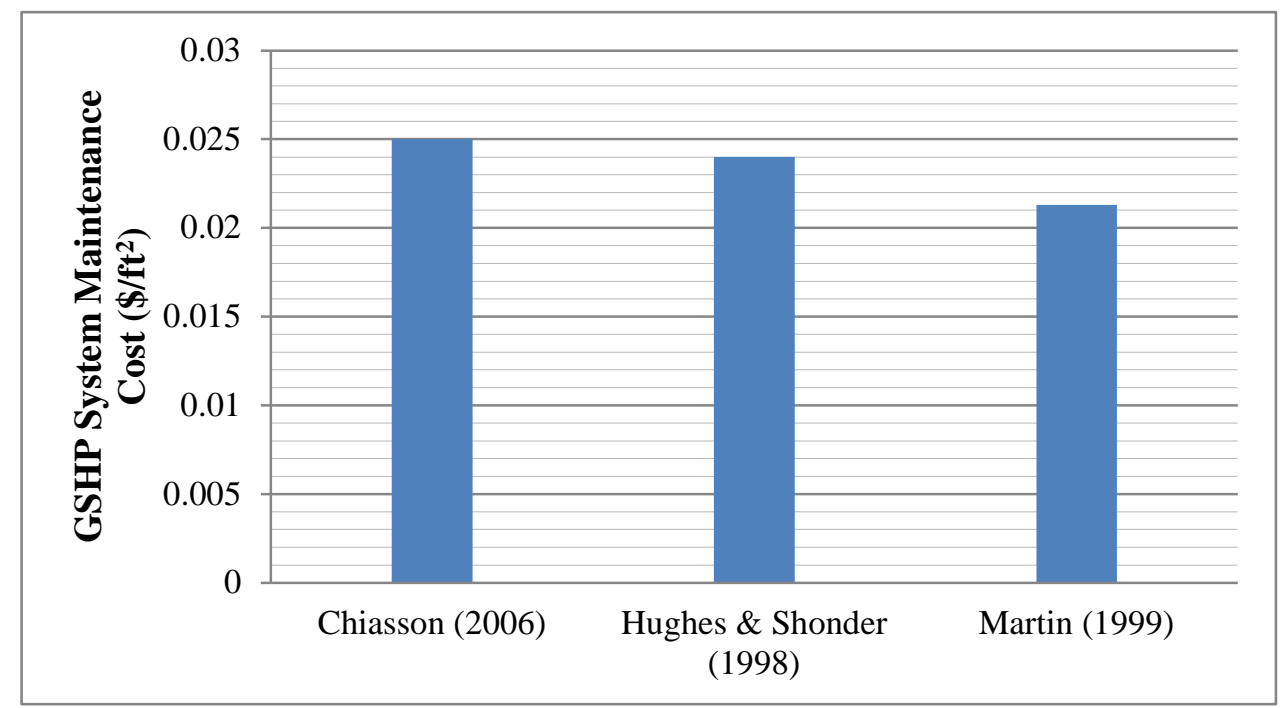

Figure 4-2: Maintenance costs for GSHP systems

For commercial and office building applications, maintenance costs were also estimated using data in literature (See Table 4-9).

A 1.5\% annual increase was applied to compound historical data the year 2011 value (Shonder et al. 2000). The @Risk fitting tool was used to determine the probability distribution of the data, which is shown in Figure 4-3. 
Table 4-9: Estimated maintenance costs using data in literature

\begin{tabular}{|c|c|c|c|c|}
\hline Year & Cost/SF/YR & \# Years to 2011 & 2011 Dollar & Source \\
\hline 1954 & 0.51 & 57 & 2.750 & Bloomquist (2001) \\
\hline 1964 & 0.05 & 47 & 0.201 & Bloomquist (2001) \\
\hline 1965 & 0.135 & 46 & 0.526 & Bloomquist (2001) \\
\hline 1971 & 0.16 & 40 & 0.522 & Bloomquist (2001) \\
\hline 1972 & 0.14 & 39 & 0.443 & Bloomquist (2001) \\
\hline 1974 & 0.13 & 37 & 0.388 & Bloomquist (2001) \\
\hline 1980 & 0.11 & 31 & 0.275 & Bloomquist (2001) \\
\hline 1981 & 0.12 & 30 & 0.291 & Bloomquist (2001) \\
\hline 1982 & 0.11 & 29 & 0.259 & Bloomquist (2001) \\
\hline 1983 & 0.07 & 28 & 0.160 & Bloomquist (2001) \\
\hline 1987 & 0.135 & 24 & 0.274 & Bloomquist (2001) \\
\hline 1988 & 0.1 & 23 & 0.197 & Bloomquist (2001) \\
\hline 1989 & 0.5 & 22 & 0.958 & Bloomquist (2001) \\
\hline 1991 & 0.64 & 20 & 1.156 & Bloomquist (2001) \\
\hline 1991 & 0.2 & 20 & 0.361 & Bloomquist (2001) \\
\hline 1992 & 0.16 & 19 & 0.281 & Bloomquist (2001) \\
\hline 1993 & 0.025 & 18 & 0.043 & Bloomquist (2001) \\
\hline 1994 & 0.24 & 17 & 0.397 & Bloomquist (2001) \\
\hline 1994 & 0.12 & 17 & 0.198 & Bloomquist (2001) \\
\hline 1995 & 0.05 & 16 & 0.080 & Bloomquist (2001) \\
\hline 1995 & 0.57 & 16 & 0.915 & Bloomquist (2001) \\
\hline 1996 & 0.01 & 15 & 0.016 & Bloomquist (2001) \\
\hline 1998 & 0.1095 & 13 & 0.161 & Bloomquist (2001) \\
\hline 1999 & 0.0213 & 12 & 0.030 & Martin et al. (1999) \\
\hline 2000 & 0.0166 & 11 & 0.023 & Shonder et al. (2000) \\
\hline
\end{tabular}




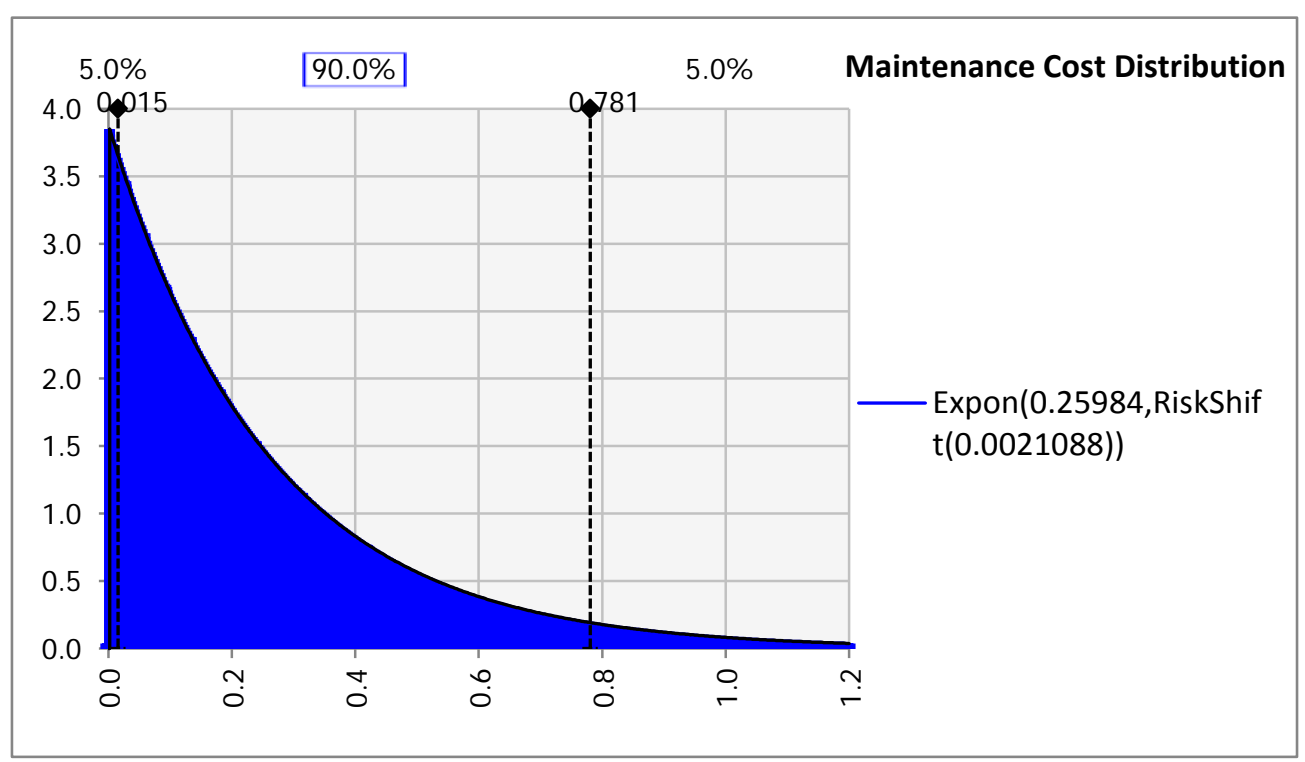

Figure 4-3: Probability distribution of the data determined using @Risk fitting tool

An Exponential distribution with a mean value of $\$ 0.262 / \mathrm{sf} /$ year was derived. Another set of data was retrieved from a report (OSD 2007), 60 data points were analyzed and @Risk was used to fit the data. It was found that the mean maintenance cost per square foot was $\$ 0.298 /$ sf/year, which is very close to the prediction $\$ 0.262 /$ sf/year.

Table 4-10: Maintenance Cost in Starting Year Value

\begin{tabular}{|c|c|c|c|}
\hline Case & Starting Year & Annual Maintenance Cost (\$/sf) & Distribution \\
\hline BR1 & 2010 & 0.027 & Exponential \\
\hline BR2 & 2010 & 0.027 & Exponential \\
\hline BR3 & 2005 & 0.027 & Exponential \\
\hline BR4 & 1998 & 0.027 & Exponential \\
\hline BC1 & 2010 & 0.262 & Exponential \\
\hline BC2 & 2010 & 0.262 & Exponential \\
\hline BC3 & 2010 & 0.262 & Exponential \\
\hline BC4 & 2002 & 0.262 & Exponential \\
\hline
\end{tabular}




\subsubsection{Replacement Costs}

According to the RS Means Facility Maintenance Cost Data, conventional systems require some parts to be replaced at the end of 10 year usage. These items include compressor, condenser fan bearing, and condenser fan motor and refrigerant. The cost of these items was estimated as $\$ 3,991$ for a 5 ton systems or $\$ 868$ per tonnage. This includes the expected parts change in HVAC systems. Certain parts of these systems will be replaced at specific intervals. The GHSP system does not require any periodic replacements during the life time used. For this study the life-time was taken as 20 years. At the end of 20 years, heat pumps may need to be replaced for open loop and closed loop systems.

According to RS Means (2008), replacement costs for heat pump range from $\$ 2,836$ for a 1.5 ton heat pump to $\$ 70,275$ for a 50 ton heat pump. Using the data set from RS Means (2008), there is a linear correlation between the tonnage of the heat pumps and the replacement costs as seen in Figure 4-4. However, it has to be noted that the data set is small, only five data points.

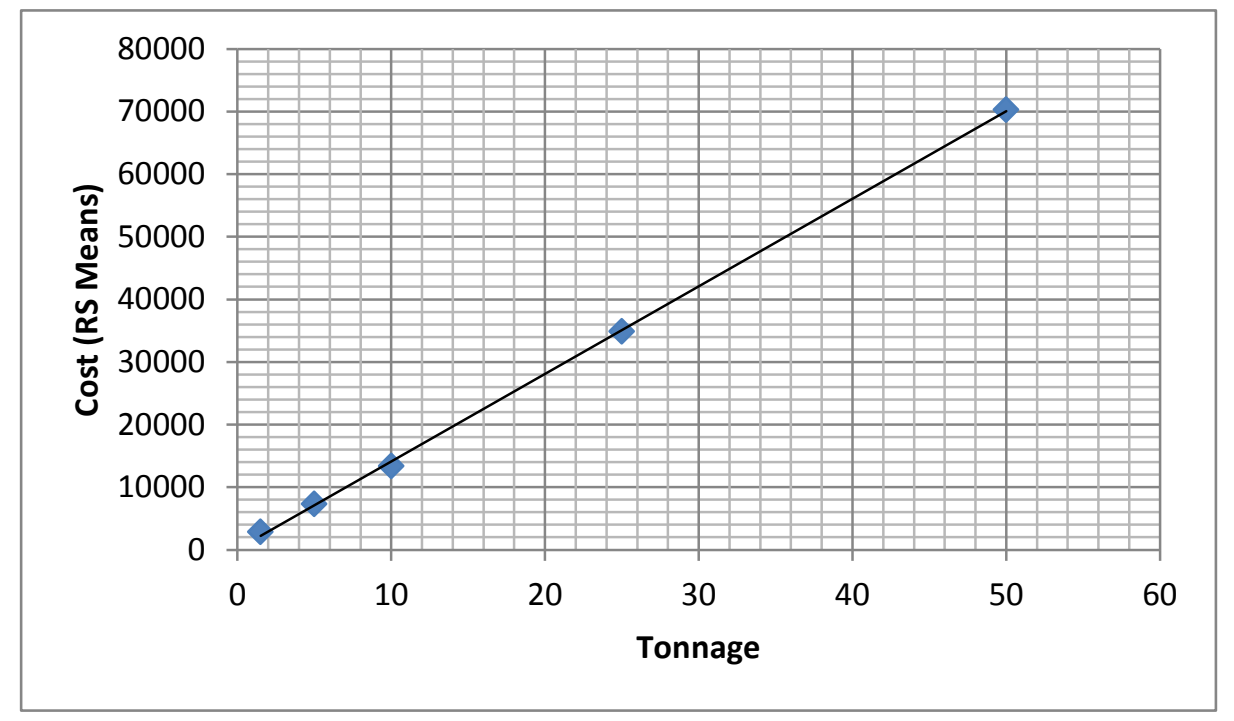

Figure 4-4: Linear correlation between the tonnage of the heat pumps and the replacement costs 
If $\mathrm{Y}$ represents cost and $\mathrm{X}$ represents tonnage, the relationship between $\mathrm{X}$ and $\mathrm{Y}$ is:

$$
\mathrm{Y}=162.24+1397.81 * \mathrm{X}
$$

Due the lack of data for uncertainty, it is assumed that the range of cost variation is $\pm 10 \%$. A triangle distribution will be applied.

Table 4-11: Replacement costs for heat pumps

\begin{tabular}{|c|c|c|c|c|c|}
\hline Case & Size & $\begin{array}{c}\text { Starting } \\
\text { Year }\end{array}$ & $\mathbf{2 0 0 8}$ Cost & $\begin{array}{c}\text { Starting } \\
\text { Year Cost }\end{array}$ & Distribution \\
\hline BR1 & 3 tons & 2010 & $\$ 4,356$ & $\$ 4,620$ & Triangle [-10\%, 10\%] \\
\hline BR2 & 4 tons & 2010 & $\$ 5,735$ & $\$ 6,104$ & Triangle [-10\%, 10\%] \\
\hline BR3 & 5 tons & 2005 & $\$ 7,153$ & $\$ 6,544$ & Triangle [-10\%, 10\%] \\
\hline BR4 & 5 tons & 1998 & $\$ 7,314$ & $\$ 5,442$ & Triangle [-10\%, 10\%] \\
\hline BC1 & 19 tons & 2010 & $\$ 27,207$ & $\$ 28,864$ & Triangle [-10\%, 10\%] \\
\hline BC2 & 13 tons & 2010 & $\$ 18,658$ & $\$ 19,795$ & Triangle [-10\%, 10\%] \\
\hline BC3 & 129 tons & 2010 & $\$ 180,253$ & $\$ 216,180$ & Triangle [-10\%, 10\%] \\
\hline BC4 & 340 tons & 2002 & $\$ 508,025$ & $\$ 425,463$ & Triangle [-10\%, 10\%] \\
\hline
\end{tabular}

The replacement costs for conventional systems were derived according to the RS Means Facility Maintenance Cost Data (2008). It was assumed that conventional systems are required to be replaced at the end of 15 years. The cost data are shown in Table 4-12. The "Start Year Cost" was calculated in 
Table 4-12: Replacement Costs for Conventional Systems

\begin{tabular}{|c|c|c|c|c|c|c|}
\hline Case & Size & $\begin{array}{c}\text { Starting } \\
\text { Year }\end{array}$ & Assumed Type & 2008 Cost & $\begin{array}{c}\text { Starting } \\
\text { Year Cost }\end{array}$ & Distribution \\
\hline BR1 & 3 tons & 2010 & One three ton, DX split & $\$ 4,374$ & $\$ 4,640$ & Triangle [-10\%, 10\%] \\
\hline BR2 & 4 tons & 2010 & One four ton, DX split & $\$ 5,832$ & $\$ 6,187$ & Triangle [-10\%, 10\%] \\
\hline BR3 & 5 tons & 2005 & One five ton, DX split & $\$ 7,290$ & $\$ 6,671$ & Triangle [-10\%, 10\%] \\
\hline BR4 & 5 tons & 1998 & $\begin{array}{c}\text { One two ton and one three } \\
\text { ton, DX split }\end{array}$ & $\$ 8,012$ & $\$ 5,962$ & Triangle [-10\%, 10\%] \\
\hline BC1 & 19 tons & 2010 & $\begin{array}{c}\text { Three five ton and one four } \\
\text { ton, single zone roof top }\end{array}$ & $\$ 32,195$ & $\$ 34,156$ & Triangle [-10\%, 10\%] \\
\hline BC2 & 13 tons & 2010 & $\begin{array}{c}\text { Two five ton and one three } \\
\text { ton, single zone roof top }\end{array}$ & $\$ 23,475$ & $\$ 24,905$ & Triangle [-10\%, 10\%] \\
\hline BC3 & 129 tons & 2010 & $\begin{array}{c}\text { Five twenty-five ton and } \\
\text { one four ton, multi-zone }\end{array}$ & $\$ 611,543$ & $\$ 648,786$ & Triangle [-10\%, 10\%] \\
\hline BC4 & 340 tons & 2002 & $\begin{array}{c}\text { Three one hundred ton, one } \\
\text { twenty-five and one fifteen } \\
\text { ton, multi-zone roof top }\end{array}$ & $\$ 921,893$ & $\$ 772,071$ & Triangle [-10\%, 10\%] \\
\hline
\end{tabular}

\subsubsection{Incentives}

There are two types of incentives, tax credit and rebate. During data collection, we identified a tax credit program, which offers tax credit up to a $30 \%$ of initial cost without cap. Also, in some parts southern States, a \$300/ton rebate program is offered by energy companies.

\subsubsection{Discount rate}

The discount rate used in this study is the real discount rated suggested by the Federal Energy Management Program, which is 3.0\%.

\subsubsection{Other considerations}

The life cycle for analysis is assumed as 30 years. The salvage value of both GHSP systems and conventional systems were not included due to the lack of data. 


\subsubsection{Life cycle cost analysis}

This chapter discusses the life cycle cost analysis model applied to this study. In this study, life-cycle costs are described as a sum at today's value. This method, known as net present value (NPV), is commonly utilized while making engineering decisions.

$$
\mathrm{LCC}=\mathrm{C}_{\mathrm{ini}}+\mathrm{C}_{\mathrm{op}}+\mathrm{C}_{\text {maint }}+\mathrm{C}_{\text {replc }}
$$

Where,

LCC - The total life cycle cost of a system under study in present value.

Cini - The initial cost of a system under study in present value such as engineering design cost and construction cost. In this study, since cost of conventional systems does not have engineering design costs, only construction costs (equipment and installation costs) are included. The initial costs also exclude tax credits and rebates. Cop - The operation cost associated with an energy system under study. In GSHPs, it refers to the cost of electricity consumption of pumps. In conventional systems, it refers to the electricity cost to run the conventional systems.

Cmaint - The maintenance cost of a system under study in present value.

Creplc - The replacement cost of a system under study in present value.

\subsubsection{Sensitivity analysis}

Two types of sensitivity analysis were performed. The single system sensitivity analysis was performed to each type of system in order to determine the most sensitive cost factors for each system. In addition, to compare the two systems, ratio sensitivity analysis was also applied. 
In this study, due to data availability, only initial cost, maintenance cost, replacement cost and energy cost are considered. Incentives and rebates are treated as initial costs. Energy cost refers to electricity cost.

\subsection{Case Studies}

\subsubsection{Case Study - BR1}

Cost data summary

Tables 4-13 and 4-14 are a summary of data used for life cycle cost analysis.

Table 4-13: Cost data for the GHSP System

\begin{tabular}{|c|c|c|c|c|c|c|c|c|c|}
\hline \multirow{2}{*}{ ID } & \multirow{2}{*}{$\begin{array}{l}\text { Building } \\
\text { Size (sf) }{ }^{1}\end{array}$} & \multirow{2}{*}{$\begin{array}{c}\text { System } \\
\text { Tonnage } \\
{\text { (ton })^{2}}^{2}\end{array}$} & \multirow{2}{*}{$\begin{array}{c}\text { Life } \\
\text { Cycle } \\
\text { (year) }^{3}\end{array}$} & \multicolumn{6}{|c|}{ Geothermal System } \\
\hline & & & & $\begin{array}{c}\text { Initial } \\
\text { Cost }(\$)^{4}\end{array}$ & $\begin{array}{c}\text { Tax } \\
\text { Credit }(\$)^{5}\end{array}$ & $\begin{array}{c}\text { Utility } \\
\text { Rebate }(\$)^{6}\end{array}$ & $\begin{array}{c}\text { Maintenance } \\
\text { Cost }(\$)^{7}\end{array}$ & $\begin{array}{l}\text { Periodic } \\
\text { Cost }(\$)^{8}\end{array}$ & $\begin{array}{l}\text { Annual Electricity } \\
\qquad \text { Cost }(\$)^{9}\end{array}$ \\
\hline BR1 & 1,600 & 3 & 30 & 29,600 & 8,880 & 900 & 43.2 & $\begin{array}{c}4,620 / 20 \\
\text { years }\end{array}$ & 790 \\
\hline
\end{tabular}

Notes: 1, 2, 4, 5 and 6 are derived from survey; 3 is assumed; 7 and 8 are estimated based on RS Means data and literature; 9 is derived based on simulation of electricity consumption and electricity rate prediction.

Table 4-14: Cost data for the Conventional System

\begin{tabular}{|c|c|c|c|c|c|c|c|}
\hline \multirow{2}{*}{ ID } & \multirow{2}{*}{$\begin{array}{l}\text { Building } \\
\text { Size (sf) }{ }^{1}\end{array}$} & \multirow{2}{*}{$\begin{array}{c}\text { System } \\
\text { Tonnage } \\
\text { (ton) }^{2}\end{array}$} & \multirow{2}{*}{$\begin{array}{c}\text { Life Cycle } \\
\text { (year) }^{3}\end{array}$} & \multicolumn{4}{|c|}{ Conventional } \\
\hline & & & & Initial Cost $(\$)^{4}$ & $\begin{array}{c}\text { Maintenance } \\
\text { Cost }(\$)^{5}\end{array}$ & Periodic Cost $(\$)^{6}$ & $\begin{array}{c}\text { Annual Electricity } \\
\text { Cost }(\$)^{7}\end{array}$ \\
\hline BR1 & 1600 & 3 & 30 & 6,592 & 112.32 & $4,540 / 15$ years & 910 \\
\hline
\end{tabular}

Notes: 1 and 2 are derived from survey; 3 is assumed; 4, 5, and 6 are estimated based on RS Means data and literature; 7 is derived based on simulation of electricity consumption and electricity rate prediction. 


\section{Life cycle cost analysis}

Life cycle cost analysis was performed by comparing the GSHP system and the conventional system in two scenarios, without incentive and with incentive. The net present value (NPV) of the two systems is presented in Table 4-15.

Data from Table 4-15 shows that the GSHP system has a higher net present mean value than the conventional system. Figure 4-5 shows that the two values are significantly apart. The probability that the life cycle cost of the GSHP system is equal to the conventional system is only $1.4 \%$. Even when incentives are considered (Figure 4-6), the probability only rises to about $13.2 \%$.

Table 4-15: Life Cycle Cost Analysis

\begin{tabular}{|c|c|c|c|c|}
\hline \multirow{2}{*}{ Year } & \multicolumn{2}{|c|}{ Without Incentive } & \multicolumn{2}{c|}{ With Incentive } \\
\cline { 2 - 5 } Total & GSHP NPV & Conventional NPV & GSHP NPV & Conventional NPV \\
(Mean) & 49,249 & 34,725 & 40,512 & 34,725 \\
\hline
\end{tabular}

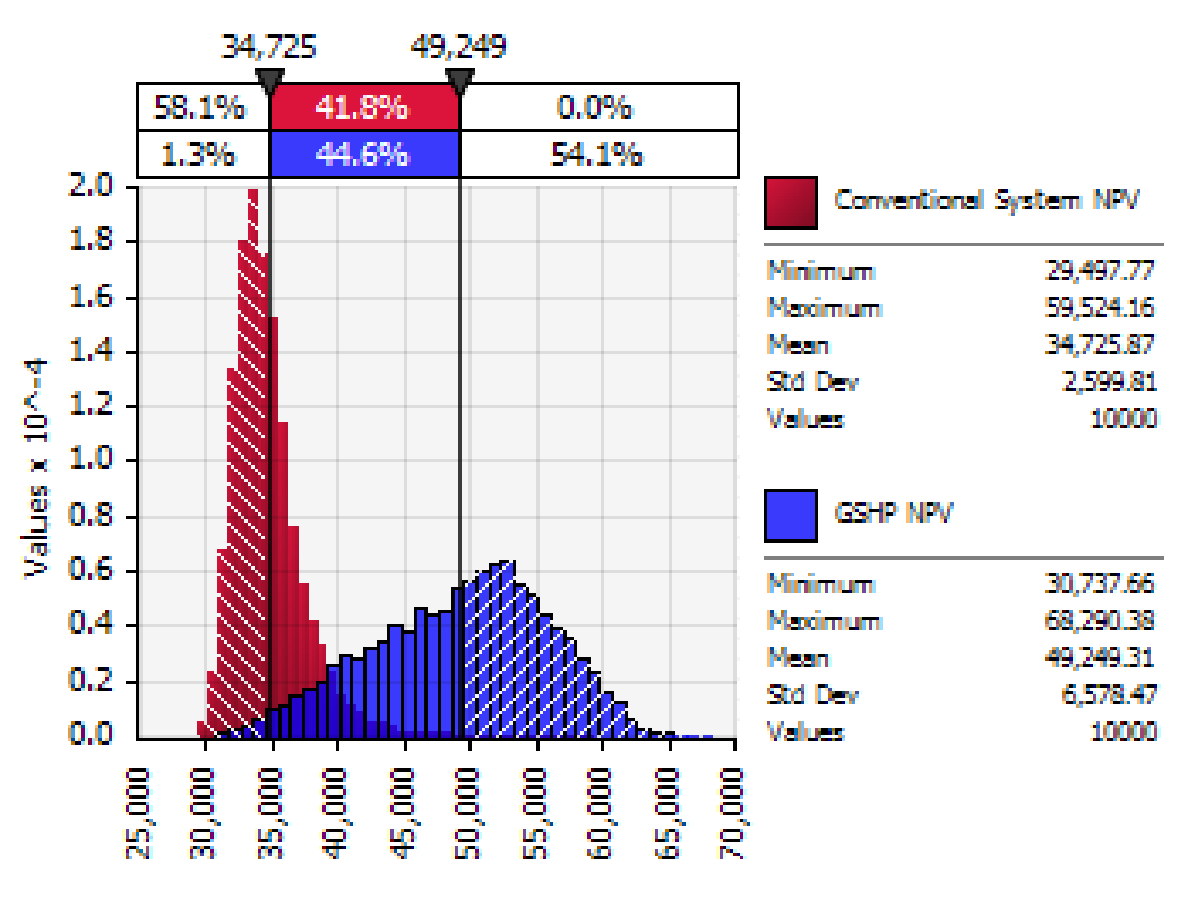

Figure 4-5: GSHP System vs. Conventional System without Incentives 


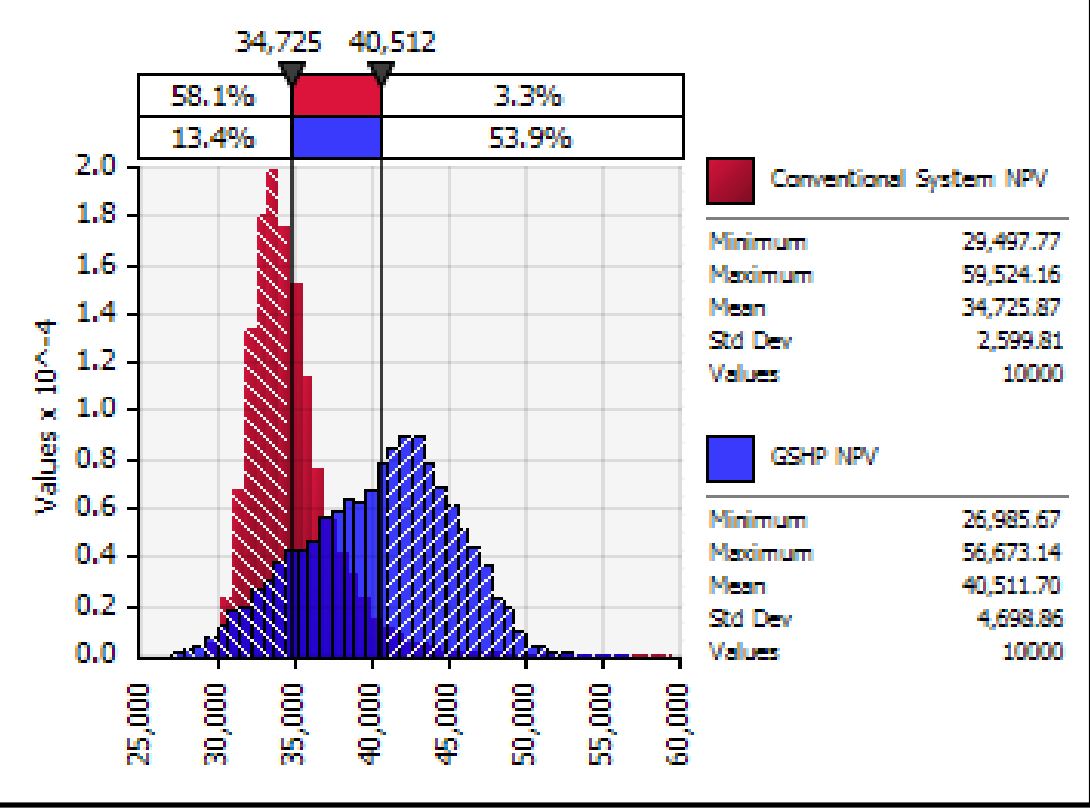

Figure 4-6: GSHP System vs. Conventional System with Incentives

Figures 4-5 and 4-6 shows that the conventional system has a lower life cycle cost than the GHSP system. When there are no incentives, the chance for lowering the GHSP life cycle cost to equal or below that of the conventional system is very small, about $1.3 \%$. With incentives, the chance increases to $13.4 \%$.

\section{Sensitivity analysis}

Figures 4-7 and 4-8 show the results of sensitivity analysis for the GSHP and the conventional systems respectively. For the GSHP system, initial cost is the most sensitivity cost factor, followed by energy cost; while for the conventional system, energy cost is by far the most sensitive cost factor.

Table 4-16 shows the results of ratio sensitivity analysis. Based on current data, it shows that to reverse the existing observation that the GSHP system has a higher life cycle cost, the initial cost of the GSHP needs to decrease $56 \%$ or the energy cost of the conventional system needs to increase $64 \%$. 
Table 4-16: Ratio Sensitivity Analysis without Incentives

\begin{tabular}{|l|r|r|r|r|}
\hline & \multicolumn{1}{|c|}{ GSHP } & \multicolumn{1}{c|}{ GSHP } & Conventional & Conventional \\
\hline Initial Cost & 26,125 & $56 \%$ & 6,592 & $220 \%$ \\
\hline Energy Cost & 19,676 & $74 \%$ & 22,841 & $64 \%$ \\
\hline Maintenance Cost & 890 & $1632 \%$ & 2,314 & $628 \%$ \\
\hline Replacement Cost & 2,558 & $568 \%$ & 2,978 & $488 \%$ \\
\hline Total & $\mathbf{4 9 , 2 4 9}$ & & $\mathbf{3 4 , 7 2 5}$ & \\
\hline
\end{tabular}

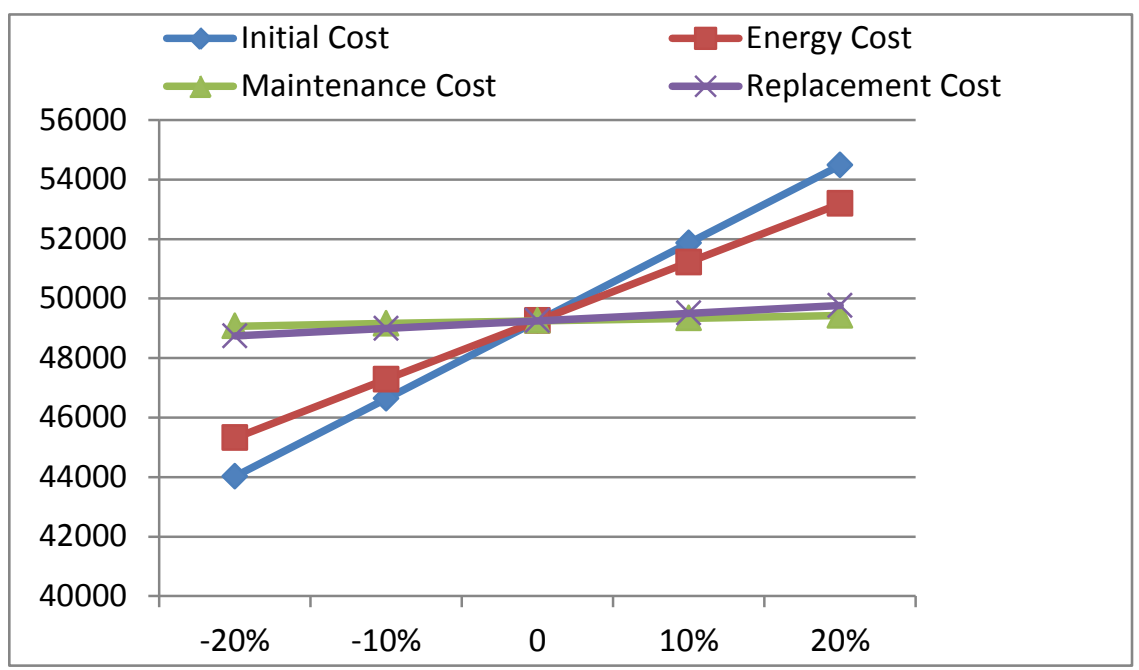

Figure 4-7: Sensitivity Analysis for GSHP

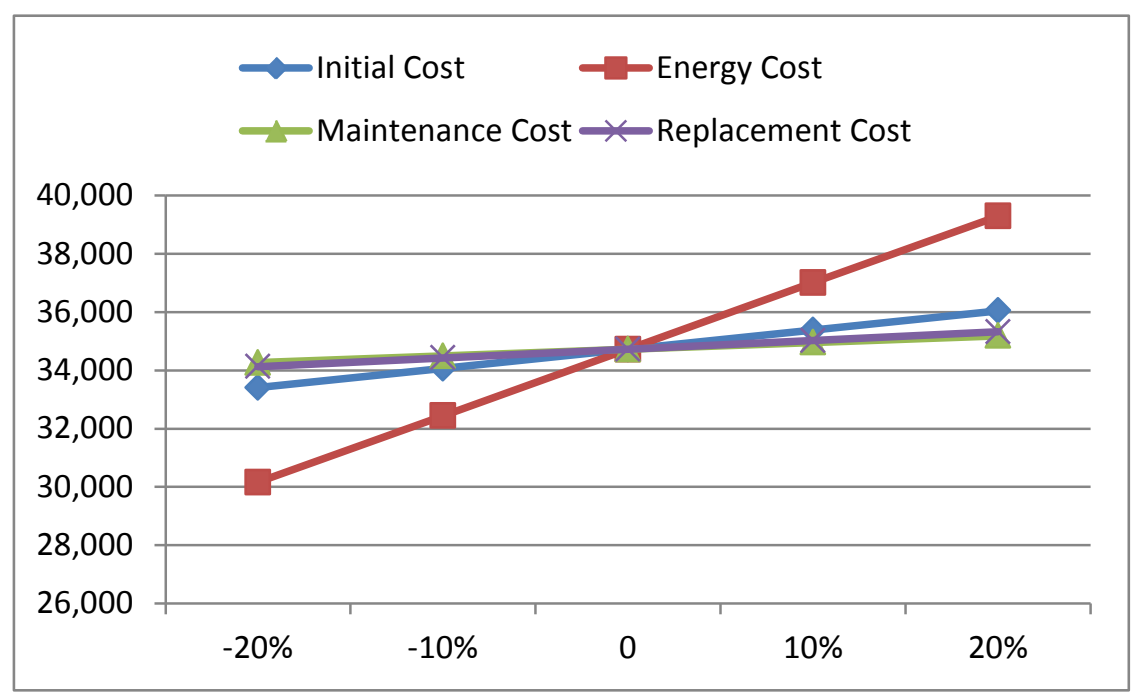

Figure 4-8: Sensitivity Analysis for Conventional System 


\section{BR1 Summary}

The analysis showed that using GSHP in this case is not economical favorable, even with the consideration of incentives. It has to be noted that the high initial costs of the conventional system is probably the major reason. The savings from energy cost, although significant, are not sufficient to offset the large initial cost.

\subsubsection{Case Study - BR2}

\section{Cost data summary}

Tables 4-17 and 4-18 are a summary of cost data used for used by the life cycle cost analysis for this case study.

Table 4-17: Cost data for the GHSP System

\begin{tabular}{|c|c|c|c|c|c|c|c|c|c|}
\hline \multirow[b]{2}{*}{ ID } & \multirow{2}{*}{$\begin{array}{l}\text { Building } \\
\text { Size (sf) }\end{array}$} & \multirow{2}{*}{$\begin{array}{c}\text { System } \\
\text { Tonnage } \\
\text { (ton) }\end{array}$} & \multirow{2}{*}{$\begin{array}{l}\text { Life } \\
\text { Cycle } \\
\text { (year) }\end{array}$} & \multicolumn{6}{|c|}{ Geothermal System } \\
\hline & & & & $\begin{array}{l}\text { Initial } \\
\text { Cost } \\
(\$)\end{array}$ & $\begin{array}{c}\text { Tax } \\
\text { Credit } \\
(\$)\end{array}$ & $\begin{array}{c}\text { Utility } \\
\text { Rebate (\$) }\end{array}$ & $\begin{array}{c}\text { Maintenance } \\
\text { Cost (\$) }\end{array}$ & $\begin{array}{l}\text { Periodic } \\
\text { Cost }(\$)\end{array}$ & $\begin{array}{c}\text { Annual } \\
\text { Electricity } \\
\text { Cost (\$) }\end{array}$ \\
\hline BR2 & 1900 & 4 & 30 & 27,666 & 8300 & 1200 & 51.3 & $\begin{array}{c}6,10420 \\
\text { years }\end{array}$ & 1,045 \\
\hline
\end{tabular}

Table 4-18: Cost data for the Conventional System

\begin{tabular}{|c|c|c|c|c|c|c|c|}
\hline \multirow{2}{*}{ ID } & \multirow{2}{*}{$\begin{array}{l}\text { Building } \\
\text { Size (sf) }\end{array}$} & \multirow{2}{*}{$\begin{array}{c}\text { System } \\
\text { Tonnage } \\
\text { (ton) }\end{array}$} & \multirow{2}{*}{$\begin{array}{r}\text { Life } \\
\text { Cycle } \\
\text { (year) }\end{array}$} & \multicolumn{4}{|c|}{ Conventional } \\
\hline & & & & $\begin{array}{l}\text { Initial } \\
\text { Cost (\$) }\end{array}$ & $\begin{array}{c}\text { Maintenance } \\
\text { Cost (\$) }\end{array}$ & $\begin{array}{l}\text { Periodic } \\
\text { Cost (\$) }\end{array}$ & $\begin{array}{c}\text { Annual Electricity } \\
\text { Cost (\$) }\end{array}$ \\
\hline BR2 & 1900 & 4 & 30 & 7,828 & 133.38 & $\begin{array}{c}6,187 / 15 \\
\text { years }\end{array}$ & 1,285 \\
\hline
\end{tabular}




\section{Life cycle cost analysis}

The net present value (NPV) of the GHSP system is presented in Table 4-19.

Table 4-19: Life Cycle Cost Analysis

\begin{tabular}{|c|c|c|c|c|}
\hline \multirow{2}{*}{ Year } & \multicolumn{2}{|c|}{ Without Incentive } & \multicolumn{2}{c|}{ With Incentive } \\
\cline { 2 - 5 } & GSHP NPV & Conventional NPV & GSHP NPV & Conventional NPV \\
\hline $\begin{array}{c}\text { Total } \\
\text { (Mean) }\end{array}$ & 47,267 & 41,009 & 39,676 & 41,009 \\
\hline
\end{tabular}

Data from Table 4-19 shows that the GSHP system has a higher net present mean value than the conventional system without incentives. With incentives, the GSHP system seems more preferable. The payback time is about 23 years.

Figure 4-9 shows that the two distributions have overlaps. The probability that the life cycle cost of the GSHP system is equal to the conventional system is only $12.6 \%$. This observation suggests that in this case, with the consideration of uncertainties, there is a chance is the GSHP system can be more favorable.

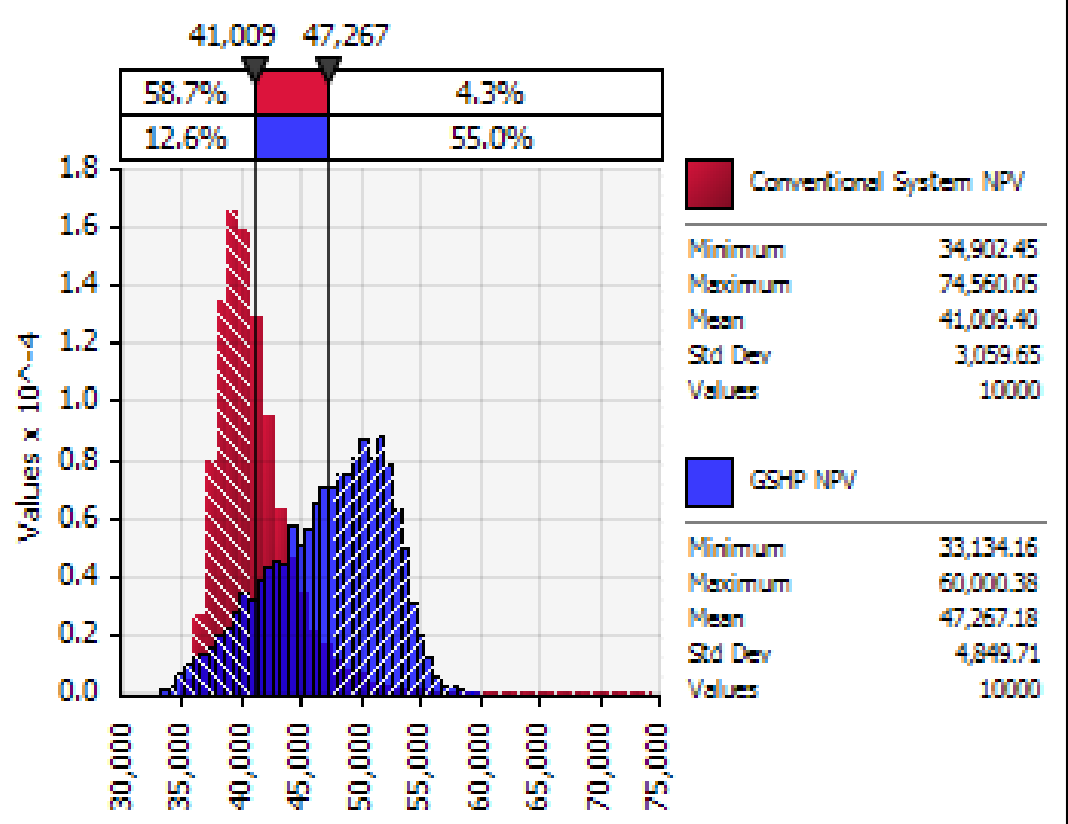

Figure 4-9: GSHP System vs. Conventional System without Incentives 


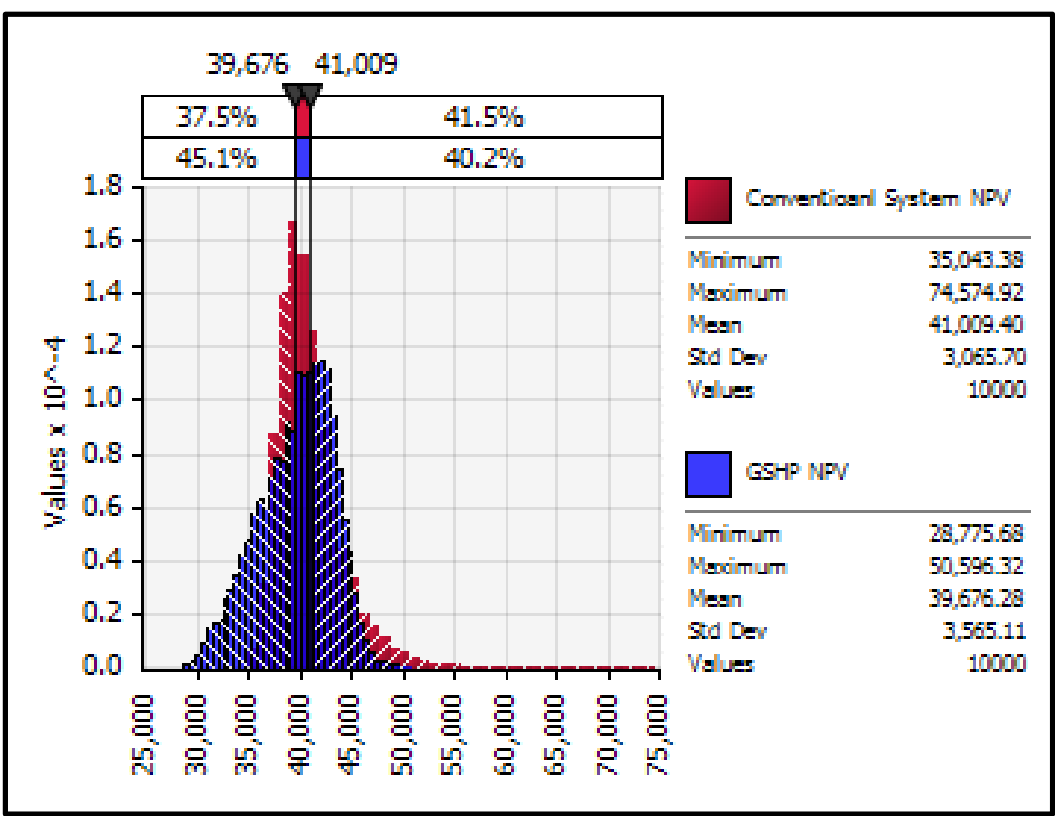

Figure 4-10: GSHP System vs. Conventional System with Incentives

When incentives are considered (Figure 4-10), the mean LCC value suggests that the GSHP system more favorable than the conventional system. However, the probability to reverse this observation is as high as $37.5 \%$. This means when the uncertainties are considered, there are about 38 times out of 100 observations in which the conventional system is economically more favorable.

\section{Sensitivity analysis}

Figures 4-11 and 4-12 show the results of sensitivity analysis for the GSHP and the conventional systems respectively. For the GSHP system, the initial cost and the energy cost are the most sensitivity cost factors; while for the conventional system, energy cost is by far the most sensitive cost factor.

Table 4-20 shows the results of ratio sensitivity analysis. Based on current data, it shows that to reverse the existing observation that the GSHP system has a higher life cycle cost, the initial cost or the energy cost of the GSHP needs to decrease 29\% or the energy cost of the conventional system needs to increase $24 \%$. 


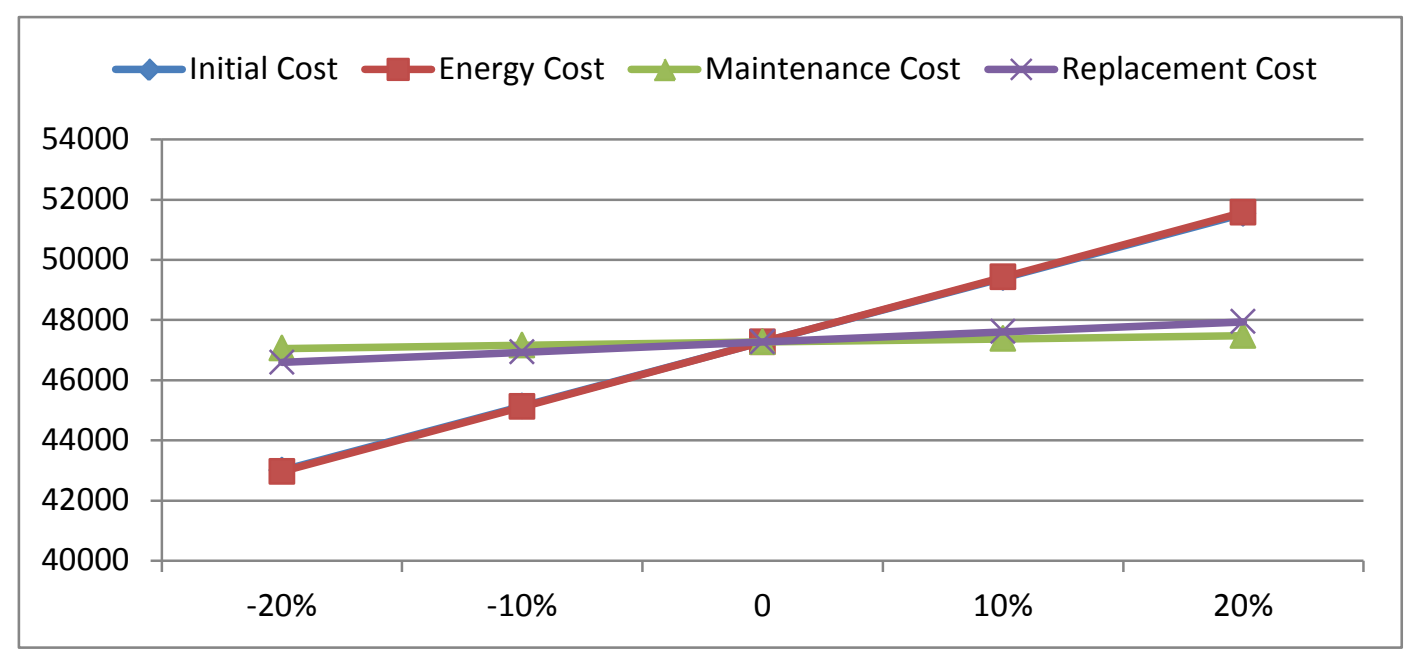

Figure 4-11: Sensitivity Analysis for GSHP without Incentives

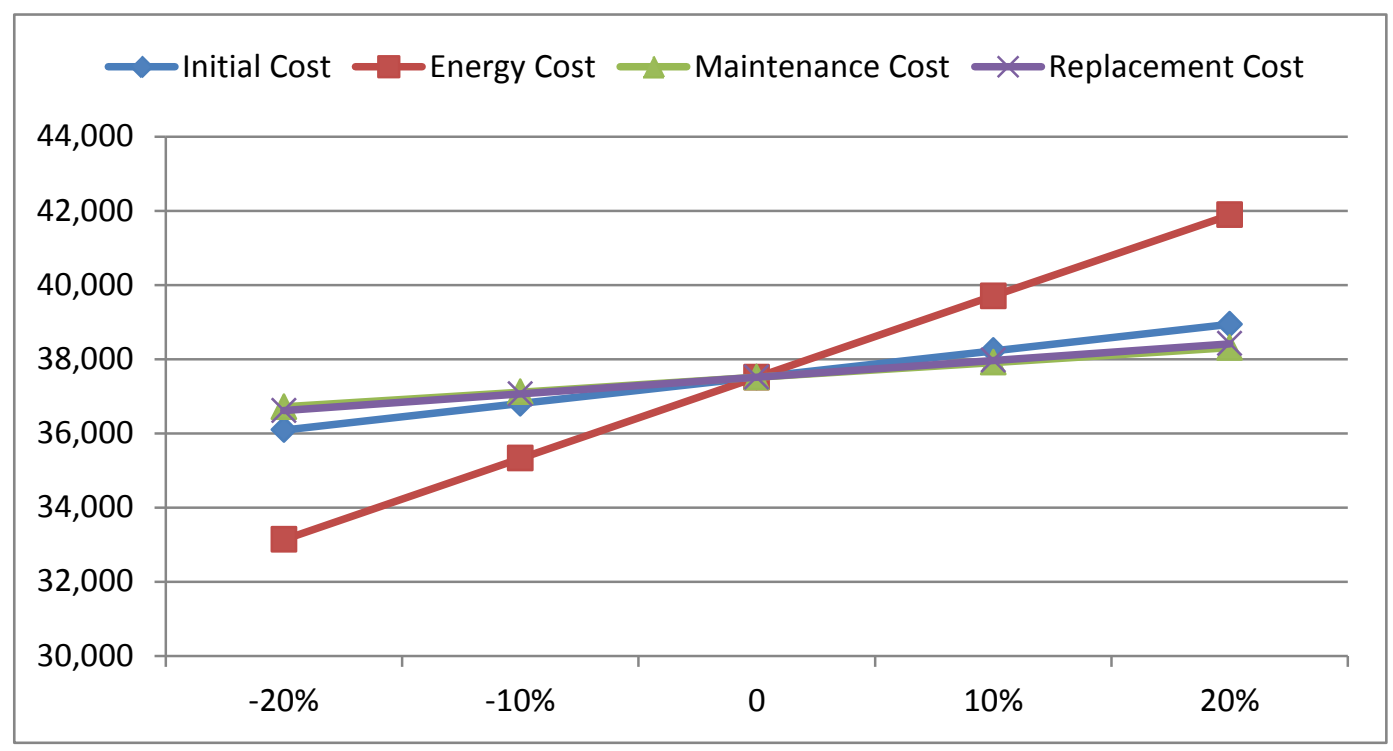

Figure 4-12: Sensitivity Analysis for Conventional System without Incentives

Table 4-20: Ratio Sensitivity Analysis without Incentives

\begin{tabular}{|l|r|r|r|r|}
\hline & \multicolumn{1}{c|}{ GSHP } & GSHP & Conventional & Conventional \\
\hline Initial Cost & 21,303 & $29 \%$ & 7,828 & $80 \%$ \\
\hline Energy Cost & 21,528 & $29 \%$ & 26,462 & $24 \%$ \\
\hline Maintenance Cost & 1,057 & $592 \%$ & 2,748 & $228 \%$ \\
\hline Replacement Cost & 3,380 & $185 \%$ & 3,971 & $158 \%$ \\
\hline Total & $\mathbf{4 7 , 2 6 7}$ & & $\mathbf{4 1 , 0 0 9}$ & \\
\hline
\end{tabular}




\section{BR2 Summary}

The case study shows that incentives play a significant role making the GSHP option more favorable if comparing the mean of life cycle costs of the two systems. However, there is a large chance, $37.3 \%$, which the conventional system can be more favorable, when the initial cost or the energy cost of GHSP is decreased or the energy cost of the conventional system is increased.

\subsubsection{Case Study - BR3}

\section{Cost data summary}

Tables 4-21 and 4-22 are a summary of cost data used for used by the life cycle cost analysis for this case study. Assumptions applied to account for uncertainties were discussed in previous sections.

Table 4-21: Cost data for the GHSP System

\begin{tabular}{|c|c|c|c|c|c|c|c|c|c|}
\hline \multirow[b]{2}{*}{ ID } & \multirow{2}{*}{$\begin{array}{l}\text { Building } \\
\text { Size (sf) }\end{array}$} & \multirow{2}{*}{$\begin{array}{c}\text { System } \\
\text { Tonnage } \\
\text { (ton) }\end{array}$} & \multirow{2}{*}{$\begin{array}{l}\text { Life } \\
\text { Cycle } \\
\text { (year) }\end{array}$} & \multicolumn{6}{|c|}{ Geothermal System } \\
\hline & & & & $\begin{array}{l}\text { Initial } \\
\text { Cost } \\
(\$)\end{array}$ & $\begin{array}{c}\text { Tax } \\
\text { Credit } \\
(\$)\end{array}$ & $\begin{array}{c}\text { Utility } \\
\text { Rebate (\$) }\end{array}$ & $\begin{array}{c}\text { Maintenance } \\
\text { Cost (\$) }\end{array}$ & $\begin{array}{l}\text { Periodic } \\
\text { Cost (\$) }\end{array}$ & $\begin{array}{c}\text { Annual } \\
\text { Electricity } \\
\text { Cost }\end{array}$ \\
\hline BR3 & 2800 & 5 & 30 & 25,000 & 7,500 & 2,000 & 75.6 & $\begin{array}{c}6,545 / 20 \\
\text { years }\end{array}$ & 576 \\
\hline
\end{tabular}

Table 4-22: Cost data for the Conventional System

\begin{tabular}{|c|c|c|c|c|c|c|c|}
\hline \multirow{2}{*}{ ID } & \multirow{2}{*}{ Building } & System & Life & \multicolumn{4}{|c|}{ Conventional } \\
& Size (sf) & $\begin{array}{c}\text { Tonnage } \\
\text { (ton) }\end{array}$ & $\begin{array}{c}\text { Cycle } \\
\text { (year) }\end{array}$ & $\begin{array}{c}\text { Initial } \\
\text { Cost (\$) }\end{array}$ & $\begin{array}{c}\text { Maintenance } \\
\text { Cost (\$) }\end{array}$ & $\begin{array}{c}\text { Periodic } \\
\text { Cost (\$) }\end{array}$ & $\begin{array}{c}\text { Annual Electricity } \\
\text { Cost (\$) }\end{array}$ \\
\hline BR3 & 2800 & 5 & 30 & 11,144 & 196.56 & 6,671 & 829 \\
\hline
\end{tabular}




\section{Life cycle cost analysis}

The net present value (NPV) of the GHSP system is presented in Table 4-23.

Table 4-23: Life Cycle Cost Analysis

\begin{tabular}{|c|c|c|c|c|}
\hline \multirow{2}{*}{ Year } & \multicolumn{2}{|c|}{ Without Incentive } & \multicolumn{2}{c|}{ With Incentive } \\
\cline { 2 - 5 } & GSHP NPV & Conventional NPV & GSHP NPV & Conventional NPV \\
\hline Total & 41,347 & 36,952 & 32,647 & 36,952 \\
(Mean) & & & & \\
\hline
\end{tabular}

Data from Table 4-23 shows that the GSHP system has a higher net present value than the conventional system when there is no incentive. Figure 4-13 shows that, when incentives are not considered, the life cycle cost of the GSHP is always higher than the conventional system.

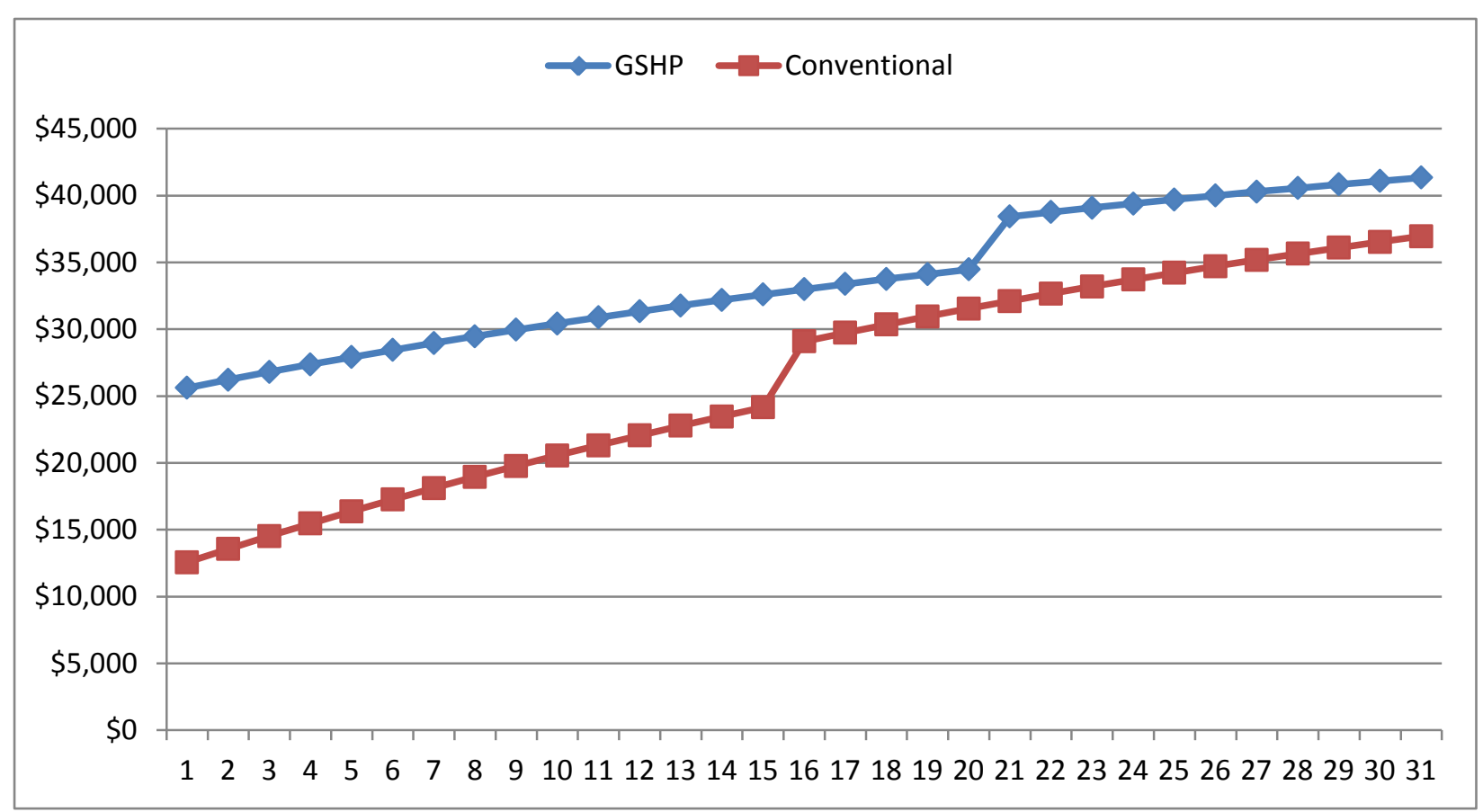

Figure 4-13: Cumulative Net Present Value Comparison of the Two Systems without Incentives 


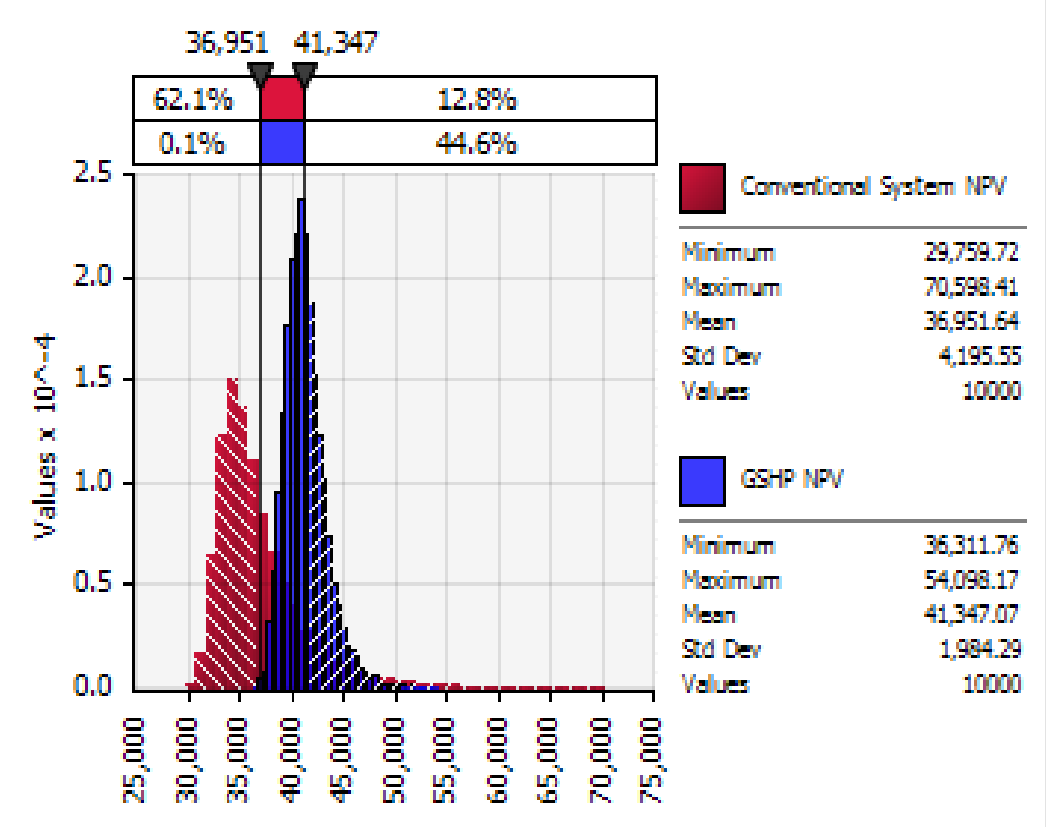

Figure 4-14: GSHP System vs. Conventional System without Incentives

Figure 4-14 compares the two distributions of life cycle cost. The probability for the GSHP system to reach the mean life cycle cost of the conventional system is very negligible, $0.1 \%$, which suggests that without incentives, it is unlikely that the GSHP system option is economically preferable.

On the other hand, when incentives are considered (See Figure 4-15), the life cycle cost of GSHP is more favorable. Around year 15, there is a positive cumulative cash flow, which means the payback time is about 15 years. The probability for the conventional system to reach the mean life cycle cost of the GSHP system is small, 7\% (See Figure 4-15). 


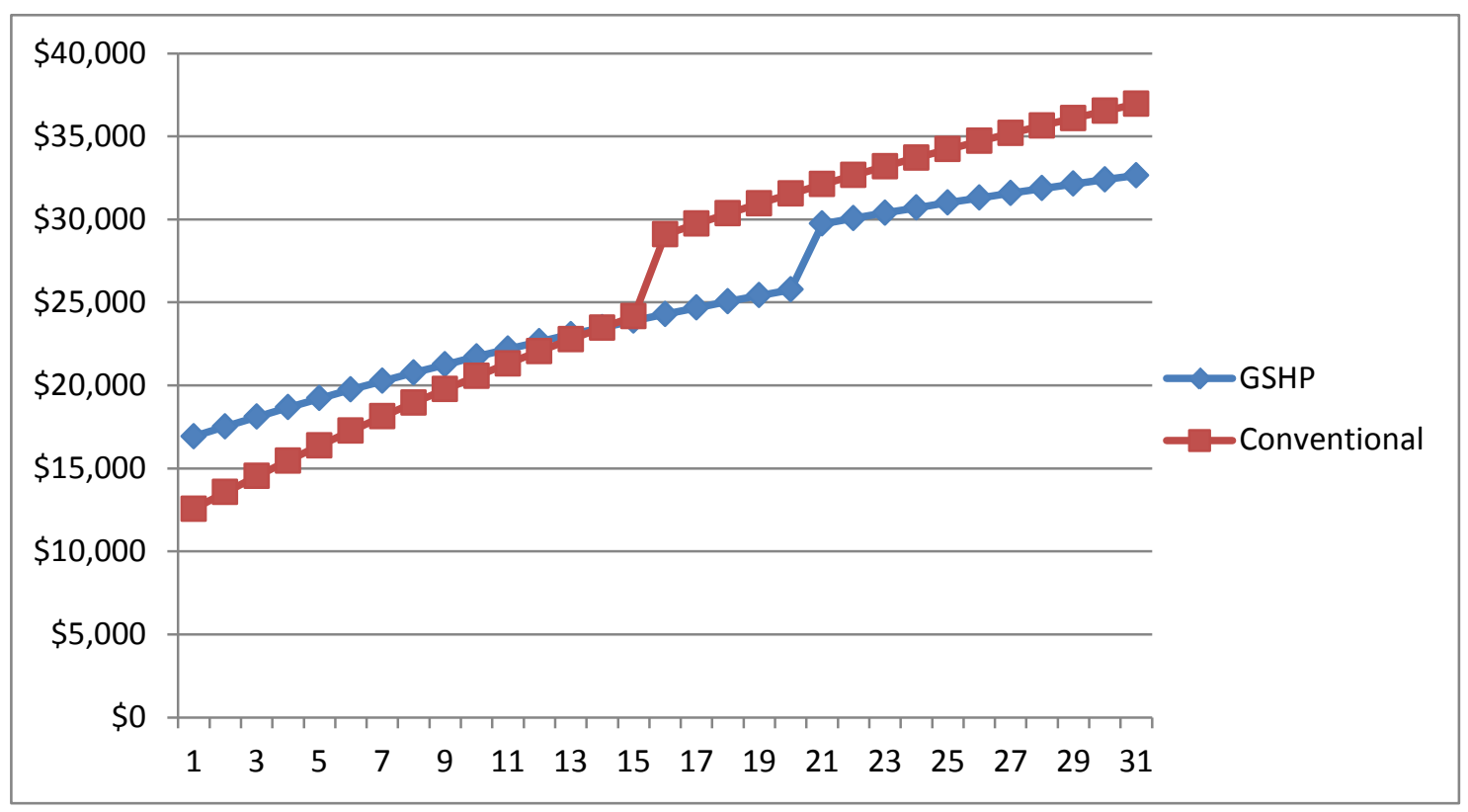

Figure 4-15: Cumulative Net Present Value Comparison of the Two Systems with Incentives

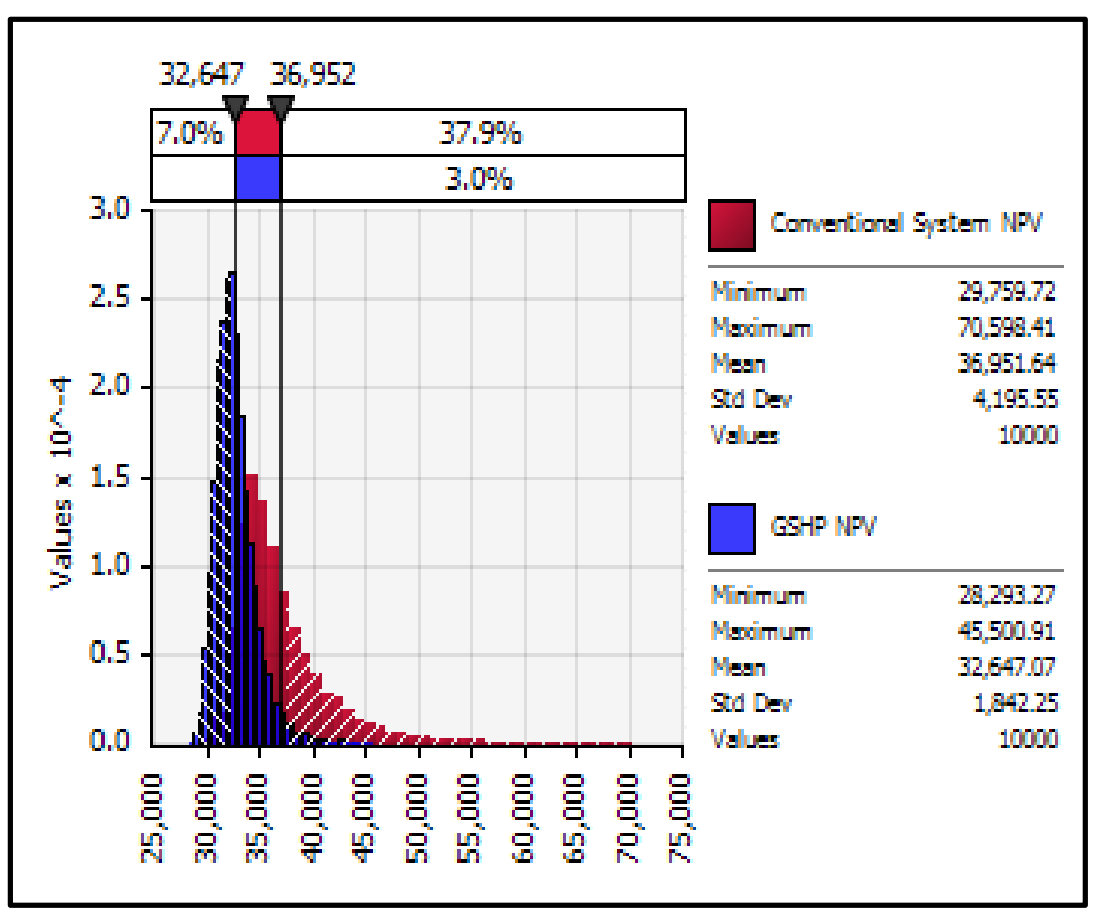

Figure 4-16: GSHP System vs. Conventional System with Incentives 


\section{Sensitivity analysis}

Figures 4-17 and 4-18 show the results of sensitivity analysis for the GSHP and the conventional systems respectively. For the GSHP system, initial cost is the most sensitivity cost factor, followed by energy cost; while for the conventional system, energy cost is by far the most sensitive cost factor.

Table 4-24 shows the results of ratio sensitivity analysis. Based on current data, it shows that to reverse the existing observation that, without incentives, the GSHP system has a higher life cycle cost, the initial cost of the GSHP needs to reduce $18 \%$ or the energy cost of the conventional system needs to increase $26 \%$. The incentives represent a $54 \%$ saving on the initial cost, which is why when incentives are considered, the life cycle cost of GSHP is smaller. In addition, other factors are also very sensitive with relatively small percentages, which indicate that uncertainties associated with the data may change the results.

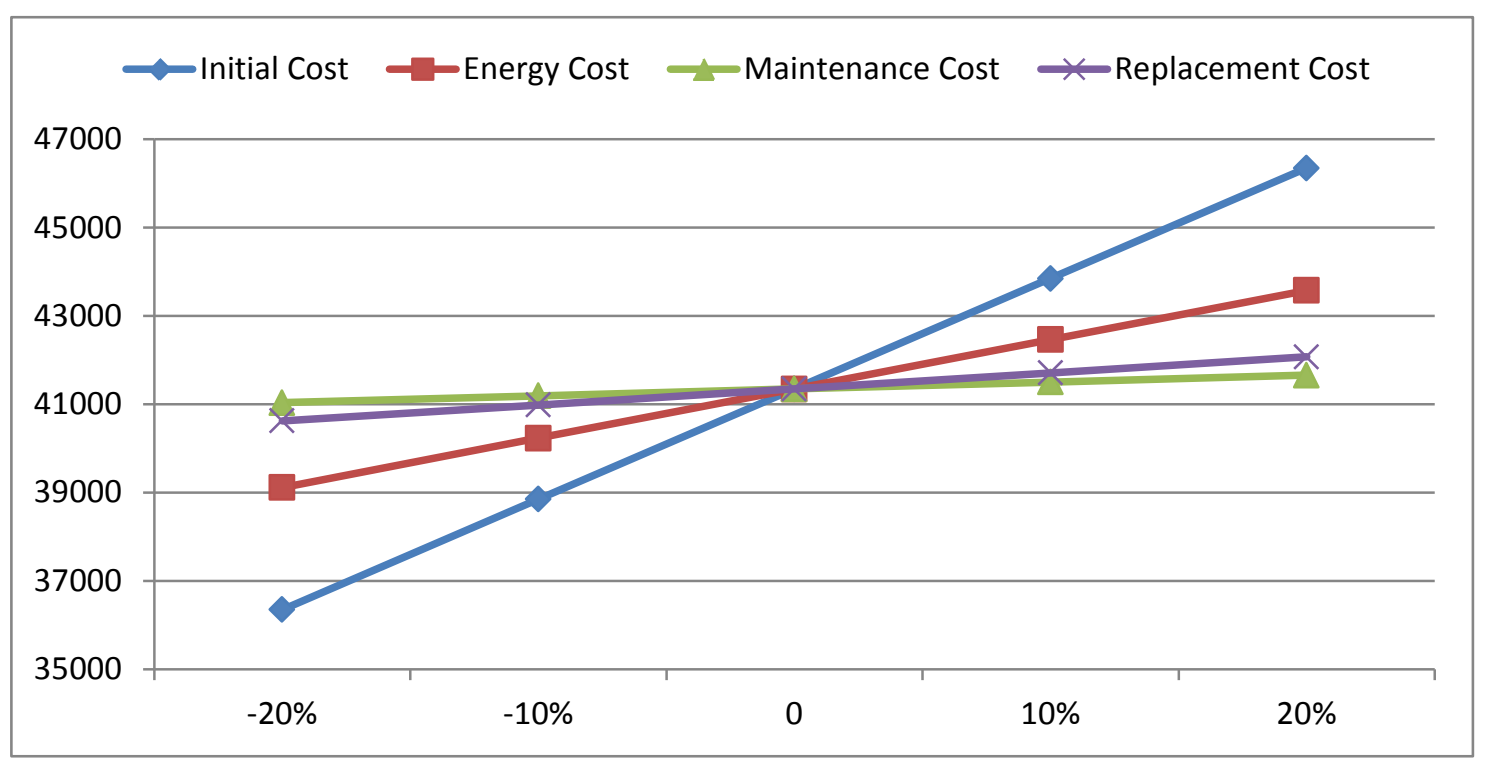

Figure 4-17: Sensitivity Analysis for GSHP 


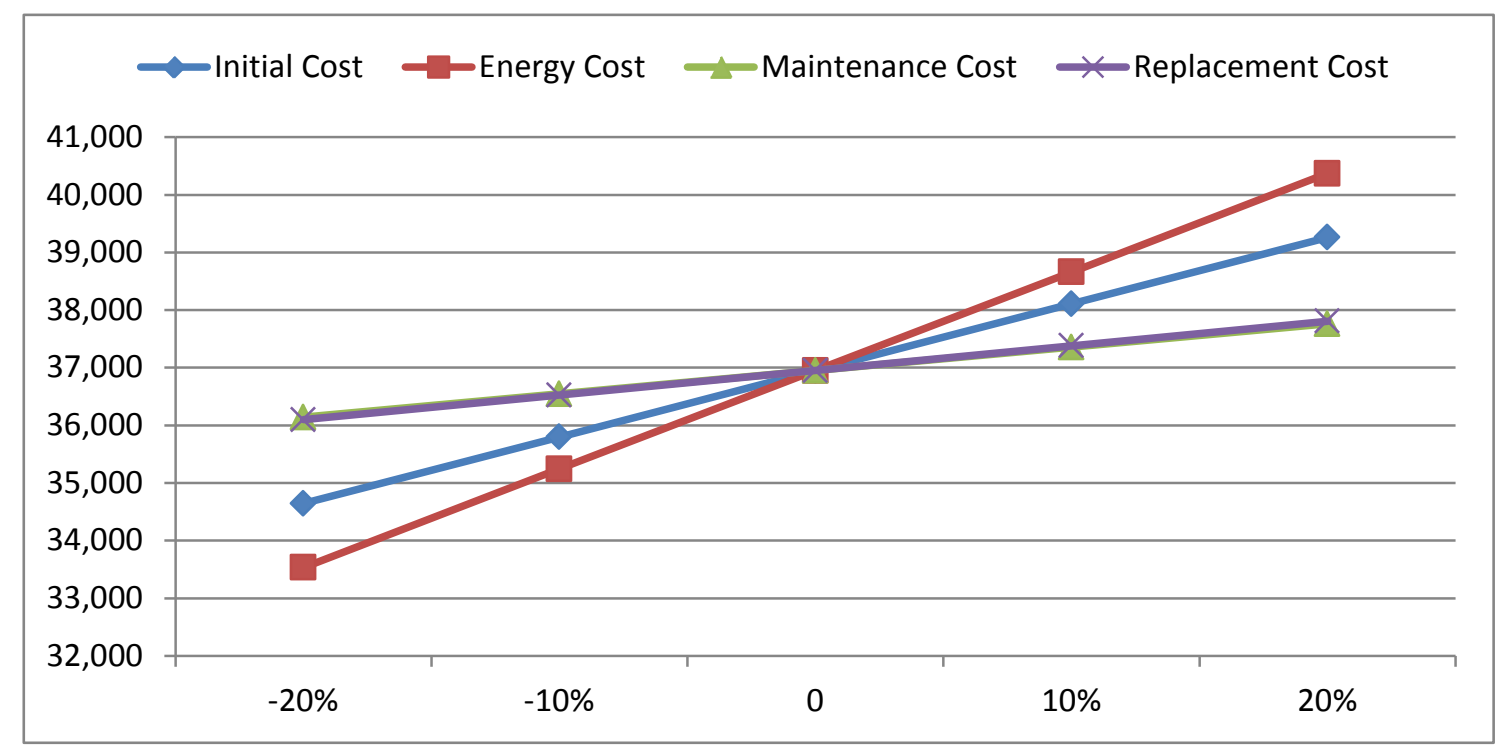

Figure 4-18: Sensitivity Analysis for Conventional System

Table 4-24: Ratio Sensitivity Analysis

\begin{tabular}{|l|r|r|r|r|}
\hline & \multicolumn{1}{|c|}{ GSHP } & \multicolumn{1}{c|}{ GSHP } & Conventional & Conventional \\
\hline Initial Cost & 25,000 & $18 \%$ & 11,536 & $38 \%$ \\
\hline Electricity Cost & 11,166 & $39 \%$ & 17,085 & $26 \%$ \\
\hline Maintenance Cost & 1,557 & $282 \%$ & 4,049 & $109 \%$ \\
\hline Replacement Cost & 3,623 & $121 \%$ & 4,282 & $103 \%$ \\
\hline Total & $\mathbf{4 1 , 3 4 7}$ & & $\mathbf{3 6 , 9 5 2}$ & \\
\hline
\end{tabular}

\section{BR3 Summary}

This case shows that without incentives, the GSHP seems unfavorable than the conventional system. Reduction in initial cost made the GSHP option a better option eventually, which is also shown by the sensitivity of initial cost. With $18 \%$ reduction in initial cost, the GSHP system will become more favorable. 


\subsubsection{Case Study - BR4}

\section{Cost data summary}

Tables 4-25 and 4-26 are a summary of cost data used for used by the life cycle cost analysis for this case study.

Table 4-25: Cost data for the GHSP System

\begin{tabular}{|c|c|c|c|c|c|c|c|c|c|}
\hline \multirow[b]{2}{*}{ ID } & \multirow{2}{*}{$\begin{array}{l}\text { Building } \\
\text { Size (sf) }\end{array}$} & \multirow{2}{*}{$\begin{array}{c}\text { System } \\
\text { Tonnage } \\
\text { (ton) }\end{array}$} & \multirow{2}{*}{$\begin{array}{l}\text { Life } \\
\text { Cycle } \\
\text { (year) }\end{array}$} & \multicolumn{6}{|c|}{ Geothermal System } \\
\hline & & & & $\begin{array}{l}\text { Initial } \\
\text { Cost } \\
(\$)\end{array}$ & $\begin{array}{c}\text { Tax } \\
\text { Credit } \\
(\$)\end{array}$ & $\begin{array}{c}\text { Utility } \\
\text { Rebate (\$) }\end{array}$ & $\begin{array}{c}\text { Maintenance } \\
\text { Cost (\$) }\end{array}$ & $\begin{array}{l}\text { Periodic } \\
\text { Cost }(\$)\end{array}$ & $\begin{array}{c}\text { Annual } \\
\text { Energy Cost } \\
(\$)\end{array}$ \\
\hline BR4 & 2,800 & 5 & 30 & 25,000 & 7,500 & 2,000 & 75.6 & 5,442 & 576 \\
\hline
\end{tabular}

Table 4-26: Cost data for the Conventional System

\begin{tabular}{|c|c|c|c|c|c|c|c|}
\hline \multirow{2}{*}{ ID } & \multirow{2}{*}{$\begin{array}{l}\text { Building } \\
\text { Size (sf) }\end{array}$} & \multirow{2}{*}{$\begin{array}{c}\text { System } \\
\text { Tonnage } \\
\text { (ton) }\end{array}$} & \multirow{2}{*}{$\begin{array}{l}\text { Life } \\
\text { Cycle } \\
\text { (year) }\end{array}$} & \multicolumn{4}{|c|}{ Conventional } \\
\hline & & & & $\begin{array}{c}\text { Initial } \\
\text { Cost }(\$)\end{array}$ & $\begin{array}{c}\text { Maintenance } \\
\text { Cost (\$) }\end{array}$ & $\begin{array}{l}\text { Periodic } \\
\text { Cost (\$) }\end{array}$ & $\begin{array}{c}\text { Annual Energy Cost } \\
\text { (\$) }\end{array}$ \\
\hline BR4 & 2,800 & 5 & 30 & 11,536 & 196.56 & 5,962 & 669 \\
\hline
\end{tabular}

\section{Life cycle cost analysis}

The net present value (NPV) of the GHSP system is presented in Table 4-27.

Table 4-27: Life Cycle Cost Analysis

\begin{tabular}{|c|c|c|c|c|}
\hline \multirow{2}{*}{ Year } & \multicolumn{2}{|c|}{ Without Incentive } & \multicolumn{2}{c|}{ With Incentive } \\
\cline { 2 - 5 } Total & GSHP NPV & Conventional NPV & GSHP NPV & Conventional NPV \\
\hline
\end{tabular}

Data from Table 4-27 shows that the GSHP system has a higher net present value than the conventional system when incentives are not considered. 


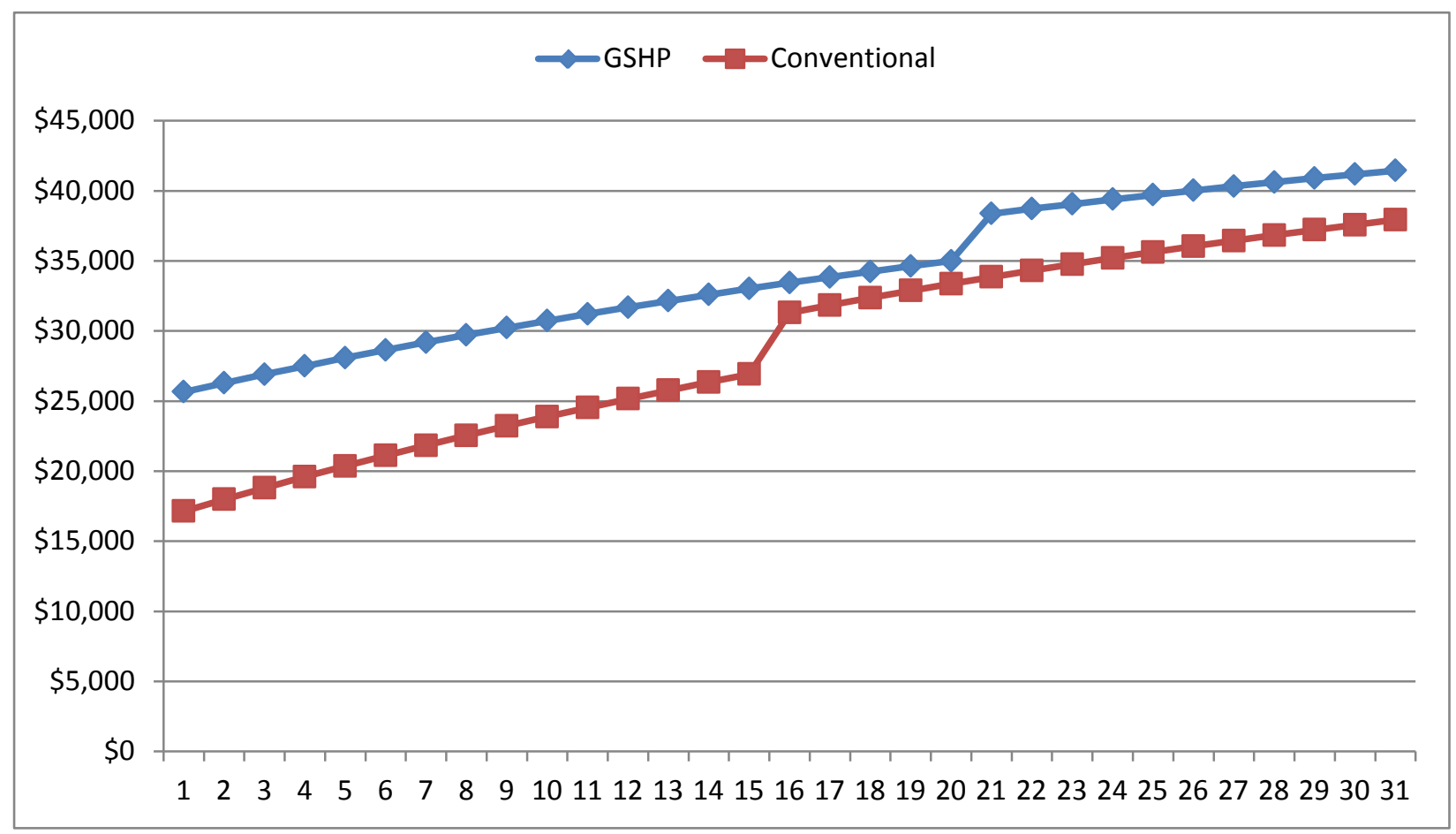

Figure 4-19: Cumulative Net Present Value Comparison of the Two Systems without Incentives

Figure 4-20 shows the distribution of the life cycle cost of GSHP and the conventional system. The probability for the GSHP system to reach the mean life cycle cost of the conventional system is very small, around $1.3 \%$.

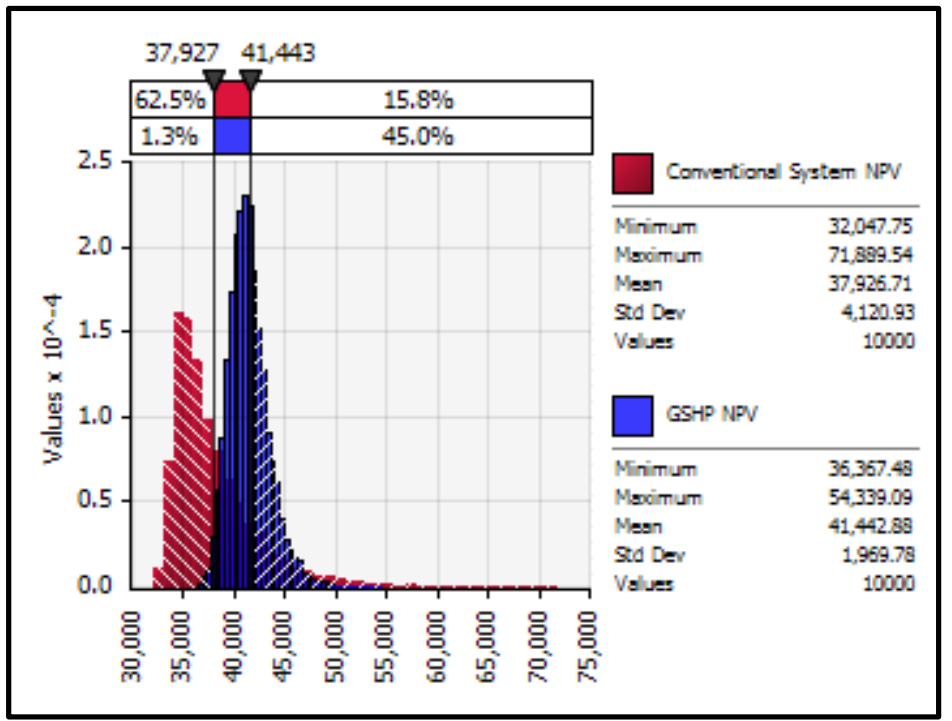

Figure 4-20: GSHP System vs. Conventional System without Incentives 
On the other hand, when incentives are considered (See Figure 4-21), the life cycle cost of GSHP is smaller from the very beginning of the project. Also, the probability that the conventional system has a smaller life cycle cost than the mean of the GSHP is very small, 0.2\% (See Figure 4-22).

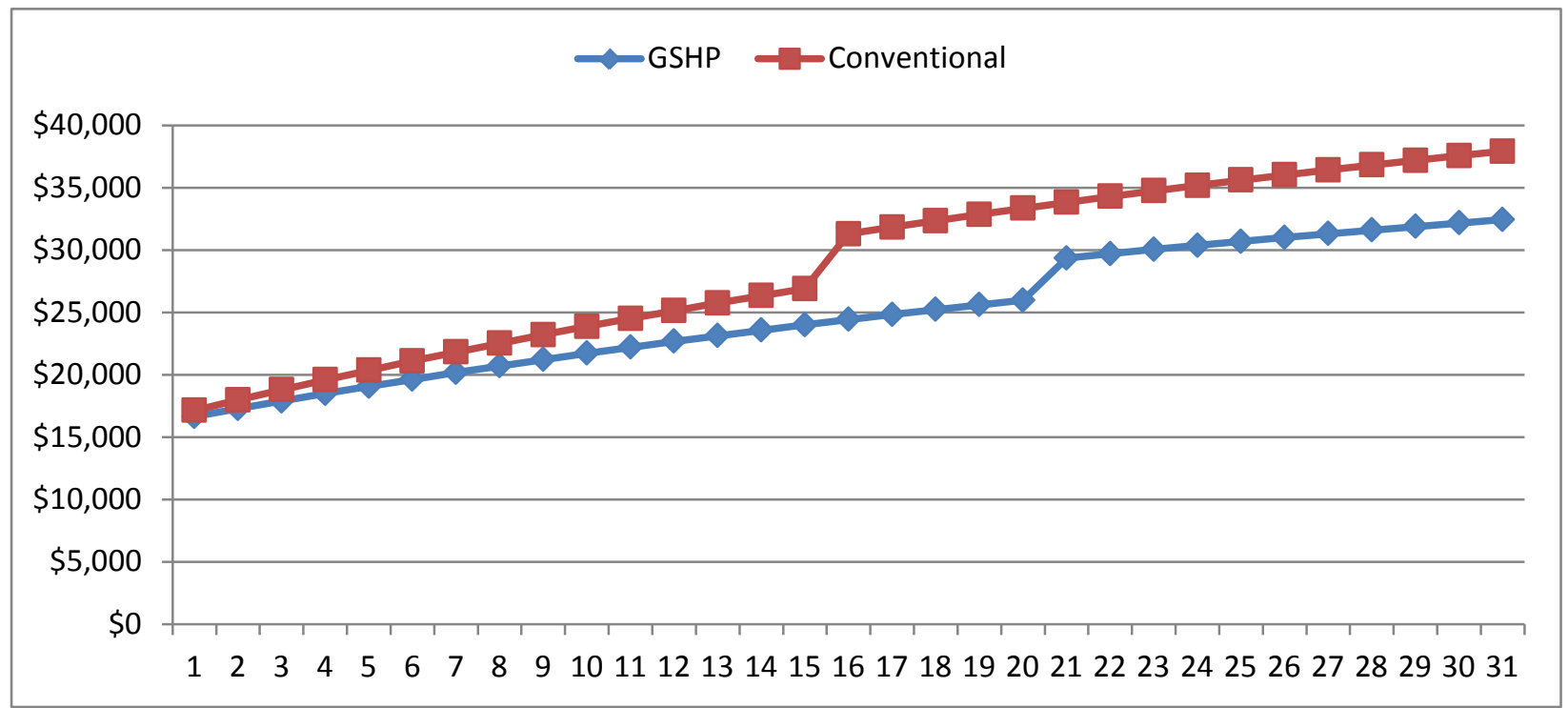

Figure 4-21: Cumulative Net Present Value Comparison of the Two Systems with Incentives

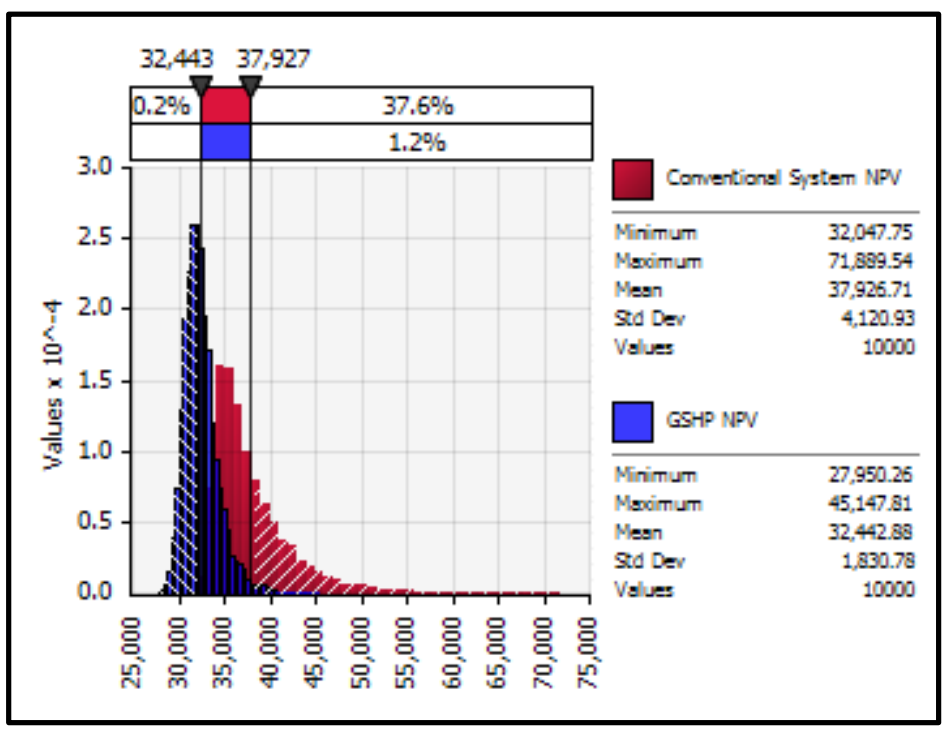

Figure 4-22: GSHP System vs. Conventional System with Incentives 


\section{Sensitivity analysis}

Figures 4-23 and 4-24 show the results of sensitivity analysis for the GSHP and the conventional systems respectively. For both systems, initial cost is the most sensitivity cost factor, followed by energy cost.

Table 4-28 shows the results of ratio sensitivity analysis. Based on current data, it shows that to reverse the existing observation that the GSHP system has a higher life cycle cost without incentives, the initial cost of the GSHP needs to decrease $14 \%$ or the initial cost of the conventional system needs to increase $22 \%$. In addition, energy costs in both cases are also very sensitive with relatively small percentages, which indicate that uncertainties associated with the data may change the results.

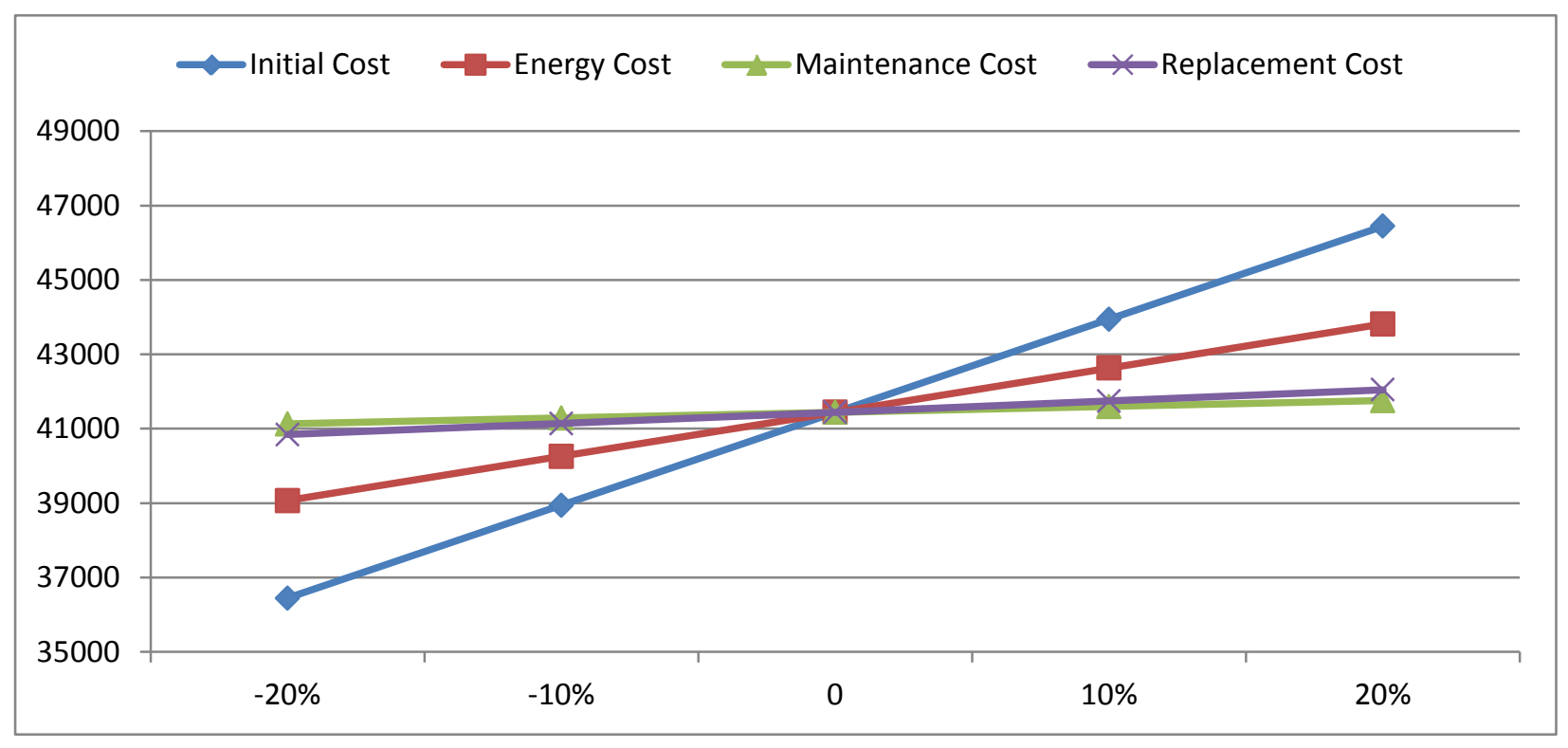

Figure 4-23: Sensitivity Analysis for GSHP without Incentives 


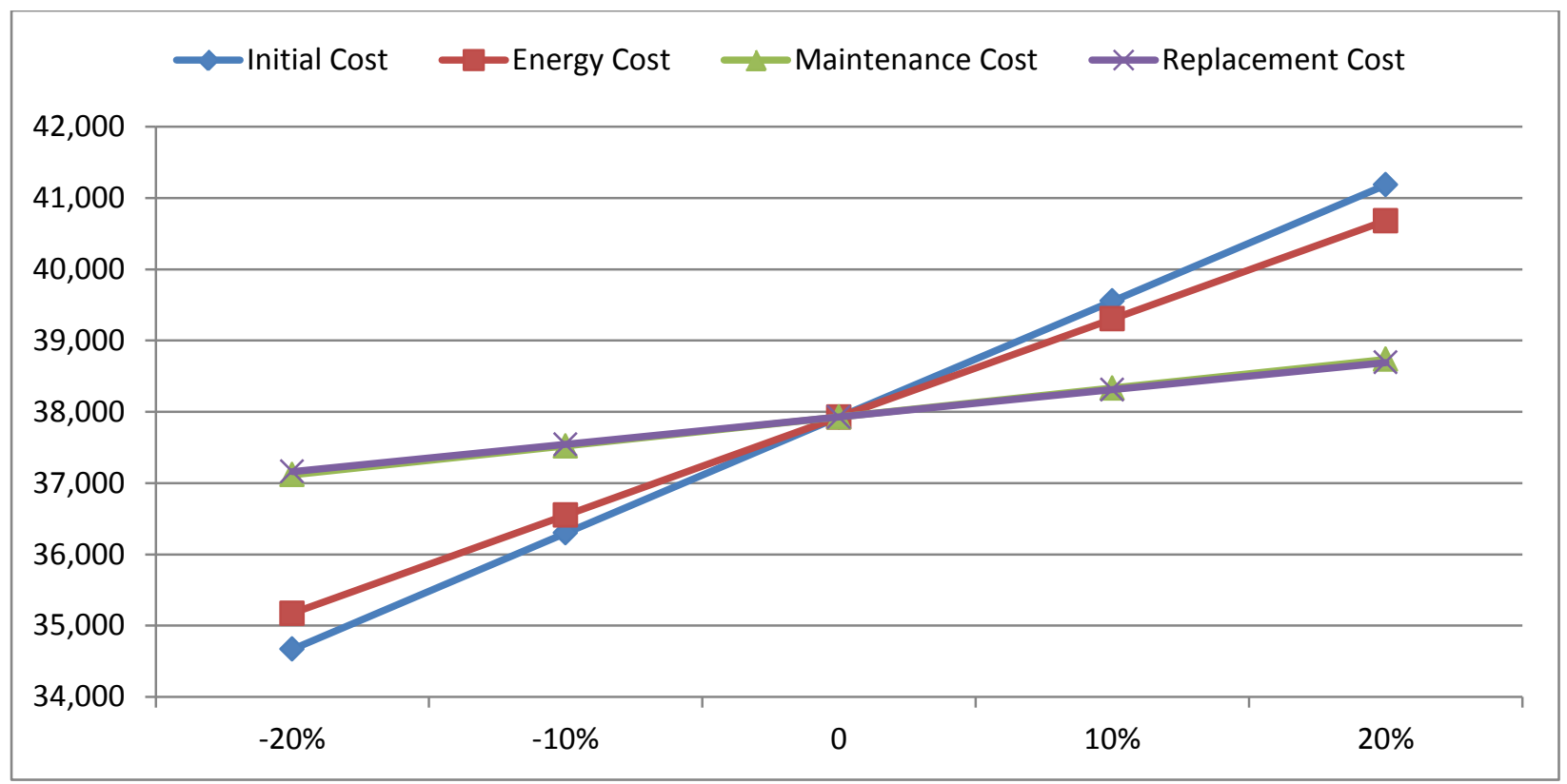

Figure 2-24: Sensitivity Analysis for Conventional System

Table 4-28: Ratio Sensitivity Analysis

\begin{tabular}{|l|r|r|r|r|}
\hline & \multicolumn{1}{|c|}{ GSHP } & \multicolumn{1}{c|}{ GSHP } & Conventional & Conventional \\
\hline Initial Cost & 25,000 & $14 \%$ & 16,280 & $22 \%$ \\
\hline Electricity Price & 11,872 & $30 \%$ & 13,771 & $26 \%$ \\
\hline Maintenance Cost & 1,557 & $226 \%$ & 4,049 & $87 \%$ \\
\hline Replacement Cost & 3,013 & $117 \%$ & 3,827 & $92 \%$ \\
\hline Total & $\mathbf{4 1 , 4 4 3}$ & & $\mathbf{3 7 , 9 2 7}$ & \\
\hline
\end{tabular}

\section{BR4 Summary}

The case study has showed a similar pattern as pervious residential cases, in which the incentives eventually made the GSHP option economically favorable because the initial cost of GSHP is very sensitive.

\subsubsection{Case Study - BC1}

\section{Cost data summary}

Tables 4-29 and 4-30 are a summary of cost data used for used by the life cycle cost analysis for this case study. 
Table 4-29: Cost data for the GHSP System

\begin{tabular}{|c|c|c|c|c|c|c|c|c|c|}
\hline \multirow[b]{2}{*}{ ID } & \multirow{2}{*}{$\begin{array}{l}\text { Building } \\
\text { Size (sf) }\end{array}$} & \multirow{2}{*}{$\begin{array}{c}\text { System } \\
\text { Tonnage } \\
\text { (ton) }\end{array}$} & \multirow{2}{*}{$\begin{array}{l}\text { Life } \\
\text { Cycle } \\
\text { (year) }\end{array}$} & \multicolumn{6}{|c|}{ Geothermal System } \\
\hline & & & & $\begin{array}{l}\text { Initial } \\
\text { Cost } \\
(\$)\end{array}$ & $\begin{array}{c}\text { Tax } \\
\text { Credit } \\
\text { (\$) }\end{array}$ & $\begin{array}{c}\text { Utility } \\
\text { Rebate (\$) }\end{array}$ & $\begin{array}{c}\text { Maintenance } \\
\text { Cost (\$) }\end{array}$ & $\begin{array}{l}\text { Periodic } \\
\text { Cost (\$) }\end{array}$ & $\begin{array}{c}\text { Annual } \\
\text { Electricity } \\
\text { Cost (\$) }\end{array}$ \\
\hline BC1 & 6000 & 19 & 30 & 87500 & 26,250 & 7,600 & 1,572 & 28,864 & 4,919 \\
\hline
\end{tabular}

Table 4-30: Cost data for the Conventional System

\begin{tabular}{|c|c|c|c|c|c|c|c|}
\hline \multirow{2}{*}{ ID } & \multirow{2}{*}{$\begin{array}{l}\text { Building } \\
\text { Size (sf) }\end{array}$} & \multirow{2}{*}{$\begin{array}{c}\text { System } \\
\text { Tonnage } \\
\text { (ton) }\end{array}$} & \multirow{2}{*}{$\begin{array}{l}\text { Life } \\
\text { Cycle } \\
\text { (year) }\end{array}$} & \multicolumn{4}{|c|}{ Conventional } \\
\hline & & & & $\begin{array}{c}\text { Initial } \\
\text { Cost (\$) }\end{array}$ & $\begin{array}{c}\text { Maintenance } \\
\text { Cost (\$) }\end{array}$ & $\begin{array}{l}\text { Periodic } \\
\text { Cost (\$) }\end{array}$ & $\begin{array}{c}\text { Annual Electricity } \\
\text { Cost (\$) }\end{array}$ \\
\hline BC1 & 6000 & 19 & 30 & 60,000 & 4,087 & 34,156 & 7,183 \\
\hline
\end{tabular}

\section{Life cycle cost analysis}

The net present value (NPV) of the GHSP system is presented in Table 4-31.

Table 4-31: Life Cycle Cost Analysis

\begin{tabular}{|c|c|c|c|c|}
\hline \multirow{2}{*}{ Year } & \multicolumn{2}{|c|}{ Without Incentive } & \multicolumn{2}{c|}{ With Incentive } \\
\cline { 2 - 5 } & GSHP NPV & Conventional NPV & GSHP NPV & Conventional NPV \\
\hline Total & 237,195 & 314,087 & 205,245 & 314,087 \\
\hline
\end{tabular}

Data from Table 4-31 shows that the GSHP system has a smaller net present value than the conventional system even when incentives are not considered.

Figure 4-25 shows that after about seven years there is a positive cash flow in net present value for the GSHP system. Around the $7^{\text {th }}$ year, there starts to show a positive cumulative cash flow, suggesting that the payback time is around 7 years. The probability for the conventional system to reach the mean life cycle cost of the GSHP system is very small, around 8.7\% (See Figure 4-26). 


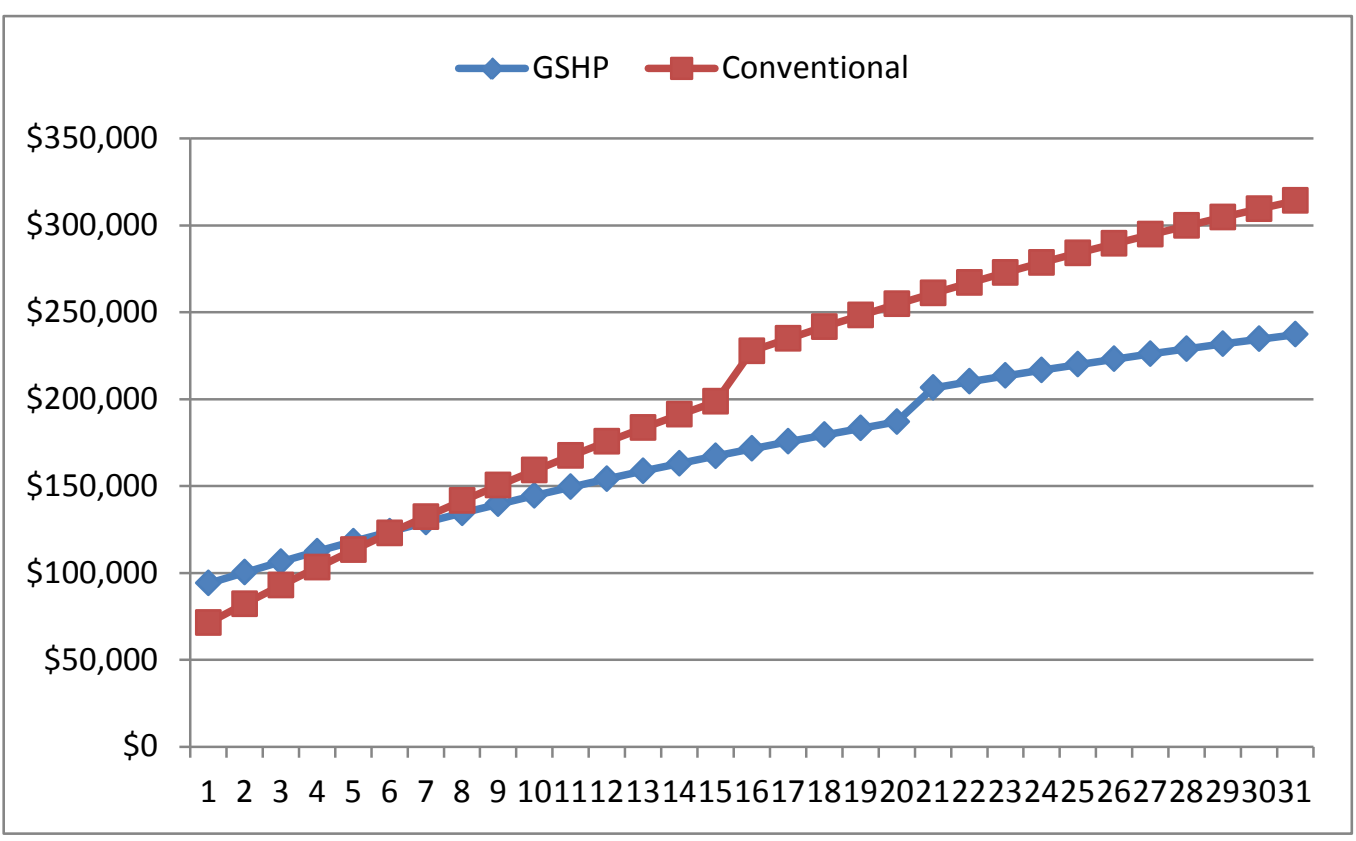

Figure 4-25: Cumulative Net Present Value Comparison of the Two Systems without Incentives

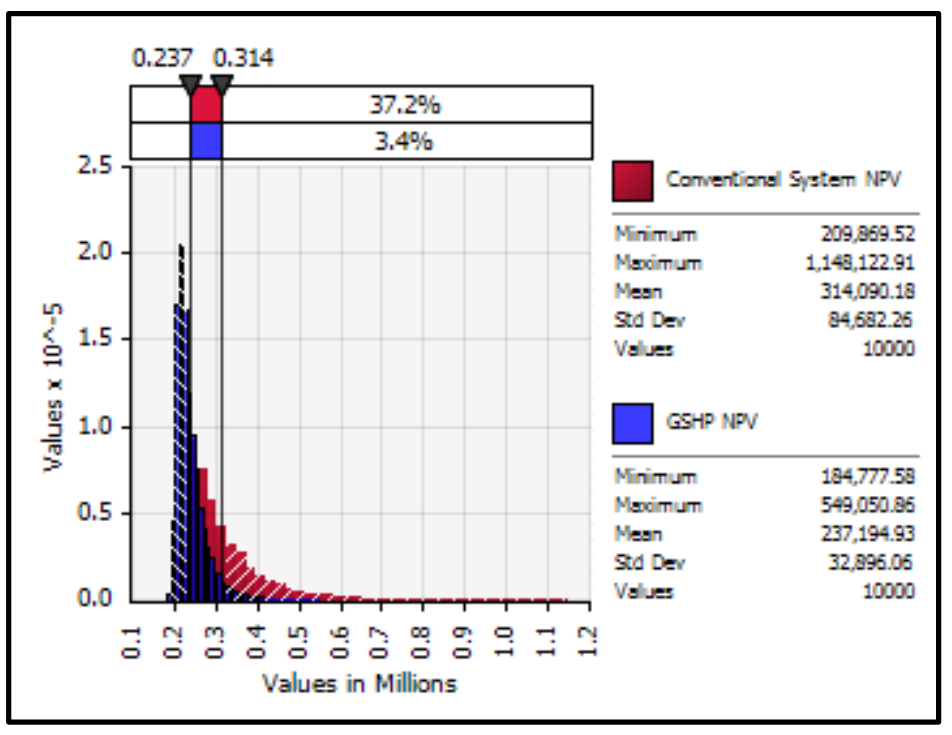

Figure 4-26: GSHP System vs. Conventional System without Incentives

If incentives are considered, the GSHP application is profitable from the beginning (Figure 4-27). The probability that the conventional system has a lower life cycle cost is negligible when incentives are considered (See Figure 4-28). 


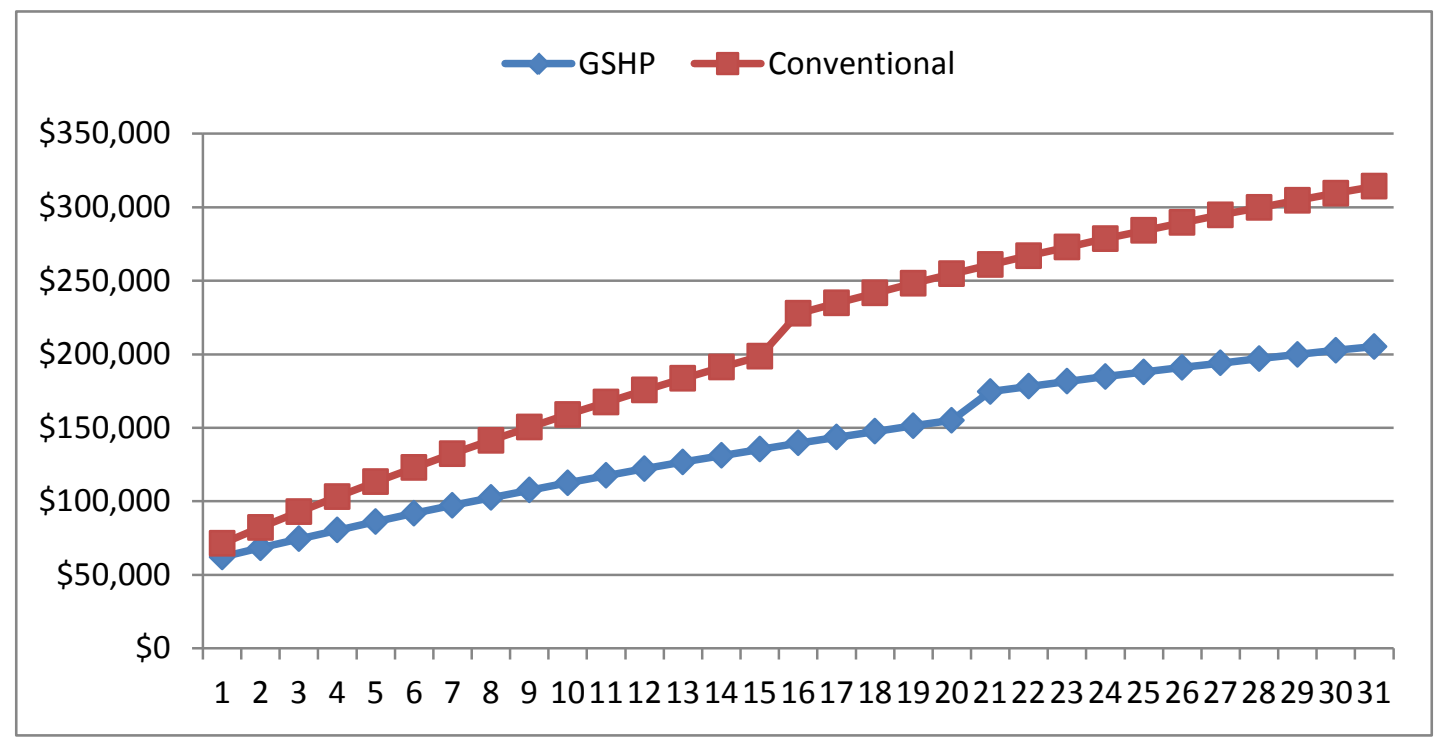

Figure 4-27: Cumulative Net Present Value Comparison of the Two Systems with Incentives

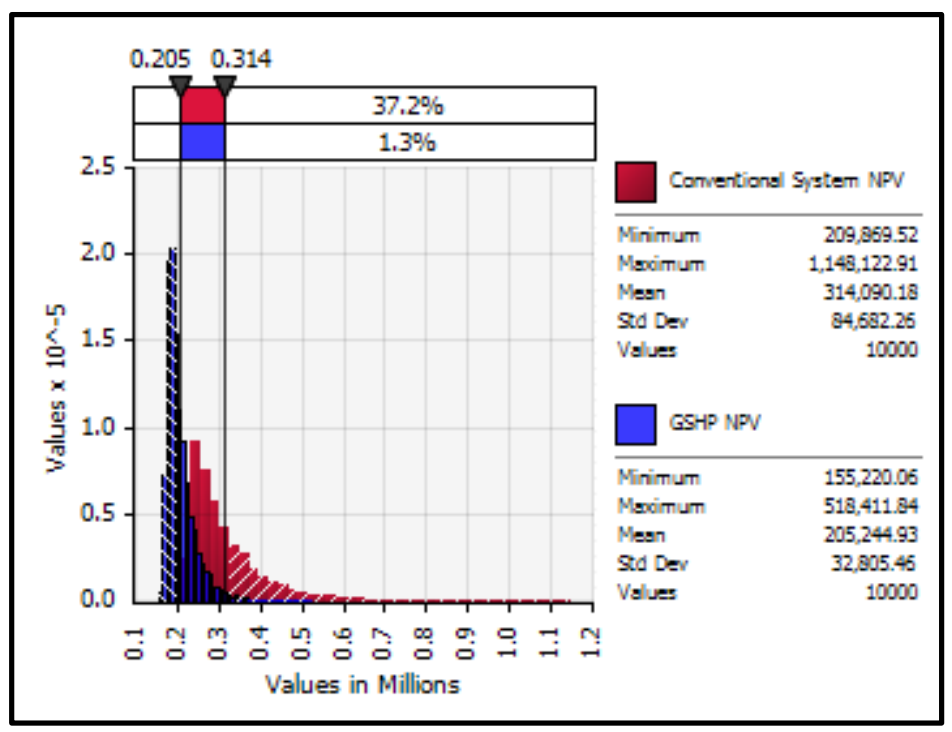

Figure 4-28: GSHP System vs. Conventional System with Incentives

\section{Sensitivity analysis}

Figures 4-29 and 4-30 show the results of sensitivity analysis for the GSHP and the conventional systems respectively. For the GSHP system, energy cost is the most 
sensitivity cost factor, followed by initial cost; while for the conventional system, energy cost is by far the most sensitive cost factor.

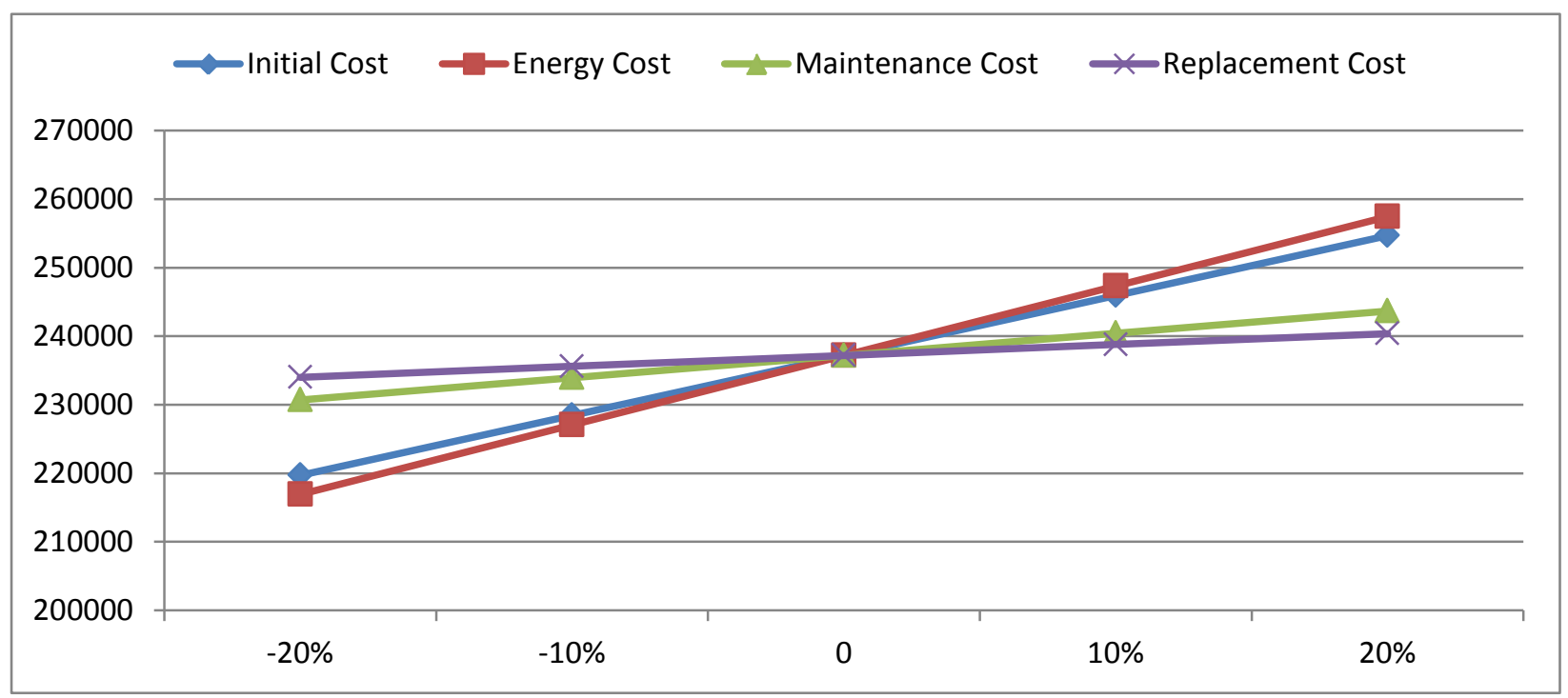

Figure 4-29: Sensitivity Analysis for GSHP without Incentives

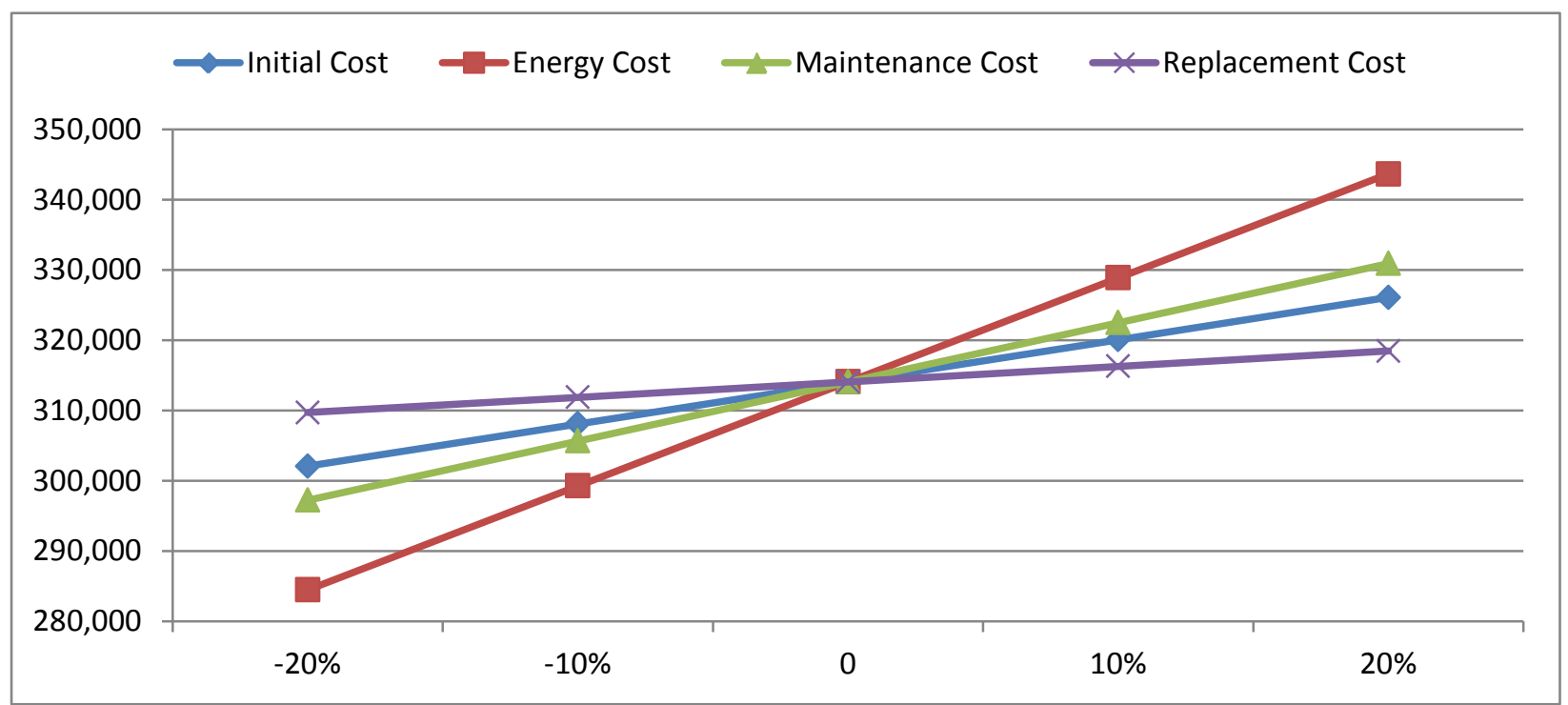

Figure 4-30: Sensitivity Analysis for Conventional System without Incentives 
Table 4-32 shows the results of ratio sensitivity analysis. Based on current data, it shows that to reverse the existing observation that the GSHP system has a smaller life cycle cost, the energy cost of the GSHP needs to increase $76 \%$ or the energy cost of the conventional system needs to decrease $52 \%$.

Table 4-32: Ratio Sensitivity Analysis

\begin{tabular}{|l|r|r|r|r|}
\hline & \multicolumn{1}{|c|}{ GSHP } & \multicolumn{1}{c|}{ GSHP } & Conventional & Conventional \\
\hline Initial Cost & 87,500 & $88 \%$ & 60,000 & $128 \%$ \\
\hline Electricity Price & 101,330 & $76 \%$ & 147,966 & $52 \%$ \\
\hline Maintenance Cost & 32,384 & $237 \%$ & 84,198 & $91 \%$ \\
\hline Replacement Cost & 15,981 & $481 \%$ & 21,923 & $351 \%$ \\
\hline Total & $\mathbf{2 3 7 , 1 9 5}$ & & $\mathbf{3 1 4 , 0 8 7}$ & \\
\hline
\end{tabular}

\section{BC1 Summary}

The case study shows that the application of GSHP has an obvious advantage over the conventional system even when incentives are not considered. For both systems, the energy cost is the most sensitive factor.

\subsubsection{Case Study - BC2}

\section{Cost data summary}

Tables 4-33 and 4-34 are a summary of cost data used for used by the life cycle cost analysis for this case study.

Table 4-33: Cost data for the GHSP System

\begin{tabular}{|c|c|c|c|c|c|c|c|c|c|}
\hline \multirow[b]{2}{*}{ ID } & \multirow{2}{*}{$\begin{array}{l}\text { Building } \\
\text { Size (sf) }\end{array}$} & \multirow{2}{*}{$\begin{array}{c}\text { System } \\
\text { Tonnage } \\
\text { (ton) }\end{array}$} & \multirow{2}{*}{$\begin{array}{c}\text { Life } \\
\text { Cycle } \\
\text { (year) }\end{array}$} & \multicolumn{6}{|c|}{ Geothermal System } \\
\hline & & & & $\begin{array}{l}\text { Initial } \\
\text { Cost } \\
(\$)\end{array}$ & $\begin{array}{c}\text { Tax } \\
\text { Credit } \\
(\$)\end{array}$ & $\begin{array}{c}\text { Utility } \\
\text { Rebate (\$) }\end{array}$ & $\begin{array}{c}\text { Maintenance } \\
\text { Cost (\$) }\end{array}$ & $\begin{array}{l}\text { Periodic } \\
\text { Cost (\$) }\end{array}$ & $\begin{array}{l}\text { Annual } \\
\text { Electricity } \\
\text { Cost (\$) }\end{array}$ \\
\hline BC2 & 4250 & 13 & 30 & 72,555 & 21,767 & 3,900 & 1,115 & 19,795 & 2,530 \\
\hline
\end{tabular}


Table 4-34: Cost data for the Conventional System

\begin{tabular}{|c|c|c|c|c|c|c|c|}
\hline \multirow{2}{*}{ ID } & \multirow{2}{*}{$\begin{array}{l}\text { Building } \\
\text { Size (sf) }\end{array}$} & \multirow{2}{*}{$\begin{array}{c}\text { System } \\
\text { Tonnage } \\
\text { (ton) }\end{array}$} & \multirow{2}{*}{$\begin{array}{l}\text { Life } \\
\text { Cycle } \\
\text { (year) }\end{array}$} & \multicolumn{4}{|c|}{ Conventional } \\
\hline & & & & $\begin{array}{r}\text { Initial } \\
\text { Cost (\$) }\end{array}$ & $\begin{array}{c}\text { Maintenance } \\
\text { Cost (\$) }\end{array}$ & $\begin{array}{l}\text { Periodic } \\
\text { Cost (\$) }\end{array}$ & $\begin{array}{c}\text { Annual Electricity } \\
\text { Cost (\$) }\end{array}$ \\
\hline BC2 & 4250 & 13 & 30 & 42,500 & 2,895 & 24,905 & 2,885 \\
\hline
\end{tabular}

\section{Life cycle cost analysis}

The net present value (NPV) of the GHSP system is presented in Table 4-35.

Table 4-35: Life Cycle Cost Analysis

\begin{tabular}{|c|c|c|c|c|}
\hline \multirow{2}{*}{ Year } & GSHP NPV & Conventional NPV & GSHP NPV & Conventional NPV \\
\cline { 2 - 5 } Total & 158,572 & 177,568 & 133,121 & 177,565 \\
(Mean) & & & & \\
\hline
\end{tabular}

. Data from Table 4-35 shows that the GSHP system has a smaller net present value than the conventional system before and after incentives. Figure 4-31 shows that, if without incentives, after about 16 years there is a positive cash flow in net present value for the GSHP system.

Figure 4-32 shows that there is a big overlap between the two distributions of life cycle cost. There are about $49.1 \%$ of the chances that the conventional system is actually more favorable based on the data we have. 


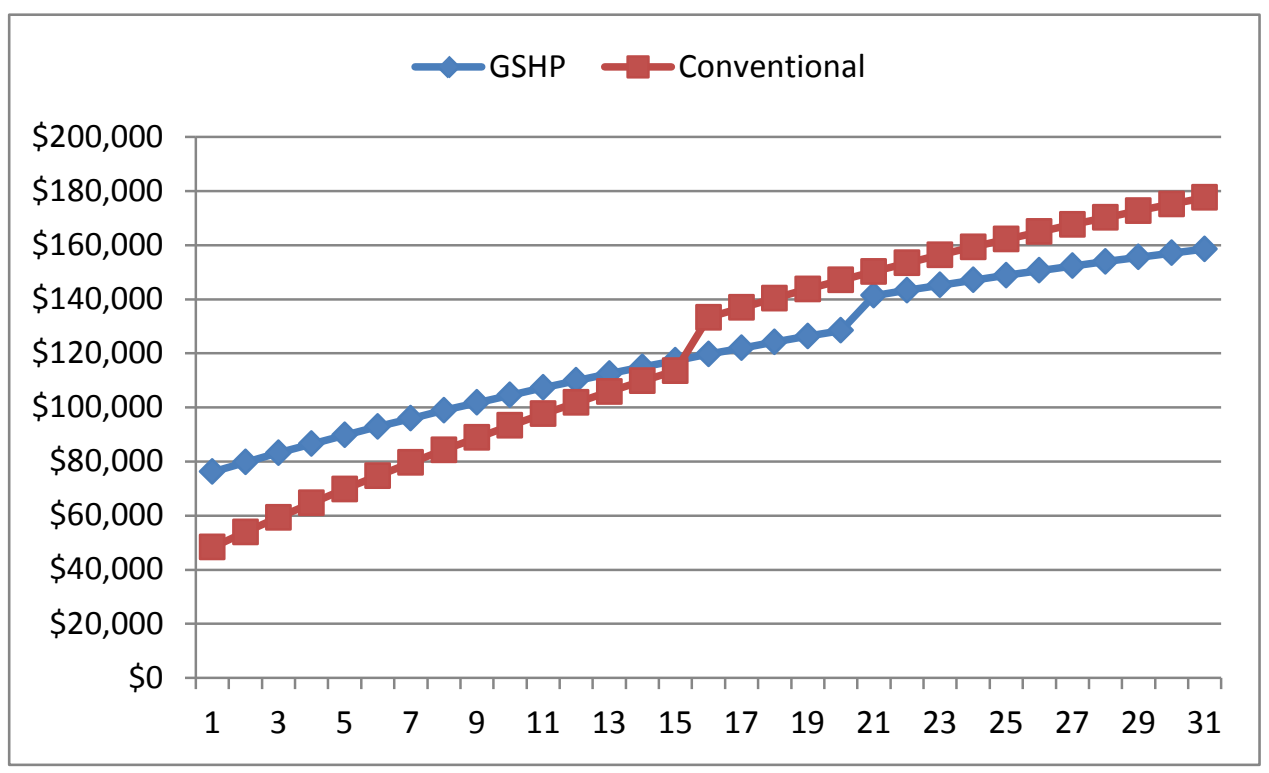

Figure 4-31: Cumulative Net Present Value Comparison of the Two Systems without Incentives

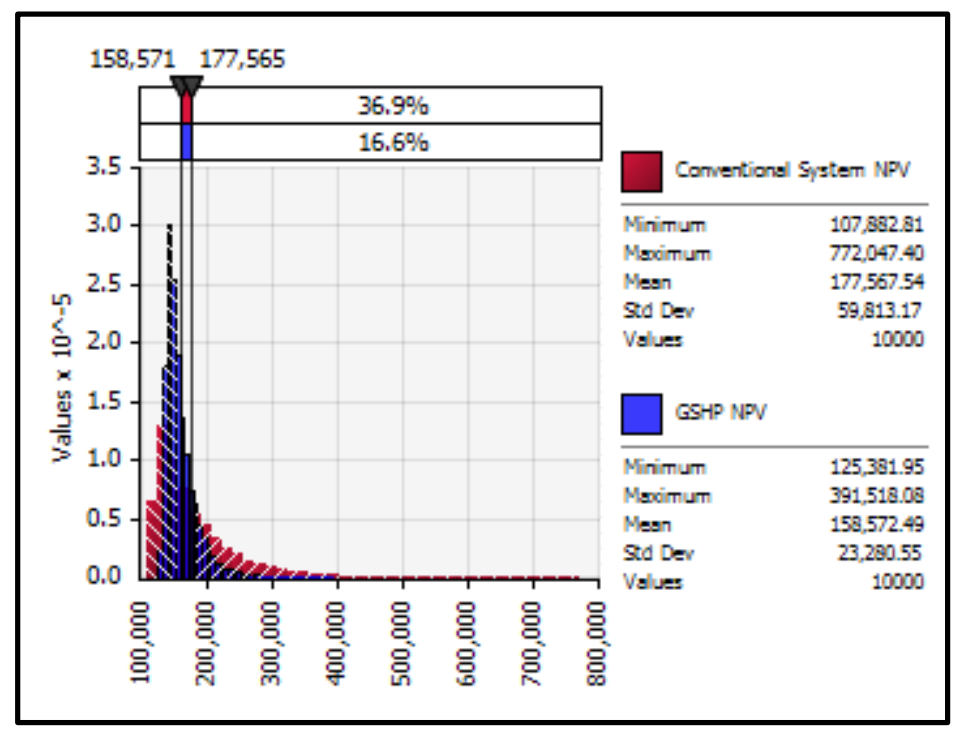

Figure 4-32: GSHP System vs. Conventional System without Incentives

When incentives are considered, the GSHP system becomes more favorable with a shorter payback time, which is around three years (Figure 4-33). In this case, the chance that the conventional system becomes more favorable is reduced to 22.6\% (Figure 4-34). 


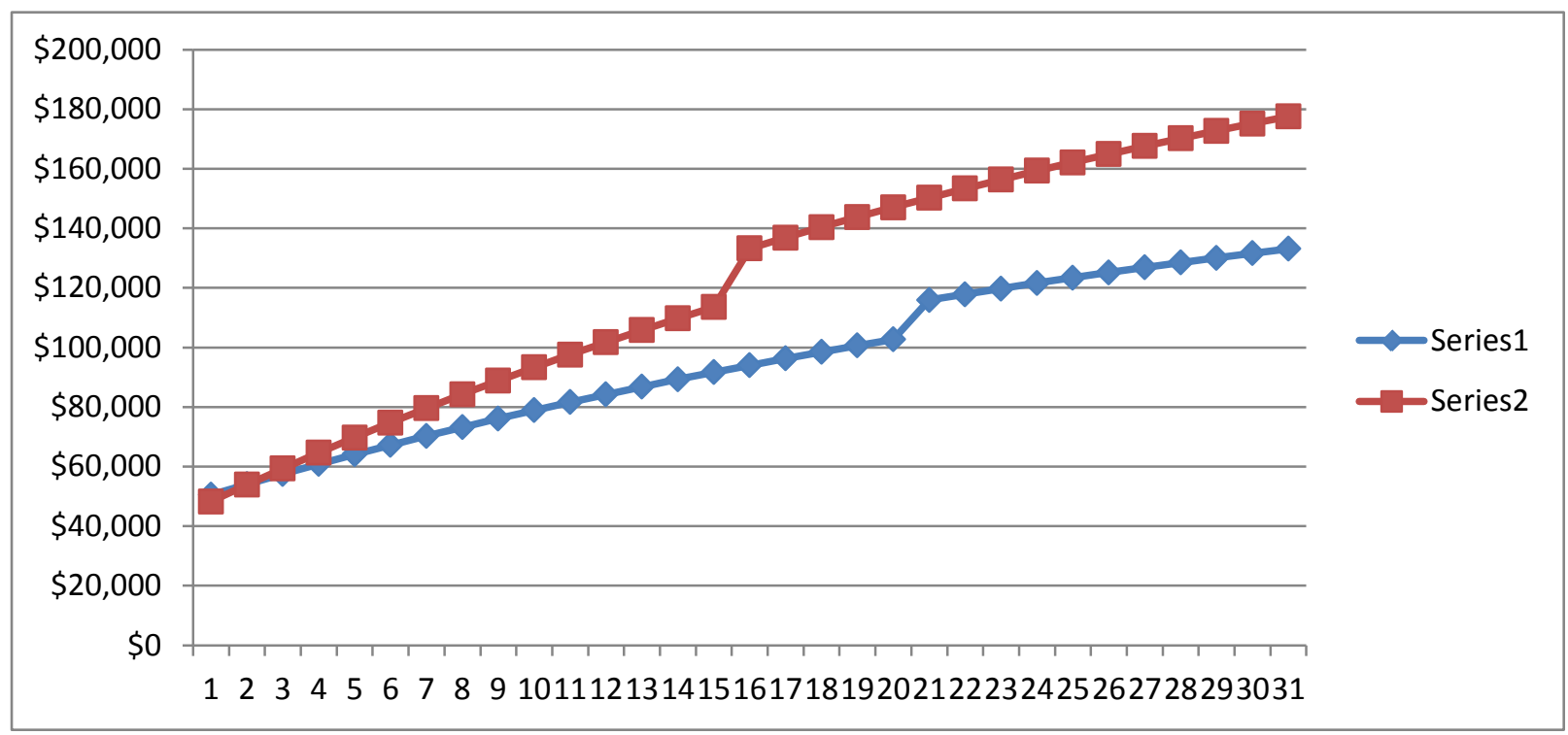

Figure 4-33: Cumulative Net Present Value Comparison of the Two Systems with Incentives

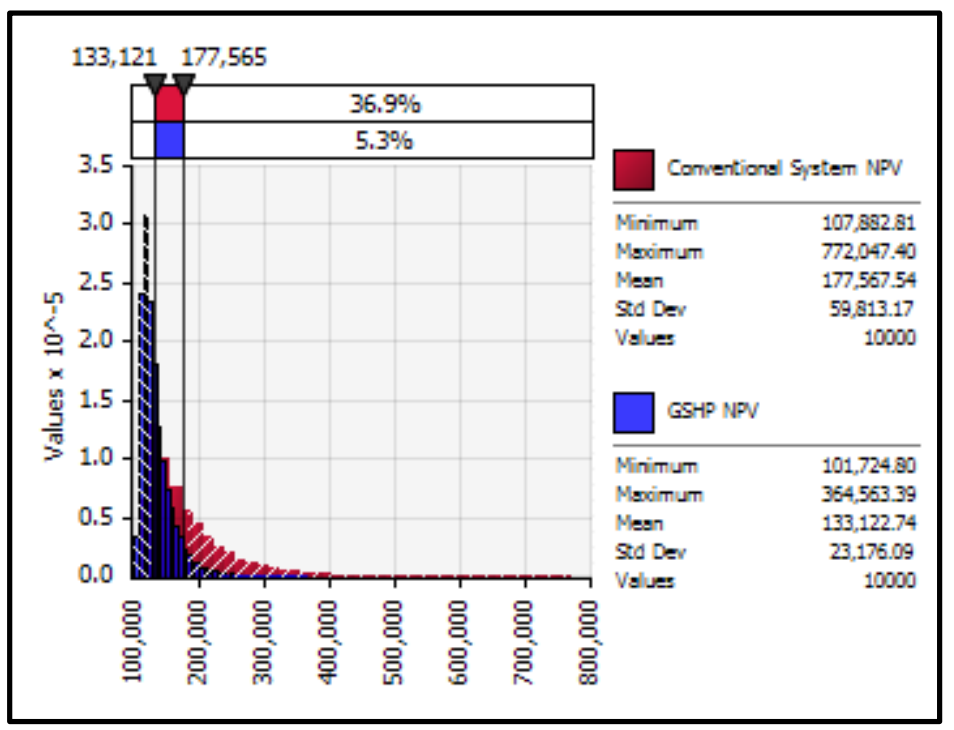

Figure 4-34: GSHP System vs. Conventional System with Incentives

\section{Sensitivity analysis}

Figures 4-35 and 4-36 show the results of sensitivity analysis for the GSHP and the conventional systems respectively. For the GSHP system, initial cost is the most sensitivity cost factor, followed by energy cost; while for the conventional system, energy cost and maintenance cost are the most sensitive cost factors, which are closely followed by the initial cost. 


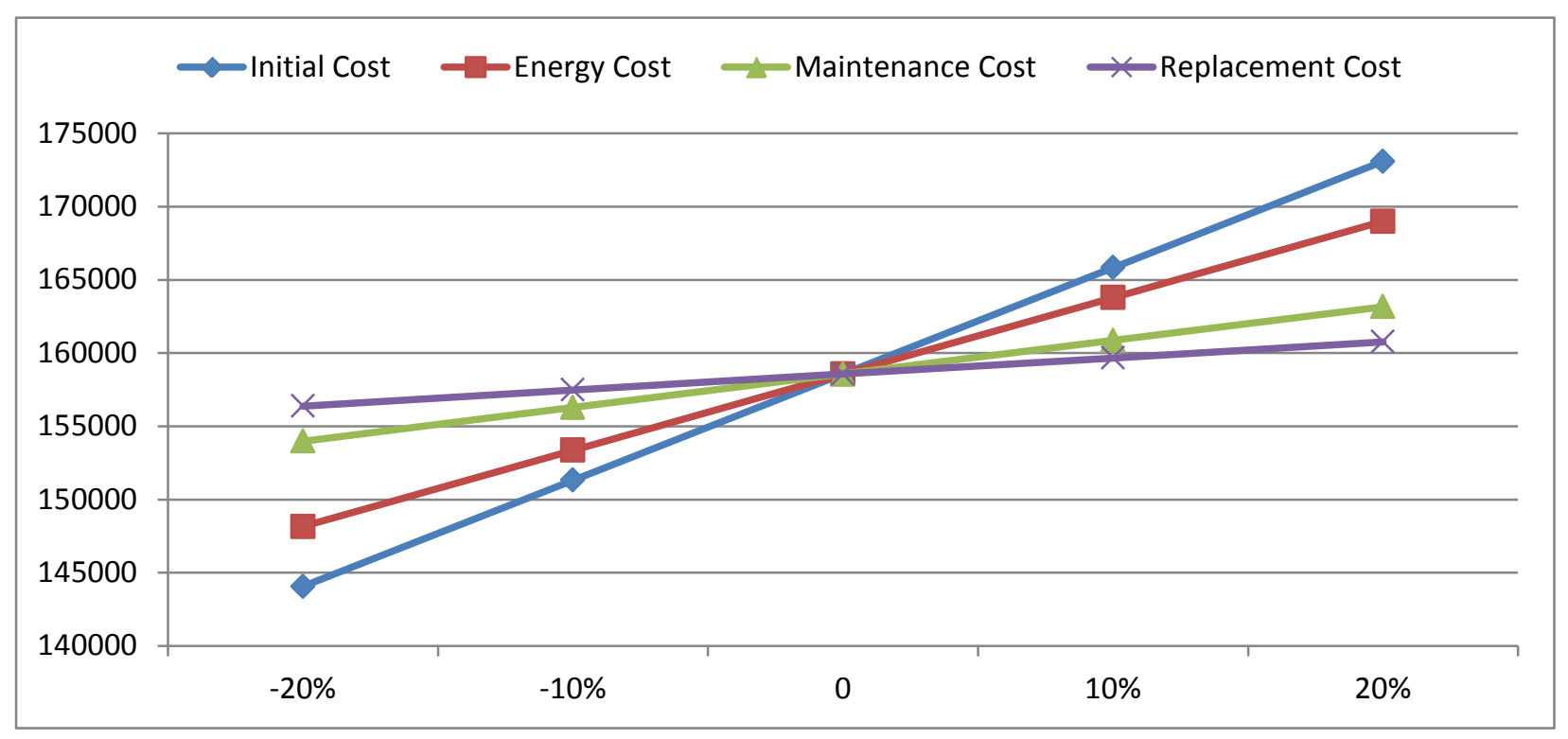

Figure 4-35: Sensitivity Analysis for GSHP without Incentives

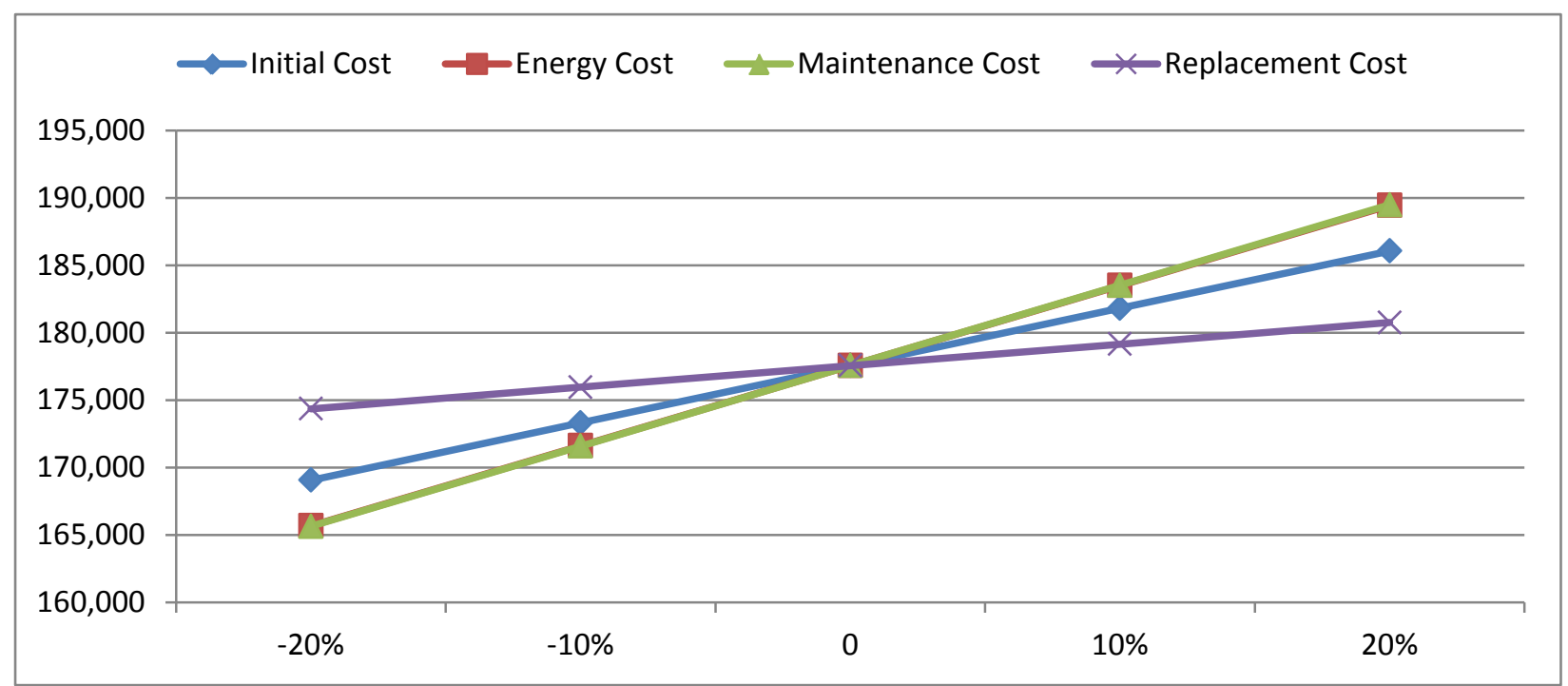

Figure 4-36: Sensitivity Analysis for Conventional System without Incentives

Table 4-36 shows the results of ratio sensitivity analysis. Based on current data, it shows that to reverse the existing observation that the GSHP system has a smaller life cycle cost, the initial cost of the GSHP needs to increase $26 \%$ or the energy cost or maintenance 
cost of the conventional system needs to decrease 32\%. In addition, the energy cost of GSHP and the initial cost of the conventional system are also very sensitive.

Table 4-36: Ratio Sensitivity Analysis

\begin{tabular}{|l|r|r|r|r|}
\hline & \multicolumn{1}{|c|}{ GSHP } & \multicolumn{1}{c|}{ GSHP } & Conventional & Conventional \\
\hline Initial Cost & 72,555 & $26 \%$ & 42,500 & $45 \%$ \\
\hline Electricity Price & 52,117 & $36 \%$ & 59,438 & $32 \%$ \\
\hline Maintenance Cost & 22,939 & $83 \%$ & 59,640 & $32 \%$ \\
\hline Replacement Cost & 10,960 & $173 \%$ & 15,986 & $119 \%$ \\
\hline Total & $\mathbf{1 5 8 , 5 7 1}$ & & $\mathbf{1 7 7 , 5 6 5}$ & \\
\hline
\end{tabular}

\section{BC2 Summary}

The case study shows that the GSHP option has a better life cycle cost than the conventional system even when incentives are not considered. The incentives made the GSHP option more favorable and significantly reduced payback time.

\subsubsection{Case Study - BC3}

\section{Cost data summary}

Tables 4-37 and 4-38 are a summary of cost data used for used by the life cycle cost analysis for this case study.

Table 4-37: Cost data for the GHSP System

\begin{tabular}{|c|c|c|c|c|c|c|c|c|c|}
\hline \multirow[b]{2}{*}{ ID } & \multirow{2}{*}{$\begin{array}{l}\text { Building } \\
\text { Size (sf) }\end{array}$} & \multirow{2}{*}{$\begin{array}{c}\text { System } \\
\text { Tonnage } \\
\text { (ton) }\end{array}$} & \multirow{2}{*}{$\begin{array}{l}\text { Life } \\
\text { Cycle } \\
\text { (year) }\end{array}$} & \multicolumn{6}{|c|}{ Geothermal System } \\
\hline & & & & $\begin{array}{l}\text { Initial } \\
\text { Cost (\$) }\end{array}$ & $\begin{array}{c}\text { Tax } \\
\text { Credit } \\
(\$)\end{array}$ & $\begin{array}{c}\text { Utility } \\
\text { Rebate (\$) }\end{array}$ & $\begin{array}{c}\text { Maintenance } \\
\text { Cost (\$) }\end{array}$ & $\begin{array}{l}\text { Periodic } \\
\text { Cost }(\$)\end{array}$ & $\begin{array}{c}\text { Annual } \\
\text { Electricity } \\
\text { Cost (\$) }\end{array}$ \\
\hline BC3 & 13,600 & 129 & 30 & 538,148 & 161,444 & 38,700 & 3,563 & 216,186 & 19,180 \\
\hline
\end{tabular}


Table 4-38: Cost data for the Conventional System

\begin{tabular}{|c|c|c|c|c|c|c|c|}
\hline \multirow{2}{*}{ ID } & \multirow{2}{*}{$\begin{array}{l}\text { Building } \\
\text { Size (sf) }\end{array}$} & \multirow{2}{*}{$\begin{array}{c}\text { System } \\
\text { Tonnage } \\
\text { (ton) }\end{array}$} & \multirow{2}{*}{$\begin{array}{l}\text { Life } \\
\text { Cycle } \\
\text { (year) }\end{array}$} & \multicolumn{4}{|c|}{ Conventional } \\
\hline & & & & $\begin{array}{c}\text { Initial } \\
\text { Cost (\$) }\end{array}$ & $\begin{array}{c}\text { Maintenance } \\
\text { Cost (\$) }\end{array}$ & $\begin{array}{l}\text { Periodic } \\
\text { Cost (\$) }\end{array}$ & $\begin{array}{l}\text { Annual Electricity } \\
\text { Cost (\$) }\end{array}$ \\
\hline BC3 & 13,600 & 129 & 30 & 340,000 & 9,264 & 648,786 & 21,133 \\
\hline
\end{tabular}

\section{Life cycle cost analysis}

The net present value (NPV) of the GHSP system is presented in Table 4-39.

Table 4-39: Life Cycle Cost Analysis

\begin{tabular}{|c|c|c|c|c|}
\hline \multirow{2}{*}{ Year } & \multicolumn{2}{|c|}{ Without Incentive } & \multicolumn{2}{c|}{ With Incentive } \\
\cline { 2 - 5 } Total & GSHP NPV & Conventional NPV & GSHP NPV & Conventional NPV \\
(Mean) & $1,126,370$ & $1,382,631$ & 961,025 & $1,382,631$ \\
\hline
\end{tabular}

Data from Table 4-39 shows that the GSHP system has a smaller net present value than the conventional system regardless of incentives. Figure 4-37 shows that after the $16^{\text {th }}$ year the GSHP system start to show positive cash flow without incentive. Also, based on the data used for analysis, the probability that the conventional system becomes more economically favorable is negligible (Figure 4-38). 


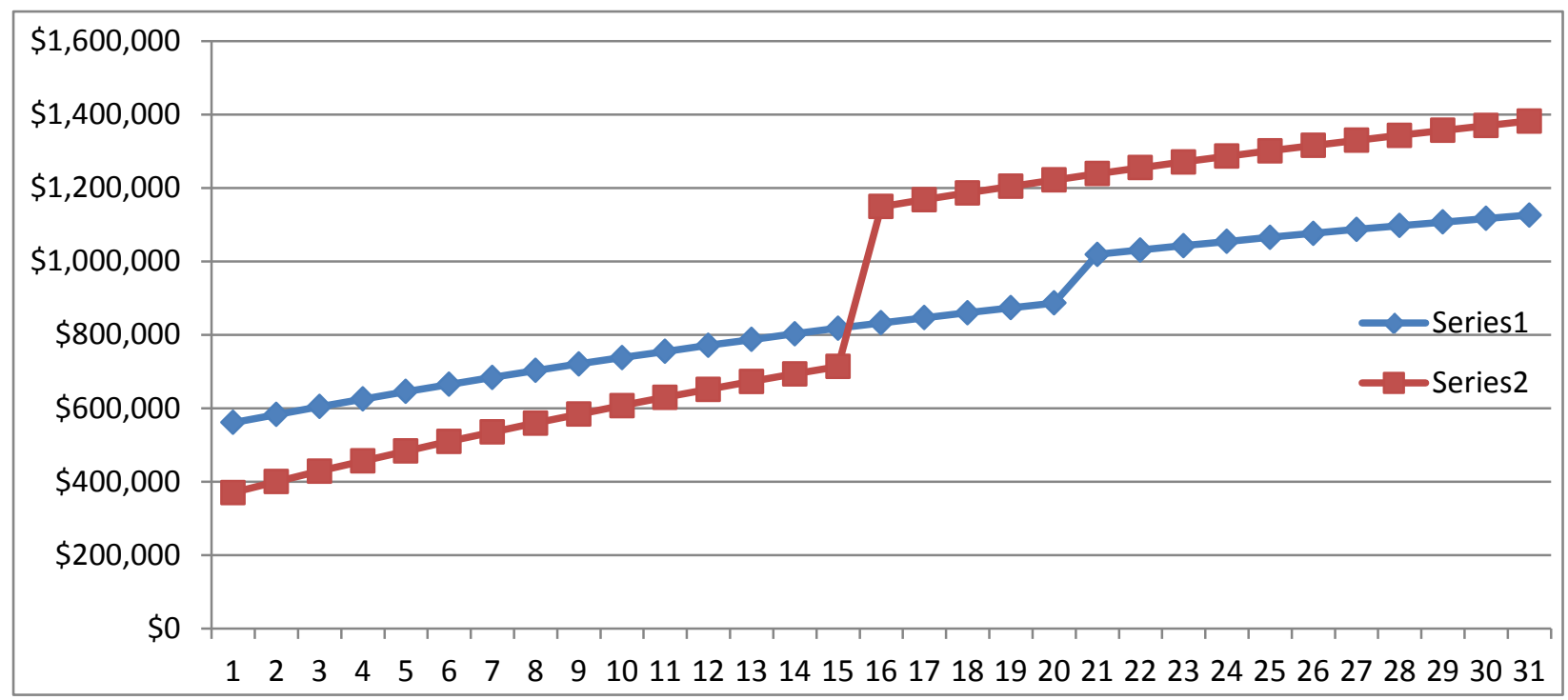

Figure 4-37: Cumulative Net Present Value Comparison of the Two Systems without Incentives

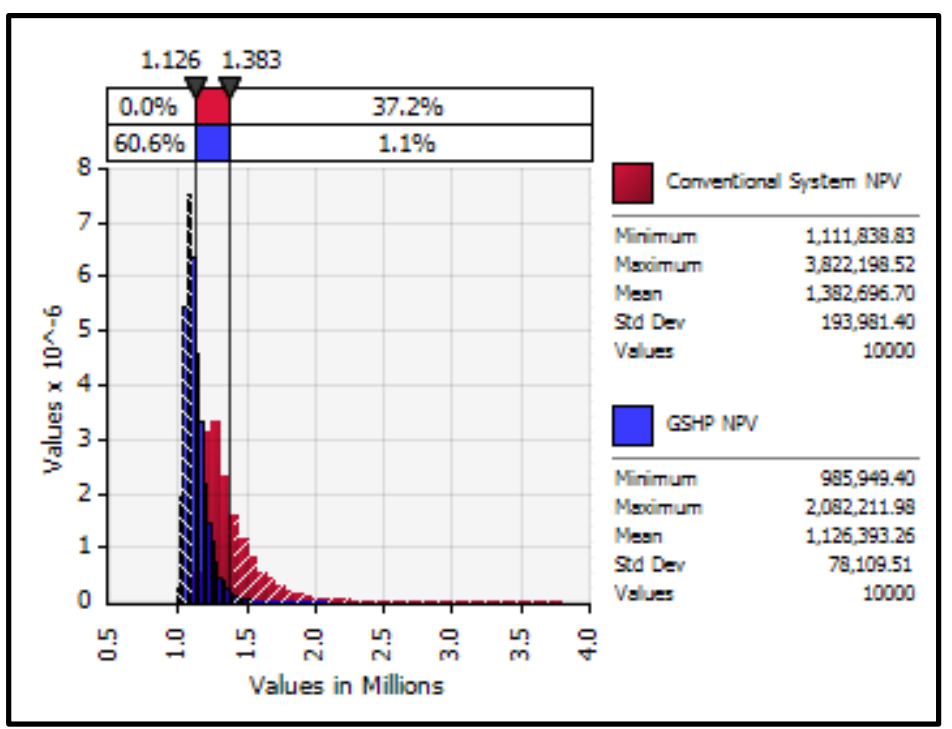

Figure 4-38: GSHP System vs. Conventional System without Incentives

If incentives are considered, the payback time is shortened to 5 years (Figure 4-39) and the probability for the conventional system to become more favorable is also negligible (Figure 4-40). 


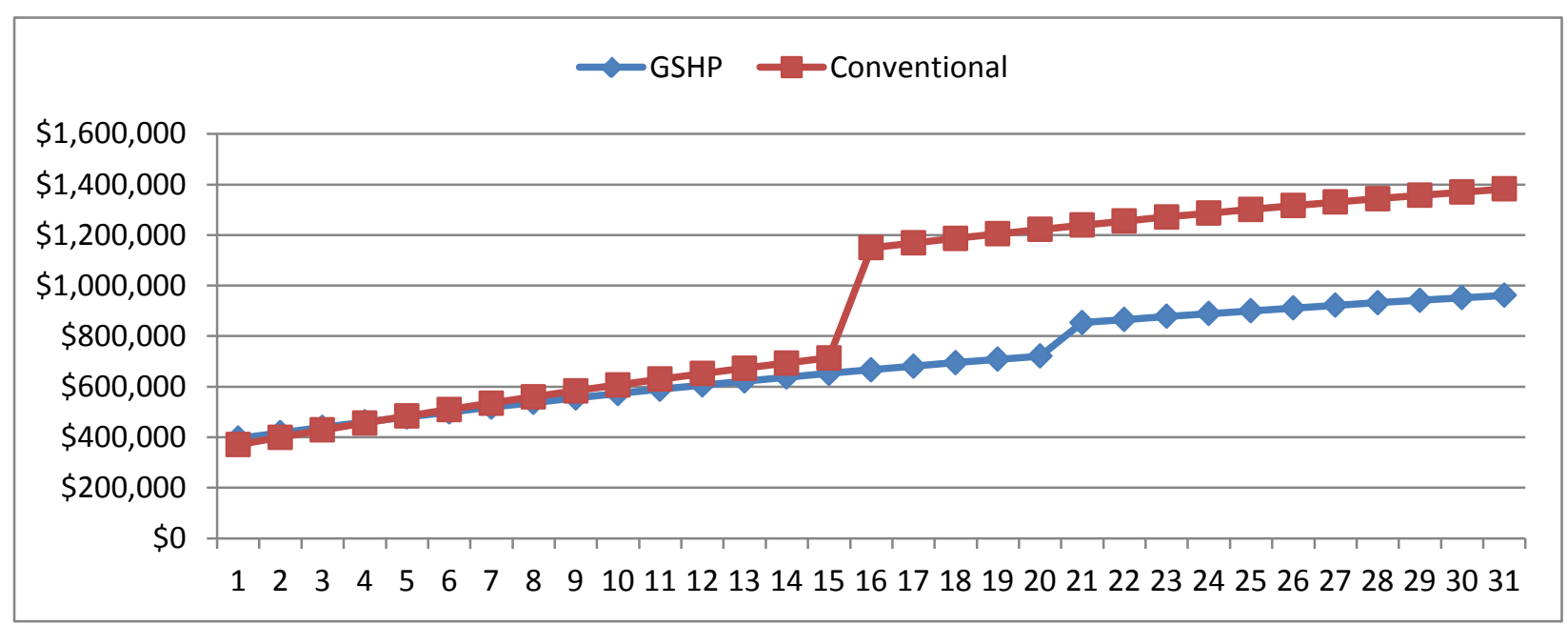

Figure 4-39: Cumulative Net Present Value Comparison of the Two Systems with Incentives

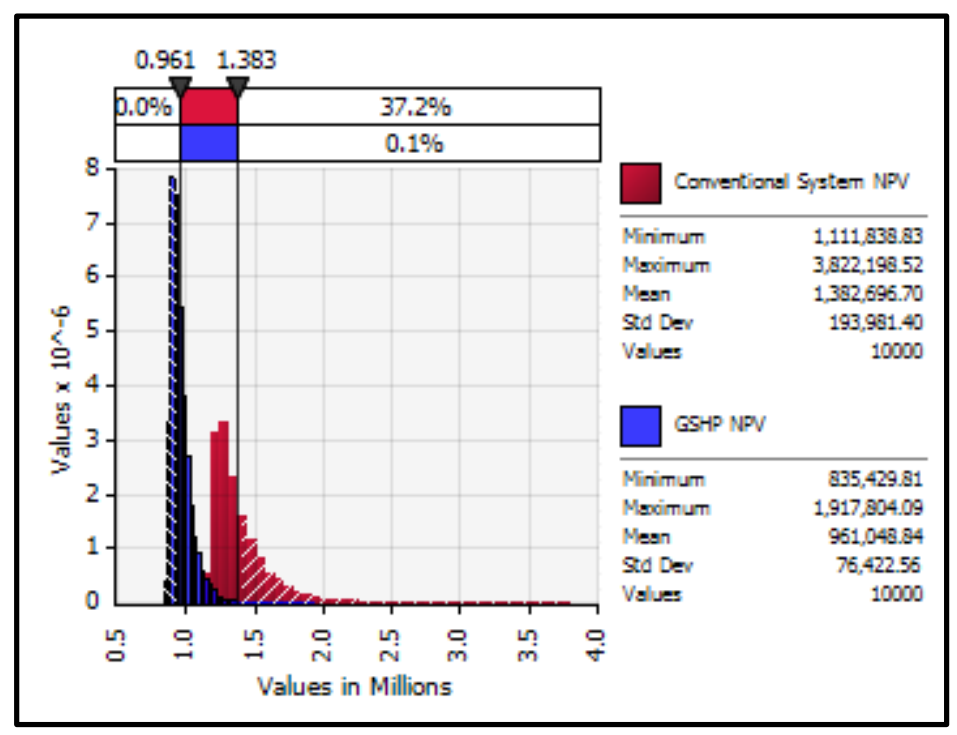

Figure 4-40: GSHP System vs. Conventional System with Incentives

\section{Sensitivity analysis}

Figures 4-41 and 4-42 show the results of sensitivity analysis for the GSHP and the conventional systems respectively. For the GSHP system, initial cost is the most sensitivity cost factor, followed by energy cost; while for the conventional system, energy cost is the most sensitive cost factor which is closely followed by the replacement cost. 


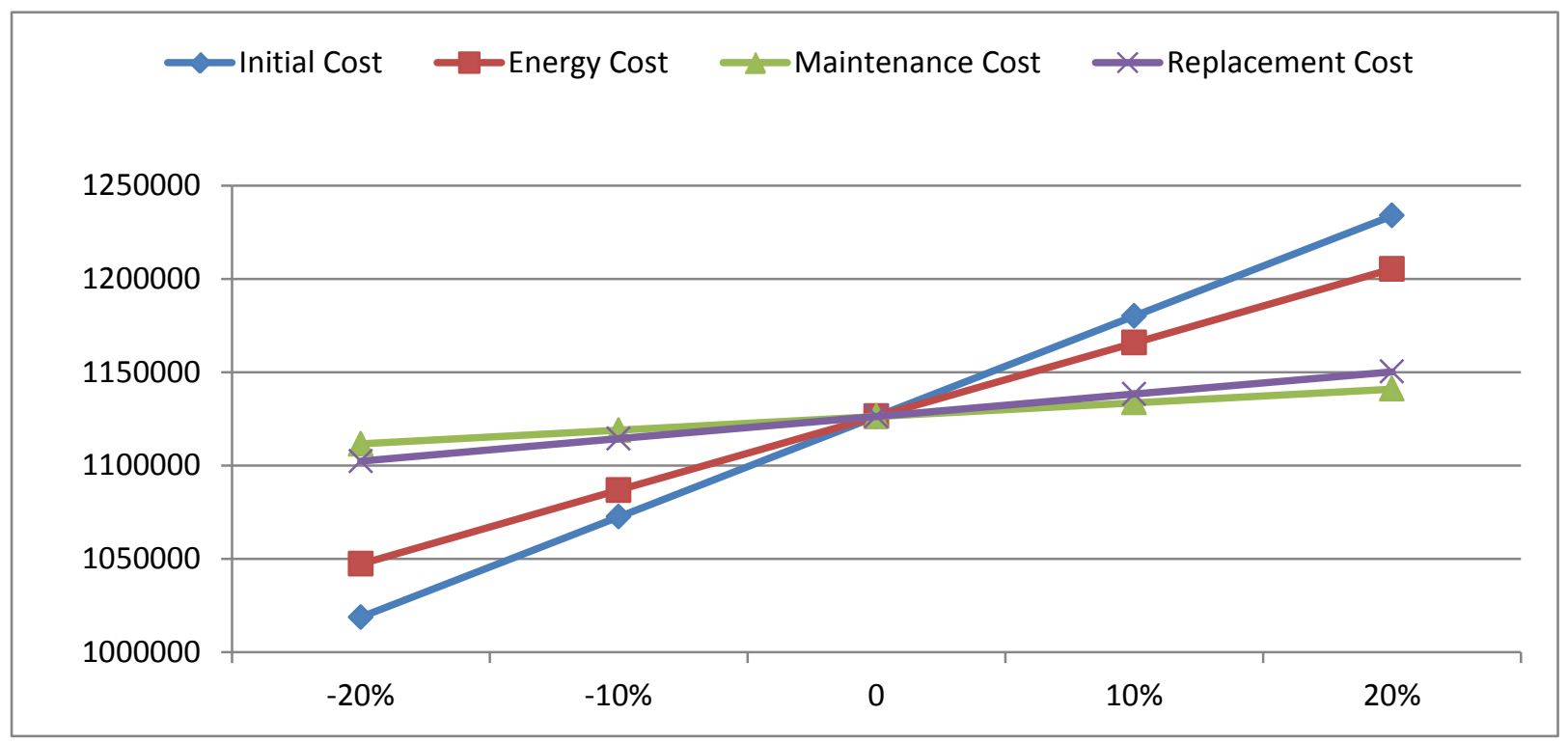

Figure 4-41: Sensitivity Analysis for GSHP without Incentives

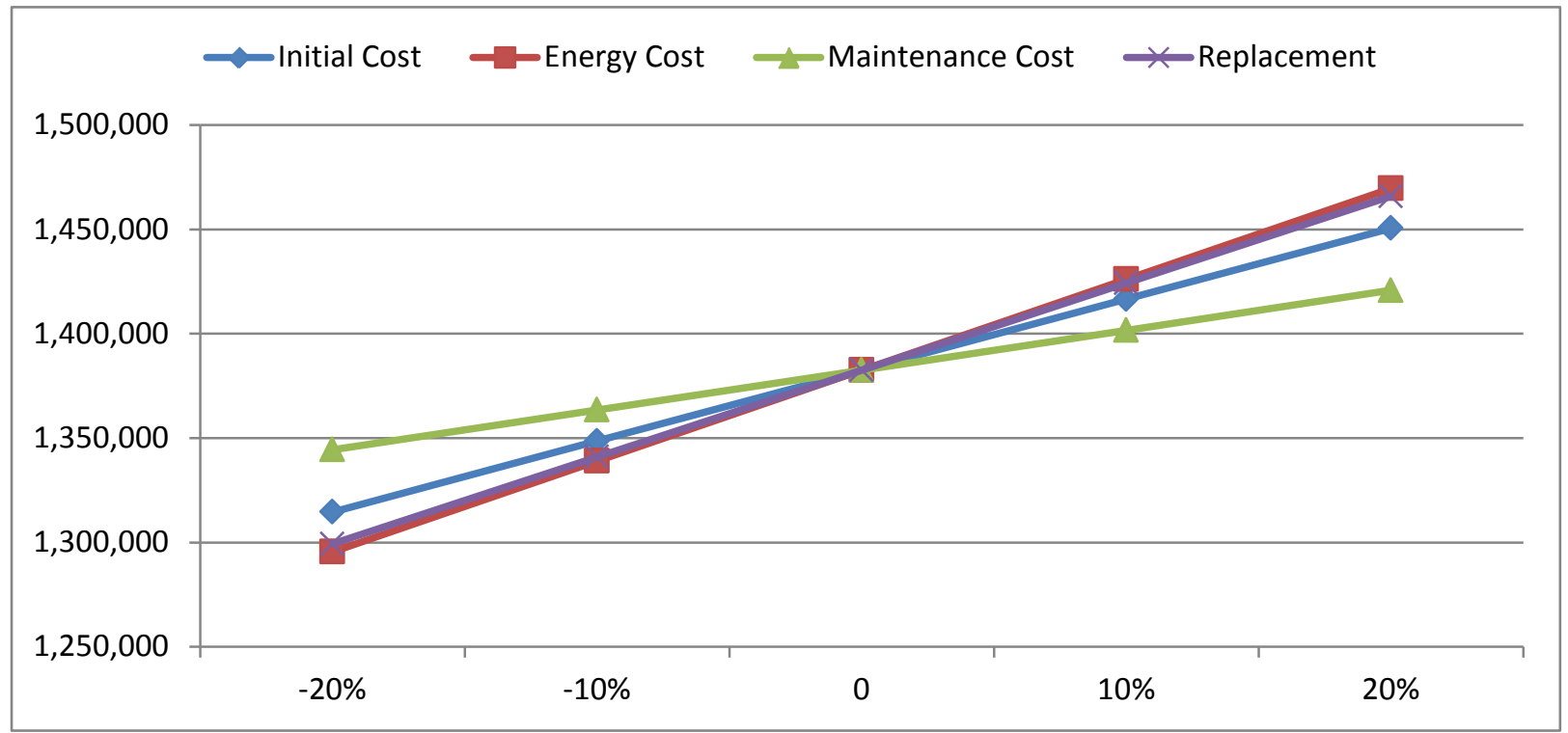

Figure 4-42: Sensitivity Analysis for Conventional System

Table 4-40 shows the results of ratio sensitivity analysis. Based on current data, it shows that to reverse the existing observation that the GSHP system has a smaller life cycle cost, the initial cost of the GSHP needs to decrease $48 \%$ or the energy cost of the conventional system needs to increase 59\%. 
Table 4-40: Ratio Sensitivity Analysis

\begin{tabular}{|l|r|r|r|r|}
\hline & \multicolumn{1}{|c|}{ GSHP } & GSHP & Conventional & Conventional \\
\hline Initial Cost & 538,148 & $48 \%$ & 340,000 & $75 \%$ \\
\hline Electricity Price & 395,125 & $65 \%$ & 435,351 & $59 \%$ \\
\hline Maintenance Cost & 73,403 & $349 \%$ & 190,849 & $134 \%$ \\
\hline Replacement Cost & 119,694 & $214 \%$ & 416,431 & $62 \%$ \\
\hline Total & $\mathbf{1 , 1 2 6 , 3 7 0}$ & & $\mathbf{1 , 3 8 2 , 6 3 1}$ & \\
\hline
\end{tabular}

\section{BC3 Summary}

The case study showed a result clearly in favor of the GSHP option. In addition, the data used for analysis have a strong support for that observation. The sensitive analysis also showed that the cost elements were not highly sensitive.

\subsubsection{Case Study - BC4}

\section{Cost data summary}

Tables 4-41 and 4-42 are a summary of cost data used for used by the life cycle cost analysis for this case study.

Table 4-41: Cost data for the GHSP System

\begin{tabular}{|c|c|c|c|c|c|c|c|c|c|}
\hline \multirow[b]{2}{*}{ ID } & \multirow{2}{*}{$\begin{array}{l}\text { Building } \\
\text { Size (sf) }\end{array}$} & \multirow{2}{*}{$\begin{array}{c}\text { System } \\
\text { Tonnage } \\
\text { (ton) }\end{array}$} & \multirow{2}{*}{$\begin{array}{l}\text { Life } \\
\text { Cycle } \\
\text { (year) }\end{array}$} & \multicolumn{6}{|c|}{ Geothermal System } \\
\hline & & & & $\begin{array}{l}\text { Initial } \\
\text { Cost (\$) }\end{array}$ & $\begin{array}{c}\text { Tax } \\
\text { Credit } \\
(\$)\end{array}$ & $\begin{array}{c}\text { Utility } \\
\text { Rebate (\$) }\end{array}$ & $\begin{array}{c}\text { Maintenance } \\
\text { Cost (\$) }\end{array}$ & $\begin{array}{l}\text { Periodic } \\
\text { Cost }(\$)\end{array}$ & $\begin{array}{c}\text { Annual } \\
\text { Electricity } \\
\text { Cost (\$) }\end{array}$ \\
\hline BC4 & 80,145 & 340 & 30 & 874,900 & 262,470 & 102000 & 20,988 & 425,463 & 47,390 \\
\hline
\end{tabular}


Table 4-42: Cost data for the Conventional System

\begin{tabular}{|c|c|c|c|c|c|c|c|}
\hline \multirow{2}{*}{ ID } & \multirow{2}{*}{$\begin{array}{l}\text { Building } \\
\text { Size (sf) }\end{array}$} & \multirow{2}{*}{$\begin{array}{c}\text { System } \\
\text { Tonnage } \\
\text { (ton) }\end{array}$} & \multirow{2}{*}{$\begin{array}{l}\text { Life } \\
\text { Cycle } \\
\text { (year) }\end{array}$} & \multicolumn{4}{|c|}{ Conventional } \\
\hline & & & & $\begin{array}{l}\text { Initial } \\
\text { Cost (\$) }\end{array}$ & $\begin{array}{c}\text { Maintenance } \\
\text { Cost (\$) }\end{array}$ & $\begin{array}{l}\text { Periodic } \\
\text { Cost (\$) }\end{array}$ & $\begin{array}{l}\text { Annual Electricity } \\
\qquad \text { Cost (\$) }\end{array}$ \\
\hline BC4 & 80,145 & 340 & 30 & 801450 & 54,595 & 772,071 & 50,259 \\
\hline
\end{tabular}

\section{Life cycle cost analysis}

The net present value (NPV) of the GHSP system is presented in Table 4-43.

Table 4-43: Life Cycle Cost Analysis

\begin{tabular}{|c|c|c|c|c|}
\hline \multirow{2}{*}{ Year } & \multicolumn{2}{|c|}{ Without Incentive } & \multicolumn{2}{c|}{ With Incentive } \\
\cline { 2 - 5 } & GSHP NPV & Conventional NPV & GSHP NPV & Conventional NPV \\
\hline Total & $2,529,348$ & $3,457,207$ & $2,252,921$ & $3,457,041$ \\
(Mean) & & & & \\
\hline
\end{tabular}

Data from Table 4-43 shows that the GSHP system has a smaller net present value than the conventional system regardless of incentives. Figure 4-43 shows that after the third year the GSHP system start to show positive cash flow without incentive. The comparison of the distributions of the two life cycle cost shows that there are about $15 \%$ changes that the conventional system will become more favorable.

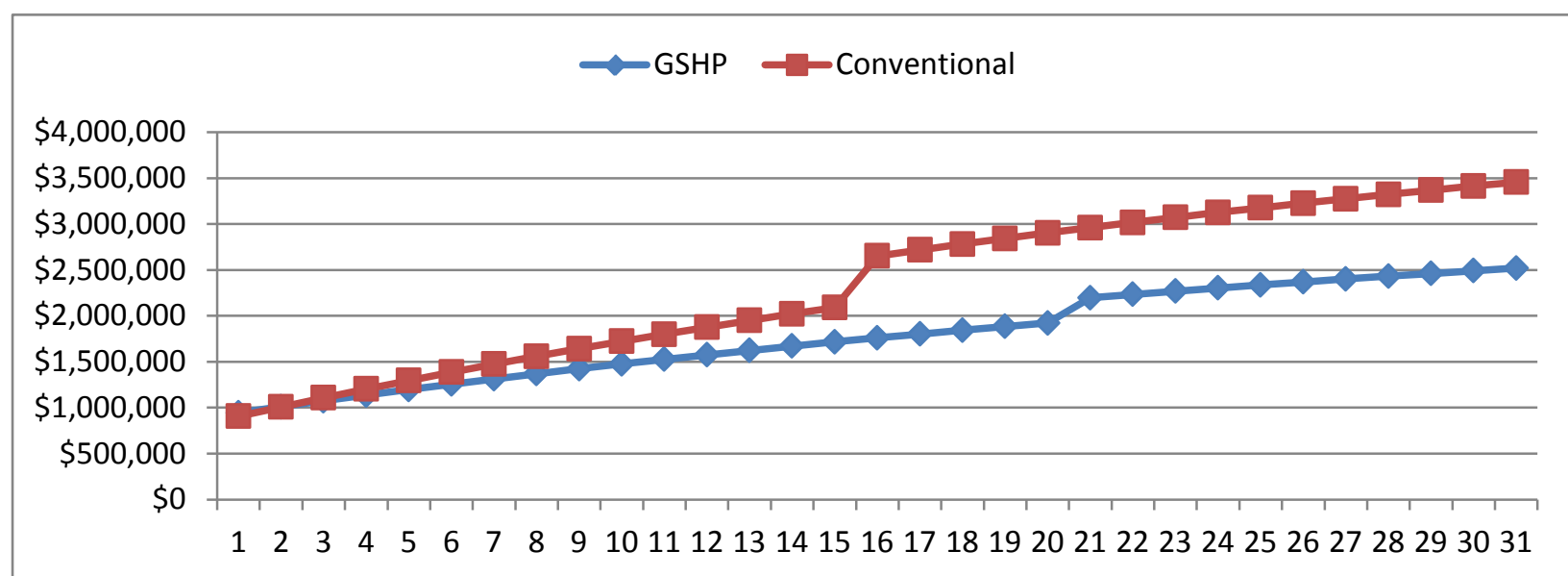

Figure 4-43: Cumulative Net Present Value Comparison of the Two Systems without Incentives 


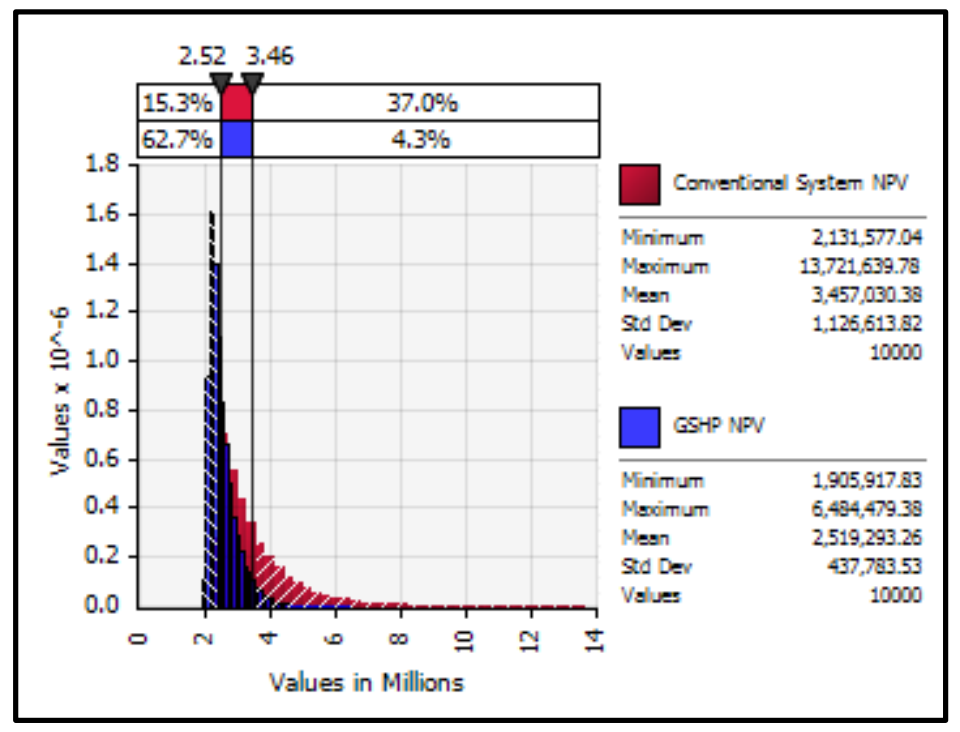

Figure 4-44: GSHP System vs. Conventional System without Incentives

If incentives are considered, the payback time is shortened to zero years (Figure 445). In addition, the chance for the conventional system to be more favorable is reduced to negligible (Figure 4-46).

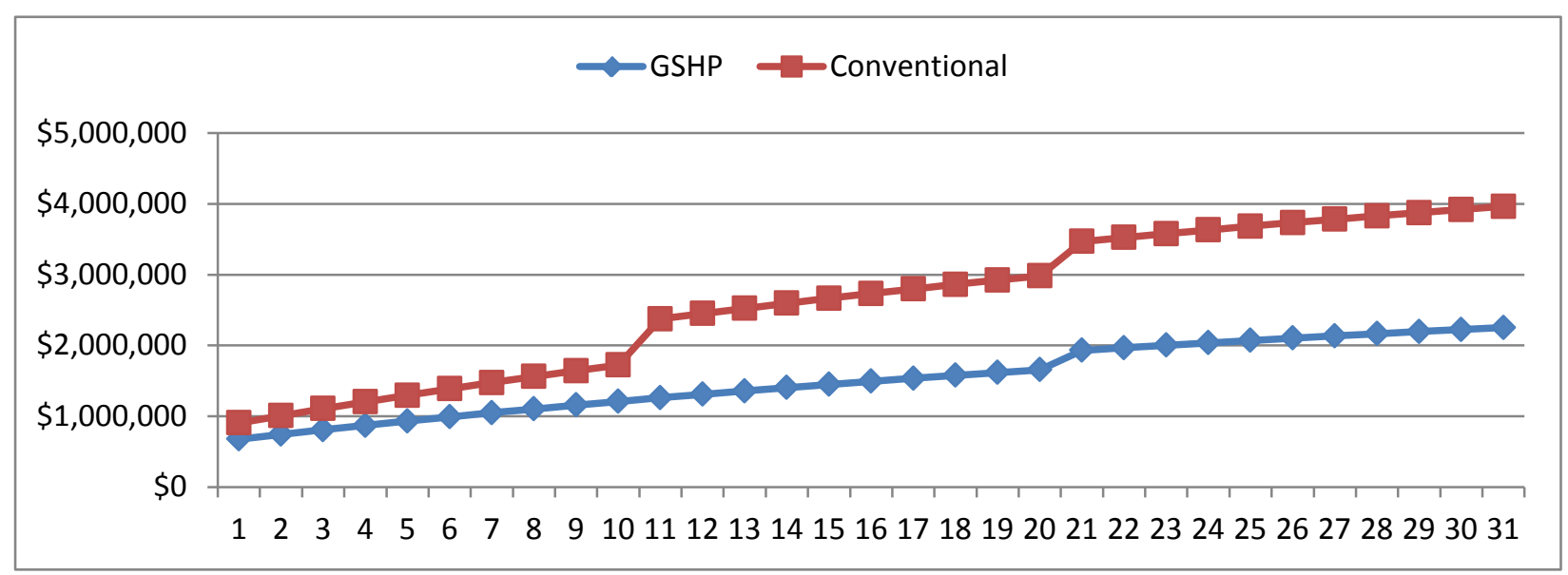

Figure 4-45: Cumulative Net Present Value Comparison of the Two Systems with Incentives 


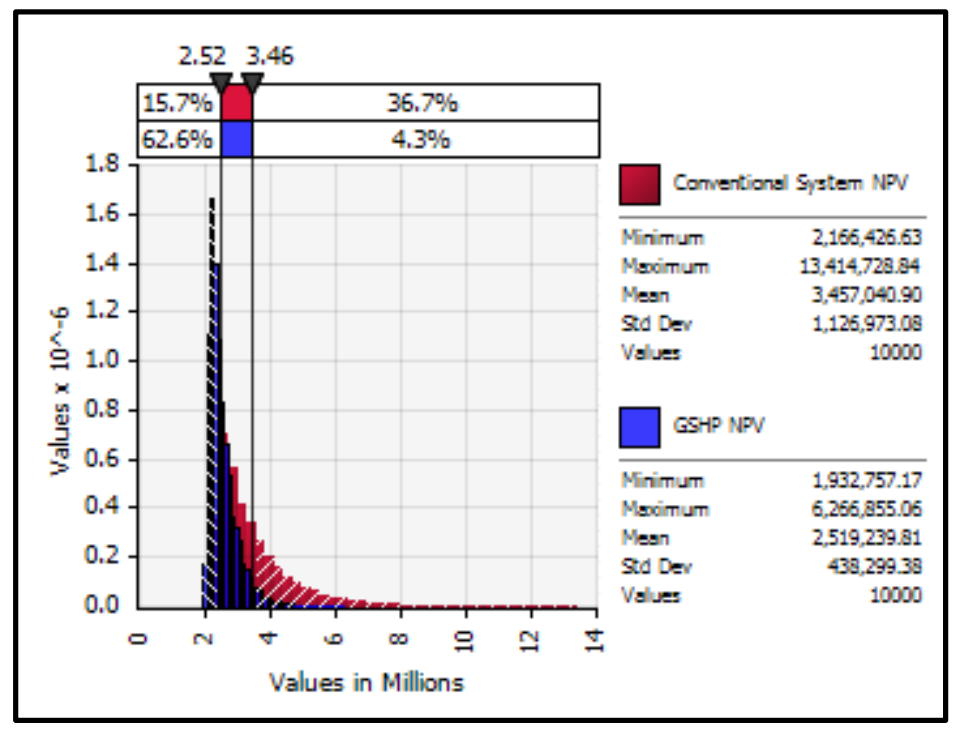

Figure 4-46: GSHP System vs. Conventional System with Incentives

\section{Sensitivity analysis}

Figures 4-47 and 4-48 show the results of sensitivity analysis for the GSHP and the conventional systems respectively. For the GSHP system, energy cost is the most sensitivity cost factor, closely followed by initial cost; while for the conventional system, maintenance cost is the most sensitive cost factor which is closely followed by the energy cost.

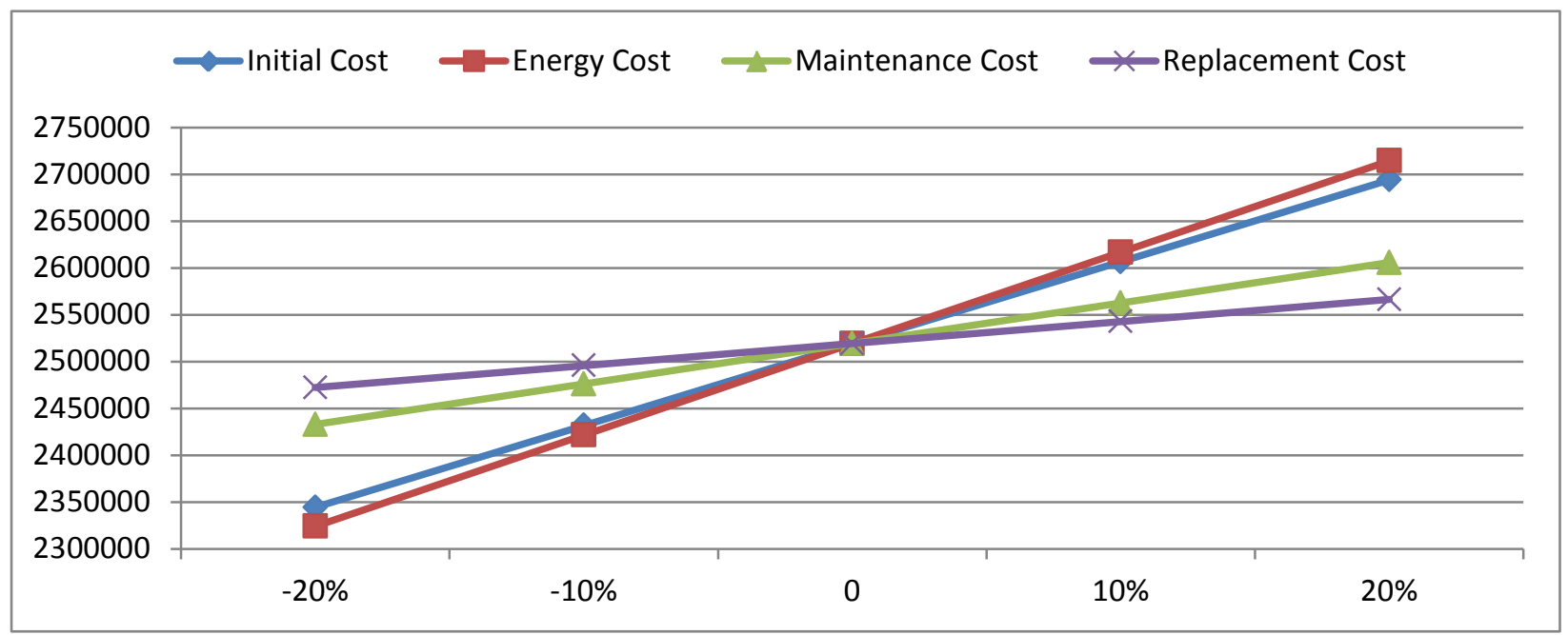

Figure 4-47: Sensitivity Analysis for GSHP without Incentives 


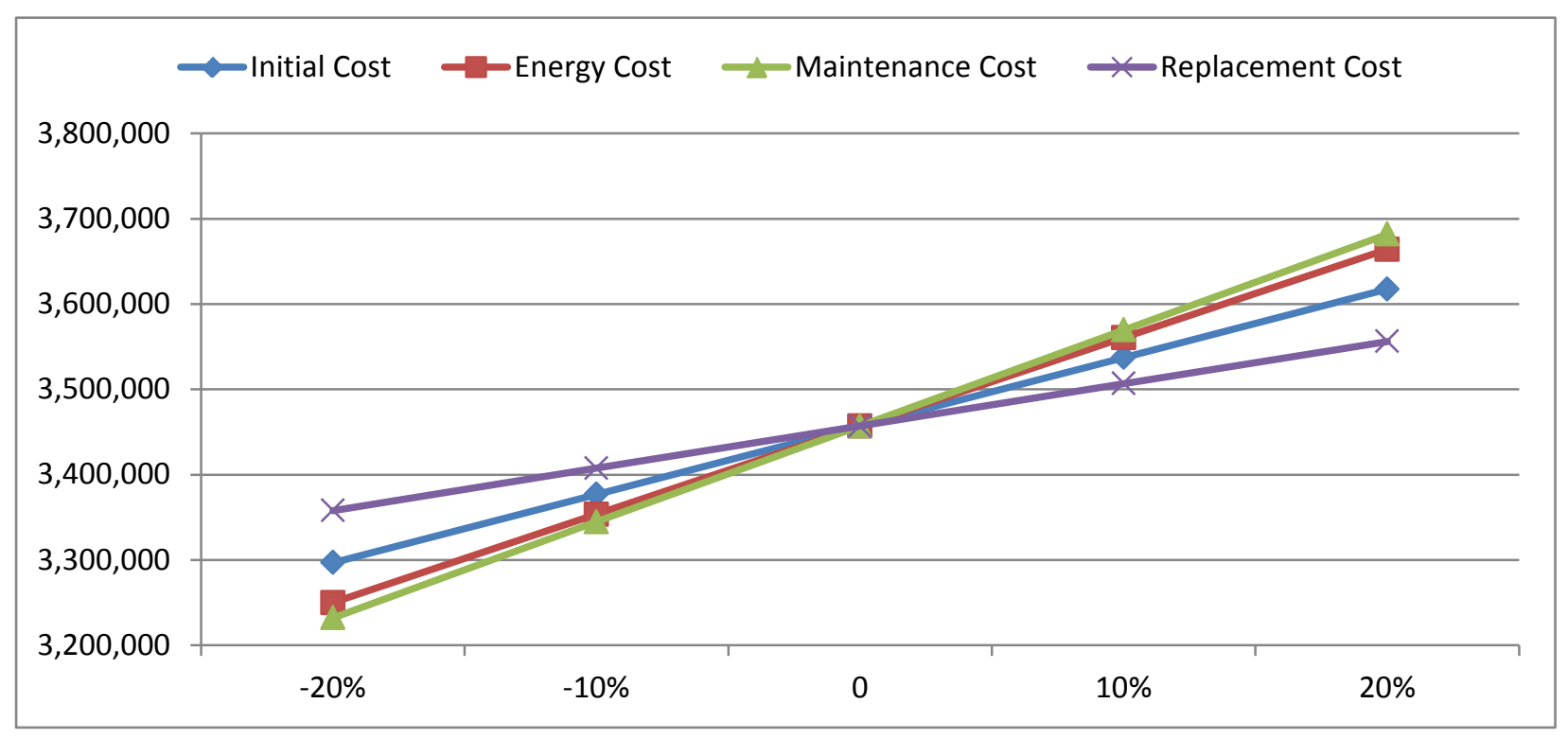

Figure 4-48: Sensitivity Analysis for Conventional System

Table 4-44 shows the results of ratio sensitivity analysis. Based on current data, it shows that to reverse the existing observation that the GSHP system has a smaller life cycle cost, the initial cost of the GSHP needs to decrease $48 \%$ or the energy cost of the conventional system needs to increase $59 \%$.

Table 4-44: Ratio Sensitivity Analysis

\begin{tabular}{|l|r|r|r|r|}
\hline & \multicolumn{1}{c|}{ GSHP } & \multicolumn{1}{c|}{ GSHP } & Conventional & Conventional \\
\hline Initial Cost & 874,900 & $107 \%$ & 801,450 & $11 \%$ \\
\hline Electricity Price & 976,255 & $96 \%$ & $1,035,351$ & $91 \%$ \\
\hline Maintenance Cost & 432,568 & $217 \%$ & $1,124,676$ & $83 \%$ \\
\hline Replacement Cost & 235,569 & $398 \%$ & 495,563 & $189 \%$ \\
\hline Total & $\mathbf{2 , 5 1 9 , 2 9 1}$ & & $\mathbf{3 , 4 5 7 , 0 4 1}$ & \\
\hline
\end{tabular}




\section{BC4 Summary}

The case study demonstrated that the GSHP option was more favorable than the conventional system. This observation was supported by data, especially when incentives were considered.

\subsection{Conclusions}

The case studies show that the application of GSHP systems to residential buildings is more uncertain than commercial or office buildings. This may be because the initial costs are relatively too high and the savings from energy costs cannot easily offset the initial costs. Incentives, in this case, are critical to make residential applications feasible. It appears that initial costs and energy costs are relatively more sensitive than maintenance costs and replacement costs. Thus, the rising energy costs may become a driver for more GSHP applications as well in the future.

The application of GSHP in commercial or office buildings show a different pattern than residential applications. All case demonstrated favorable results for GSHP application even without incentives. The application of incentives helps to reduce payback time. In such applications, it seems that maintenance costs, sometimes even replacement costs, may become more sensitive than initial costs or energy costs.

Based on the data used in this analysis, it appears that the application of GSHP in Florida has good potential, especially for commercial or office applications, where the initial costs for conventional systems are not trivial and the savings from energy costs can be significant. 


\section{CHAPTER 5: Summary and Conclusions}

\subsection{Main findings and Recommendations}

For eight building cases studied in this project, we have performed vigorous analysis of the impact of the installed geothermal heat pump (GHP) performance on the whole building energy consumption. Both field monitoring and building energy simulation result in the following major findings:

\subsubsection{The existing GSHP systems studied consume less energy in comparison to conventional ASHP system on an annual basis regardless of the ground loop type, size of the system, and the building application.}

The ranging of saving is from $5.7 \%$ to $34.6 \%$. The highest energy saving percentage by employing GSHP has been achieved in a residential building with a vertical closed-loop system. The amount of energy which is saved by using GSHP system in a building should be considered in addition to the percentage of annual energy saving. For big systems, each percent of energy consumption of GSHP system is equal to a greater amount of energy. It can be seen from simulation results that the largest amount of energy saving belongs to a hotel with lowest energy saving percentage. For this reason the amount of annual energy saving and its percentage should be considered at the same time to evaluate the effect of the GSHP system on the annual energy consumption of the system.

\subsubsection{Closed-loop GSHP systems save more energy than the open loop systems in hot and humid climate.}

Both simulation results and electricity consumption indices (i.e., $\mathrm{KWH} / \mathrm{sq} \mathrm{ft}$ floor area) confirm that the best result is achieved in a residential building with a vertical closedloop ground heat exchanger. The reduction of energy consumption for HVAC system could 
be as high as $60 \%$. This finding has not been completely confirmed for the commercial building applications in this study due to the lack of cases of buildings with the open-loop GSHP system.

The energy saving percentage of vertical closed loop system in Pensacola area is much lower than open loop systems in Tampa area which cannot be a result of difference between the weather condition in Tampa and Pensacola. The higher required pumping power for the open loop systems ( $1 \mathrm{hp}$ for the studied cases) in comparison to the required pumping power for the vertical closed loop ( $1 / 2 \mathrm{hp}$ for the studied case) is one of the reasons which makes the vertical closed loop system a better choice. The higher depth of the vertical closed loop (250 ft. for the studied case) in comparison to the well depth of the open loop systems in the area (80 ft. and $150 \mathrm{ft}$. for the studied cases) definitely enhance the performance of the vertical closed loop GSHP system with respect to the open loop system. It means that we can consider the vertical closed-loop system is the best GSHP system for the average scale residential systems in hot and humid climate. For residential applications the benefits of energy saving for the open-loop system and horizontal closedloop system in hot and humid climate are nearly the same in comparison with the ASHP.

For three commercial buildings studied with the close-loop GSHP systems, the electricity consumption index varies greatly with changing the application of a commercial building. However, it is observed that in general the electricity consumption index increases with the complexity of the GSHP system. As will be discussed below, our study shows that for a given building, employing GSHP system will reduce the energy consumption significantly compared with the same building with the traditional systems.

\subsubsection{In general more complex GSHP systems with higher number of heat pumps present lower energy saving percentage in comparison to conventional systems.}


The difference among energy consumption patterns of commercial buildings due to their different internal gains (e.g. people and equipment) can be a factor which affects the percentage of energy saving for GSHP system in comparison to conventional system.

\subsubsection{The cost of the system plays a key role to decide which portion of the load is compensated by the ground loop heat exchanger.}

The amount of energy which is saved by a GSHP system in a building should be considered in addition to the percentage of annual energy saving. For big systems, a small percentage of energy saving from adopting a GSHP system could be a fairly large amount of energy.

The results show that the largest amount of energy saving from a building GHSP system could have a lower energy saving percentage compared with other cases. It is due to the size of the building and GSHP system. For this reason the amount of annual energy saving and its percentage should be considered at the same time to evaluate the effect of the GSHP system on the annual energy consumption of the system.

\subsubsection{Within the scope of the project the wider application of GSHP systems to residential buildings is more uncertain than commercial or office buildings.}

This may be because the initial costs are relatively too high and the savings from energy costs cannot easily offset the initial costs. Incentives, in this case, are critical to make residential applications feasible. It appears that initial costs and energy costs are relatively more sensitive than maintenance costs and replacement costs. Thus, the rising energy costs may become a driver for more GSHP applications as well in the future.

The application of GSHP in commercial or office buildings show a different pattern than residential applications. All cases demonstrated favorable results for GSHP application even without incentives. The application of incentives helps to reduce payback time. In 
such applications, it seems that maintenance costs, sometimes even replacement costs, may become more sensitive than initial costs or energy costs.

\subsubsection{Overall, the application of GSHP in Florida (and hot and humid climate in general) shows a good potential.}

This finding is especially true for commercial or office applications, where the initial costs for conventional systems are not trivial, and the savings from energy costs can be significant.

\subsection{General guidelines for promoting the wider-adoption of GHP in the hot and humid climate.}

\begin{tabular}{|c|c|}
\hline $\begin{array}{l}\text { Comfort level } \\
\text { enhancement }\end{array}$ & $\begin{array}{l}\text { - GSHPs offer a great noise reduction due to elimination of outdoor } \\
\text { equipment }\end{array}$ \\
\hline $\begin{array}{c}\text { Energy saving in } \\
\text { comparison to } \\
\text { conventional } \\
\text { ASHP }\end{array}$ & $\begin{array}{l}\text { - The ranging of saving is from } 13.6 \% \text { to } 34.6 \% \text { for the average-scale } \\
\text { residential buildings. } \\
\text { - The ranging of saving is from } 5.7 \% \text { to } 17.2 \% \text { for commercial } \\
\text { buildings. } \\
\text { - The amount of annual energy saving and its percentage should be } \\
\text { considered at the same time to evaluate the energy saving of the } \\
\text { GSHP system in comparison to ASHP system. } \\
\text { - Application of the commercial building has the great effect on the } \\
\text { amount of annual energy saving. } \\
\text { - In general more complex GSHP systems with higher number of heat } \\
\text { pumps present lower energy saving percentage in comparison to } \\
\text { conventional systems. } \\
\text { The total power consumption of the system will be decreased if the } \\
\text { running time of the circulation pump (if there is any for big systems) } \\
\text { is synchronized with the heat pump units' running time by using a } \\
\text { proper controller. } \\
\text { Hybrid GSHPs consume more energy than fully GSHP systems but } \\
\text { the initial cost of them is much less than fully GSHP systems. }\end{array}$ \\
\hline $\begin{array}{l}\text { Ground loop type } \\
\text { considerations }\end{array}$ & $\begin{array}{l}\text { - In residential buildings vertical closed loop system shows better } \\
\text { performance than horizontal closed loop and open loop systems. }\end{array}$ \\
\hline
\end{tabular}




\begin{tabular}{|c|c|}
\hline & $\begin{array}{l}\text { - In residential buildings horizontal closed loop and open loop system } \\
\text { show same energy saving level in comparison to conventional air } \\
\text { cooled system. } \\
\text { - Land availability is a key factor to select the type of ground loop in a } \\
\text { GSHP system. }\end{array}$ \\
\hline $\begin{array}{c}\text { Cost } \\
\text { considerations }\end{array}$ & $\begin{array}{l}\text { - Incentives to make the GSHP system feasible for residential buildings } \\
\text { are inevitable. } \\
\text { - Incentives for commercial buildings help reducing payback period of } \\
\text { GSHP system. }\end{array}$ \\
\hline
\end{tabular}




\section{Appendix 1: Ground Source Heat Pumps Data Gathering Protocol in a Specific Climate Region}

\section{A. Introduction}

This document is a protocol for data gathering phase of costs and benefits evaluation of Ground Source Heat Pump (GSHP) systems utilized in a specific climate region.

\section{B. Objectives}

The main goal of this protocol is to provide a guideline to collect data about GSHP systems in a specific climate region. The data gathering procedure includes both technical and nontechnical data gathering through companies’ databases and end-user surveys.

\section{Scope of Work}

This protocol will provide a procedure to collect technical and non-technical data, required for costs and benefits evaluation of GSHP systems in a specific climate region. Technical data will be employed in quantitative analysis that leads to numbers to evaluate the energy saving percentage compared to conventional air conditioning systems. Non-technical data will be employed in qualitative evaluation of end-user satisfaction and psychological barriers to use GSHP systems in that region.

\section{Data gathering steps}

\section{D.1 Identification of potential participants}

1. Look for GSHP related organizations and also businesses like installers, consulting engineers, and contractors in the desired climate region.

The most comprehensive sources are: 
http://www.geoexchange.org/geothermal-directory/find-a-pro

http://www.igshpa.okstate.edu/directory/directory.asp

In these websites GSHP related businesses have been categorized by state.

2. Find contact information of each business from sources mentioned at step 1 and prepare a mailing list.

3. Search for GSHP projects information of each business through their websites.

4. Find Contact information of the owner/key player of each GSHP project and add them to the mailing list prepared at step 2 .

\section{D.2 Get potential participants on board}

1. Prepare a participation request letter explaining the project goals and benefits and send it to the mailing list prepared at step 2. (Appendix 1-A)

2. Arrange for teleconferences with businesses that responded the participation request in the affirmative, to clarify breadth and width of the project, type of data needed, and roles and expectations on collaboration.

3. Prepare an agreement letter for businesses to participate in the GSHP project. (Appendix 1-B)

4. Finalize agreement letter with each company based on their own policies.

5. Make the agreement letter signed by businesses.

6. Request for GSHP system end-users contact information from businesses that signed the agreement letter. 
7. Send the participation request letter to the end-users whose contact information provided by involved businesses.

8. Prepare an agreement letter for the owners/key players of the buildings to transfer required data. (Appendix 1-C)

9. Make the consent letter signed by owners/key players that responded to the participation request in the affirmative.

\section{D.3 Gathering existing (non-monitoring) data}

1. Prepare a short questionnaire that asks about basic information of each GSHP site. (Appendix 1-D)

2. Send short questionnaire to businesses that signed the agreement letter and ask them to fill it.

3. Prepare a long questionnaire containing all information to do the energy/cost saving analysis or energy/cost saving simulation (Appendix 1-E).

4. Arrange with businesses (teleconferences, emails and other electronic means, site visit, etc) to fill the long questionnaire for the projects that expansive information about the GSHP system is available.

5. Organize all the received data based on their application, location, capacity, and type of the ground loop heat exchanger.

\section{D.4 Gathering monitoring data}


1. Select sites for onsite monitoring based on their application, location, capacity, and type of the ground loop heat exchanger.

2. Prepare a ground source heat pump monitoring protocol for monitoring procedure (Appendix 1-F)

3. Arrange for onsite monitoring of selected sites (instruments, time, transportation, onsite certified electrician for installing instruments, etc)

4. Implement monitoring process for selected sites based on prepared monitoring protocol at step 14 . 
Appendix 1-A: A template for participation request letter to the potential participants

Dear friends,

I would like to invite you and your organization to participate in this important project, which aims at providing a sound conclusion as whether or not GSHP/Hybrid GSHP will be a vital solution as one of energy efficiency building solutions and towards zero-energy buildings, especially for hot and humid climate. One of our specific objectives of the study is to gather technical, cost, financial incentive data on installed GSHP/Hybrid GSHP applications in residential, commercial and schools in hot and humid climate regions. Detailed project scopes and tasks can be found on the US Department of Energy (DOE) web site:

\section{Project electronic address}

Your organization has been identified as having contracted a construction of GSHP system. In order to be successful for this project, we need your help to assist us in providing any relevant data, including, but not limited to, system capacity, site features, energy consumption, any past performance data reported or researched, and other pertinent nontechnical information such as incentives and financial structure. We will contact you further in term of the detailed survey questionnaires and possible site visits; but first we would like to get your permission to participate. Your commitment to the project will be limited to complete one or two survey questionnaires, and entertain a site visit if selected. 
Your participation in this project will greatly contribute to filling the gap of uncertainty of benefits and trade-off of the applications of GSHP/HGSHP systems in hot and humid climate. By sharing your experience or best practice, you will help create opportunities in consulting, and construction industry, financial institutions, GSHP manufacturers and utility companies in making right decisions on adopting GSHP technology. Your organization will be properly acknowledged and recognized on the DOE web site and all the pertinent publications.

Please kindly reply to this project email at project email address to acknowledge the receipt of this letter and inform us your decision of participation. We will contact you shortly after hearing from you.

Sincerely,

Name of the project director

Project Director

Company/Institution name

Date: 
Appendix 1-B: A template for agreement letter for businesses to participate in GSHP project

TO: Name of the person in charge

The research team at Company/Institution name is conducting a DOE funded project on a cost shared basis, entitled, Analysis of Energy, Environmental and Life Cycle Cost

Reduction Potential of Ground Source Heat Pump (GSHP) in Hot and Humid Climate. The project summary is attached to this agreement and also posted on the DOE web site:

\section{Project electronic address}

We appreciate your acceptance to participate in this important project, which aims at providing a sound conclusion as whether or not GSHP/Hybrid GSHP will be a vital solution as one of energy efficiency building solutions and towards zero-energy buildings, especially for hot and humid climate. In order to achieve this stated objective we need to gather and analyze independent and statistically valid technical, cost, financial incentive data on installed GSHP/HGSHP applications in residential, commercial and schools in hot and humid climate regions.

Your company, Company name, has years of experience installing and operating GSHP systems and we would like to have your help and commitment in providing the following information:

\section{Data related to properties which Gulf Power owns or controls:}

- System capacity (size or tonnage), 
- System installation and maintenance cost,

- Site features (loop type),

- Electricity consumption (monthly and annually or up-to-date),

- Past performance data (energy saving and or cost saving) reported or researched,

- Non-technical information such as incentives and financial structure, and

- Design cost.

\section{Data not owned:}

After obtaining the consent of the affected customer(s), Company name will provide FIU with a list of customer names and contact information for customers who have installed GSHP/HGSHP systems.

3. Assistance to install monitoring equipment in selected sites of your controlled GSHP installations. Our project team will be responsible to acquire the instruments for this task, and visit the identified sites. There is no cost to your company other than providing access.

\section{Any other data that is determined by mutual consent of the parties to be relevant or significant. Methods of participation}

You will be contacted through teleconference, emails and other electronic means, and can provide the available data via electronic means. Our project team may visit your site(s) should an on-site data validation be required. In that case, your cooperation in providing access and agreement for installing monitoring devices will be required. 
Your participation is completely on a volunteer basis, and there will be no financial obligation by or compensation to your company as a result of participation in this survey. However, by sharing your experience or best practice, you will help create opportunities in consulting, and construction industry, financial institutions, GSHP manufacturers and utility companies in making right decisions on adopting GSHP technology. Your participation in this project will be properly acknowledged and recognized on the project web site, and a link will be provided to you for your own purpose. All the pertinent publications, pending approval from DOE, will include a statement acknowledging the contribution of the data from your company.

If you accept the terms in this agreement, please sign below and send it back to the project POC.

Sincerely,

Name of the project director

Project Director

Company/Institution name

Date:

Date:

\author{
Name of the person in charge \\ Position of the person in charge \\ Company name
}

\section{Appendix: Project Summary}

It has been widely recognized that the energy saving benefits of GSHP systems are best realized in the northern and central regions where heating needs are dominant or both heating and cooling loads are comparable. For hot and humid climate such as in the states 
of FL, LA, TX, southern AL, MS, GA, NC and SC, buildings have much larger cooling needs than heating needs. The Hybrid GSHP (HGSHP) systems therefore have been developed and installed in some locations of those states, which use additional heat sinks (such as cooling tower, domestic water heating systems) to reject excess heat. Despite the development of HGSHP the comprehensive analysis of their benefits and barriers for wide application has been limited and often yields non-conclusive results. In general, GSHP/HGSHP systems often have higher first costs than conventional systems making short-term economics unattractive. Addressing these technical and financial barriers call for additional evaluation of innovative utility programs, incentives and delivery approaches. From scientific and technical point of view, the potential for wide applications of GSHP especially HGSHP in hot and humid climate is significant, especially towards building zero energy homes where the combined energy efficient GSHP and abundant solar energy production in hot climate can be an optimal solution. To address these challenges, Florida International University propose gathering and analyzing data on the costs and benefits of GSHP/HGSHP systems utilized in southern states using a representative sample of building applications. 
Appendix 1-C: A template for agreement letter for owners/key players to participate in GSHP project

TO: Name of the owner/key player

The research team at Company/Institution name is conducting a DOE funded project on a cost shared basis, entitled, Analysis of Energy, Environmental and Life Cycle Cost

Reduction Potential of Ground Source Heat Pump (GSHP) in Hot and Humid Climate. The project summary is attached to this agreement and also posted on the DOE web site:

\section{Project electronic address}

The project aims at providing a sound conclusion as whether or not GSHP/Hybrid GSHP will be a vital solution as one of energy efficiency building solutions and towards zeroenergy buildings, especially for hot and humid climate. In order to achieve this stated objective we need to gather and analyze independent and statistically valid technical, cost, financial incentive data on installed GSHP/HGSHP applications in residential, commercial and schools in hot and humid climate regions.

Your building has been identified as having installed and operating a GSHP system and we would like to have your help and commitment in providing the following information and by filling out the questionnaire provided either on line (Online questionnaire URL address) or in a hard copy. Some typical questions include but not limited to system capacity (size or tonnage), system design installation and maintenance cost, site features (loop type), electricity consumption (monthly and annually or up-to-date), past performance data (energy saving and or cost saving) reported or researched, and non-technical information 
such as incentives and financial structure. If you do not know answers for some of the questions, you can find from your associated parties (a contractor, an engineer, etc.) or just simply leave it unfilled.

\section{Methods of participation}

You may be contacted through teleconference, emails, or other electronic means, and can provide the available data via electronic means. Our project team may visit your site(s) should an on-site data validation is required. In that case, your cooperation in providing access and agreement for installing monitoring devices will be required. Your participation is completely on a volunteer basis, and there will be no financial compensation to you for participation in this survey. However, by sharing your experience in using GSHP system, you will help create opportunities in consulting and construction industries, financial institutions, GSHP manufacturers and utility companies in making right decisions on adopting GSHP technology. Your participation in this project will be properly acknowledged and recognized on the project web site, and a link will be provided to you later on for your own purpose. All the pertinent publications, pending approval from DOE, will include a statement acknowledging your contribution in the data gathering process.

If you accept the terms in this agreement, please sign below and send it back to the project POC.

Sincerely, 
Name of the project director

Project Director

Company/Institution name
Name of the owner/key player

Address:

Date:

Date:

Appendix: Project Summary

It has been widely recognized that the energy saving benefits of GSHP systems are best realized in the northern and central regions where heating needs are dominant or both heating and cooling loads are comparable. For hot and humid climate such as in the states of FL, LA, TX, southern AL, MS, GA, NC and SC, buildings have much larger cooling needs than heating needs. The Hybrid GSHP (HGSHP) systems therefore have been developed and installed in some locations of those states, which use additional heat sinks (such as cooling tower, domestic water heating systems) to reject excess heat. Despite the development of HGSHP the comprehensive analysis of their benefits and barriers for wide application has been limited and often yields non-conclusive results. In general, GSHP/HGSHP systems often have higher first costs than conventional systems making short-term economics unattractive. Addressing these technical and financial barriers call for additional evaluation of innovative utility programs, incentives and delivery approaches. From scientific and technical point of view, the potential for wide applications of GSHP especially HGSHP in hot and humid climate is significant, especially towards building zero energy homes where the combined energy efficient GSHP and abundant solar energy production in hot climate can be an optimal solution. To address these challenges, Florida 
International University propose gathering and analyzing data on the costs and benefits of GSHP/HGSHP systems utilized in southern states using a representative sample of building applications. 
Appendix 1-D: GSHP project short questionnaire

\begin{tabular}{|c|c|c|c|}
\hline & & & Comment \\
\hline Project address & & & \\
\hline Ground loop construction initial and end date & I.D: & E.D: & \\
\hline $\begin{array}{l}\text { The whole GSHP system installation (including } \\
\text { corresponding construction) initial and end date }\end{array}$ & I.D: & E.D: & \\
\hline System operation start date & & & \\
\hline Building type (Residential, Commercial, School, etc) & & & \\
\hline Building Floor area, $\left[\mathrm{ft}^{2}\right]$ or $\left[\mathrm{m}^{2}\right]$ & & & \\
\hline Number of stories & & & \\
\hline Approximate number of occupants & & & \\
\hline Location type(Urban center, Suburb, Rural) & & & \\
\hline Number of heat pump units & & & \\
\hline Capacity of unit(s), [Ton] or [W] & & & \\
\hline $\begin{array}{l}\text { Type of Loop } \\
\text { (A:Vertical, Horizontal, Spiral } \quad \text { B:Hybrid } \\
\text { GSHP, GSHP) }\end{array}$ & A: & B: & \\
\hline Number of boreholes(for vertical ground loops) & & & \\
\hline $\begin{array}{l}\text { Type of System (Groundwater,Ground-coupled, Lake } \\
\text { loop, etc) }\end{array}$ & & & \\
\hline Type of incentive (State, federal, municipal, utility) & & & \\
\hline $\begin{array}{l}\text { Could you provide us more information (i.e. } \\
\text { drawings, system specifications, monitoring data, } \\
\text { saving analysis, ...)? }\end{array}$ & Yes: & No: & \\
\hline
\end{tabular}


Appendix 1-E: GSHP project long questionnaire

\begin{tabular}{|c|c|c|c|}
\hline 1. General & & & Comment \\
\hline \multicolumn{4}{|l|}{ Project address } \\
\hline $\begin{array}{l}\text { Ground loop construction initial and } \\
\text { end date }\end{array}$ & I.D: & E.D: & \\
\hline $\begin{array}{l}\text { The whole GSHP system installation } \\
\text { (including corresponding construction) } \\
\text { initial and end date }\end{array}$ & I.D: & E.D: & \\
\hline \multicolumn{4}{|l|}{$\begin{array}{l}\text { Building type (Residential, Commercial, } \\
\text { School, etc) }\end{array}$} \\
\hline \multicolumn{4}{|l|}{ Building Floor area, $\left[\mathrm{ft}^{2}\right]$ or $\left[\mathrm{m}^{2}\right]$} \\
\hline \multicolumn{4}{|l|}{ Number of stories } \\
\hline \multicolumn{4}{|l|}{ Total occupants } \\
\hline \multicolumn{4}{|l|}{$\begin{array}{l}\text { Location type(Urban center, Suburb, } \\
\text { Rural) }\end{array}$} \\
\hline \multicolumn{4}{|l|}{ Number of heat pump units } \\
\hline \multicolumn{4}{|l|}{ Capacity of unit (s), [Ton] or [W] } \\
\hline \multicolumn{4}{|l|}{$\begin{array}{l}\text { Type of Loop } \\
\text { (A:Vertical, Horizontal, Spiral } \\
\text { B:Hybrid GSHP, GSHP) }\end{array}$} \\
\hline \multicolumn{4}{|l|}{$\begin{array}{l}\text { Type of System (Groundwater,Ground- } \\
\text { coupled, Lake loop, etc) }\end{array}$} \\
\hline \multicolumn{4}{|l|}{$\begin{array}{l}\text { Type and capacity of the additional } \\
\text { unit(s)(for hybrid systems) }\end{array}$} \\
\hline 2. Available metered/monitored data & & & Comment \\
\hline \multicolumn{4}{|l|}{ Monitoring equipment (s) } \\
\hline \multicolumn{4}{|l|}{ Locations monitored } \\
\hline \multicolumn{4}{|l|}{ Time data were collected } \\
\hline \multicolumn{4}{|l|}{$\begin{array}{l}\text { The available electricity consumption } \\
\text { data from June } 2009 \text { to May } 2010 \\
\text { [Kwh] }\end{array}$} \\
\hline Jun-09: & & Jul-09: & \\
\hline
\end{tabular}




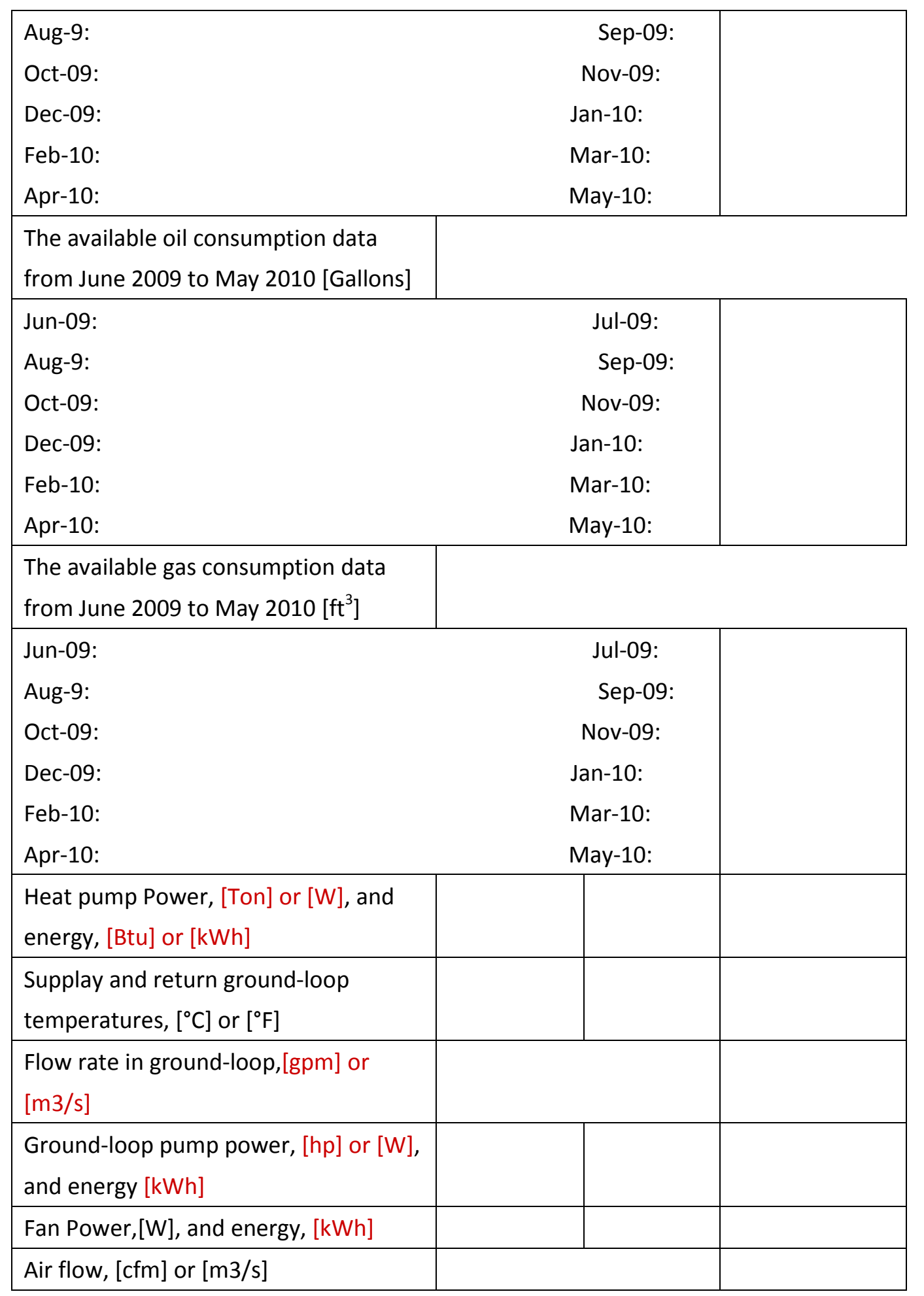




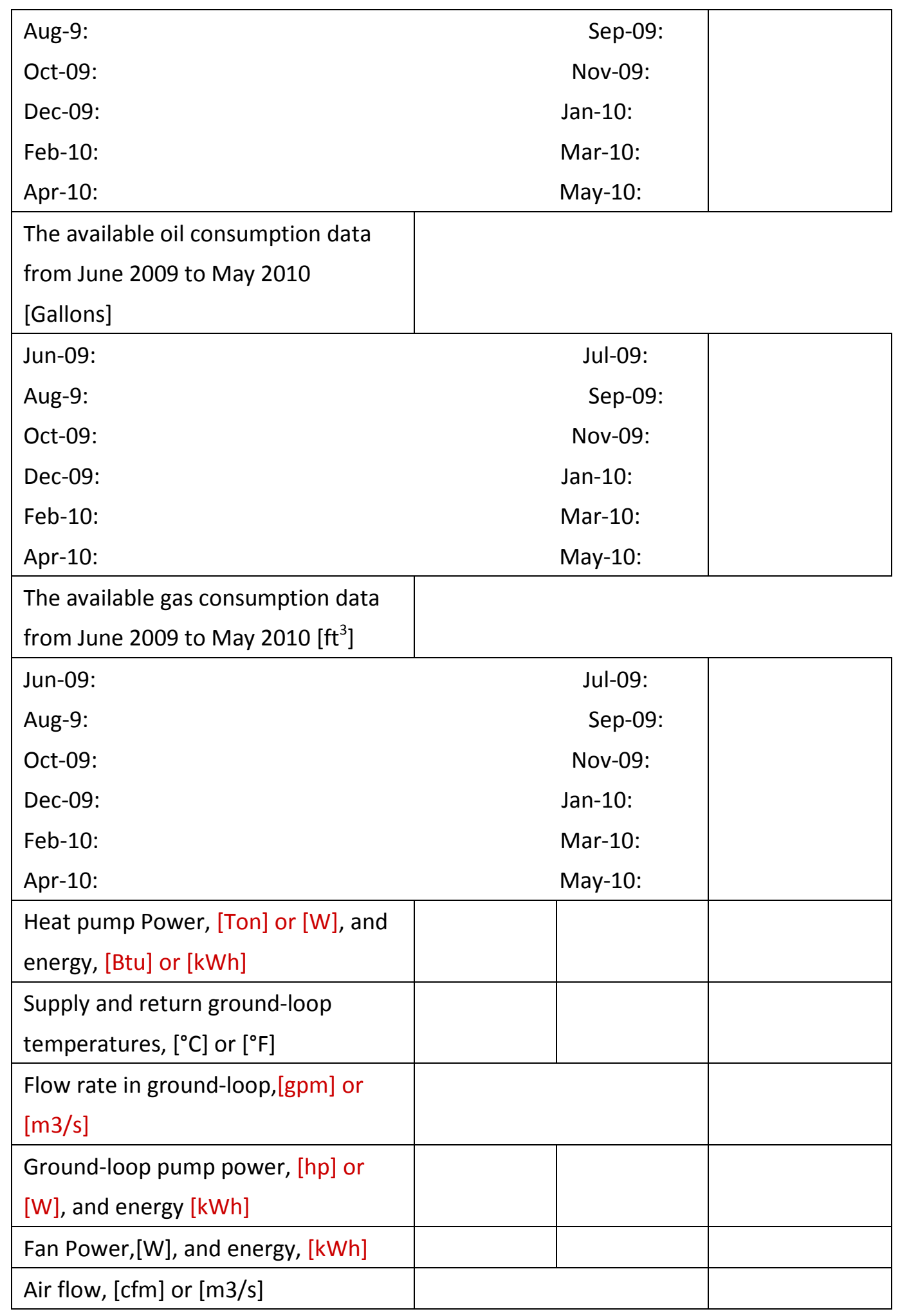




\begin{tabular}{|l|l|l|l|}
\hline $\begin{array}{l}\text { Ground temperature data (separate } \\
\text { answers with a comma if there is } \\
\text { more than one data point) }\end{array}$ & $\begin{array}{l}\text { Distance } \\
\text { from the } \\
\text { ground } \\
\text { loop }[\mathrm{ft}]\end{array}$ & $\begin{array}{l}\text { Ground } \\
\text { temperature } \\
{\left[{ }^{\circ} \mathrm{C}\right] \text { or }\left[{ }^{\circ} \mathrm{F}\right]}\end{array}$ & \\
\cline { 2 - 4 } & & & \\
\hline $\begin{array}{l}\text { Air supply and return temperatures, } \\
{\left[{ }^{\circ} \mathrm{C}\right] \text { or }\left[{ }^{\circ} \mathrm{F}\right]}\end{array}$ & & & \\
\hline $\begin{array}{l}\text { Space and outside temperatures, }\left[{ }^{\circ} \mathrm{C}\right] \\
\text { or }\left[{ }^{\circ} \mathrm{F}\right]\end{array}$ & & \\
\hline Run-time & & \\
\hline Control system-set points/deadband & & \\
\hline $\begin{array}{l}\text { Is there any additional } \\
\text { metered/monitored data you'd like } \\
\text { to share? }\end{array}$ & & \\
\hline
\end{tabular}

\section{Required data for modeling and} simulation

3.1 Building simulation Lighting data

Estimated total lighting wattage Approximate number of fluorescent tubes

Approximate number of light bulbs Estimated total appliance wattage Envelope assumptions $\left(R_{\text {value }}\right.$ or $\mathbf{U}_{\text {value) }}$

$R_{\text {value }}\left[\mathrm{m}^{2} \mathrm{~K} / \mathrm{W}\right]$ or $\left[\mathrm{h}^{\circ} \mathrm{F} \mathrm{ft}^{2} / \mathrm{Btu}\right]$

$\mathrm{U}_{\text {value }}\left[\mathrm{W} / \mathrm{m}^{2} \mathrm{~K}\right]$ or $\left[\mathrm{BTU} / \mathrm{h}^{\circ} \mathrm{F} \mathrm{ft}^{2}\right.$ ]

Walls

Windows

Roof

Floor

Air changes per hour ( $\mathrm{ACH})$

\subsection{Equipment simulation}

EER or COP of the heat pump unit(s) 


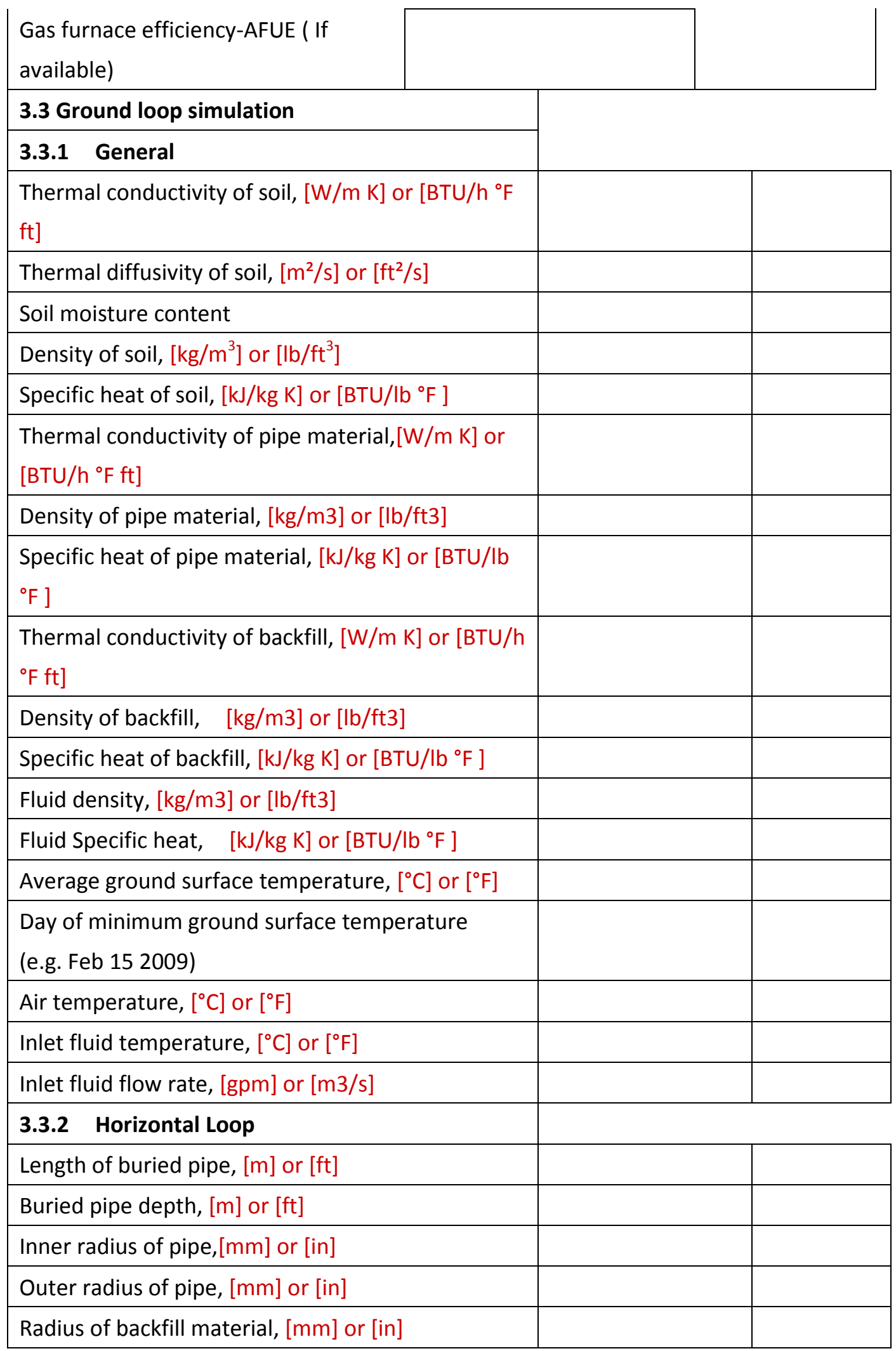




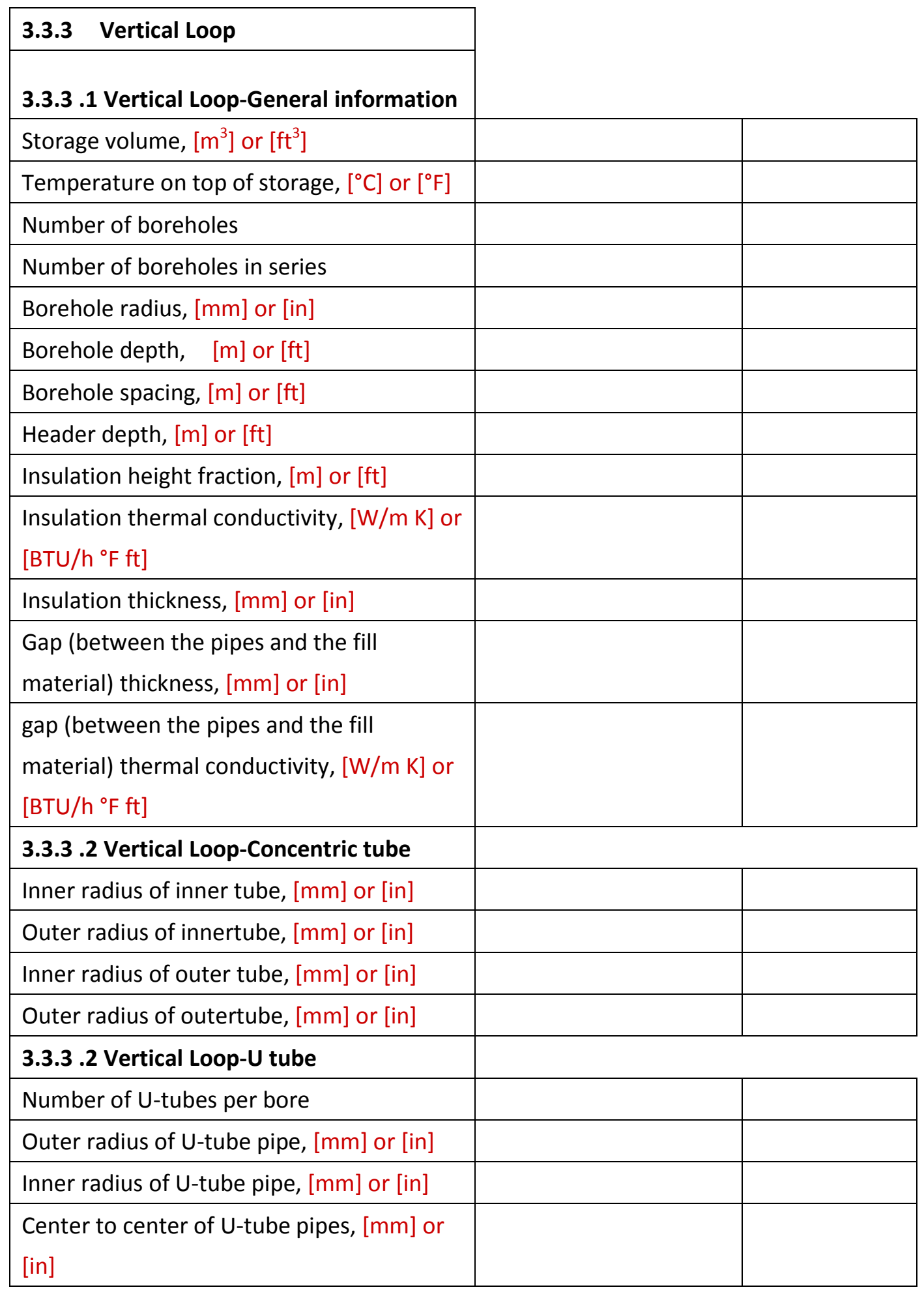




\begin{tabular}{|l|l|l|} 
4. Benefits to utility & & Comment \\
\hline Peak demand reduction (\%) & & \\
\hline Annual load reduction (\%) & & \\
\hline Higher load factor & & \\
\hline Higher efficiency (\%) & & \\
\hline
\end{tabular}

\begin{tabular}{|c|c|c|c|c|}
\hline $\begin{array}{l}\text { 5. Required data for life cycle cost } \\
\text { analysis }\end{array}$ & & & & \\
\hline \multirow{2}{*}{$\begin{array}{l}\text { Engineering Design Cost (Mechanical } \\
\text { Design and/or Civil Design) }\end{array}$} & \multirow[t]{2}{*}{ Total } & \multicolumn{2}{|c|}{ Please Define Included Items } & \\
\hline & & \multicolumn{2}{|c|}{ 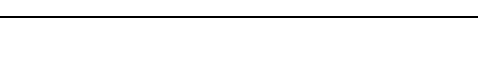 } & \\
\hline $\begin{array}{l}\text { Construction Management Cost (if } \\
\text { applicable) }\end{array}$ & Total & \multicolumn{2}{|c|}{ Please Define Included Items } & \\
\hline \multirow[b]{2}{*}{$\begin{array}{l}\text { Drilling Cost (Including Both of the } \\
\text { Wells) }\end{array}$} & Equipment & Labor & Total & \\
\hline & $\begin{array}{l}\text { Diameter of } \\
\text { Hole (in.) }\end{array}$ & $\begin{array}{c}\text { Depth of } \\
\text { Hole, each } \\
\text { (ft) }\end{array}$ & $\begin{array}{c}\text { Type of } \\
\text { Equipment } \\
\text { Used }\end{array}$ & \\
\hline \multirow{3}{*}{ Well Casing (Including Both of the Wells) } & Equipment & Material & Labor & Total \\
\hline & $\begin{array}{l}\text { Diameter of } \\
\text { Casing (in.) }\end{array}$ & $\begin{array}{l}\text { Length of } \\
\text { Casing, } \\
\text { each }(\mathrm{ft})\end{array}$ & \multicolumn{2}{|c|}{ Material/Type of Casing } \\
\hline & Equipment & Material & Labor & Total \\
\hline $\begin{array}{l}\text { Grouting Cost (Including Both of the } \\
\qquad \text { Wells) }\end{array}$ & $\begin{array}{l}\text { Type of } \\
\text { Material }\end{array}$ & $\begin{array}{c}\text { Volume of } \\
\text { Material } \\
\left(\mathrm{ft}^{3}\right)\end{array}$ & & \\
\hline \multirow{2}{*}{ Water Pump } & Material & Labor & Total & Type/Model \\
\hline & & & & \\
\hline
\end{tabular}




\begin{tabular}{|c|c|c|c|c|}
\hline Pump controls (if not included in Water & Material & Labor & Total & Type/Model \\
\hline Pump Cost) & & & & \\
\hline
\end{tabular}

\begin{tabular}{|c|c|c|c|c|}
\hline \multirow[b]{2}{*}{$\begin{array}{l}\text { Pipe Cost (For Pipes and Fittings used } \\
\text { Underground in Both Wells) }\end{array}$} & Material & Labor & \multicolumn{2}{|c|}{ Total } \\
\hline & $\begin{array}{l}\text { Diameter of } \\
\text { Pipe (in.) }\end{array}$ & $\begin{array}{l}\text { Length of } \\
\text { Pipe (ft) }\end{array}$ & & \\
\hline Heat Pump & Material & Labor & Total & \\
\hline \multirow[b]{2}{*}{$\begin{array}{l}\text { Pipes and Fittings (From Wells to Heat } \\
\text { Pump) }\end{array}$} & Material & Labor & \multicolumn{2}{|c|}{ Total } \\
\hline & $\begin{array}{l}\text { Diameter of } \\
\text { Pipe (in.) }\end{array}$ & $\begin{array}{l}\text { Length of } \\
\text { Pipe (ft) }\end{array}$ & & \\
\hline \multirow[b]{2}{*}{ Any Cost Items you'd like to provide } & Equipment & Material & Labor & Total \\
\hline & & & & \\
\hline Project Total & & & & \\
\hline
\end{tabular}


Appendix 1-F: Ground source heat pump monitoring protocol

A combination of instantaneous measurements and short term logging is used to calibrate the simulation and to evaluate the real time performance of the system. The following parameters are measured during the monitoring period:

- Heat transfer rate of the heat pump to the ground water

- Power consumption of the heat pump

- Total heat transfer rate to the ground water ( For systems with more than one heat pumps)

- Total power consumption of the heat pump system ( For systems with more than one heat pumps)

- Cooling/Heating load of the heat pump coil (Optional: Due to the availability of the monitoring equipment)

- Air temperature and humidity of the occupied areas of the building

- Temperature and humidity of the outside air

Table AI-1 shows the suggested sensors and loggers to measure above mentioned parameters.

Fluxus F601 ultrasonic Btu meter (Figure AI-1) is a non-invasive measurement using the clamp-on technology for precise, bi-directional and highly dynamic flow measurements. Fluxus F601 is a portable, easy-to-use flow transmitter with 2 flow channels, 
multiple inputs \& outputs and an integrated data logger with a serial interface. Transducers are available for a wide range of inner pipe diameters (0.25 to 256 in) and fluid temperatures in the range of $\left(-40\right.$ to $\left.+752^{\circ} \mathrm{F}\right)$, applications down to $-276^{\circ} \mathrm{F}$ possible.

Table AI-1: Suggested sensors and loggers for measuring process

\begin{tabular}{|c|c|c|c|}
\hline Parameter & Suggested Measuring Device & Suggested Data Logger & $\begin{array}{c}\text { Measuring } \\
\text { Device Location }\end{array}$ \\
\hline $\begin{array}{l}\text { Heat transfer rate to } \\
\text { the ground water } \\
\text { (Pipe diameter greater } \\
\text { than } 1 \frac{1}{4} \text { inch) }\end{array}$ & $\begin{array}{l}\text { Fluxus F601 ultrasonic Btu } \\
\text { meter }\end{array}$ & Internal logger & $\begin{array}{l}\text { Inlet and Outlet } \\
\text { of ground } \\
\text { water into } \\
\text { HP/ground }\end{array}$ \\
\hline $\begin{array}{l}\text { Heat transfer rate to } \\
\text { the ground water } \\
\text { (Pipe diameter less } \\
\text { than } 1 \frac{1}{4} \text { inch) }\end{array}$ & $\begin{array}{l}\text { Schenitec STUFF-300F } \\
\text { ultrasonic Btu meter }\end{array}$ & SD-card data logger & $\begin{array}{l}\text { Inlet and Outlet } \\
\text { of ground } \\
\text { water into } \\
\text { HP/ground }\end{array}$ \\
\hline Power consumption & $\begin{array}{l}\text { Watt Node Transducer } \\
\text { WNA-1P-240-P (For } 1 \text { Phase } \\
\text { powered buildings) } \\
\text { WNA-3Y-208-P (For } 3 \text { Phase } \\
\text { powered buildings) }\end{array}$ & Campell Scientific CR-206 & $\begin{array}{c}\text { Electrical } \\
\text { Breaker Box }\end{array}$ \\
\hline $\begin{array}{l}\text { Cooling/Heating load } \\
\text { of the heat pump coil }\end{array}$ & HOBO Sensor* & Internal logger & $\begin{array}{l}\text { Before and } \\
\text { after heat } \\
\text { pump coil }\end{array}$ \\
\hline $\begin{array}{l}\text { Air temperature and } \\
\text { humidity of the } \\
\text { occupied areas of the } \\
\text { building }\end{array}$ & HOBO Sensor & Internal logger & Occupied Area \\
\hline $\begin{array}{c}\text { Temperature and } \\
\text { humidity of the } \\
\text { outside air }\end{array}$ & HOBO Sensor & Internal logger & $\begin{array}{l}\text { Outside of the } \\
\text { building }\end{array}$ \\
\hline
\end{tabular}

* Temperature and relative humidity of the air before and after the coil and nominal CFM of the heat pump fan are used to calculate the cooling/heating load of the heat pump coil. 
Schenitec STUFF-300F ultrasonic Btu meter (Figure AI-2) provides abundant capabilities for accurate thermal energy measurement of a liquid-based thermal energy production/transferring system. It is the 3rd generation energy meter from Shenitech. Compared with its predecessors, the 3rd generation offers better performance and a richer feature set, all at a lower price. This system is consisted of the high performance ultrasonic flow meter and a pair of standard PT100 temperature sensors. The ultrasonic flow meter is based on our cutting-edge clamp-on flow measurement technology, which is capable of measuring the flow from outside of a pipe accurately and reliably. Due to the non-intrusive nature of this technology, there is no pipe cutting, no moving parts, no pressure drop, no leak and no risk of contamination. In addition, the installation is simple and requires no special skills or tools.

WattNode transducer (Figure AI-3) is a true RMS AC watt-hour transducer with pulse output (solid state relay closure) proportional to kWh consumed. The WattNode provides an accurate measurement at low cost to meet your needs for sub-metering, netmetering, energy management, and performance contracting applications. The complete Pulse Output family measures 1,2 , or 3 phases in 2, 3, or 4 wire configurations. With voltage ratings from 120 to $600 \mathrm{Vac}$ and current transformer (CT) ratings from 5 to 6000 amps, there is a WattNode combination to meet your AC power measurement requirements. 


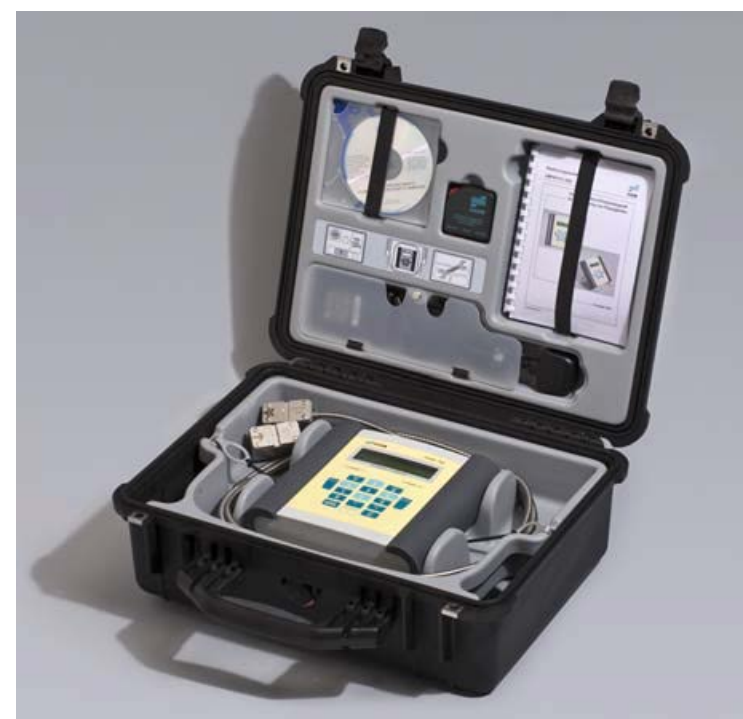

(a)

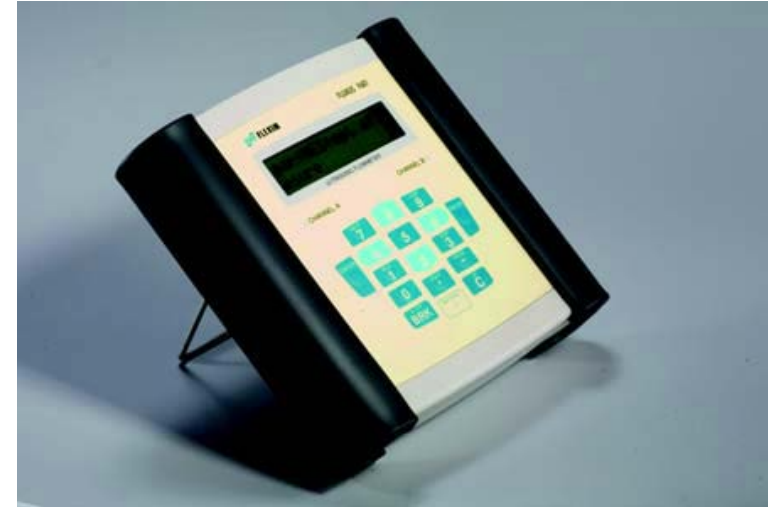

(b)

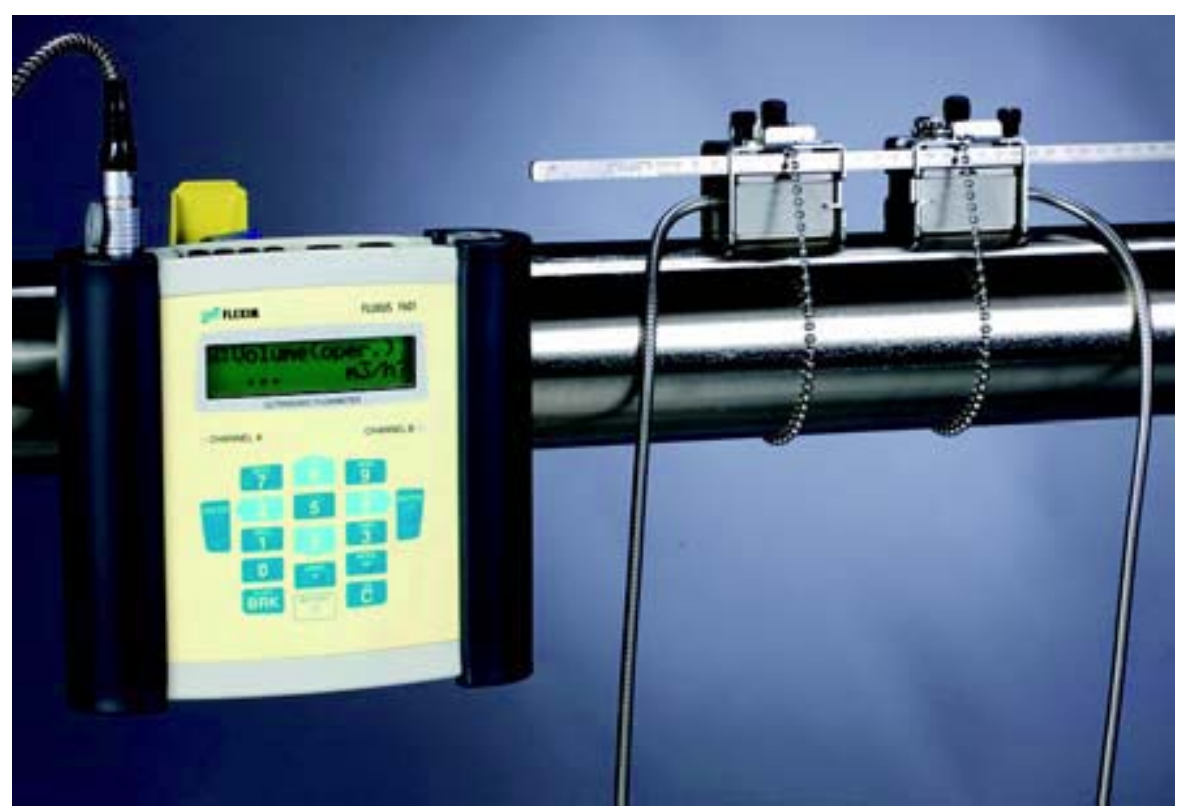

(c)

Figure AI-1: Fuxus F601 Btu meter (a) in transport case (b) supported by handle (C) mounted on a pipe 


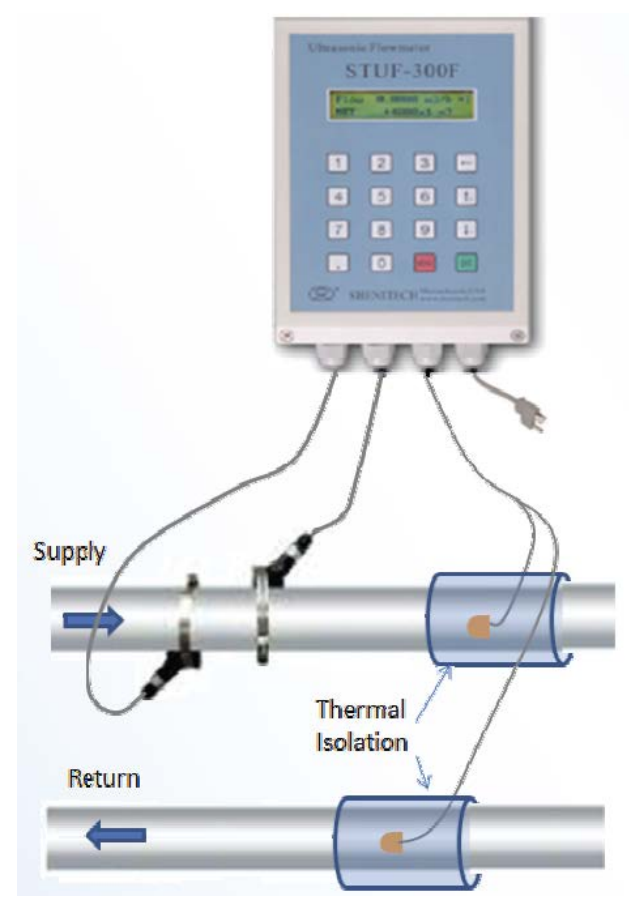

Figure AI-2: Schenitec STUFF-300F ultrasonic Btu meter

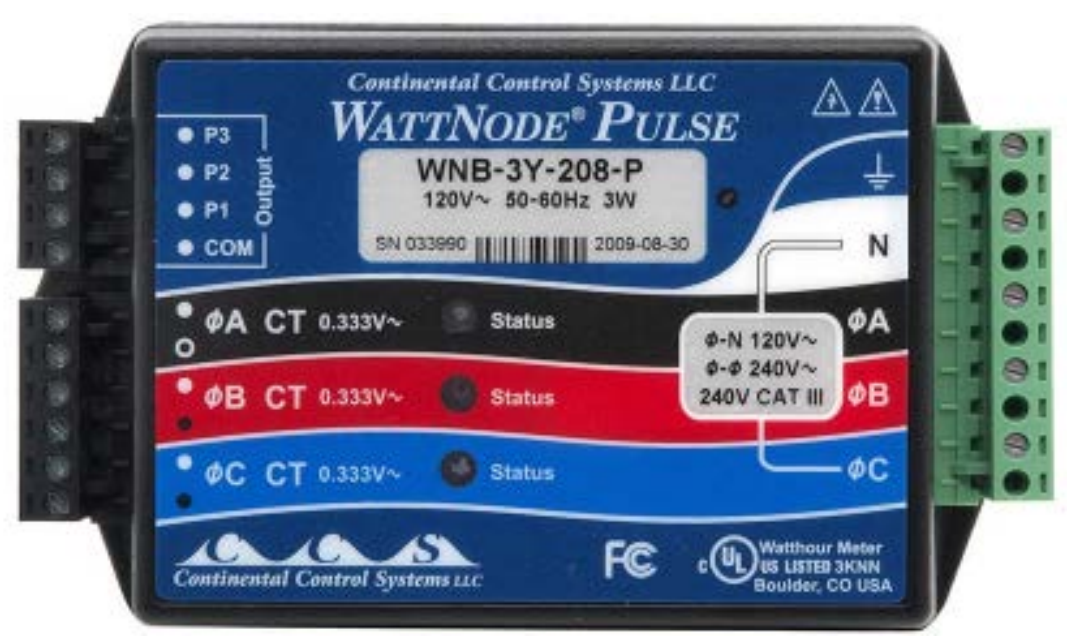

Figure AI-3: WattNode transducer 
HOBO Temperature Data Logger (Figure AI-4) is an economical choice for indoor temperature and relative humidity monitoring. Its small size and large memory capacity make it a great multi-purpose logger.

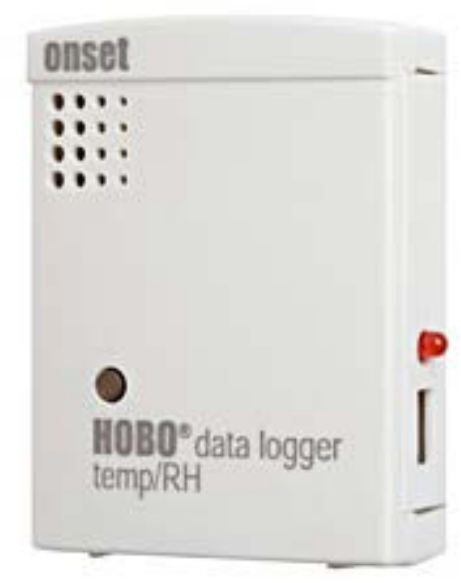

Figure AI-4: HOBO sensor (Temperature/Relative humidity)

Campbell Scientific CR-206 data logger (Figure AI-5) has five single-ended analog inputs, one switch closure pulse input, one low level ac pulse input, two control ports, two excitation channels, and one switched battery output. Programs and data are stored in a non-volatile Flashmemory. Final storage has 512 kbytes of memory that provides approximately 128,000 data points in thetable-based memory structure. The datalogger uses PakBus communication protocol to communicate with the network. 


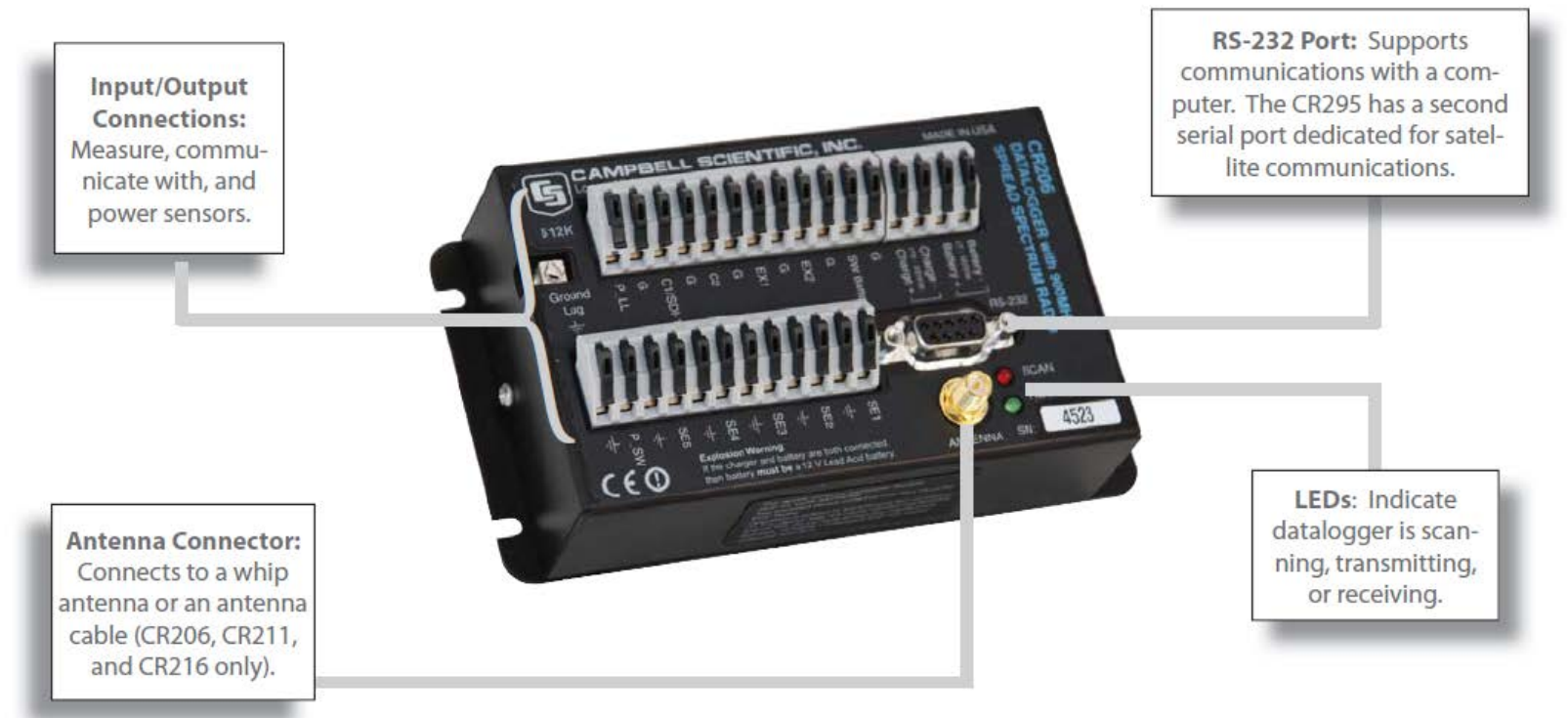

Figure AI-5: Campbell Scientific CR-206 data logger 